NBSIR 85-3026

\title{
ROUND ROBINS ON THE APPARENT THERMAL CONDUCTIVITY OF LOW- DENSITY GLASS FIBER INSULATIONS USING GUARDED HOT PLATE AND HEAT FLOW METER APPARATUS
}

J. G. Hust

C. M. Pelanne

National Bureau of Standards U.S. Department of Commerce Boulder, Colorado 80303

May 1985 



\section{ROUND ROBINS ON THE APPARENT THERMAL CONDUCTIVITY OF LOW- DENSITY GLASS FIBER INSULATIONS USING GUARDED HOT PLATE AND HEAT FLOW METER APPARATUS}

\section{J. G. Hust}

Chemical Engineering Science Division

National Engineering Laboratory

National Bureau of Standards

U.S. Department of Commerce

Boulder, Colorado 80303

C. M. Pelanne

Consultant-Thermal Insulation

4900 Pinyon

Littleton, Colorado 80123

May 1985

Sponsored, in part, by:

Department of Energy/ORNL

American Society for Testing and Materials (ASTM)

Mineral Insulation Manufacturers Association (MIMA)

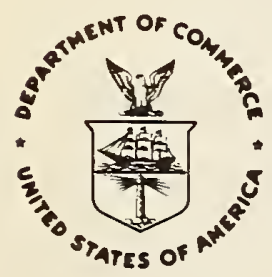

U.S. DEPARTMENT OF COMMERCE, Malcolm Baldrige, Secretary 

Abstract

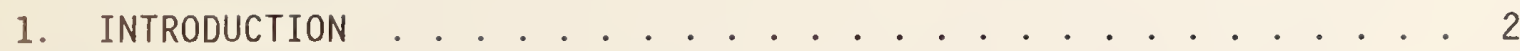

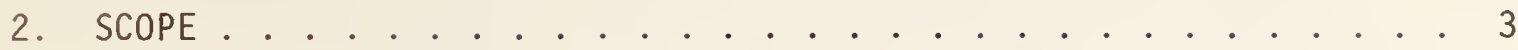

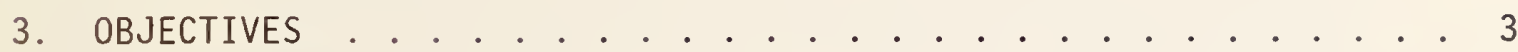

4. EXPERIMENTAL DATA . . . . . . . . . . . . . 4

5. REFERENCE EQUATION ..................... 5

6. ROUND ROBIN I ...................... 33

6.1 Overview................. . . 33

6.2 Test Specimens ............... . . 33

6.3 Test Equipment . . . . . . . . . . . . 34

6.4 Results .................. . . 34

7. ROUND ROBIN II ................. 51

7.1 Overview ................. . . 51

7.2 Test Specimens . . . . . . . . . . . . 51

7.3 Test Equipment . . . . . . . . . . . . 52

7.4 Results ................. 52

8. ROUND ROBIN III ....................... 71

8.1 Overview................. . . 71

8.2 Test Specimens . . . . . . . . . . . . 72

8.3 Test Equipment . . . . . . . . . . . 73

8.4 Results ................... . . 73

9. SUMMARY AND CONCLUSIONS .................. 89

9.1 Separation of Variabilities . . . . . . . . . 89

9.2 Round Robin I . . . . . . . . . . . . . . . . . 91

9.3 Round Robin II . . . . . . . . . . . . . . . 91

9.4 Round Robin III . . . . . . . . . . . . . . . 91

9.5 General Summary . . . . . . . . . . . . . 92

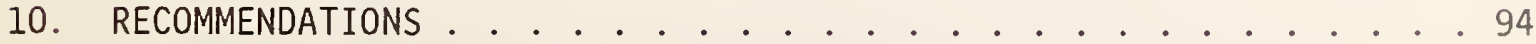

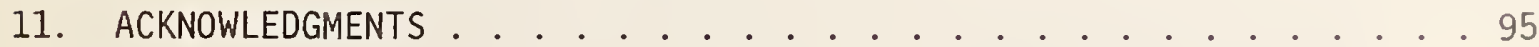

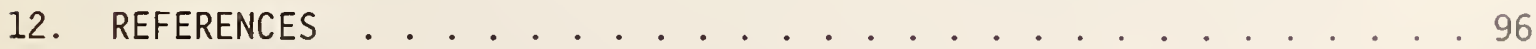

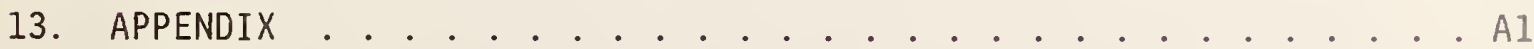


Figure 5.1 Thermal Conductivity versus Density of NBS Data on Round Robin II and III (The lines show the approximate temperature of the data.)................ 11

Figure 5.2 Thermal Conductivity versus Temperature of NBS Data on Round Round II and III . . . . . . . . . . . . . 12

Figure 5.3 Thermal Conductivity versus Thickness of NBS Data on Round Robin II and III . . . . . . . . . . . . . 13

Figure 5.4 Thermal Conductivity versus Density of NBS Data on Round Robin II. (The lines show the approximate temperature of the data.) .................... 14

Figure 5.5 Thermal Conductivity versus Density of NBS Data on Round Robin III

Figure 5.6 Thermal Conductivity versus Temperature of NBS Data on Round Robin II

Figure 5.7 Thermal Conductivity versus Thickness of NBS Data on Round Robin III

Figure 5.8 Deviations between Thermal Conductivity Data of NBS on Round Robin II and III and Values Calculated from the Model versus Density.

Figure 5.9 Deviations between Thermal Conductivity Data of NBS on Round Robin II and III and Values Calculated from the Model versus Temperature

Figure 5.10 Deviations between Thermal Conductivity Data of NBS on Round Robin II and III and Values Calculated from the Model versus Thickness

Figure 5.11 Deviations between Thermal Conductivity Data of NBS on Round Robin II and Values Calculated from the Model versus Density

Figure 5.12 Deviations between Thermal Conductivity Data of NBS on Round Robin III and Values Calculated from the Model versus Density

Figure 5.13 Deviations between Thermal Conductivity Data of NBS on Round Robin II and Values Calculated from the Model versus Temperature

Figure 5.14 Deviations between Thermal Conductivity Data of NBS on Round Robin III versus Thickness

Figure 5.15 Thermal Conductivity versus Density for Several Temperature as Calculated from the Model. Emittance $=0.95$, Thickness $=2.54 \mathrm{~cm}$, and Fiber Diameter $=5.0 \mu \mathrm{m}$ 
Figure 5.16 Thermal Conductivity versus Temperature for Several Densities as Calculated from the Mode1. Emittance $=$ 0.95 , Thickness $=2.54 \mathrm{~cm}$, and Fiber Diameter $=5.0 \mu \mathrm{m} .26$

Figure 5.17 Thermal Conductivity versus Thickness for Several Densities as Calculated from the Mode1. Emittance $=$ 0.95 , Temperature $=300 \mathrm{~K}$, and Fiber Diameter $=5.0 \mu \mathrm{m}$.

Figure 5.18 Thermal Conductivity versus Emittance for Several Thicknesses as Calculated from the Mode1. Temperature $=$ $300 \mathrm{~K}$, Density $=10 \mathrm{~kg} / \mathrm{m}^{3}$, and Fiber Diameter $=5.0 \mu \mathrm{m}$.

Figure 5.19 Thermal Conductivity versus Fiber Diameter as Calculated from the Model. Emittance $=0.95$, Temperature $=300 \mathrm{~K}$, Density $=10 \mathrm{~kg} / \mathrm{m}^{3}$, and Thickness $=2.54 \mathrm{~cm} . . . .29$

Figure 5.20 Thermal Conductivity versus Thickness for Several Emittances as Calculated from the Model. Temperature $=300 \mathrm{~K}$, Density $=10 \mathrm{~kg} / \mathrm{m}^{3}$, and Fiber Diameter $=5.0 \mu \mathrm{m} . . .30$

Figure 5.21 Thermal Conductivity Components (air, solid, radiation and total) versus Density as Calculated from the Model. Emittance $=0.95$, Temperature $=300 \mathrm{~K}$, Thickness $=2.54 \mathrm{~cm}$, and Fiber Diameter $=5.0 \mu \mathrm{m} . . . . . . . .331$

Figure 5.22 Thermal Conductivity Components (air, solid, radiation, and total) versus Temperature as calculated from the Mode1. Emittance $=0.95$, Density $=10 \mathrm{~kg} / \mathrm{m}^{3}$, Thickness $=$ $2.54 \mathrm{~cm}$, and Fiber Diameter $=5.0 \mu \mathrm{m}$. . . . . . . 32

Figure 6.1 Thermal Conductivity versus Density for the 915-406 mm and 915-305 mm Heat Flow Meter Apparatus from Round Robin I. . 40

Figure 6.2 Thermal Conductivity versus Density for the 610-254 mm Heat Flow Meter Apparatus from Round Robin I . . . . .

Figure 6.3 Thermal Conductivity versus Density for the Guarded Hot Plate Apparatus from Round Robin I. . . . . . . . . . .

Figure 6.4 Thermal Conductivity versus Density for all of the Data from Round Robin I..................

Figure 6.5 Deviations between Thermal Conductivity Data for the 915-406 mm and 915-305 mm Heat Flow Meter Apparatus from Round Robin I and Values Calculated from the Model versus Density

Figure 6.6 Deviations between Thermal Conductivity Data for the 610-254 mm Heat Flow Meter Apparatus from Round Robin I and Values Calculated from the Model versus Density

Figure 6.7 Deviations between Thermal Conductivity Data from the Guarded Hot Plate Apparatus from Round Robin I and Values Calculated from the Model versus Density 
Figure 6.8 Deviations between all Thermal Conductivity Data from Round Robin I and Values Calculated from the Model versus Density...................

Figure 6.9 Thermal Conductivity versus Density for Control Data taken by Lab 17 for Round Robin I over the period 1976 to 1980

Figure 6.10 Deviations between Control Data from Lab 17 and Values Calculated from the Model versus Density . . . . . . .

Figure 6.11 Deviations between Control Data from Lab 17 for Round Robin I and Values Calculated from the Model versus

Figure 7.1 Thermal Conductivity versus Density for Heat Flow Meter Apparatus from Round Robin II

Figure 7.2 Thermal Conductivity versus Density for Guarded Hot Plate Apparatus from Round Robin II

Figure 7.3 Thermal Conductivity versus Density for all Primary Round Robin II Data.

Figure 7.4 Thermal Conductivity versus Density for Supplementary Round Robin II Data ................. 62

Figure 7.5 Deviations between Thermal Conductivity Data for Heat Flow Meter Apparatus from Round Robin II and Values Calculated from the Model versus Density . . . . . . .

Figure 7.6 Deviations between Thermal Conductivity Data for Guarded Hot Plate Apparatus from Round Robin II and Values Calculated from the Model versus Density. . . . . . . . .

Figure 7.7 Deviations between al1 Primary Thermal Conductivity Data from Round Robin II and Values Calculated from the Model versus Density

Figure 7.8 Deviations between Supplementary Thermal Conductivity Data from Round Robin II and Values Calculated from the Model versus Density

Figure 7.9 Thermal Conductivity versus Density of Control Data taken by Lab 17 for Round Robin II over the Period 1974 to 1983.

Figure 7.10 Deviations between Control Data from Lab 17 for Round Robin II and Values Calculated from the Model versus Density

Figure 7.11 Deviations between Control Data from Lab 17 for Round Robin II and Values Calculated from the Model versus Time (Set 1) 
Figure 7.12 Deviations between Control Data from Lab 17 for Round Robin II and Values Calculated from the Model versus Time (Set 2) . . . . . . . . . . . . 70

Figure 8.1 Thermal Conductivity versus Density of all Round Robin III Data . . . . . . . . . . . . . . . . . . . 78

Figure 8.2 Thermal Conductivity versus Thickness of all Round Robin II I Data . . . . . . . . . . . . . . . . . . . . 79

Figure 8.3 Deviations between al1 Thermal Conductivity Data From Round Robin III and Values Calculated from the Model versus Density. . . . . . . . . . . . . 80

Figure 8.4 Deviations between All Thermal Conductivity Data from Round Robin III and Values Calculated from the Model versus Thickness................. . 81

Figure 8.5 Deviations between the Thermal Conductivity Data from Round Robin III at a Thickness of $25.4 \mathrm{~mm}$ and Values Calculated from the Model versus Density . . . . . . . . 82

Figure 8.6 Deviations between the Thermal Conductivity Data from Round Robin III at a Thickness of $50.8 \mathrm{~mm}$ and values Calculated from the Model versus Density . . . . 83

Figure 8.7 Deviations between the Thermal Conductivity Data from Round Robin III at a Thickness of $76.2 \mathrm{~mm}$ and values Calculated from the Model versus Density . . . . . 84

Figure 8.8 Deviations between the Thermal Conductivity Data from Round Robin III at a Thickness of $101.6 \mathrm{~mm}$ and values Calculated from the Model versus Density . . . . 85

Figure 8.9 Deviations between the Thermal Conductivity Data from Round Robin III at a Nominal Density of $11 \mathrm{~kg} / \mathrm{m}^{3}$ and Values Calculated from the Model versus Thickness . . . . . . . . 86

Figure 8.10 Deviations between the Thermal Conductivity Data from Round Robin III at a Nominal Density of $16 \mathrm{~kg} / \mathrm{m}^{3}$ and Values Calculated from the Model versus Thickness . . . 87

Figure 8.11 Deviations between the Thermal Conductivity Data from Round Robin III at a Nominal Density of $19 \mathrm{~kg} / \mathrm{m}^{3}$ and Values Calculated from the Model versus Thickness . . . 88

Figure 13.1 Description of Samples for Round Robin . . . . . . . . A2

Figure 13.2 Standardized Reference Values for the Round Robin II Samples................. A3 


\section{LIST OF TABLES}

Table 5.1 ASTM C-16.30/MIMA Round Robins. National Bureau of Standards Test Results. Reference Base for Calibrated Specimens used for Round Robin II

Table 5.2 ASTM C-16.30/MIMA Round Robins. National Bureau of Standards Data for Round Robin III . . . . . . . . . . . . . 10

Table 6.1 ASTM C-16.30/MIMA Round Robins. Data from the 915-406 mm and 915-305 mm Heat Flow Meter Apparatus for Round Robin I. 36

Table 6.2 ASTM C-16.30/MIMA Round Robins. Data from 610-254 mm Heat Flow Meter Apparatus for Round Robin I

Table 6.3 ASTM C-16.30/MIMA Round Robins. Data from the Guarded Hot Plate Apparatus for Round Robin I . . . . . . . . . . . 38

Table 6.4 ASTM C-16.30/MIMA Round Robins. Data from Lab 17 over the Time Period from 1976 to 1980 for Round Robin I . . . . . . 39

Table 7.1 ASTM C-16.30/MIMA Round Robins. Data from Heat Flow Meter Apparatus for Round Robin II . . . . . . . . . . 54

Table 7.2 ASTM C-16.30/MIMA Round Robins. Data from Guarded Hot Plate Apparatus for Round Robin II . . . . . . . . . . 55

Table 7.3 ASTM C-16.30/MIMA Round Robins. Data from Lab 17 over the Time Period from 1974 to 1983 for Round Robin II (610-254 mm plates).................. 56

Table 7.4 ASTM C-16.30/MIMA Round Robins. Data from Lab 17 over the Time Period from 1974 to 1983 for Round Robin II (305$152 \mathrm{~mm}$ plates)

Table 7.5 ASTM C-16.30/MIMA Round Robins. Special Tests with Thickness and Temperature as Variables (with and without septum) . . 58

Table 8.1 ASTM C-16.30/MIMA Round Robins. Primary Data for Round Robin III.................. . . . 75

Table 8.2 ASTM C-16.30/MIMA Round Robins. Secondary Data for Round Robin III. . . . . . . . . . . . . . . . . . 76

Table 8.3 ASTM C-16.30/MIMA Round Robins. Tests Performed at Lab 17 on Individual Stacked Sets of Specimens from Round Robin III using Heat Meter Apparatus . . . . . . . . . . . 77

Table 9.1 Average Deviations and 2s Values For Selected Subsets and Data For Each of the Round Robins . . . . . . . . . . . . 90

Table 13.1 ASTM C-16.30/MIMA Round Robins. Participants and Reviewers

Table 13.2 ASTM C-16.30/MIMA Round Robins. Coding Methodology . . . . A5 
Table 13.3 Typical Data Form used for Reporting Test Results . . . . A7

Table 13.4 Specimen Sizes, Weights, and Densities for Round Robin I . A8

Table 13.5 Specimen Sizes, Weights, and Densities for Round Robin II. A9

Table 13.6 Specimen Sizes, Weights, and Densities for Round Robin II I

Table 13.5.1 ASTM C-16.30/MIMA Round Robins. National Bureau of Standards Test Results. Reference Base for Calibrated Specimens used for Round Robin II . . . . . . . .

Table 13.5.2 ASTM C-16.30/MIMA Round Robins. National Bureau of Standards Data for Round Robin III

Table 13.6.1 ASTM C-16.30/MIMA Round Robins. Data from the 915-406 mm and 915-305 mm Heat Flow Meter Apparatus for Round Robin I

Table 13.6.2 ASTM C-16.30/MIMA Round Robins. Data from 610-254 mm Heat Flow Meter Apparatus for Round Robin I

Table 13.6.3 ASTM C-16.30/MIMA Round Robins. Data from the Guarded Hot Plate Apparatus for Round Robin I. . . . . . . . A15

Table 13.6.4 ASTM C-16.30/MIMA Round Robins. Data from Lab 17 over the Time Period from 1976 to 1980 for Round Robin I . . A16

Table 13.7.1 ASTM C-16.30/MIMA Round Robins. Data from Heat Flow Meter Apparatus for Round Robin II . . . . . . . . . .

Table 13.7.2 ASTM C-16.30/MIMA Round Robins. Data from Guarded Hot Plate Apparatus for Round Robin II . . . . . . . . . A18

Table 13.7.3 ASTM C-16.30/MIMA Round Robins. Data from Lab 17 over the Time Period from 1974 to 1983 for Round Robin II (610-254 mm plates)

Table 13.7.4 ASTM C-16.30/MIMA Round Robins. Data from Lab 17 over the Time Period from 1974 to 1983 for Round Robin II (305-152 mm plates)

Table 13.7.5 ASTM C-16.30/MIMA Round Robins. Special Tests with Thickness and Temperature as Variables (with and without septum)

Table 13.8.1 ASTM C-16.30/MIMA Round Robins. Primary Data for Round Robin III

Table 13.8.2 ASTM C-16.30/MIMA Round Robins. Secondary Data for Round Robin III

Table 13.8.3 ASTM C-16.30/MIMA Round Robins. Tests Performed at Lab 17 on Individual Stacked Sets of Specimens from Round Robin III using Heat Meter Apparatus 
Avg. Dev. = Average deviation of a subset of data from the model (observed minus model)

$D=$ Specimen density

$\varepsilon=$ Plate emittance

$F=$ Fiber diameter in $\mu m$

GHP = Guarded hot plate

HFM $=$ Heat flow meter

Interlaboratory reproducibility $=$ Reproducibility between laboratories

Intralaboratory reproducibility = Reproducibility within laboratories

$\mathrm{k}_{\mathrm{a}}, \lambda=$ Apparent thermal conductivity

$\mathrm{L}=$ Specimen thickness

$\lambda_{\mathrm{g}}=$ Gas component of thermal conductivity

$\lambda_{r}=$ Radiation component of thermal conductivity

$\lambda_{S}=$ Solid component of thermal conductivity

$P_{1}, P_{2}, P_{3}, P_{4}$, and $P_{5}=$ Parameters in model

PCT $=\left[k_{a}\right.$ (obs.) $-k_{a}$ (calc.) $] 100 / k_{a}$ (calc.)

$\sigma=$ Stefan-Boltzmann constant $=5.6703 \times 10^{-5} \mathrm{~mW} \cdot \mathrm{m}^{-2} \cdot \mathrm{K}^{-4}$

Thickness effect $=$ Dependency of thermal conductivity on specimen thickness

$2 s=$ two times the standard deviation of the test results with respect to their mean (an approximation of the 95\% confidence interval) 
Round Robins on the Apparent Thermal Conductivity of Low-Density Glass

Fiber Insulations Using Guarded Hot Plate and Heat Flow Meter Apparatus

By

\author{
J.G. Hust \\ National Bureau of Standards \\ Boulder, CO 80303 \\ and \\ C.M. Pelanne \\ Consultant-Thermal Insulation \\ Littleton, CO 80123
}

This National Bureau of Standards report* presents the results and the data analysis pertaining to these results for three round robins on the thermal performance of guarded hot plates and heat flow meters when measuring the thermal resistance properties of low density glass fibrous thermal insulations. The three round robins were carried out under the sponsorship of the American Society for Testing and Materials (ASTM) Subcommittee C-16.30 on Thermal Measurements and the Mineral Insulation Manufacturers Association (MIMA).

The test results are compared to a reference equation and to each other to illustrate intralaboratory and interlaboratory reproducibility as well as the dependencies on temperature, density, plate emittance, specimen thickness, and fiber diameter.

The study shows that, with good laboratory practices, interlaboratory agreement of about $2 \%$ is obtained. Over 300 test results obtained by 12 different laboratories are reported. This report also discusses the magnitude of the specimen thickness effect and its dependence on plate emittance.

Key words: apparent thermal conductivity; guarded hot plate; heat flow meter; low density; Round Robins; thermal insulation; thickness effect.

\footnotetext{
*This work was funded, in part, by DOE/ORNL under contract number ORNL/IA-21428.
} 


\section{INTRODUCTION}

During the last 10 to 15 years considerable progress has been made in the development and improvement of the equipment and techniques for the measurement of the thermal resistance of thermal insulations, particularly low density insulations. The worldwide interest in energy conservation has resulted in increased effort toward the production of improved and more cost effective commercial insulations, primarily aimed at the building industry, which uses the greatest amount of thermal insulation. The two apparatus generally used to measure the thermal resistance of these low density insulations are, the guarded hot plate (GHP), ASTM C177 $[1]^{1}$ and the heat flow meter (HFM), ASTM C518 [2].

The development of thermally effective low density thermal insulation has had a significant impact on the technical aspect of the measurement of thermal resistance. This, combined with a better understanding of the heat transfer principles involved in low density thermal insulations [3], has prompted the producers and the users to strive toward increased accuracy in the determination of the thermal resistance. This has been reflected by the active participation of the major manufacturers of insulation, commercial laboratories, and government agencies in the debates of the American Society for Testing and Materials (ASTM). A most active forum for these debates has been ASTM C-16. 30 Subcommittee on Thermal Measurements whose scope states "Develop and maintain test methods and recommended practices relating to the transfer of energy with and through thermal insulating materials and systems" [4].

To assess the measurement capabilities in this field, a task force was established in 1976 under the sponsorship of the Mineral Insulation Manufacturers Association (MIMA)* and later co-sponsored by ASTM C-16.30 Subcommittee on Thermal Measurements, Spring 1977. The objective was to evaluate the measurement capabilities of the thermal insulation community when measuring building insulation at thicknesses beyond which reference standards were available (round robin I). Concurrently, round robin II was established to investigate the influence of plate emittance on the measurement of low density fibrous insulations. In 0ctober of 1979 round robin III was initiated to assist in the evaluation of the NBS line-source GHP [16] and to provide information on the measurement capabilities of the existing equipment when measuring increasing thicknesses of insulation. The results of these three round robins will be of value in establishing the required precision and bias statements for the test methods $\mathrm{C} 177$ and C518. The execution of these three round robins was under the responsibility of C.M. Pelanne, Chairman of Task Force 1.6 on Round Robins, ASTM C-16.30 Subcommittee on Thermal Measurements.

Past round robin studies of a similar nature have been reported [5], [6]. While they may be outdated by recent advances they should be noted for comparison. Several other round robins are currently underway. One sponsored by the International Standards Organization T. C. 163 is being carried out to evaluate the international capabilities of GHP's and HFM's, [7]. Another one sponsored by ASTM Subcommittee $\mathrm{C}-16.30$ is to access the performance of guarded and calibrated hot boxes, [8]. The reports on these two later round robins are expected in the near future.

*Tradenames are included in this report for clarity and completeness. The use of these tradenames does not imply endorsement of these organizations or their products by NBS.

\footnotetext{
${ }^{1}$ Numbers in brackets indicate the literature references at the end of the paper.
} 
Another significant event in the field of thermal insulation measurement is the establishment the National Voluntary Laboratory Accreditation Program (NVLAP) within NBS which is contributing to the improvement of interlaboratory reproducibitity.

The measurement community has made a conscientious effort to produce reliable data. The participants have demonstrated their concern with accuracy and precision of measurement through continuous participation in technical and standards writing organizations throughout the world.

This report provides the analysis of the data from the three recently completed round robins. In addition to all of the pertinent data, other related details are provided for further analysis and study by interested parties.

\title{
2. SCOPE
}

This report presents the results and analysis of data obtained during the course of three round robins carried out over a period of about six years from September 1976 to April 1983. These three round robins, identified as Round Robins I (RR I), II (RR II), and III (RR III) were co-sponsored by ASTM Subcommittee $\mathrm{C}-16.30$ on Thermal Measurement and the Mineral Insulation Manufacturers Association. Twelve testing laboratories representing the following organizations participated in part or all of these three round robins:

Certain-Teed Corporation, Blue Bel1, PA

Dynatech R/D Company, Cambridge, MA

Institute for Research, Houston, TX

Jim Walter Research Corporation, St. Petersburg, FL

Manville Corporation, Denver, CO

National Bureau of Standards, Gaithersburg, MD

National Research Council of Canada, Ottawa, Canada

Owens-Corning Fiberglas Corporation, Granville, $\mathrm{OH}$

Rockwool Industries Inc., Belton, TX

The individual participants and reviewers are listed in Table 13.1 of the Appendix. To facilitate the study of this report it is divided into the following sections:

\author{
Reference Equation \\ Round Robin I \\ Round Robin II \\ Round Robin III
}

\section{OBJECTIVES} follows:

The objectives of the three round robins covered by this report were as

Round Robin I-- To evaluate the thermal measurement capabilities of the thermal insulation community when measuring building insulations at thicknesses beyond which reference standards were available at the time. The tests were performed from September 1976 to June 1980. 
Round Robin II-- To evaluate the thermal insulation testing community's capability when measuring low density thermal insulations, where the effect of apparatus surface plate emittance can have an influence on the results due to radiative heat transfer. The tests were performed from February 1977 to May 1979.

Round Robin III-- To provide information to the National Bureau of Standards for the evaluation of the new line-source guarded hot plate. In addition, to provide information on the measurement capabilities of existing large guarded hot plates for measuring thick insulation when the "effect of thickness" may play a part on the results. The tests were performed January 1980 to April 1983.

In each of the round robins all of the participating laboratories tested the same specimens. However, it should be noted that the measuring plates were not all the same size and, therefore, different portions of the specimens were tested. Further details on the plate sizes and specimen characterization are provided in the following sections and the appendix.

\section{EXPERIMENTAL DATA}

The experimental data were compiled into tabular files for analysis by computer. They were reported by the participants on standardized forms (see appendix). The tabular listings are given in the individual sections. The data in the main body of the report are given in SI units. The original data in Btu units are given in the appendix. The coding methodology of these data tables is also given in the appendix.

Upon completion of the tests by the participants the specimens were cut into sizes corresponding to the test area of each apparatus. The weights and dimensions of the individual pieces were determined in order to calculate the actual test area densities that were used in the analysis. These weights and densities are given in the appendix.

The data are not readily illustrated in graphical form because of the number of variables present in the tables, sometimes over very restricted ranges. For this reason, the dependencies of the data will be conveyed via a reference equation that has been developed to be consistent with the data. Deviations of the data from this equation are graphically presented to illustrate the consistency among the data. The deviation graphs are convenient to determine the interlaboratory and intralaboratory reproducibility. The table below provides the nominal ranges of thickness, temperature, density, fiber diameter, and thermal conductivity for each of the round robins.

\begin{tabular}{lccccc}
$\begin{array}{l}\text { Round } \\
\text { Robin }\end{array}$ & $\begin{array}{c}\text { Thickness } \\
(\mathrm{cm})\end{array}$ & $\begin{array}{c}\text { Mean } \\
\text { Temperature } \\
(\mathrm{K})\end{array}$ & $\begin{array}{c}\text { Density } \\
\left(\mathrm{kg} / \mathrm{m}^{3}\right)\end{array}$ & $\begin{array}{c}\text { Fiber } \\
\text { Diameter } \\
(\mu \mathrm{m})\end{array}$ & $\begin{array}{c}\text { Apparent } \\
\text { Thermat } \\
\text { Conductivity } \\
\left(\mathrm{mW} \cdot \mathrm{m} \mathbf{m}^{-1} \mathrm{~K}^{1}\right)\end{array}$ \\
\hline I & 8.9 & 297 & $12.3-14.6$ & 5.27 & $39.5-43.4$ \\
II & 2.5 & $288-332$ & $10.6-33.5$ & 5.53 & $29.6-56.0$ \\
III & $2.5-10.2$ & 297 & $11.3-19.8$ & 5.00 & $37.4-45.6$
\end{tabular}

For this analysis the fiber diameter of the RR I material was not measured but was arbitrarily chosen to be the average of the fiber diameters of 
RR II and RR III. During the review process the supplier of RR I material indicated that the fiber diameter is more likely about $7 \mu \mathrm{m}$. If this value is used in the comparisons of section 6 , the systematic deviations of the data from the reference equation will be larger than shown. This is relatively unimportant because the main objective of this report is to intercompare test results. The equation is simply a convenient mechanism to accomplish these intercomparisons. The relatively large fiber diameter and concomitant large systematic deviation does indicate, however, the significance of structure parameters other than fiber diameter.

\section{REFERENCE EQUATION}

An optimized reference equation was developed to establish a base of reference for purposes of comparison of the data. The optimization of the parameters in this equation was based on the data from the National Bureau of Standards because it covered the widest range of conditions. The two sets of NBS GHP data (from RR II and RR III) covered the complete range of variables involved, (type of material, density, thickness, and temperature).

As stated earlier this equation was developed primarily as a convenient tool for the intercomparison of the round robin test results. However, the reference equation has been optimized with respect to a data set that is comprehensive and consequently may prove to be useful for future comparisons. The data set on which the equation is based is comprehensive in that it covers several materials; a range of temperature, density, and thickness; and is determined by a national reference laboratory (NBS). It should be noted that no data from RR I was used to optimize the parameters of the equation because the RR I NBS data was obtained with a HFM instead of a GHP.

The selected data are as follows:

1. The specimens used for RR II were supplied by the Manville Research and Development Center, Denver, Colorado. Material from the same lot was measured by the National Bureau of Standards using the $20 \mathrm{~cm}$ ( 8 in) GHP. The data reported by NBS for these measurements covered a 11 to $32 \mathrm{~kg} / \mathrm{m}^{3}(0.7$ to $\left.2.01 \mathrm{~b} / \mathrm{ft}^{3}\right)$ density range, and $\mathrm{a}-18^{\circ} \mathrm{C}$ to $54^{\circ} \mathrm{C}\left(0^{\circ} \mathrm{F}\right.$ to $\left.130^{\circ} \mathrm{F}\right)$ temperature range. These data are given in Table 5.1. More extensive description of this material can be found in the literature [9].

2. The specimens used for RR III were provided by the National Bureau of Standards from a lot of material which is similar to one being considered for the development of low density reference material, $[10,11]$. The material was fabricated especially for the National Bureau of Standards by the Manville corporation. This material has similar characteristics to those of the material used for RR II. Furthermore, these series of tests, as part of RR III, were carried out most extensively by NBS using the $1000 \mathrm{~mm} 7$ ine-source GHP. The specimens were all measured as $25.4 \mathrm{~mm}$ ( $1.0 \mathrm{in}$ ) pairs as well as at increasing thicknesses as required by the round robin. While these tests provided data at only one temperature $24^{\circ} \mathrm{C}\left(75^{\circ} \mathrm{F}\right)$ they provided test data over a range of densities 11.2 to $19.2 \mathrm{~kg} / \mathrm{m}^{3}\left(0.7\right.$ to $\left.1.2 \mathrm{lb} / \mathrm{ft}^{3}\right)$ and over a range of thicknesses 25.4 to $101.6 \mathrm{~mm}$ ( 1.0 to 4.0 inches). The data are shown in Table 5.2. Further explanation of the data in Tables 5.1 and 5.2 is given in the appendix. The data originally presented in Btu units are tabulated in the appendix. 
The reference equation (referred to as the model for convenience) developed for this work is based on the common assumption that the apparent thermal conductivity, $\lambda$, of an insulation is the sum of three components, as indicated in eq (1). This equation is based on the assumption that the components are acting in parallel and independently, i.e. uncoupled.

These components are the interstitial gas conductivity, $\lambda_{g}$, (here the gas is air), the solid conductivity, $\lambda_{s}$, (glass fiber plus phenolie binder), and the radiation conductivity, $\lambda_{r}$.

$$
\lambda=\lambda_{g}+\lambda_{s}+\lambda_{r}
$$

The mathematical form and justification of each of these components is given below.

$$
\begin{gathered}
\lambda_{g}=P_{3}\left[10^{-3}\left(148.503+94.5425 T-0.0263568 T^{2}\right)+\right. \\
\left.P_{5}(T / 296-1)\right](2500-D) / 2500
\end{gathered}
$$

where $T$ is temperature in $K, D$ is density in $\mathrm{kg} / \mathrm{m}^{3}$, and $P_{3}$ and $P_{5}$ parameters to be optimized.

The first three terms in eq (2) are a representation of the free-air thermal conductivity as obtained at NBS by L.J. Van Poolen (private communication). The $P_{5}$ term is a small adjustment to the temperature slope of the free-air conductivity to optimize the fit of these round robin data. The density term in eq (2) accounts for the volume fraction occupied by the glass fibers. Finally the parameter $P_{3}$ is essentially the gas form factor adjustment accounting for the distribution and structure of the glass fibers within the gas.

$$
\lambda_{S}=P_{1} D(T / 296) / 2500
$$

where $P_{1}$ is a parameter to be optimized.

Equation 3 is an approximation of the solid component (glass fiber) of thermal conductivity. The conductivity of bulk glass is known to depend on temperature with a power between 0.5 and 1.0. Since this term is a very small component of the total only a rough approximation is required. Thus, for simplicity, the power was chosen to be 1.0. The density dependence chosen indicates that the term increases linearly with increasing fiber content. The parameter, $P_{1}$, is dependent on the bulk glass conductivity and the tortuosity factor of the fibers and the phenolic binder.

$$
\lambda_{r}=P_{4} \sigma 4 T^{3} /\left(P_{2} D / F^{0.5}+(2 / \varepsilon-1) / L\right)
$$

where $\sigma=5.670310^{-5} \mathrm{~mW} \cdot \mathrm{m}^{-2} \cdot \mathrm{K}^{-4}, \mathrm{~F}=$ fiber diameter in $\mu \mathrm{m}, \mathrm{L}$ is the specimen thickness in meters, and $\varepsilon=$ emittance of the plates.

Equation 4 is the radiation component as given by the Stefan-Boltzmann radiation law for small temperature differences. The first term in the denominator accounts for the fiber density between the measuring plates and, in addition, the effect of fiber diameter on the radiation conductivity. The form of the fiber diameter dependence was based on unpublished data [18]. The second 
term in the denominator accounts for plate emittance and plate spacing. It is noted that the specific correlation of fiber diameter with thermal conductivity will depend in part on pack structure and fiber diameter distribution. Thus, the values obtained for a given product may not be applicable to other products.

As explained earlier, the two sets of NBS data were chosen to optimize the parameters in the model. The first set of NBS data was obtained on specimens taken from the same lot as RR II. The second set of NBS data was obtained on the RR III specimens. These two sets of data are plotted as a function of density in figure 5.1, as a function of temperature in figure 5.2, and as a function of thickness in figure 5.3. To distinguish the data between sets 1 and 2 , the data from set 1 are separately plotted as a function of density in figure 5.4 and as a function of temperature in figure 5.6. The data from set 2 are plotted as a function of density in figure 5.5 and as a function of thickness in figure 5.7. For convenience to the reader, in figures 5.1 and 5.4 solid 1 ines have been superimposed to identify the approximate temperatures at which the data were obtained.

Nonlinear least squares techniques were used to optimize the parameters of the model. The optimized values of the parameters are given below:

$$
\begin{array}{ll}
P_{1}=71.87 & P_{3}=1.074 \\
P_{2}=144.5 & P_{4}=2.0
\end{array} P_{5}=4.0
$$

The deviations of the NBS experimental data from the model are displayed in figures 5.8 through 5.14 in the same sequence as figures 5.1 through 5.7. In each of these and subsequent deviation plots the average deviation of the data from the model and the $2 \mathrm{~s}$ value are shown. The percentage deviations (observed minus calculated) are also listed in the last column of tables 5.1 and 5.2. Within the imprecision of the data no systematic trends in the deviations are obvious either as a function of density or temperature. Typical dependencies of the model are illustrated in figures 5.15 through 5.22 .

Figure 5.15 illustrates the dependency of thermal conductivity on density from 10 to $40 \mathrm{~kg} / \mathrm{m}^{3}$ at 250,300 , and $350 \mathrm{~K}$ and for a plate emittance of 0.95 , a thickness of $2.54 \mathrm{~cm}$ and a fiber diameter of $5.0 \mu \mathrm{m}$. The increase in thermal conductivity at decreasing densities is caused by the increase in the radiation component. The expected minimum in the curves caused by decreasing radiation component and increasing solid component with increasing density occurs above $40 \mathrm{~kg} / \mathrm{m}^{3}$.

Figure 5.16 illustrates the dependency of thermal conductivity on temperature from 250 to $350 \mathrm{~K}$ at densities of $10,20,30$, and $40 \mathrm{~kg} / \mathrm{m}^{3}$ and for an emittance of 0.95 , a thickness of $2.54 \mathrm{~cm}$, and a fiber diameter of $5.0 \mu \mathrm{m}$. At high densities the dependency is nearly linear because the conductance is caused by the gas and solid components. At low density the cubic dependency of the radiation term is more dominant.

Figure 5.17 illustrates the dependency of thermal conductivity on specimen thickness from 2 to $16 \mathrm{~cm}$ for densities of $10,12,14 \mathrm{~kg} / \mathrm{m}^{3}$ at a temperature of $300 \mathrm{~K}$, an emittance of 0.95 , and a fiber diameter of $5.0 \mu \mathrm{m}$. The 
thickness effect from 2 to $16 \mathrm{~cm}$ is $2.7,2.1$, and $1.6 \%$ at densities of 10,12 , and $14 \mathrm{~kg} / \mathrm{m}^{3}$, respectively. One, of course, expects the thickness effect to decrease with increasing density due to the decreasing radiation component.

Figure 5.18 shows the dependency of thermal conductivity on plate emittance from 0.5 to 1 for thicknesses of $2,4,8$, and $16 \mathrm{~cm}$ at a density of $10 \mathrm{~kg} / \mathrm{m}^{3}$, temperature of $300 \mathrm{~K}$, and fiber diameter of $5.0 \mu \mathrm{m}$. Plate emittances were not reported for the experimental data and are assumed to be 0.95 , consistent with the $\mathrm{C} 177$ specification. Consequently, the dependency of the model on emittance is an inherent characteristic of the design of the model rather than an indication of the behavior of the data. It is possible that the actual emittances of the various plates may range from 0.75 to 0.95 . This model would thus predict a possible variation of $1.6 \%$ in the measured conductivities at a thickness of $2 \mathrm{~cm}$. Less variation would be predicted at greater thicknesses, larger densities, and lower temperatures. This potential variation is a strong argument for requiring the documentation of the emittance for any measurement in which the radiation component is significant.

Figure 5.19 depicts the dependency of thermal conductivity on fiber diameter from 5.0 to $6.0 \mu \mathrm{m}$ at $300 \mathrm{~K}, 2.54 \mathrm{~cm}$ thickness, a density of $10 \mathrm{~kg} / \mathrm{m}^{3}$, and an emittance of 0.95. Again the depicted dependency is more an inherent characteristic of the model rather than the behavior of experimental data because fiber diameter is not well known for these insulations. In any event, the model predicts a $4.6 \%$ increase in conductivity over this range of fiber diameter.

Figure 5.20 illustrates the thermal conductivity dependency on thickness from 2 to $16 \mathrm{~cm}$ at emittances of $0.8,0.9$, and 1.0 , at a temperature of $300 \mathrm{~K}$, density of $10 \mathrm{~kg} / \mathrm{m}^{3}$, and a fiber diameter of $5.0 \mu \mathrm{m}$. The variation caused by this range of emittances at $16 \mathrm{~cm}$ thickness is only $0.2 \%$ while at $2 \mathrm{~cm}$ it is 1.4\%. This model also shows an increased thickness effect at lower plate emittance. It should be noted, however, that this is not based on experimental data, since the plate emittances were not reported in this study.

Figure 5.21 is a comparison of the magnitudes of the three components in the model as a function of density from 10 to $40 \mathrm{~kg} / \mathrm{m}^{3}$ at $300 \mathrm{~K}, 2.54 \mathrm{~cm}$ thickness, 0.95 emittance, and $5.0 \mu \mathrm{m}$ fiber diameter. A logarithmic axis was chosen here for thermal conductivity so that the three components could be more accurately compared. It should be noted that the solid component is only about $1 \%$ of the total at $10 \mathrm{~kg} / \mathrm{m}^{3}$ and about $2.5 \%$ at $40 \mathrm{~kg} / \mathrm{m}^{3}$. The radiation component is about $40 \%$ of the total at $10 \mathrm{~kg} / \mathrm{m}^{3}$ and $14 \%$ at $40 \mathrm{~kg} / \mathrm{m}^{3}$.

Figure 5.22 also compares the magnitudes of the three components but as a function of temperature from 250 to $350 \mathrm{~K}$ at $2.54 \mathrm{~cm}$ thickness, 0.95 emittance and $5.0 \mu \mathrm{m}$ fiber diameter and a density of $10 \mathrm{~kg} / \mathrm{m}^{3}$. It is noted that the radiative component becomes relatively larger with increasing temperature while the gas and solid components become relatively smaller. This is expected because the power dependence of the radiative term is cubic in temperature while the gas and solid terms are nearly linear in temperature. 


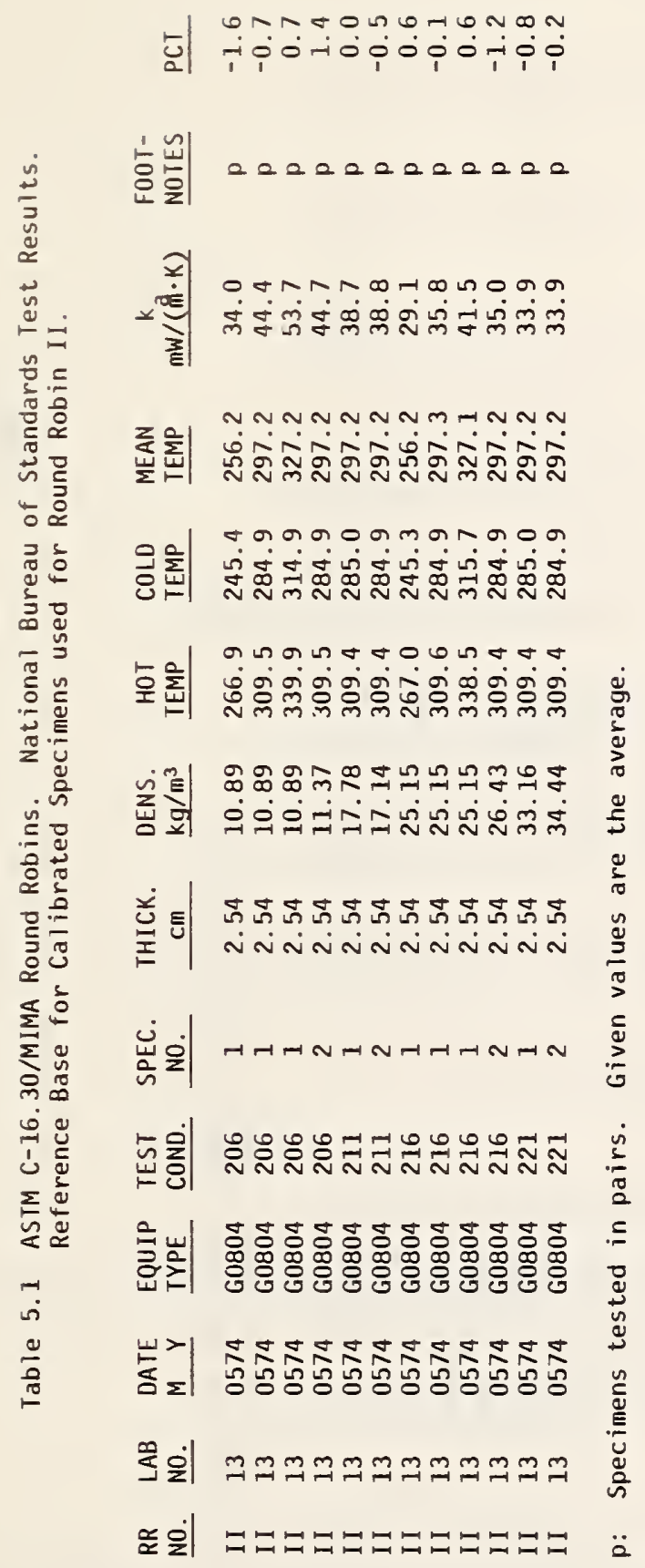




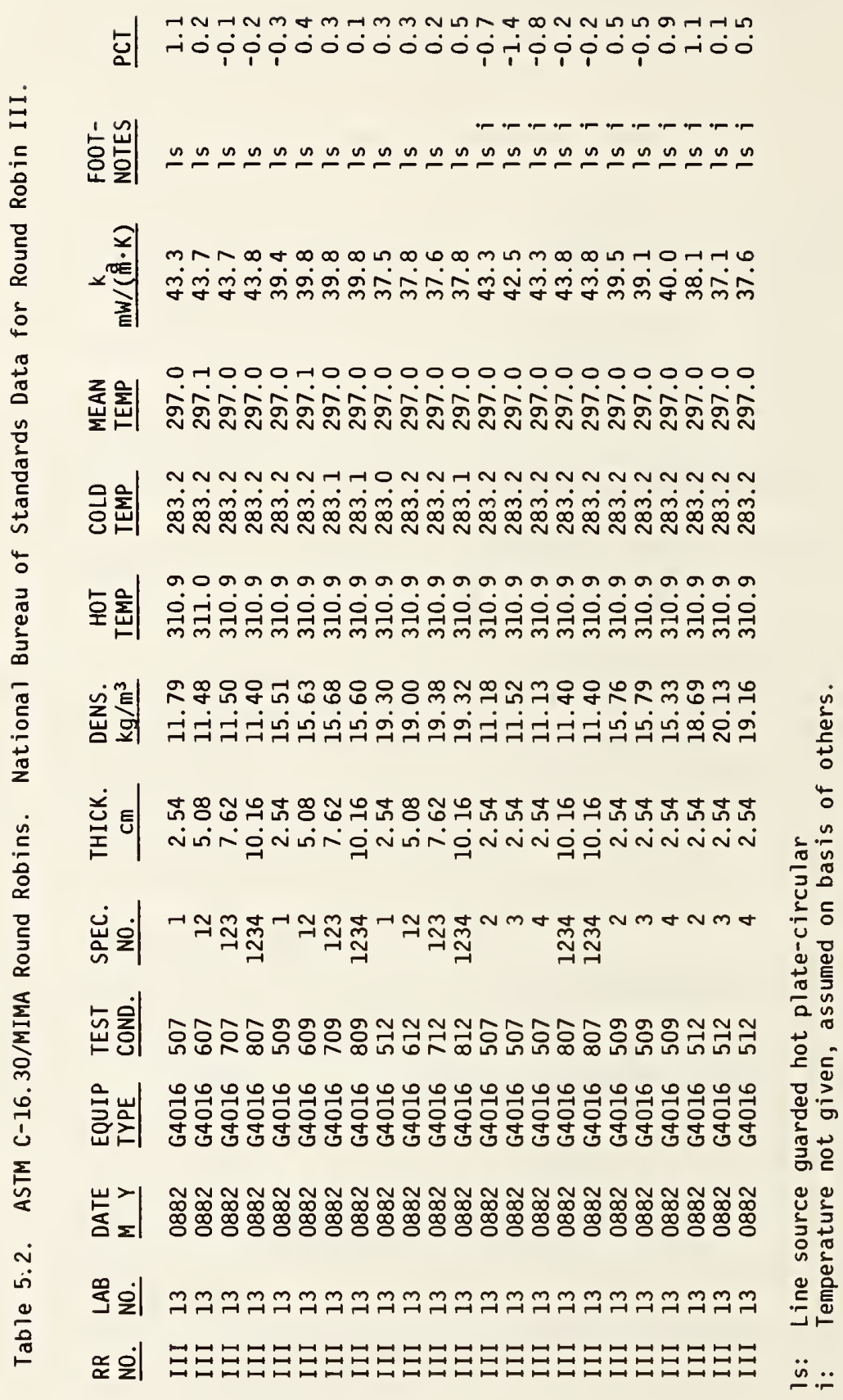




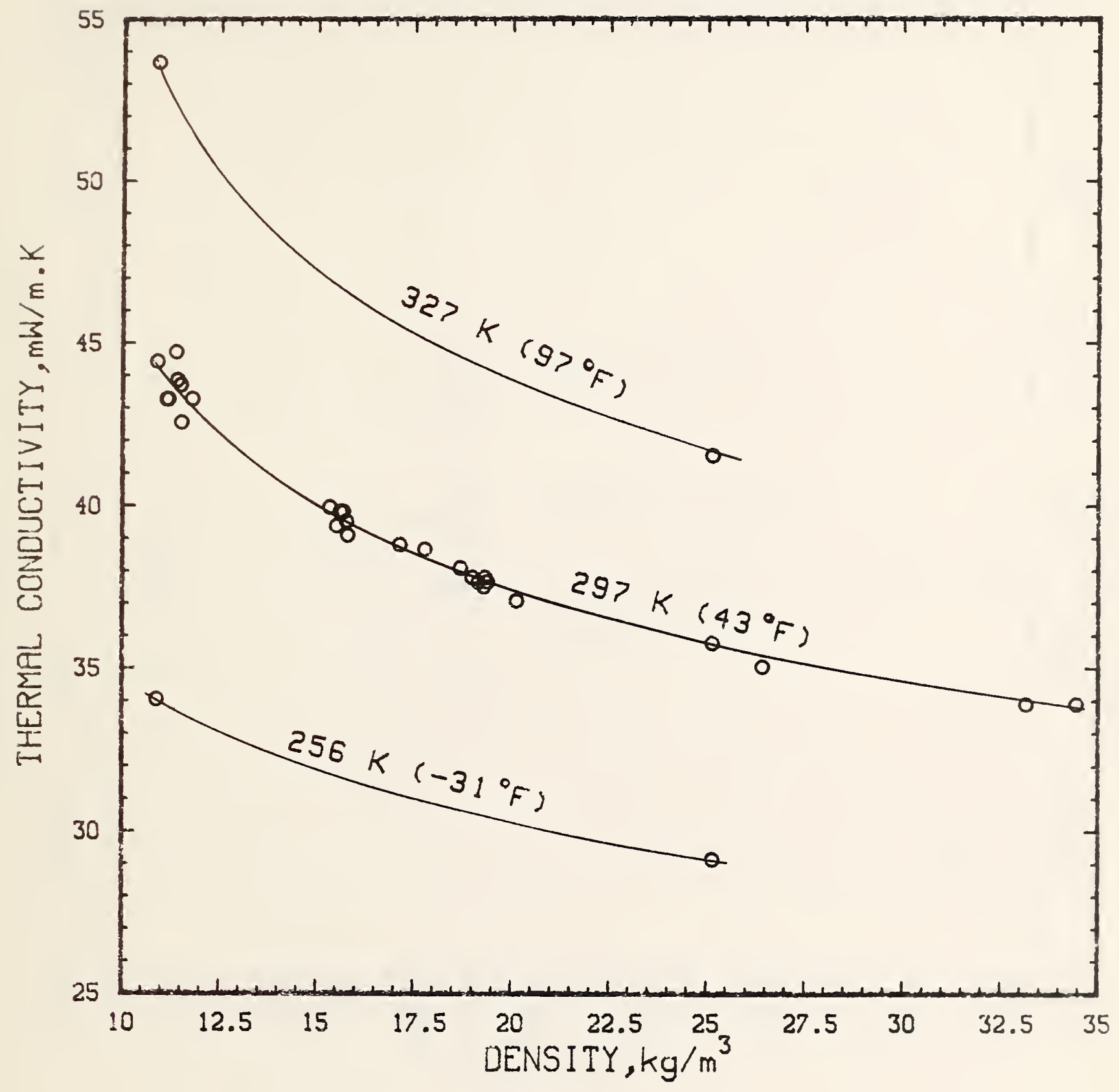

Figure 5.1 Thermal Conductivity versus Density of NBS Data on Round Robin II and III (The lines show the approximate temperature of the data.) 


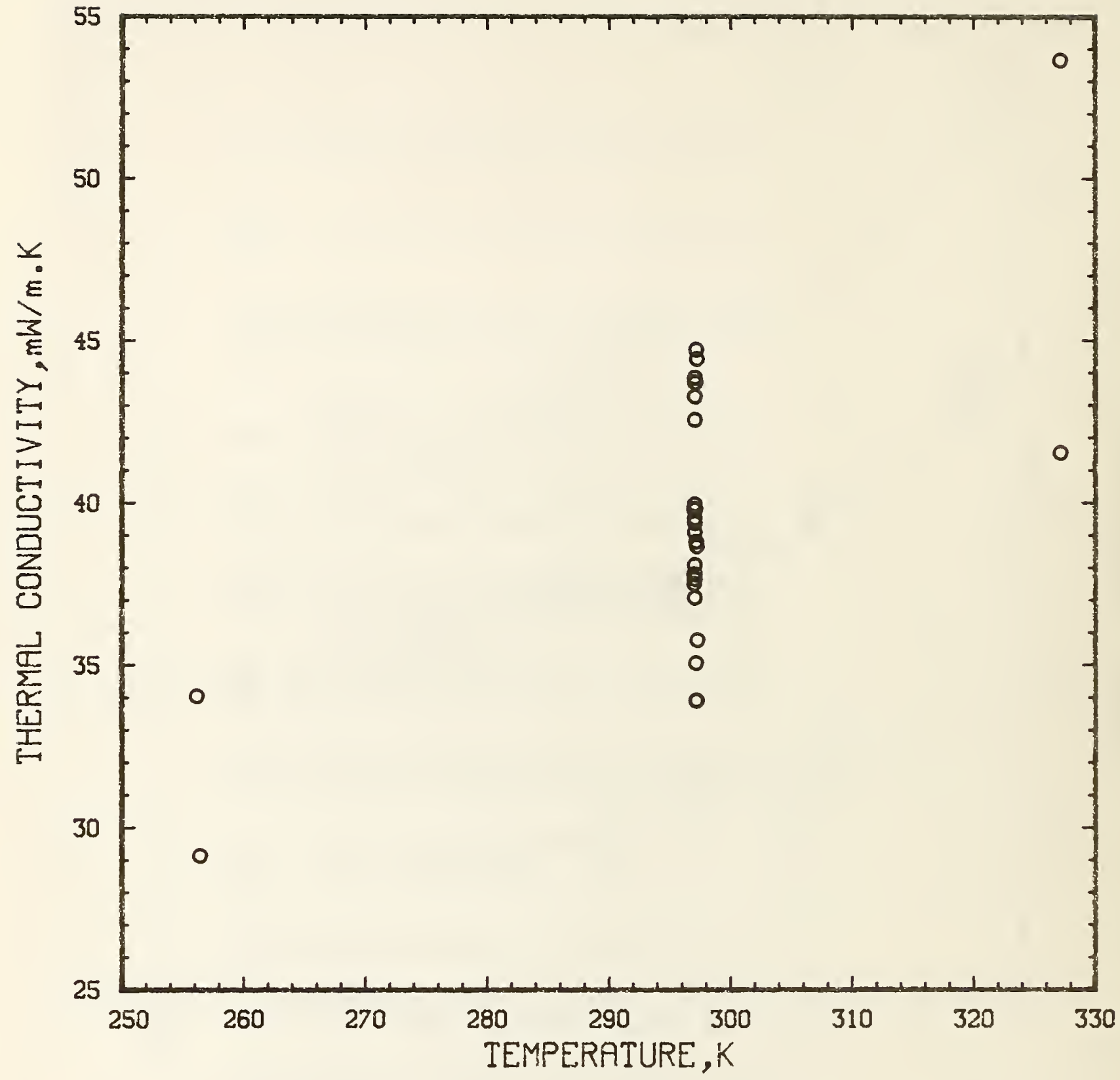

Figure 5.2 Thermal Conductivity versus Temperature of NBS Data on Round Round II and III. 


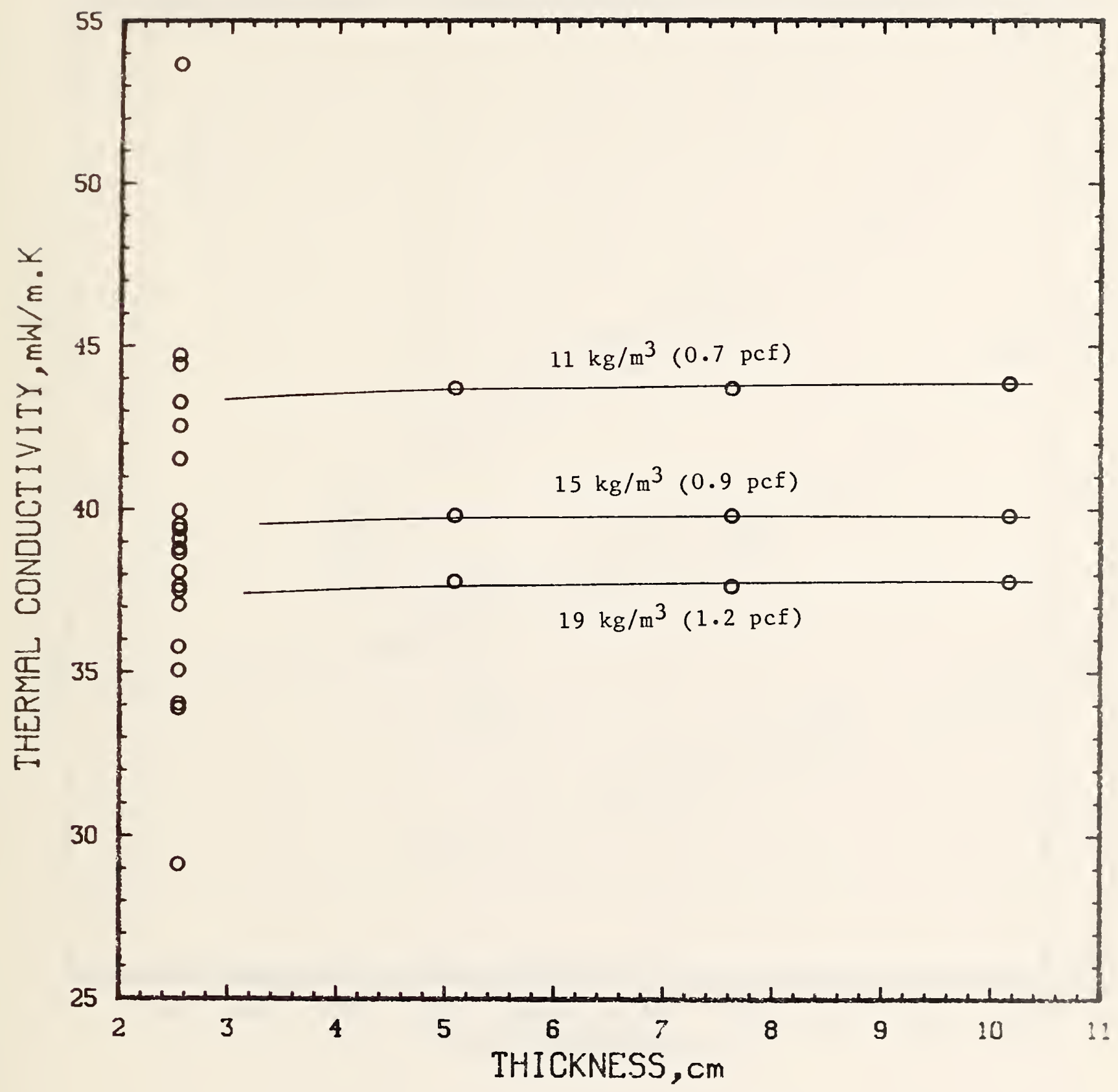

Figure 5.3 Thermal Conductivity versus Thickness of NBS Data on Round Robin II and III. (The 1 ines show the approximate densities of the data at a mean temperature of $297 \mathrm{~K}$.) 


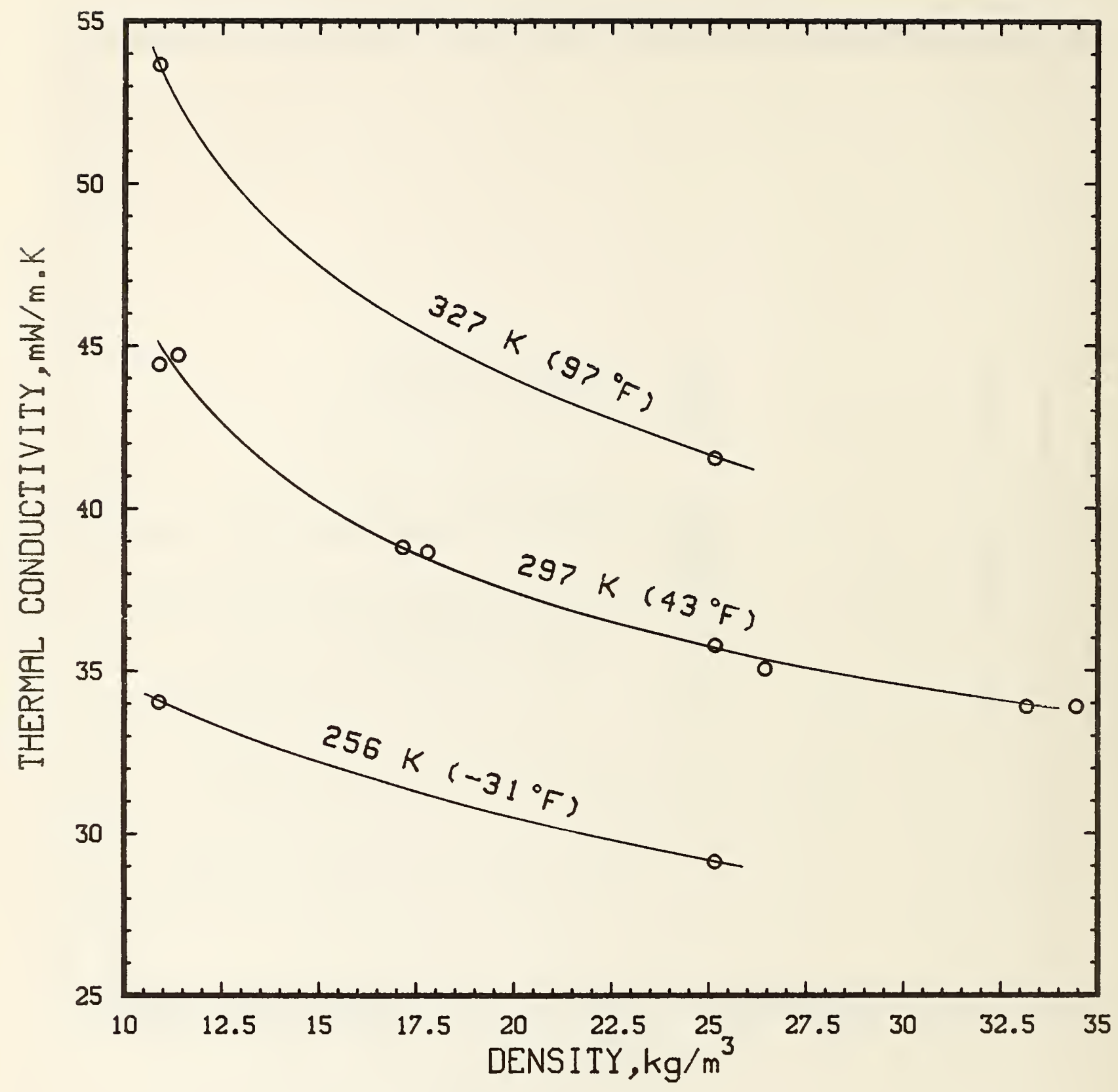

Figure 5.4 Thermal Conductivity versus Density of NBS Data on Round Robin II. (The lines show the approximate temperature of the data.) 


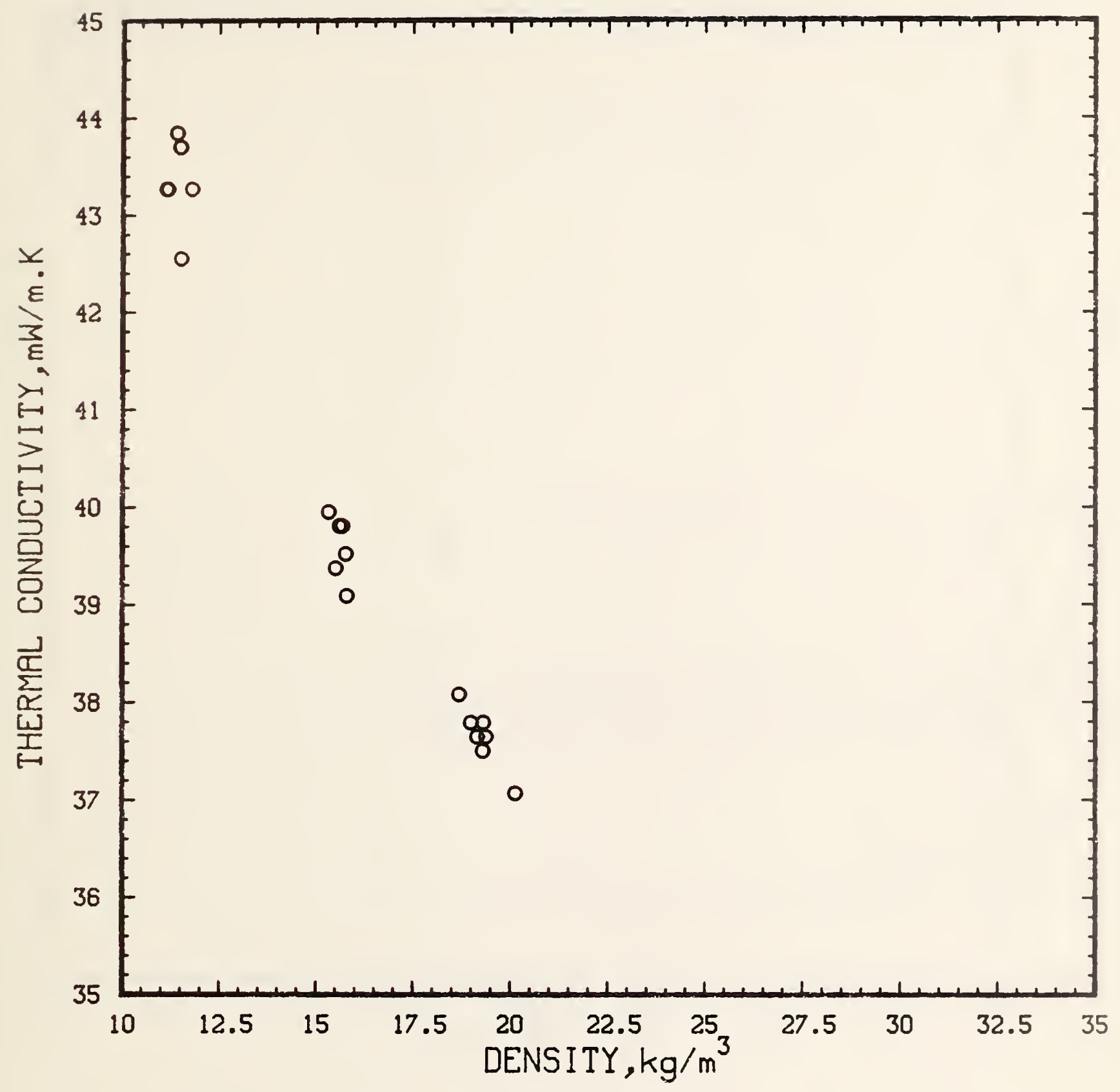

Figure 5.5 Thermal Conductivity versus Density of NBS Data on Round Robin III. 


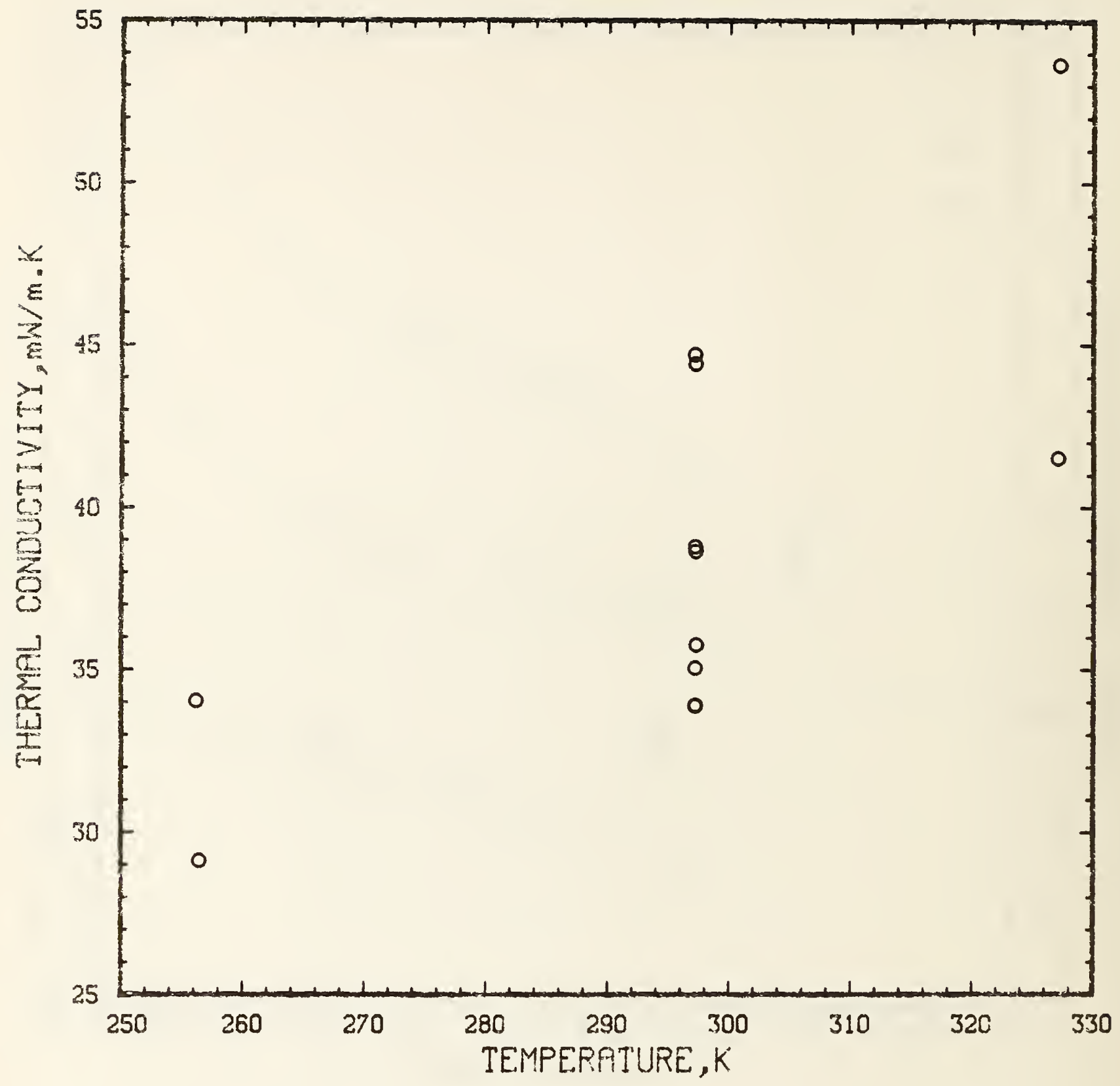

Figure 5.6 Thermal Conductivity versus Temperature of NBS Data on Round Robin II. 


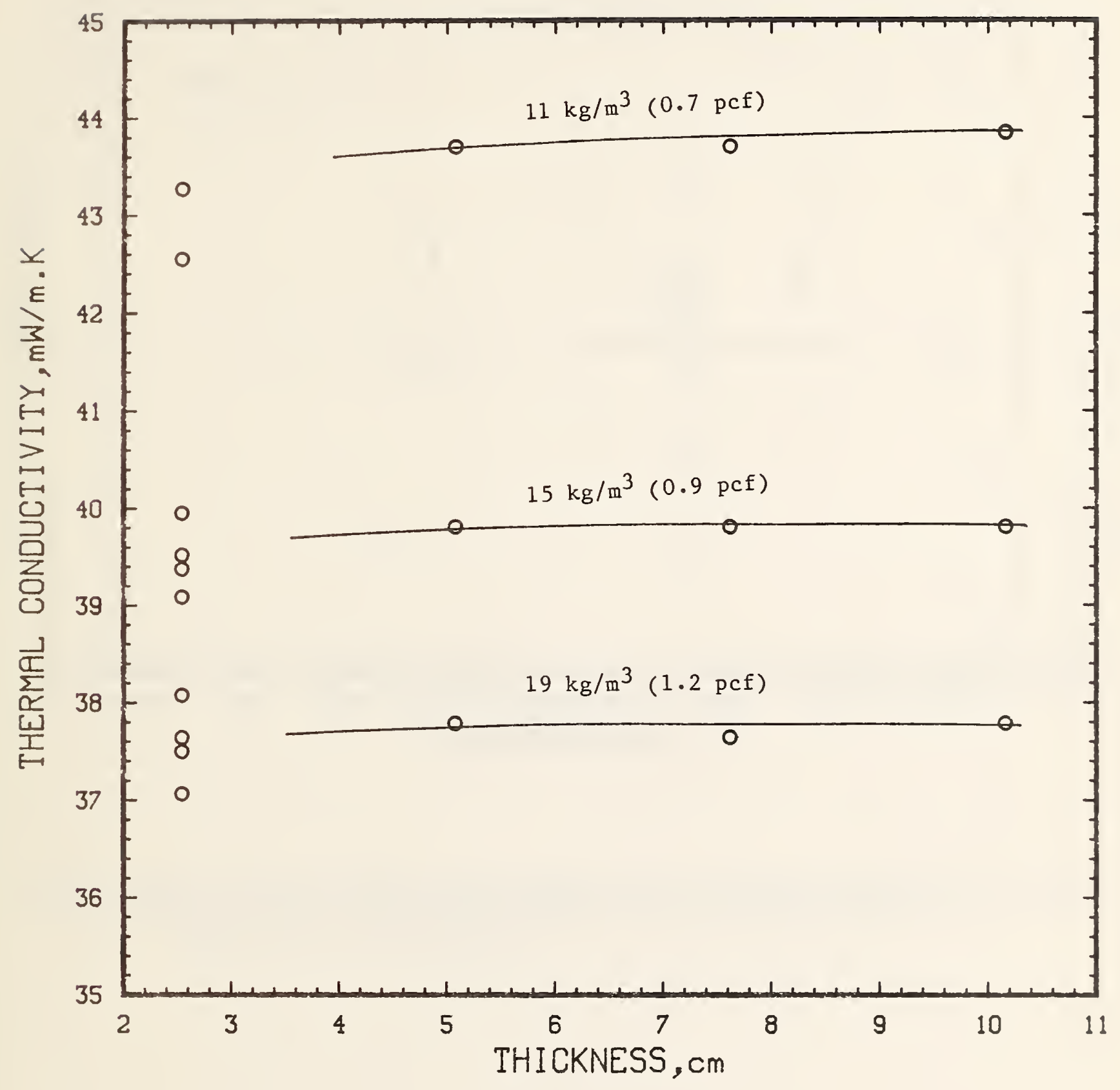

Figure 5.7 Thermal Conductivity versus Thickness of NBS Data on Round Robin III. (The 7 ines show the approximate densities of the data at a mean temperature of 297 K.) 


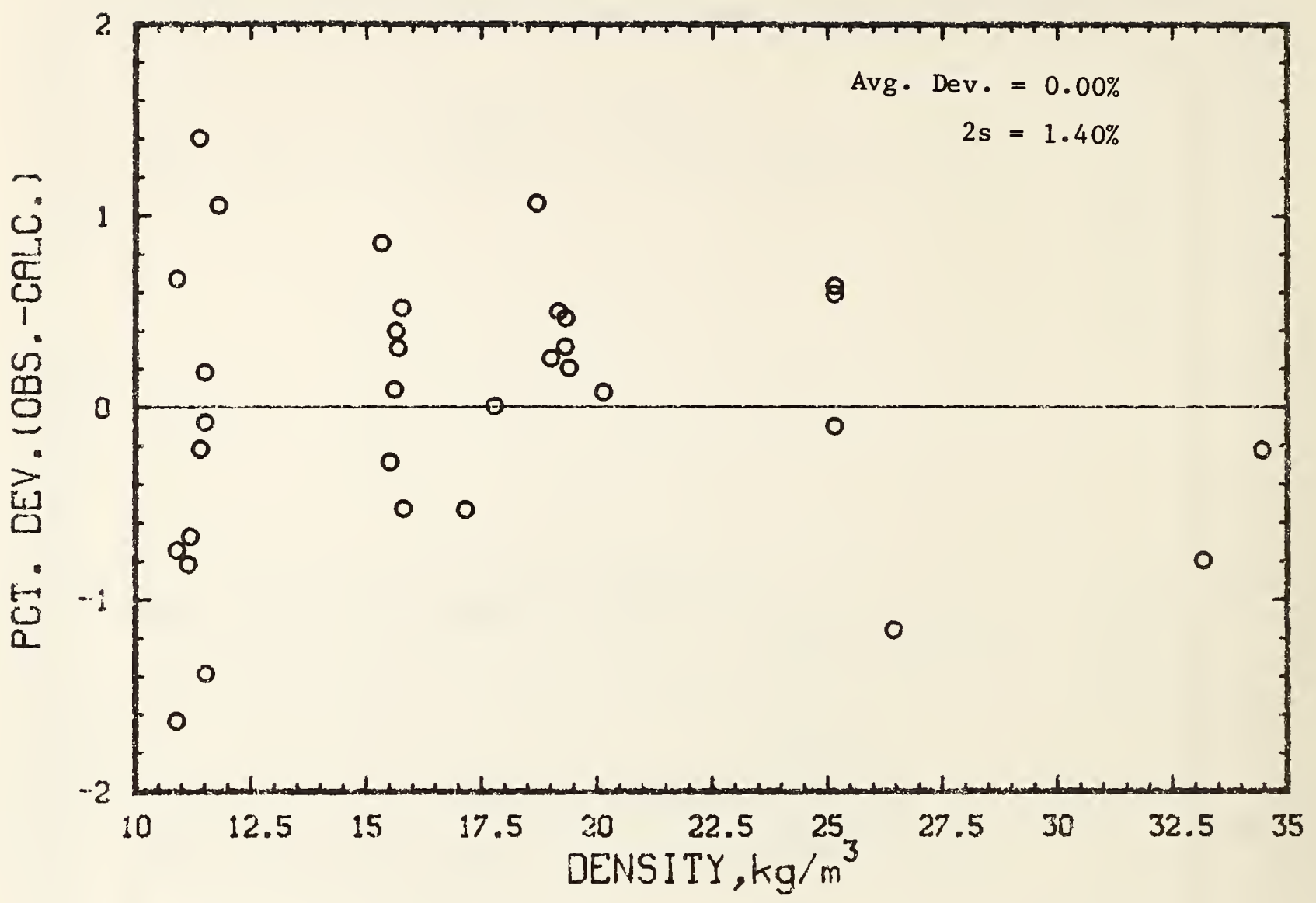

Figure 5.8 Deviations between Thermal Conductivity Data of NBS on Round Robin II and III and Values Calculated from the Model versus Density. 


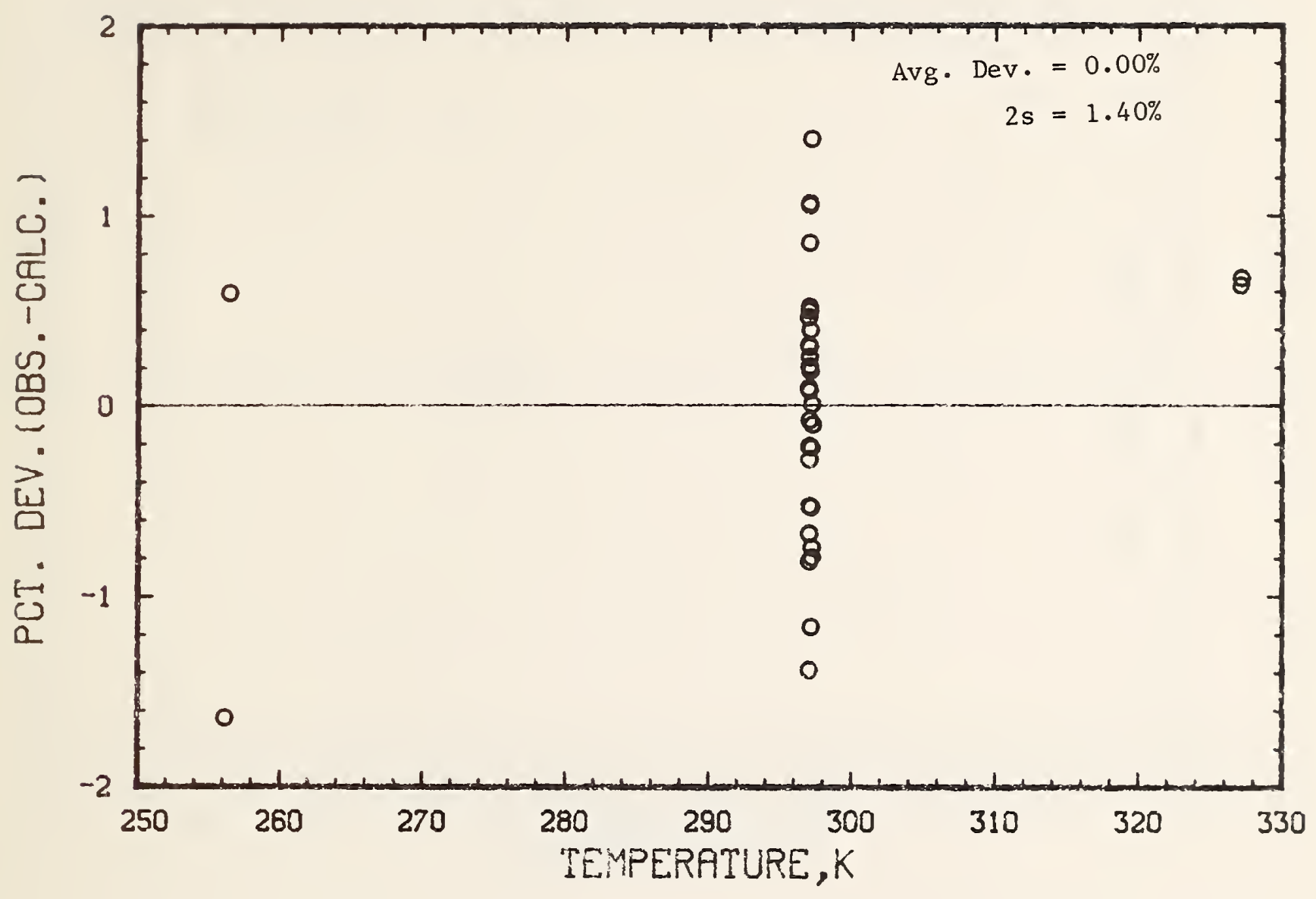

Figure 5.9 Deviations between Thermal Conductivity Data of NBS on Round Robin II and III and Values Calculated from the Model versus Temperature 


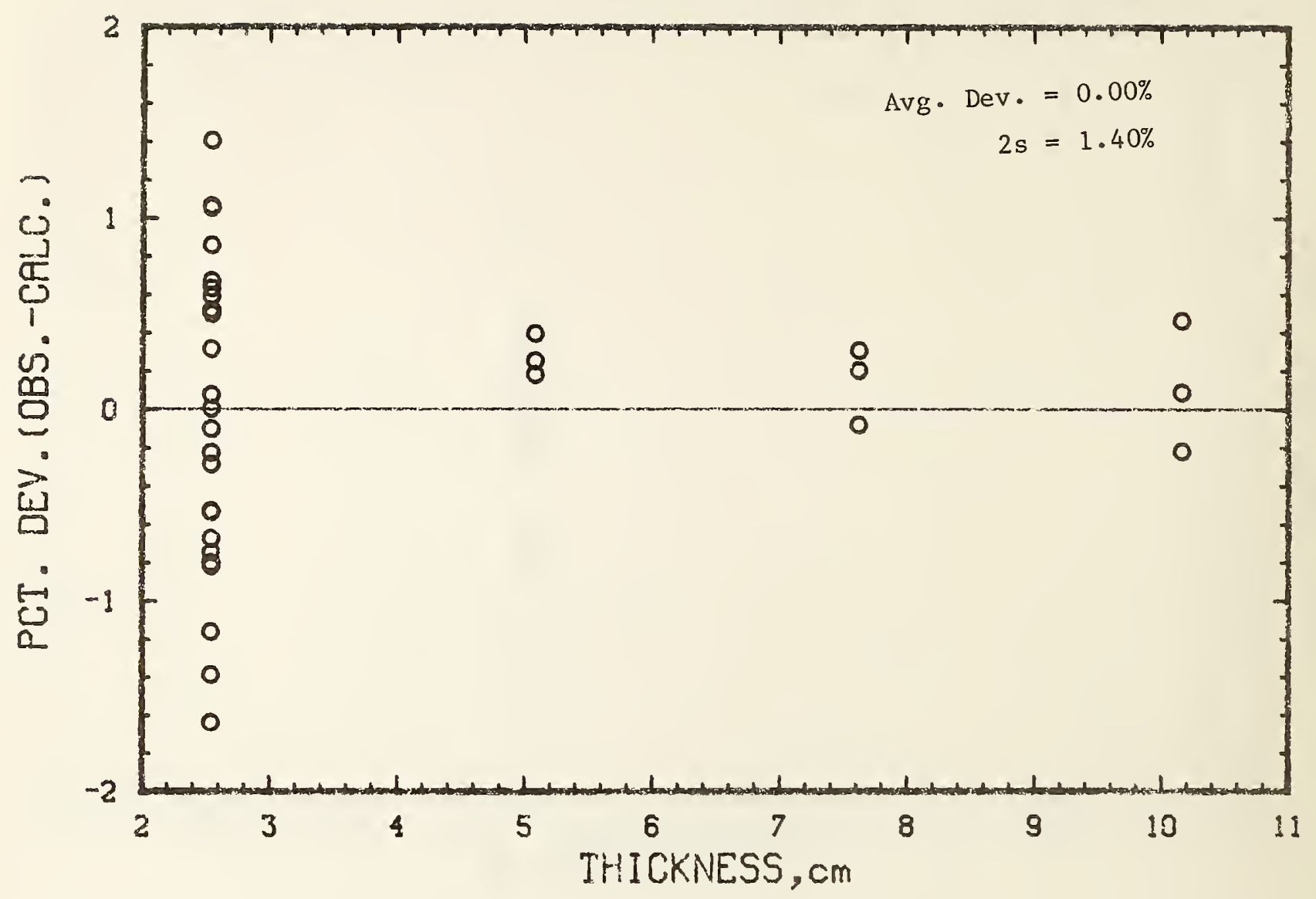

Figure 5.10 Deviations between Thermal Conductivity Data of NBS on Round Robin II and III and Values Calculated from the Model versus Thickness. 


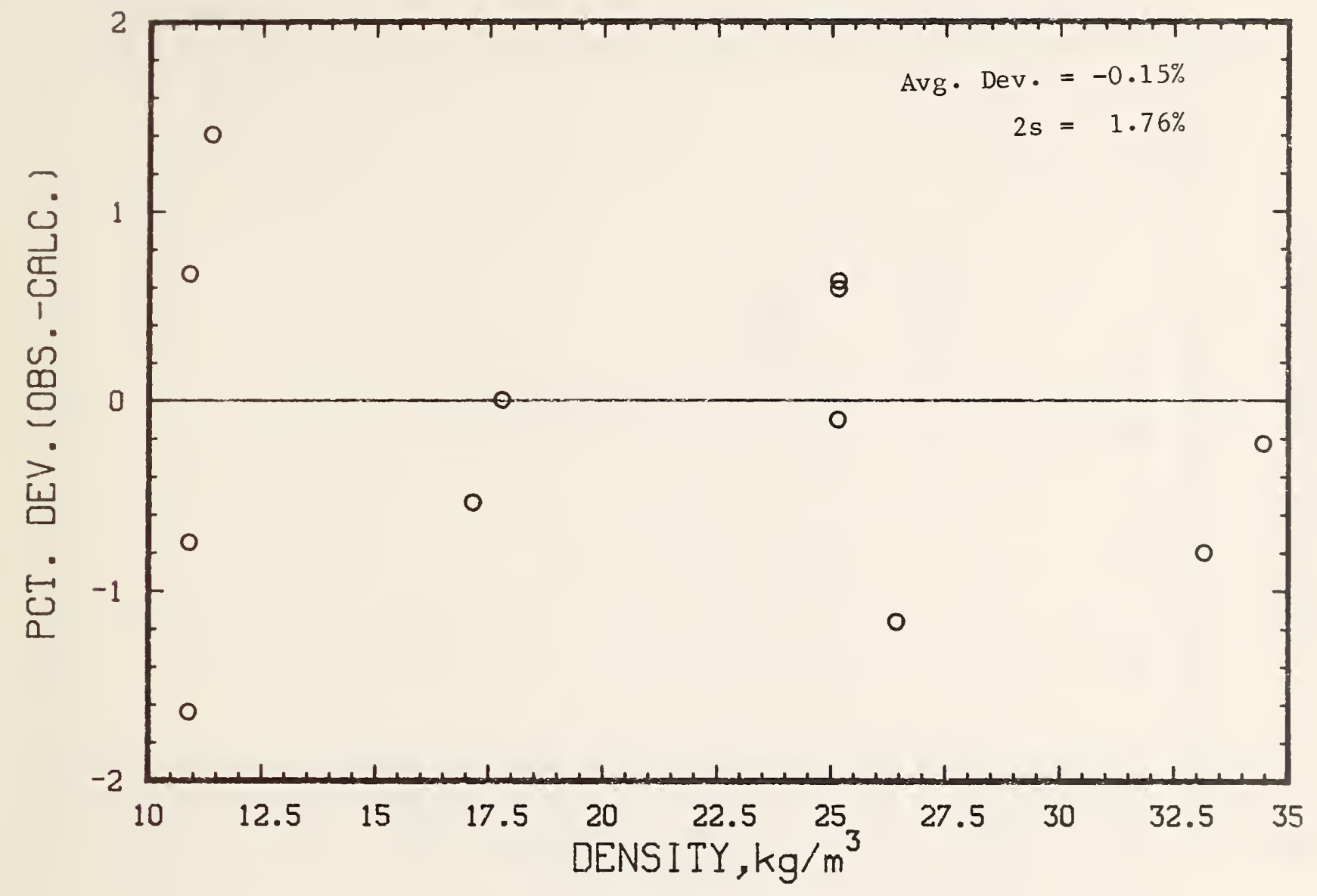

Figure 5.11 Deviations between Thermal Conductivity Data of NBS on Round Robin II and Values Calculated from the Model versus Density. 


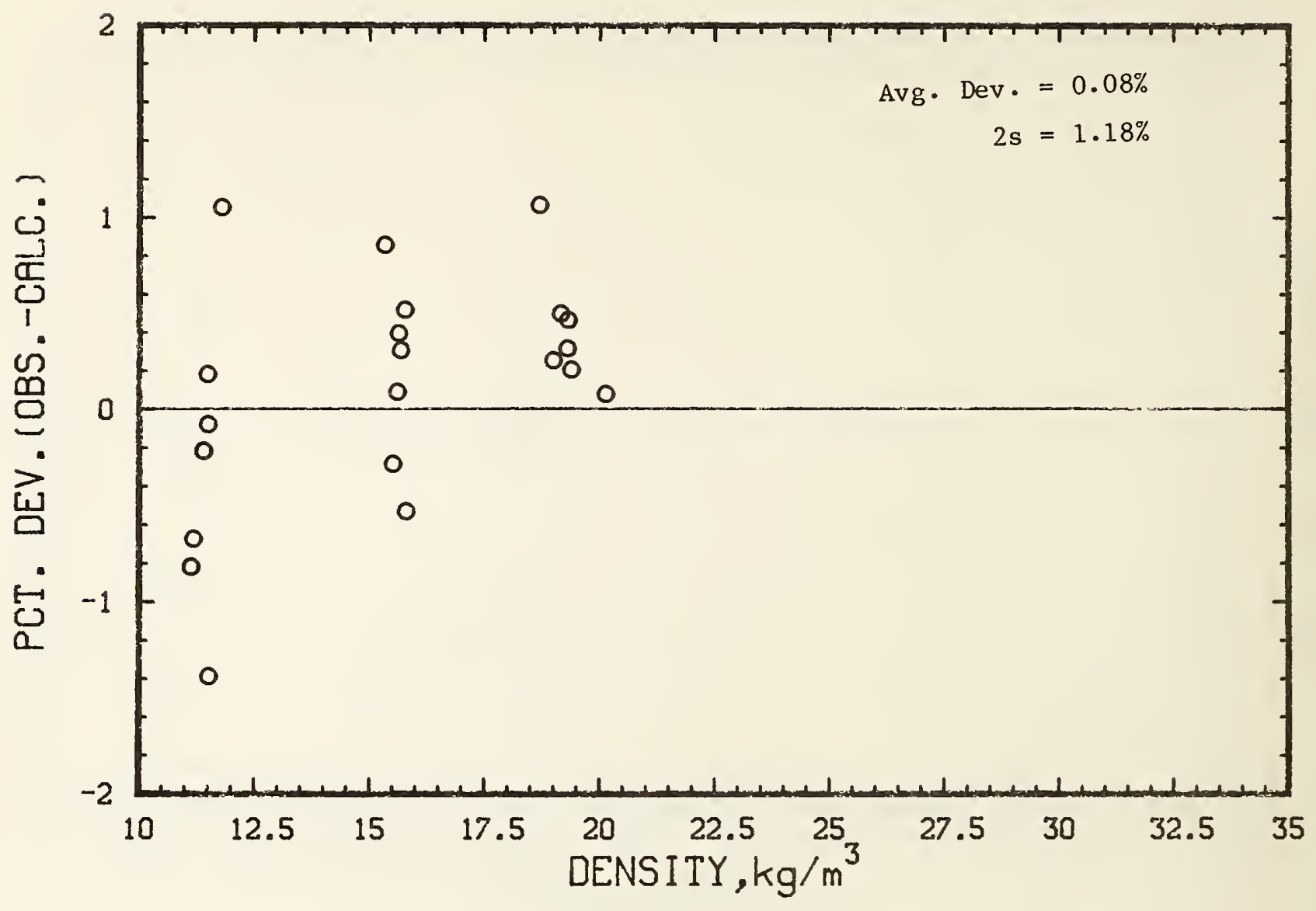

Figure 5.12 Deviations between Thermal Conductivity Data of NBS on Round Robin III and Values Calculated from the Model versus Density. 


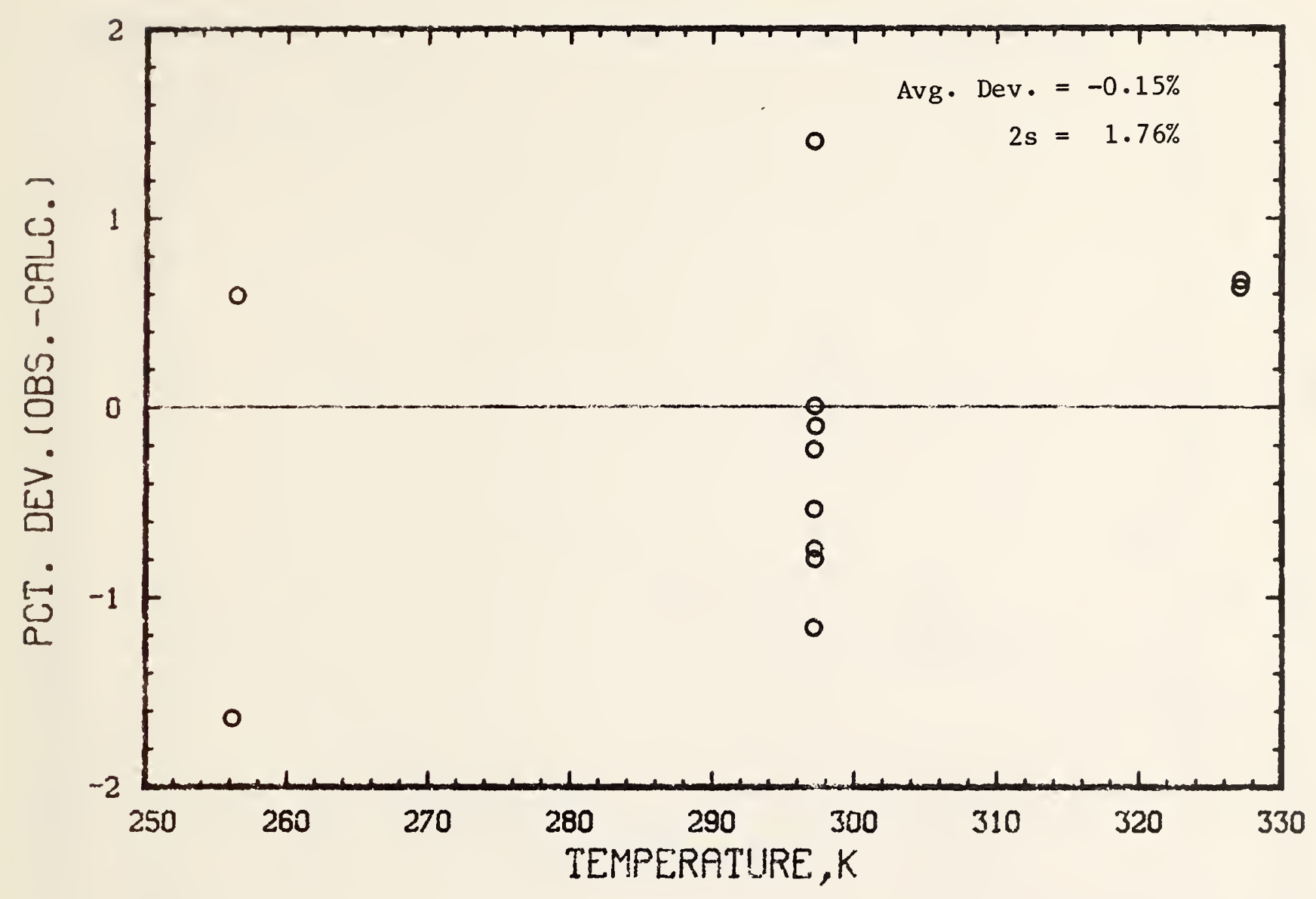

Figure 5.13 Deviations between Thermal Conductivity Data of NBS on Round Robin II and Values Calculated from the Model versus Temperature. 


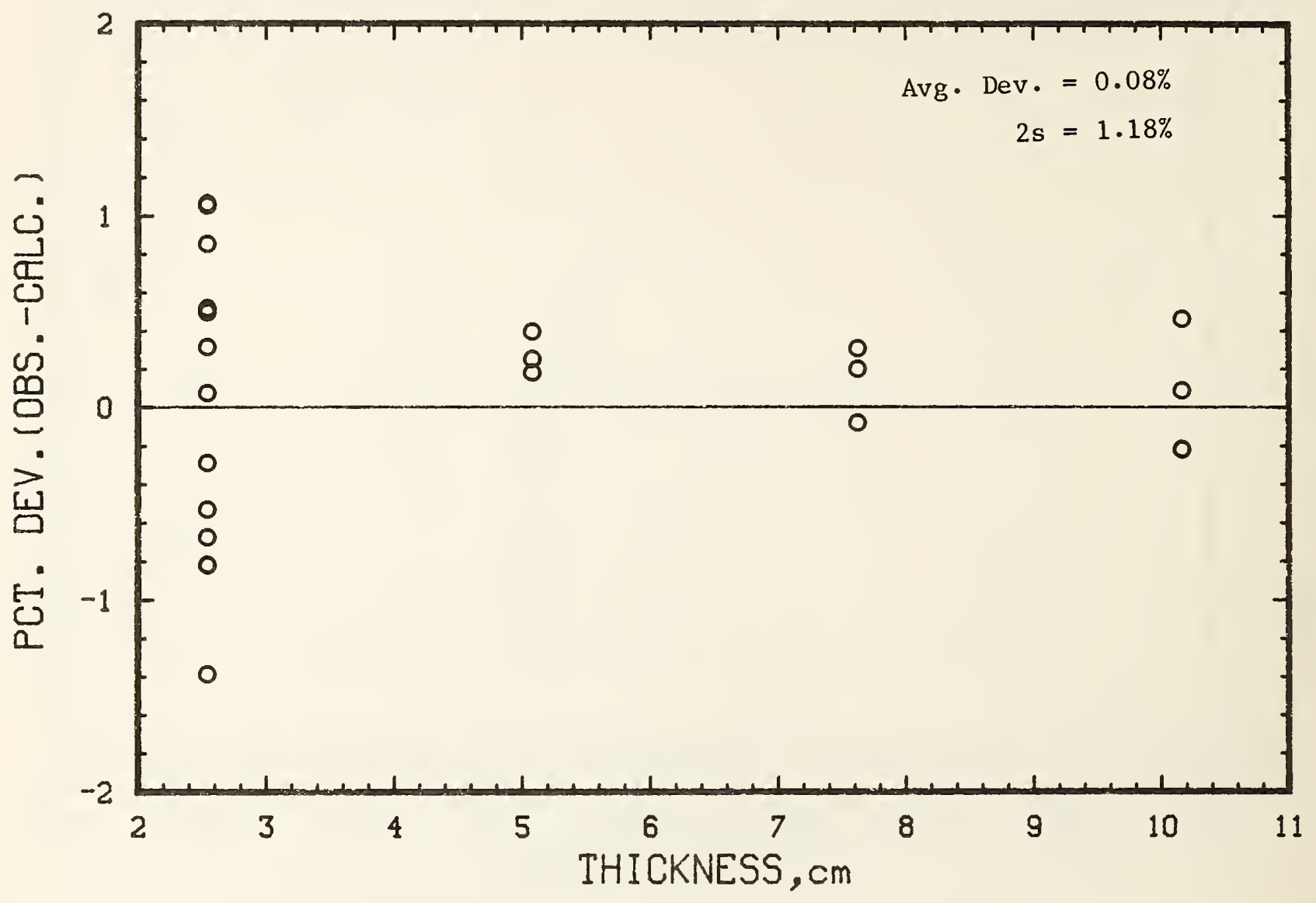

Figure 5.14 Deviations between Thermal Conductivity Data of NBS on Round Robin III versus Thickness. 


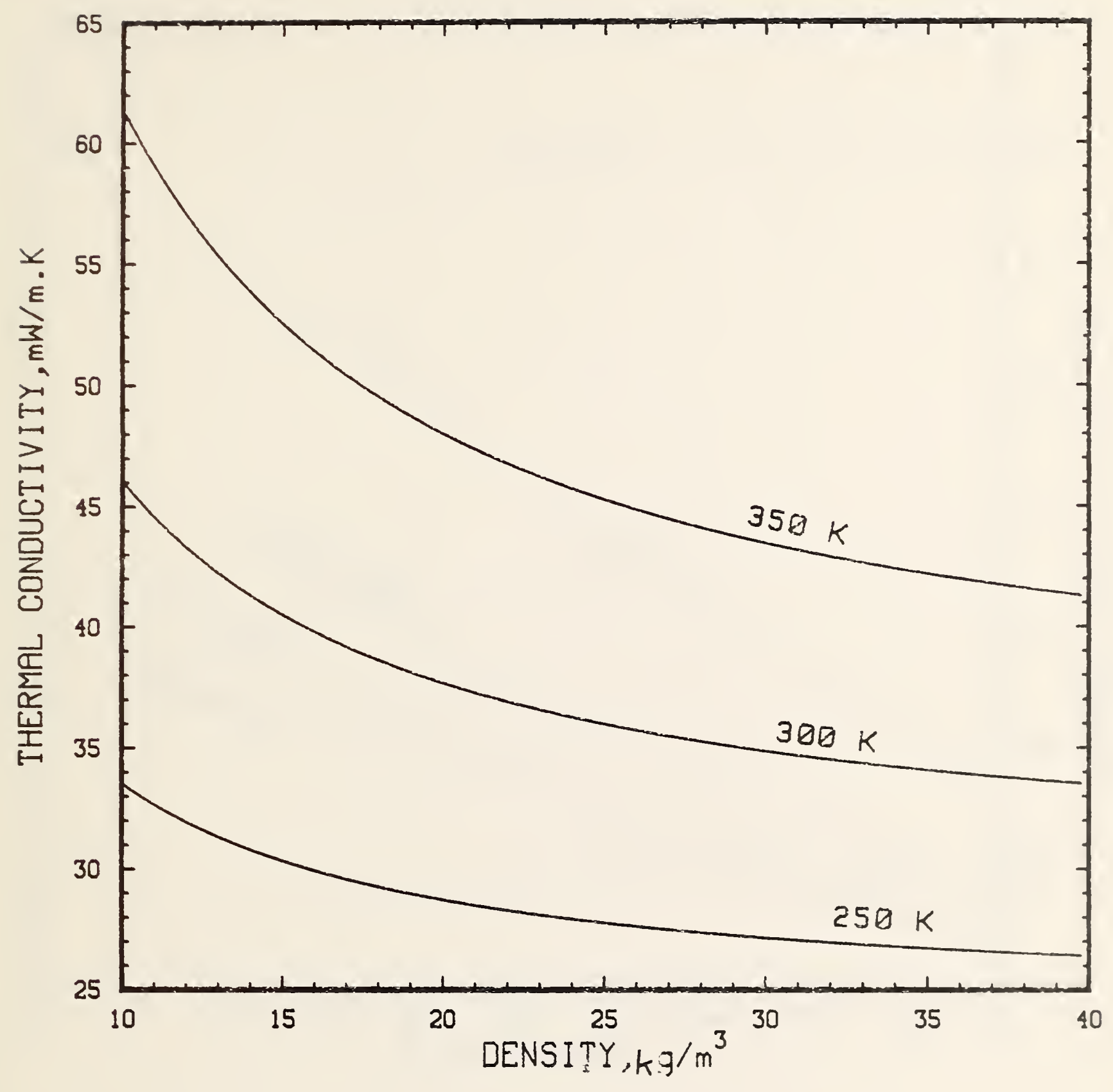

Figure 5.15 Thermal Conductivity versus Density for Several Temperatures as Calculated from the Model. Emittance $=0.95$, Thickness $=2.54 \mathrm{~cm}$, and Fiber Diameter $=5.0 \mu \mathrm{m}$ 


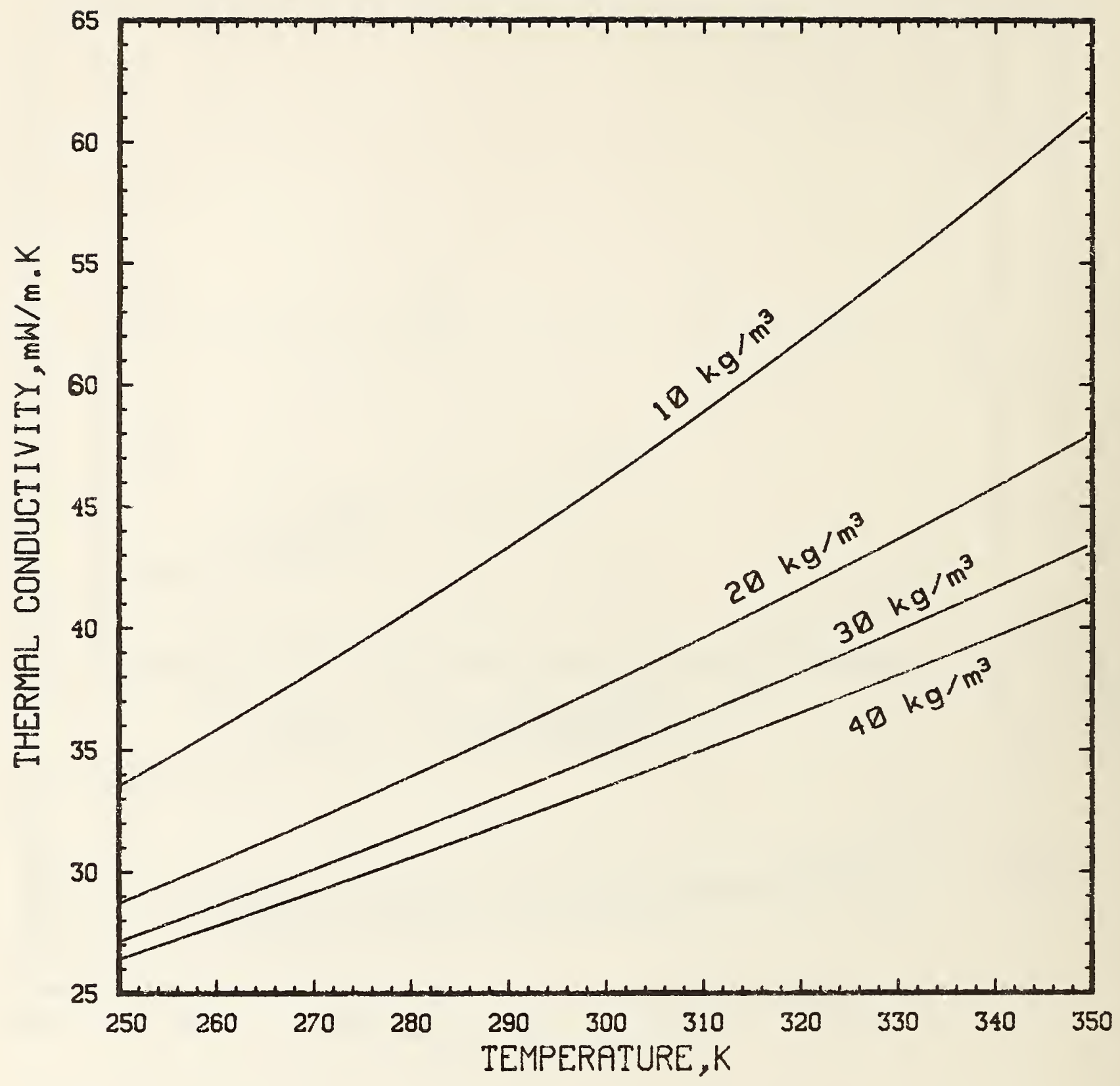

Figure 5.16 Thermal Conductivity versus Temperature for Several Densities as Calculated from the Model. Emittance $=$ 0.95 , Thickness $=2.54 \mathrm{~cm}$, and Fiber Diameter $=5.0 \mu \mathrm{m}$ 


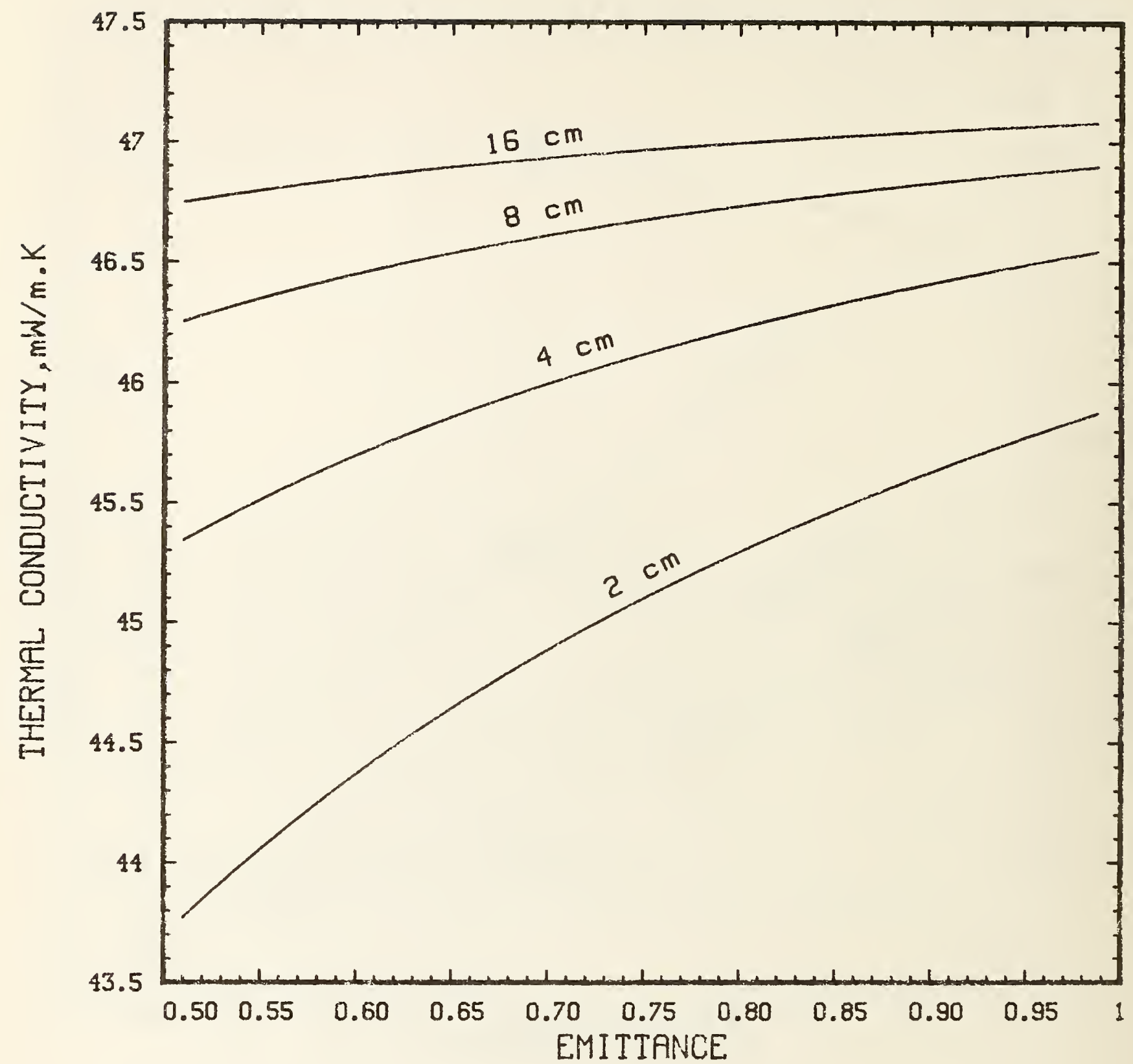

Figure 5.18 Thermal Conductivity versus Emittance for Several Thicknesses as Calculated from the Mode1. Temperature $=$ $300 \mathrm{~K}$, Density $=10 \mathrm{~kg} / \mathrm{m}^{3}$, and Fiber Diameter $=5.0 \mu \mathrm{m}$ 


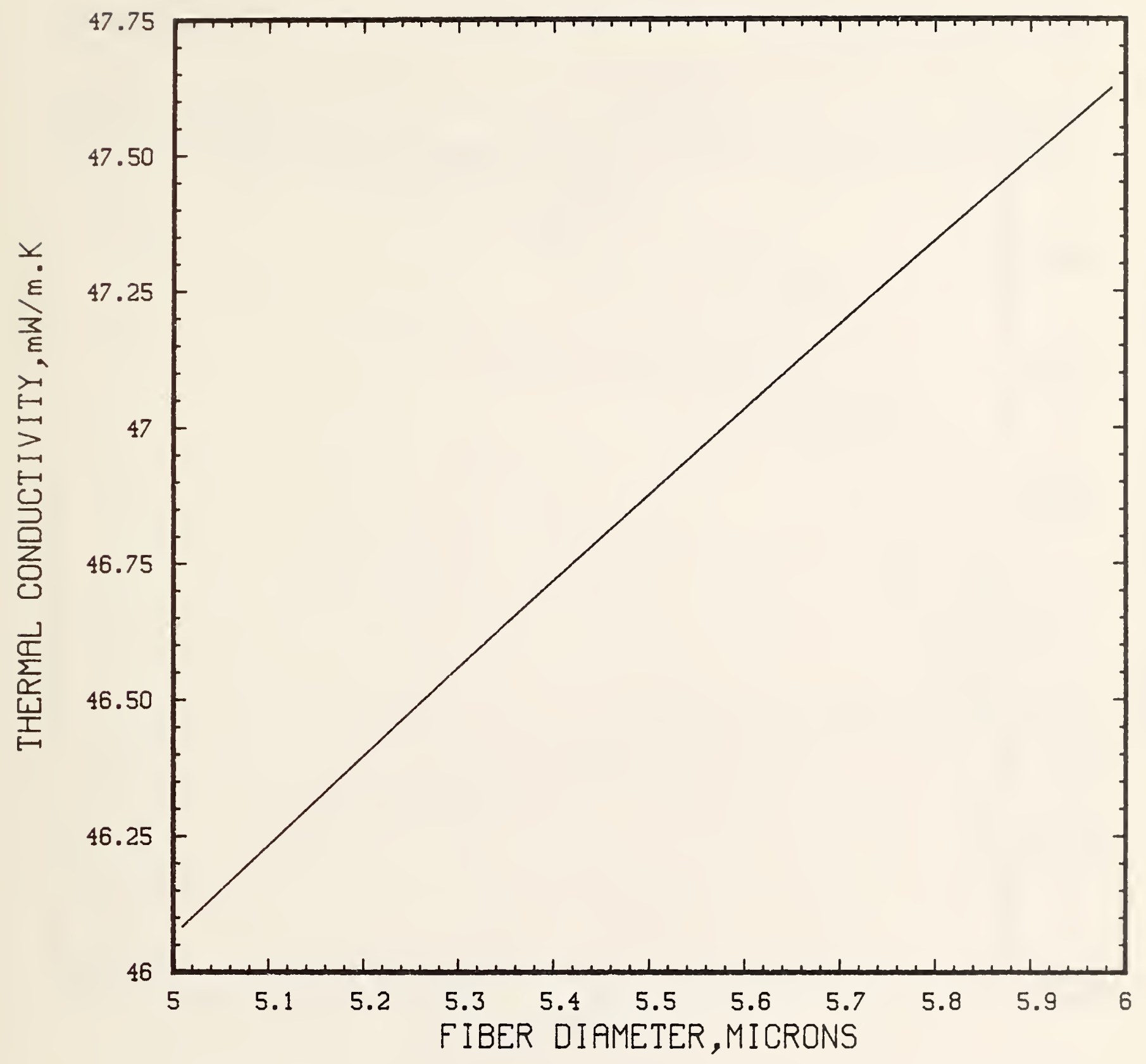

Figure 5.19 Thermal Conductivity versus Fiber Diameter as Calculated from the Mode1. Emittance $=0.95$, Temperature $=300 \mathrm{~K}$, Density $=10$ $\mathrm{kg} / \mathrm{m}^{3}$, and Thickness $=2.54 \mathrm{~cm}$. 


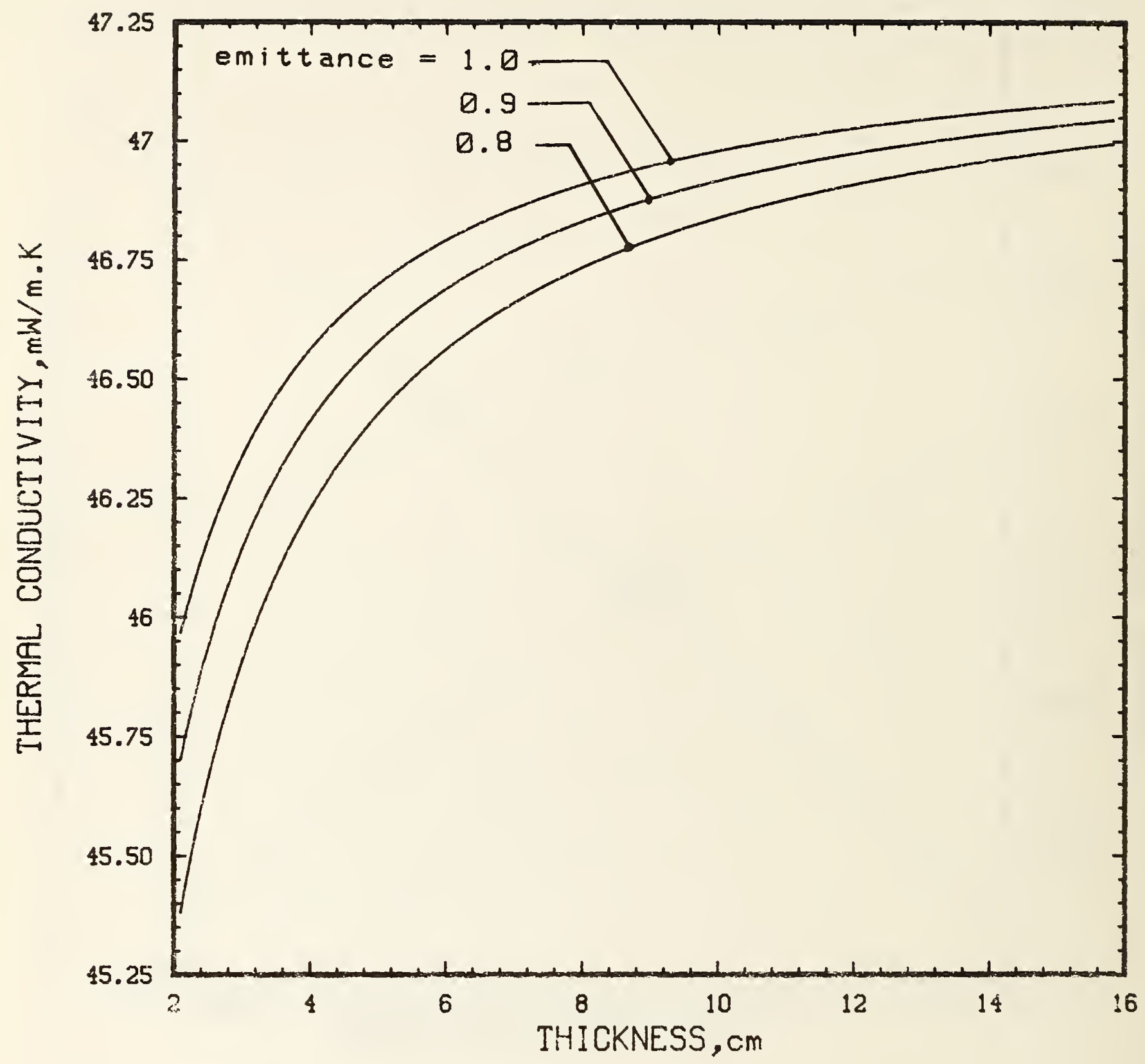

Figure 5.20 Thermal Conductivity versus Thickness for Several Emittances as Calculated from the Model. Temperature $=300 \mathrm{~K}$, Density $=10 \mathrm{~kg} / \mathrm{m}^{3}$, and Fiber Diameter $=5.0 \mu \mathrm{m}$ 


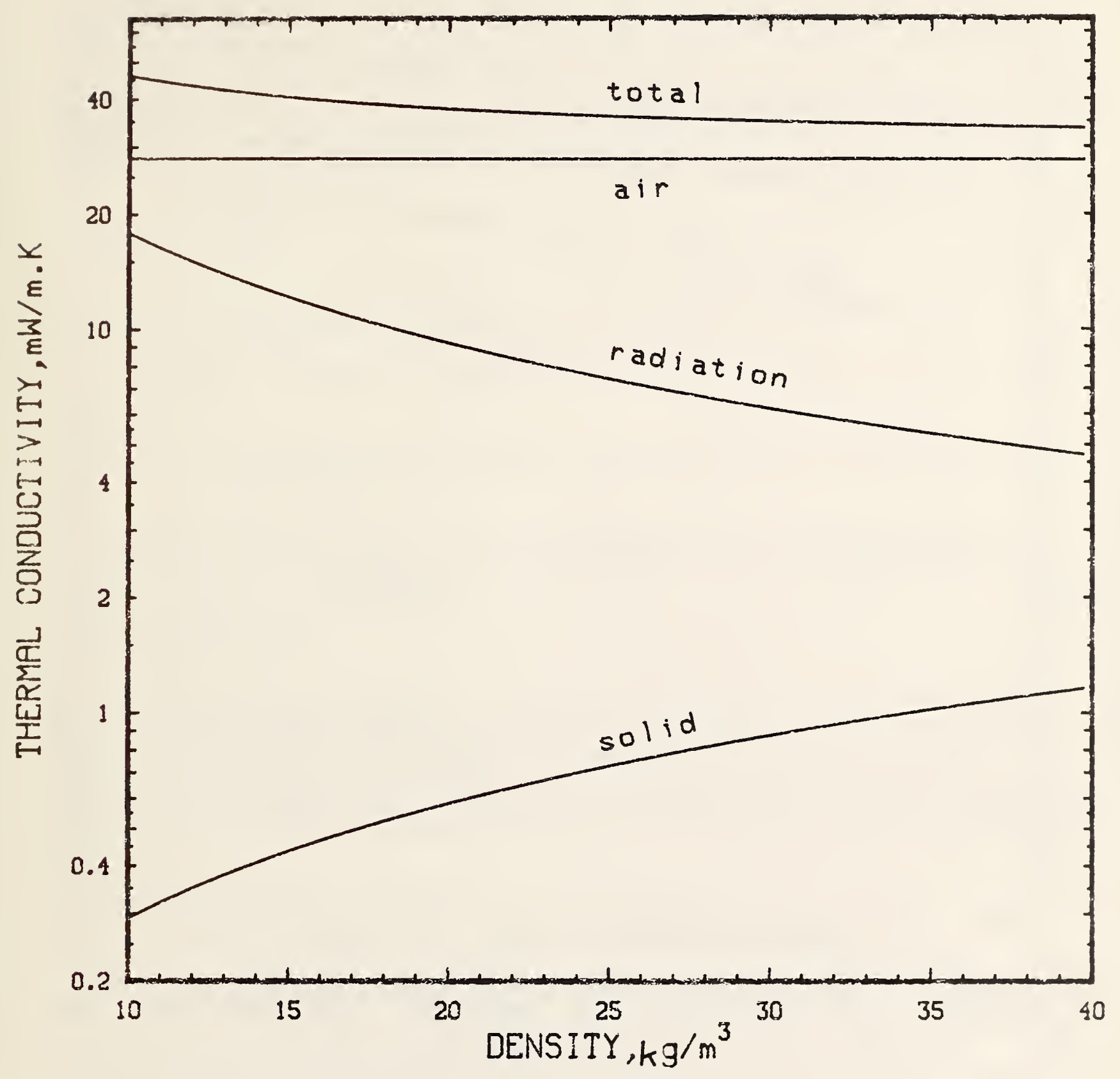

Figure 5.21 Thermal Conductivity Components (air, solid, radiation and total) versus Density as Calculated from the Model. Emittance $=0.95$, Temperature $=300 \mathrm{~K}$, Thickness $=2.54 \mathrm{~cm}$, and Fiber Diameter $=5.0 \mu \mathrm{m}$ 


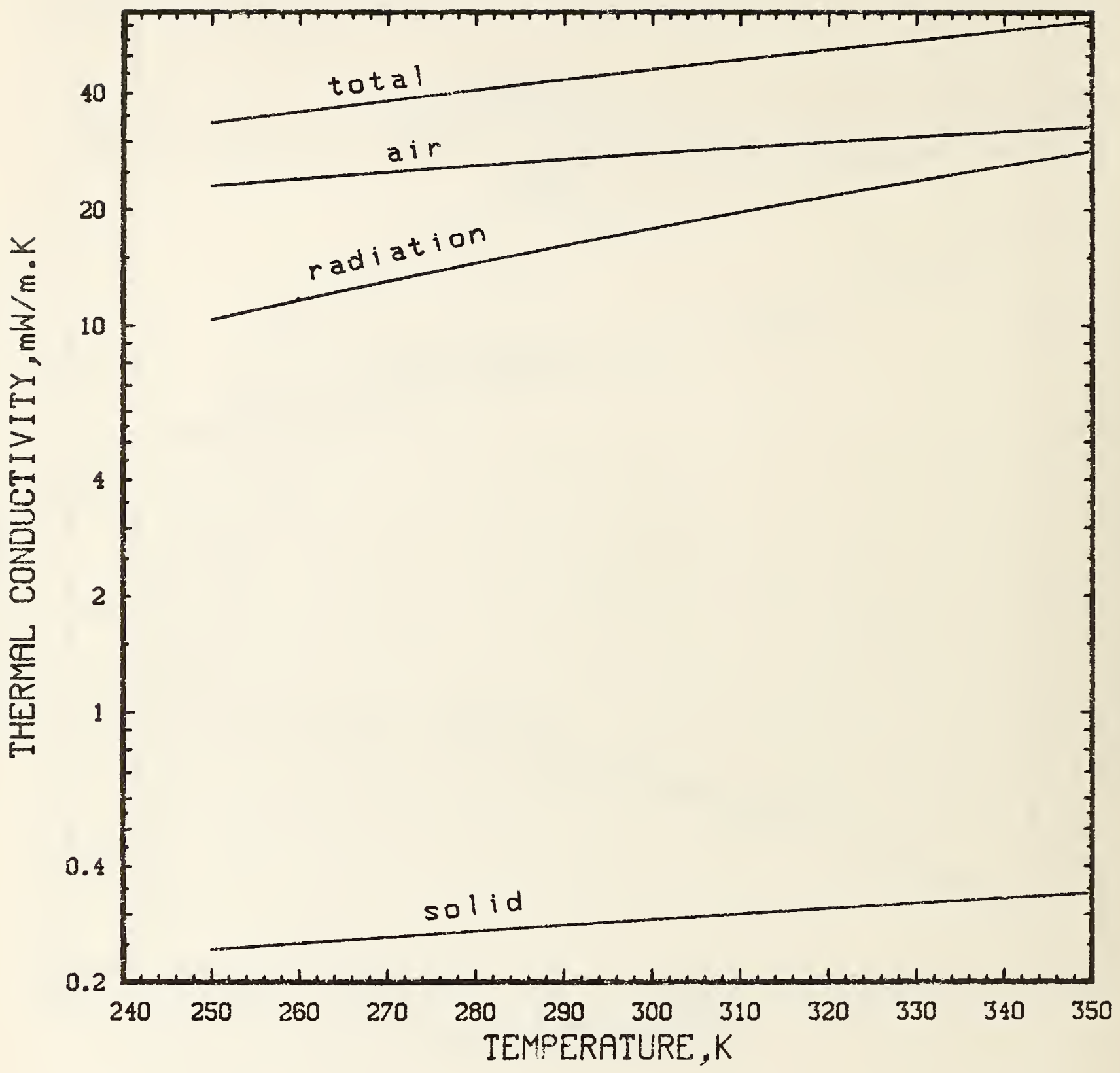

Figure 5.22 Thermal Conductivity Components (air, solid, radiation, and total) versus Temperature as calculated from the Model. Emittance $=0.95$, Density $=10 \mathrm{~kg} / \mathrm{m}^{3}$, Thickness $=$ $2.54 \mathrm{~cm}$, and Fiber Diameter $=5.0 \mu \mathrm{m}$ 


\section{ROUND ROBIN I}

\subsection{Overview}

This round robin, started in September 1976, was initiated in order to evaluate the thermal insulation testing community's capability when measuring building insulation at thicknesses beyond which reference standards were available. The same specimens were circulated among all the participating laboratories. The tests were carried out from September 1976 to June 1980.

The C-16.30 Task Force members were C.M. Pelanne-Chairman, M. Lacher, and S. Cady $[19,20]$.

The material, R-11 building insulation, used for this round robin was supplied by the Owens-Corning Laboratories in Granville, $\mathrm{OH}$.

Nine HFM's (C518) [2], and three GHP's (C177) [1] were involved in these measurements.

A11 of the tests were performed at $89 \mathrm{~mm}\left(3.5^{\prime \prime}\right)$ test thickness and $24^{\circ} \mathrm{C}$ $\left(75^{\circ} \mathrm{F}\right)$ mean temperature.

Tables $6.1,6.2$, and 6.3 show the results of all the measurements as obtained during the course of this round robin. Further explanation of these tables is given in the appendix.

\subsection{Test Specimens}

The specimans consisted of four, $8.9 \mathrm{~cm}\left(3.5^{\prime \prime}\right)$ thick, $38.7 \mathrm{~cm}\left(15.25^{\prime \prime}\right)$ wide and $122 \mathrm{~cm}$ ( $\left.48^{\prime \prime}\right)$ long R-11 friction fit building insulation batts. The batts were obtained from the center of a package of standard building insulation selected at random from stock. The batts were identified by a series of single numbers, $8,9,10$ and 11 . The actual test densities determined for these specimens ranged from $12.3 \mathrm{~kg} / \mathrm{m}^{3}\left(0.771 \mathrm{~b} / \mathrm{ft}^{3}\right)$ to $14.6 \mathrm{~kg} / \mathrm{m}^{3}(0.91$ $\left.\mathrm{lb} / \mathrm{ft}^{3}\right)$.

In order for the specimens to conform to the various equipment sizes, similar insulation material was used for peripheral guarding.

The densities were determined on the total specimen and, in order to relate the test density to the test area of the apparatus, the specimens were cut and weighed to successively smaller sizes matching the test areas. Thus for this series of tests eighteen individual density determinations were made. The details of these measurements are given in Table 13.4. 


\subsection{Test Equipment}

The apparatus involved in this round robin were as follows;

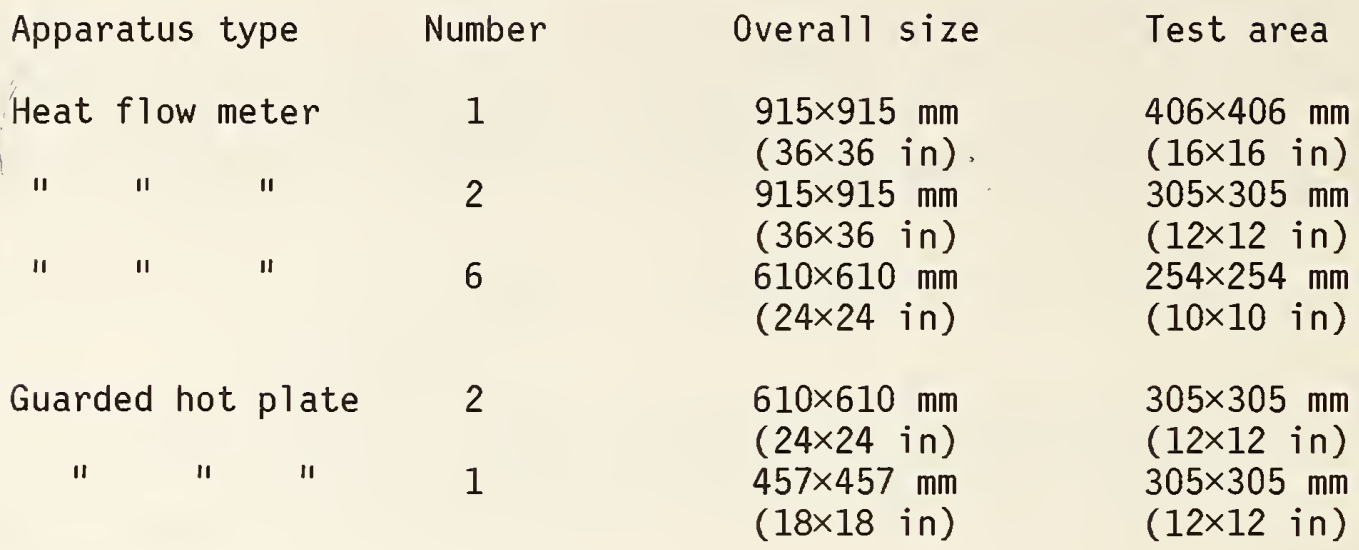

\subsection{Results}

The apparent thermal conductivity data obtained during this round robin are plotted in Figures 6.1 to 6.4. Figure 6.1 shows the $915-406 \mathrm{~mm}$ (4 points) and the $915-305 \mathrm{~mm}$ ( 12 points) HFM data. Figure 6.2 shows the $610-254 \mathrm{~mm}$ (22 points) HFM data. All of these data were obtained on single specimens. The GHP data are plotted in Figure 6.3. These data ( 8 points) represent results of tests on pairs of matched specimens. Figure 6.4 is a composite plot of all of the 46 data points. All of these tests were performed at $24^{\circ} \mathrm{C}\left(75^{\circ} \mathrm{F}\right.$ ) mean temperature and $89 \mathrm{~mm}\left(3.5^{\prime \prime}\right)$ test thickness.

The deviations of the RR I data from the model described earlier are shown in Figures 6.5 to 6.8 in the same sequence as Figures 6.1 to 6.4. The deviations (observed - calculated) are also listed in the last column of Tables $6.1,6.2$, and 6.3. The average deviation from the model and the $2 \mathrm{~s}$ value for each subset of data are shown on each deviation plot.

As mentioned earlier the tests were performed over a long period of time (September 1976 - June 1980). In order to verify that the thermal resistance of each specimen had not changed over the extent of the project, they were periodically measured by laboratory 17 . These results (Table 6.4 and Figures 6.9 and 6.10), while obtained on two separate apparatus*, showed no detectable change with time and use, as shown on Figure 6.11.

Figure 6.8, which is a composite of the deviations shows that the interlaboratory differences range about $2.5 \%$ on either side of the experimental mean values. The model values are about $1.5 \%$ greater than the mean experimental values. This systematic difference is probably because these specimens were supplied by a different manufacturer than those used in RR II and III.

*Note-The calibration of the two apparatus was assured through the same reference specimens. 
RR I data were not used to optimize the parameters in the model. The intralaboratory scatter is about one-third of the interlaboratory scatter. There does not appear to be any significant trend between the HFM and GHP results.

Since the three round robins are closely related, detailed discussion of the significance of these is relegated to section 9 of this report. 


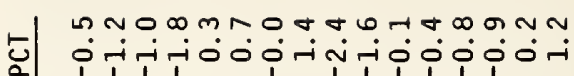

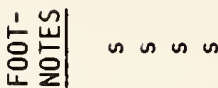

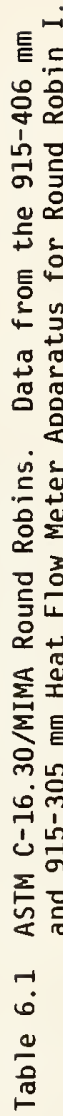

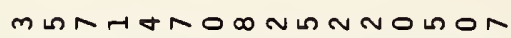
ஸु

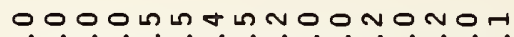

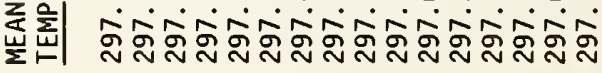

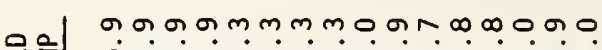

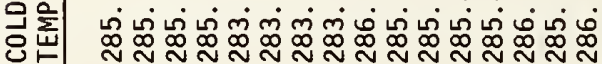

:

- บNNNNTLNmombNmN

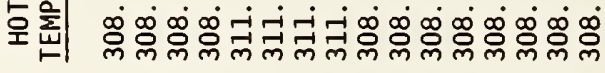

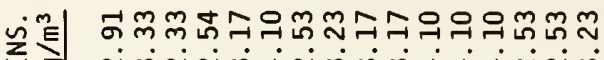

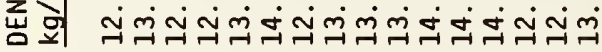

艺 E $\infty \dot{\infty} \infty \dot{\infty} \infty \dot{\infty} \infty \dot{\infty} \infty \dot{\infty} \infty \dot{\infty} \infty \dot{\infty} \infty \dot{\infty} \infty \dot{\infty}$

幽完|

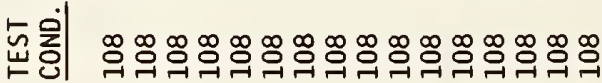

일

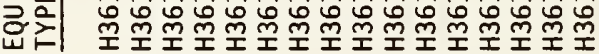

แ

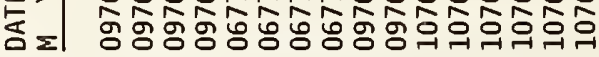

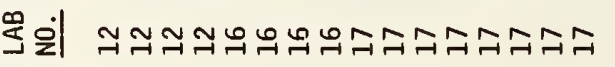

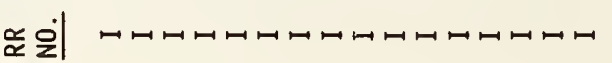




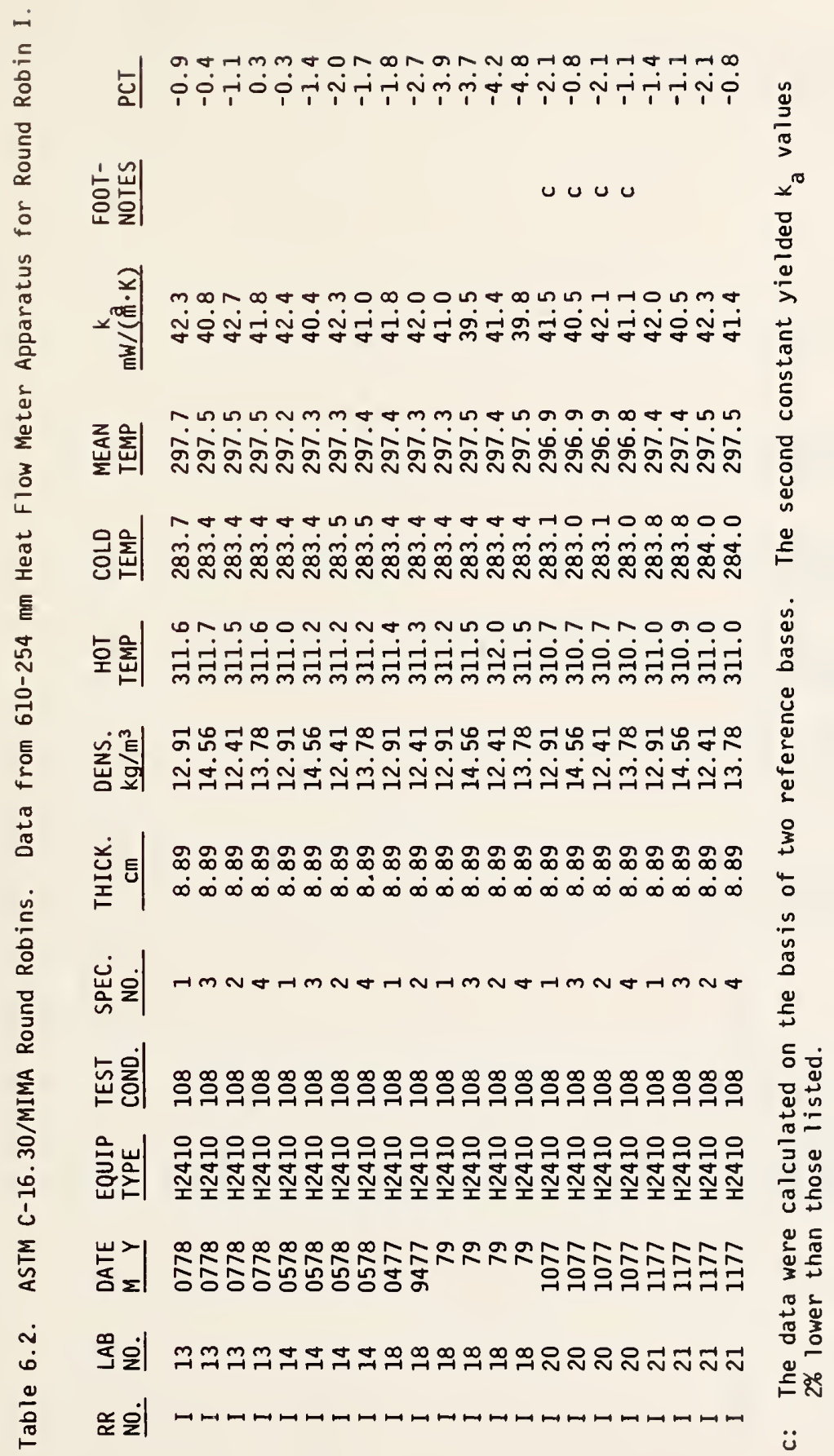




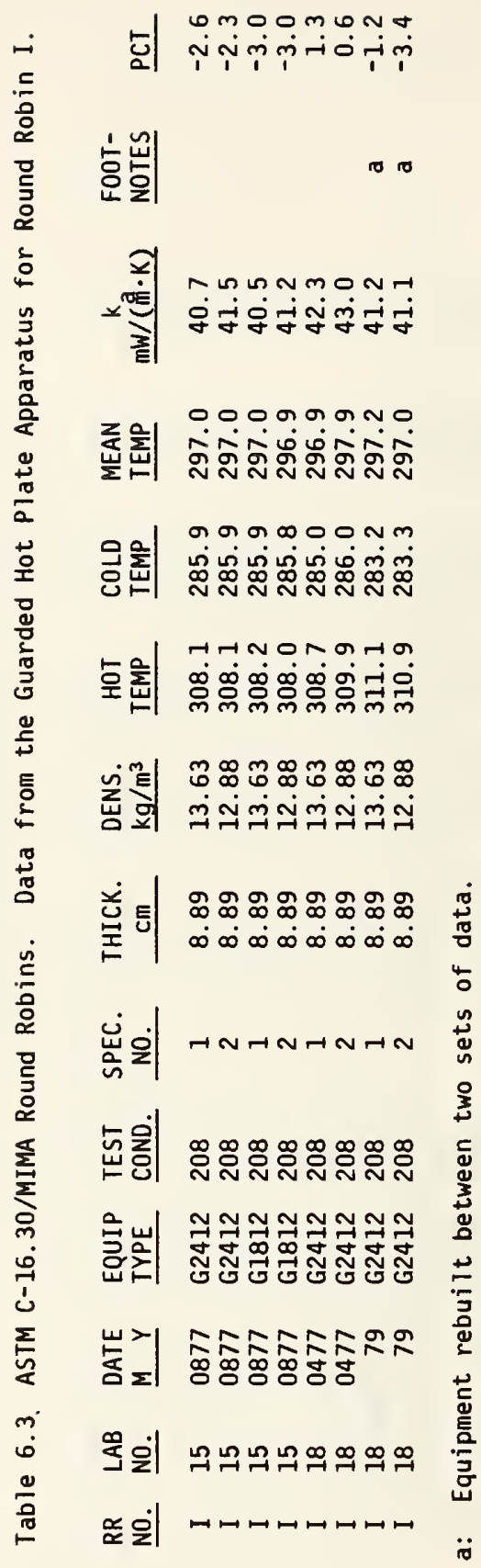


|

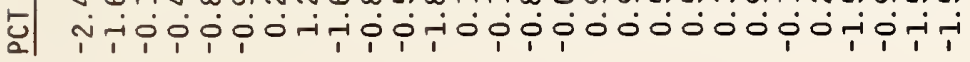

농뉸인|

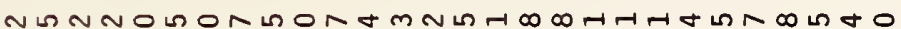

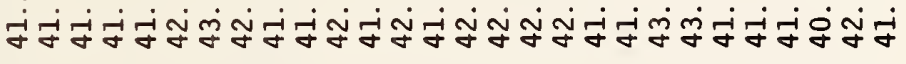

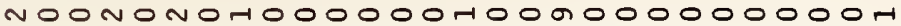

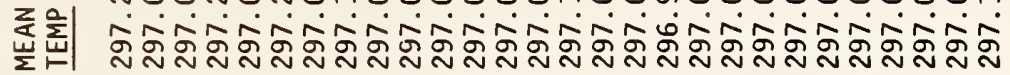

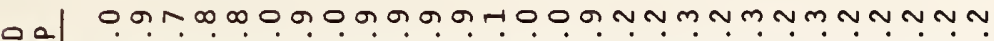

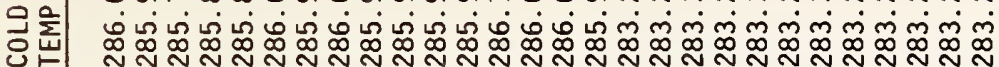

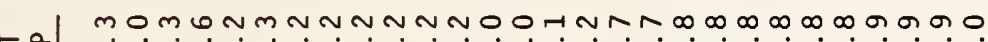

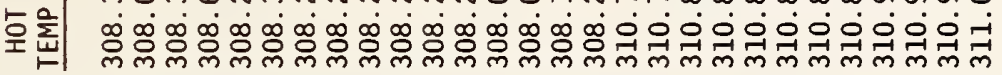

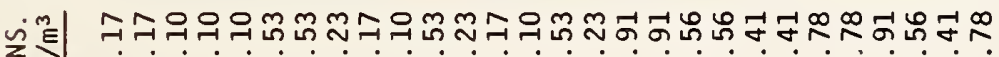
岁 可

艺可

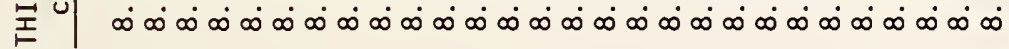

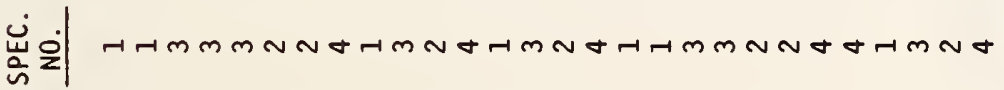

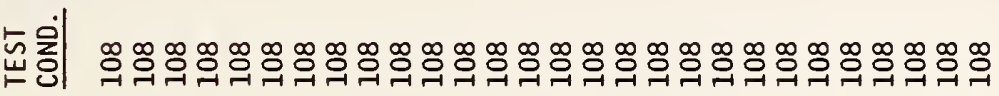

은

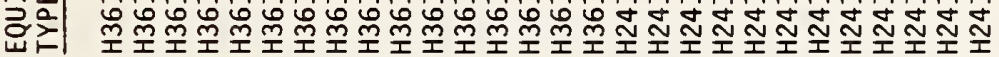

山入

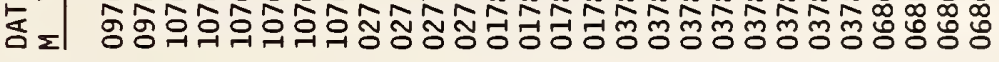

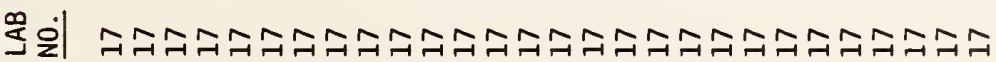
谷戞 


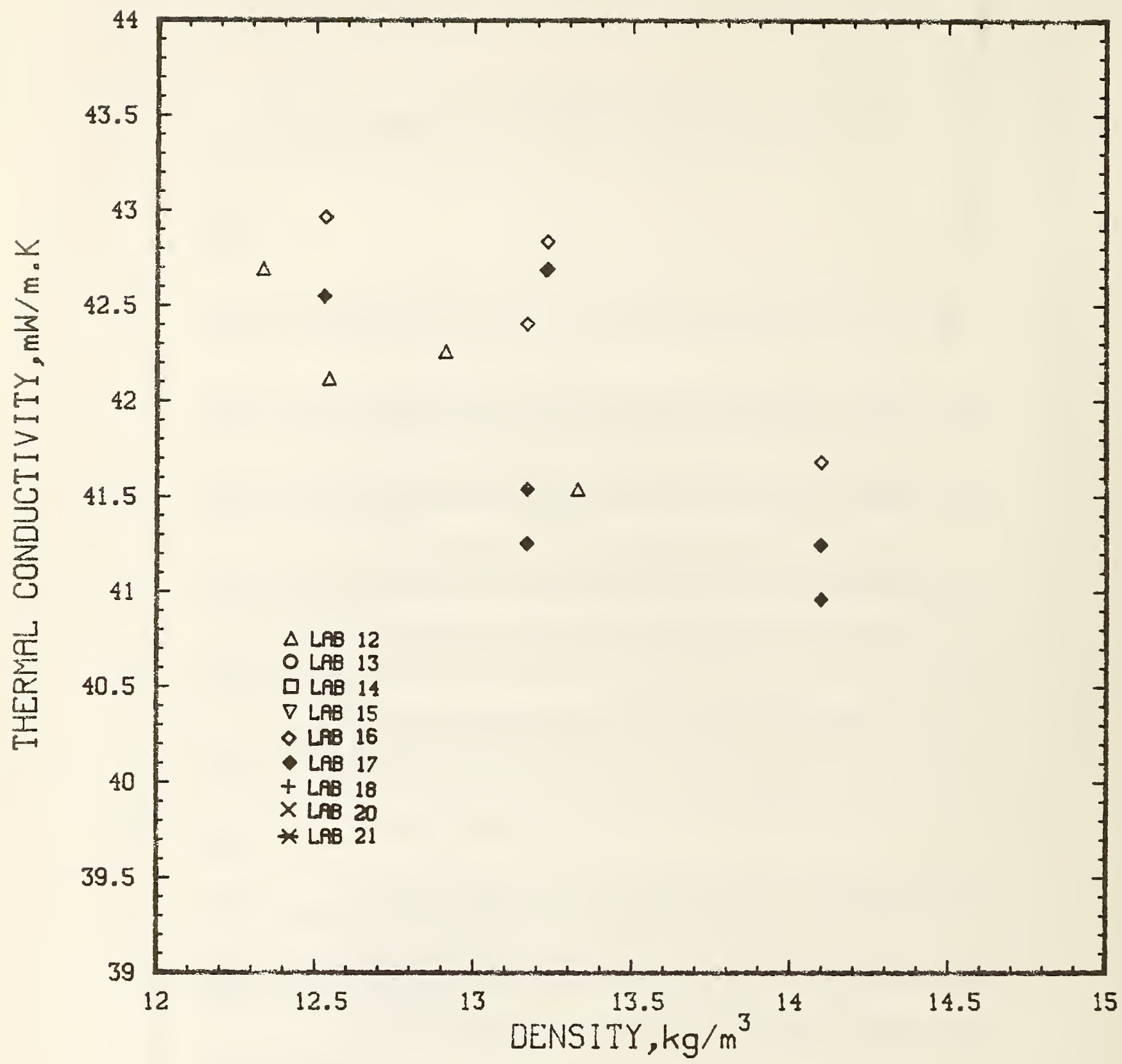

Figure 6.I Thermal Conductivity versus Density for the 915-406 mm and 915-305 mm Heat Flow Meter Apparatus from Round Robin I. 


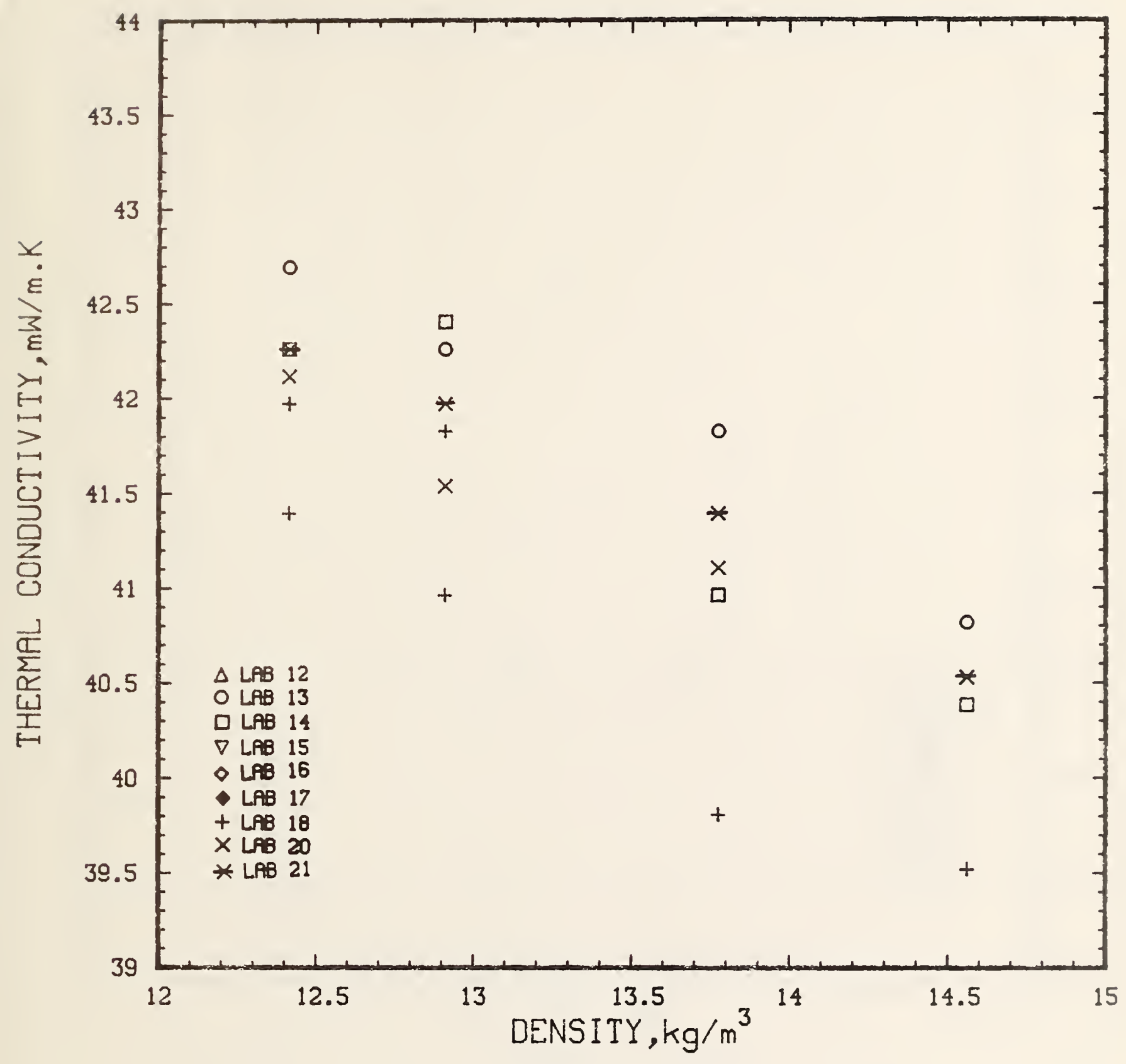

Figure 6.2 Thermal Conductivity versus Density for the 610-254 mm Heat Flow Meter Apparatus from Round Robin I. 


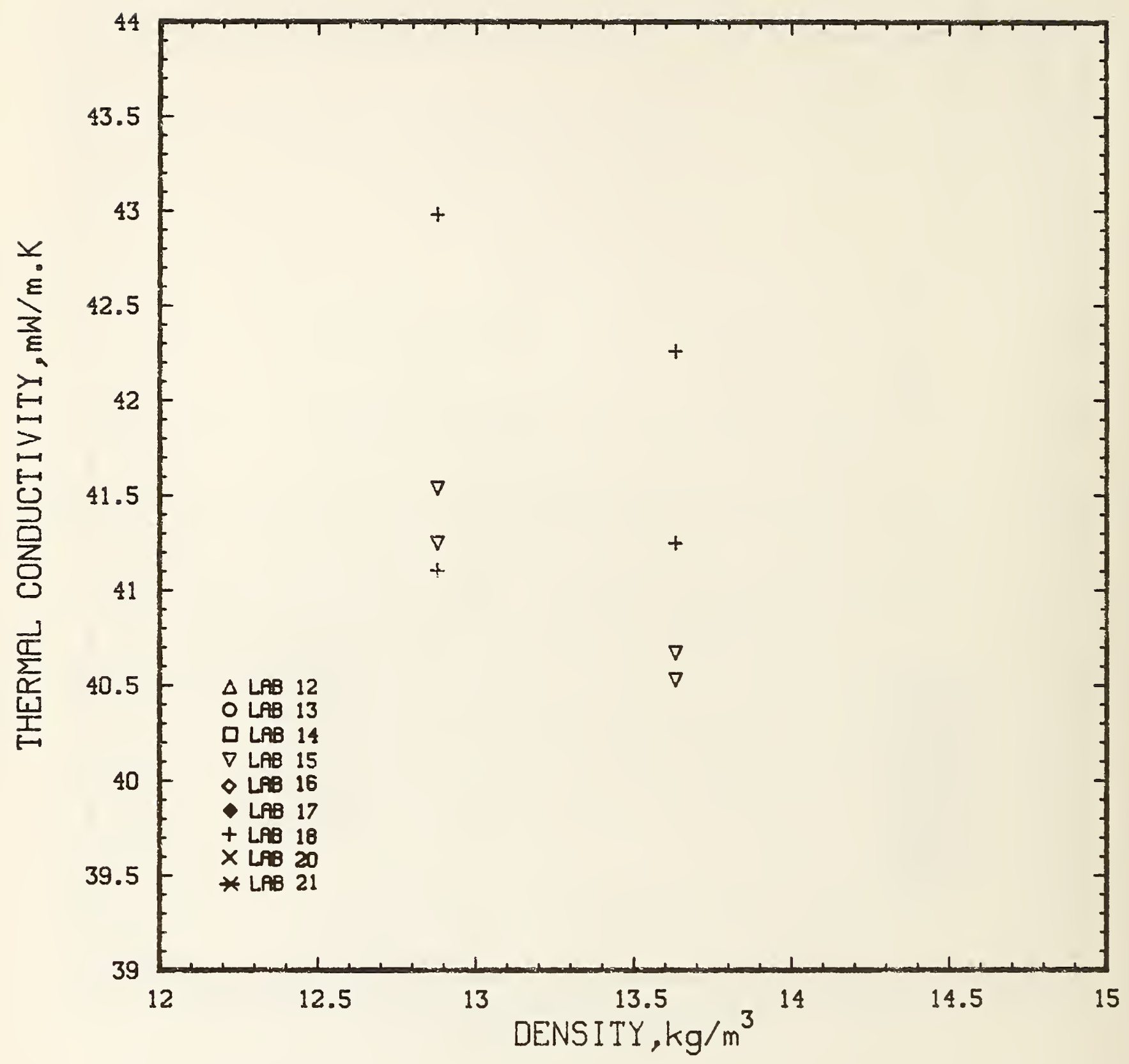

Figure 6.3 Thermal Conductivity versus Density for the Guarded Hot Plate Apparatus from Round Robin I. 


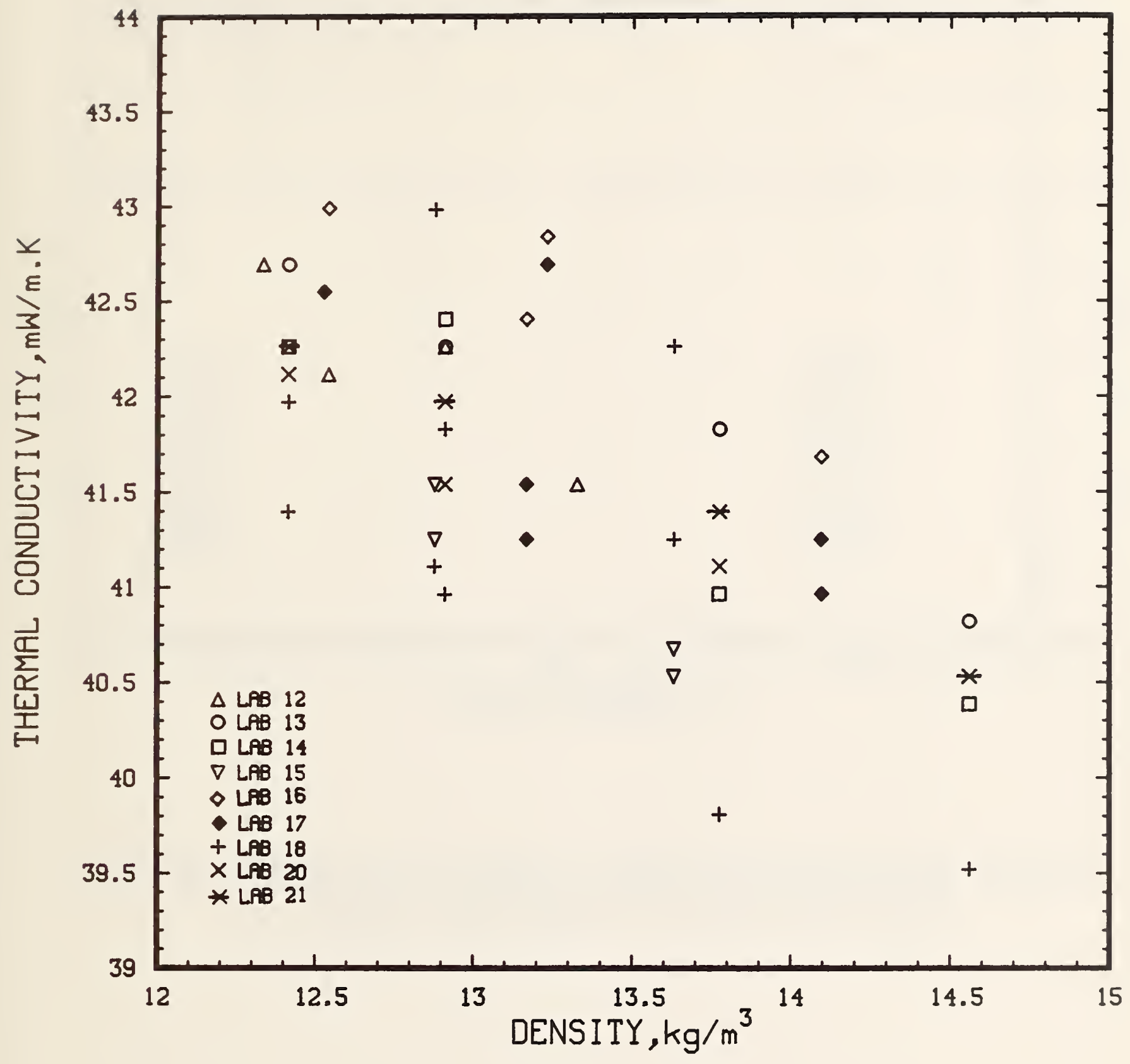

Figure 6.4 Thermal Conductivity versus Density for all of the Data from Round Robin I. 


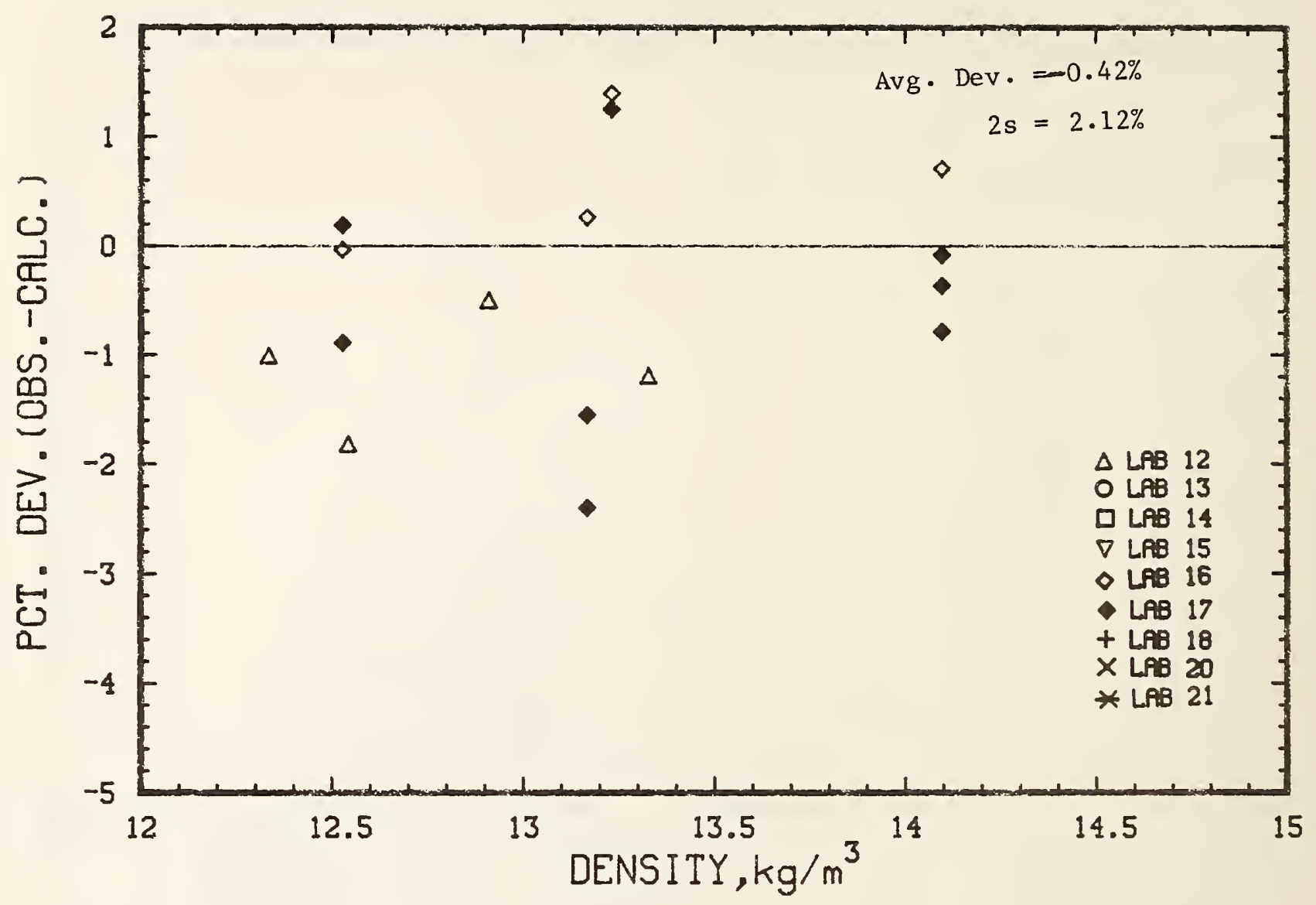

Figure 6.5 Deviations between Thermal Conductivity Data for the 915-406 mm and 915-305 mm Heat Flow Meter Apparatus from Round Robin I and Values Calculated from the Model versus Density. 


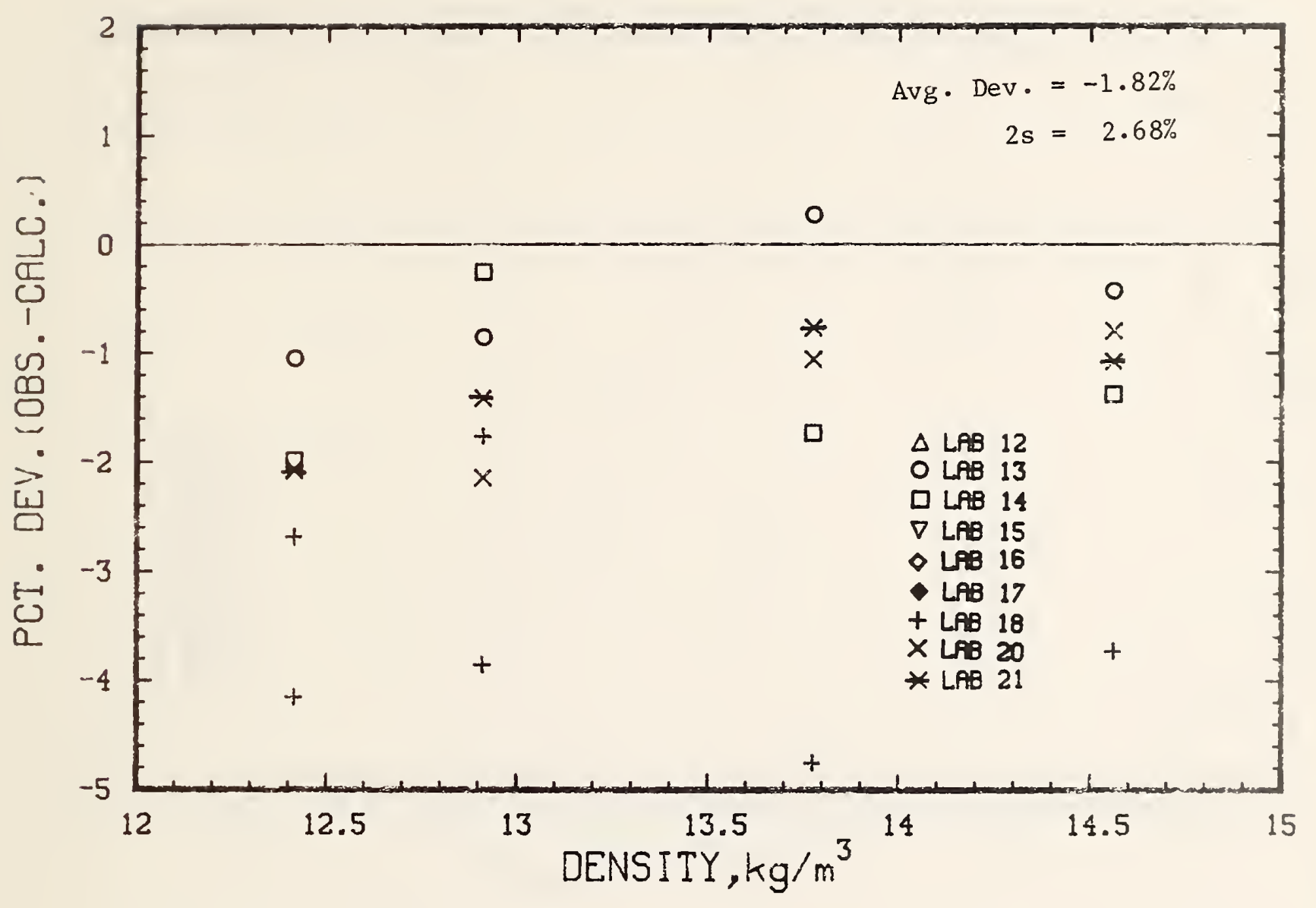

Figure 6.6 Deviations between Thermal Conductivity Data for the $610-254 \mathrm{~mm}$ Heat Flow Meter Apparatus from Round Robin I and Values Calculated from the Model versus Density. 


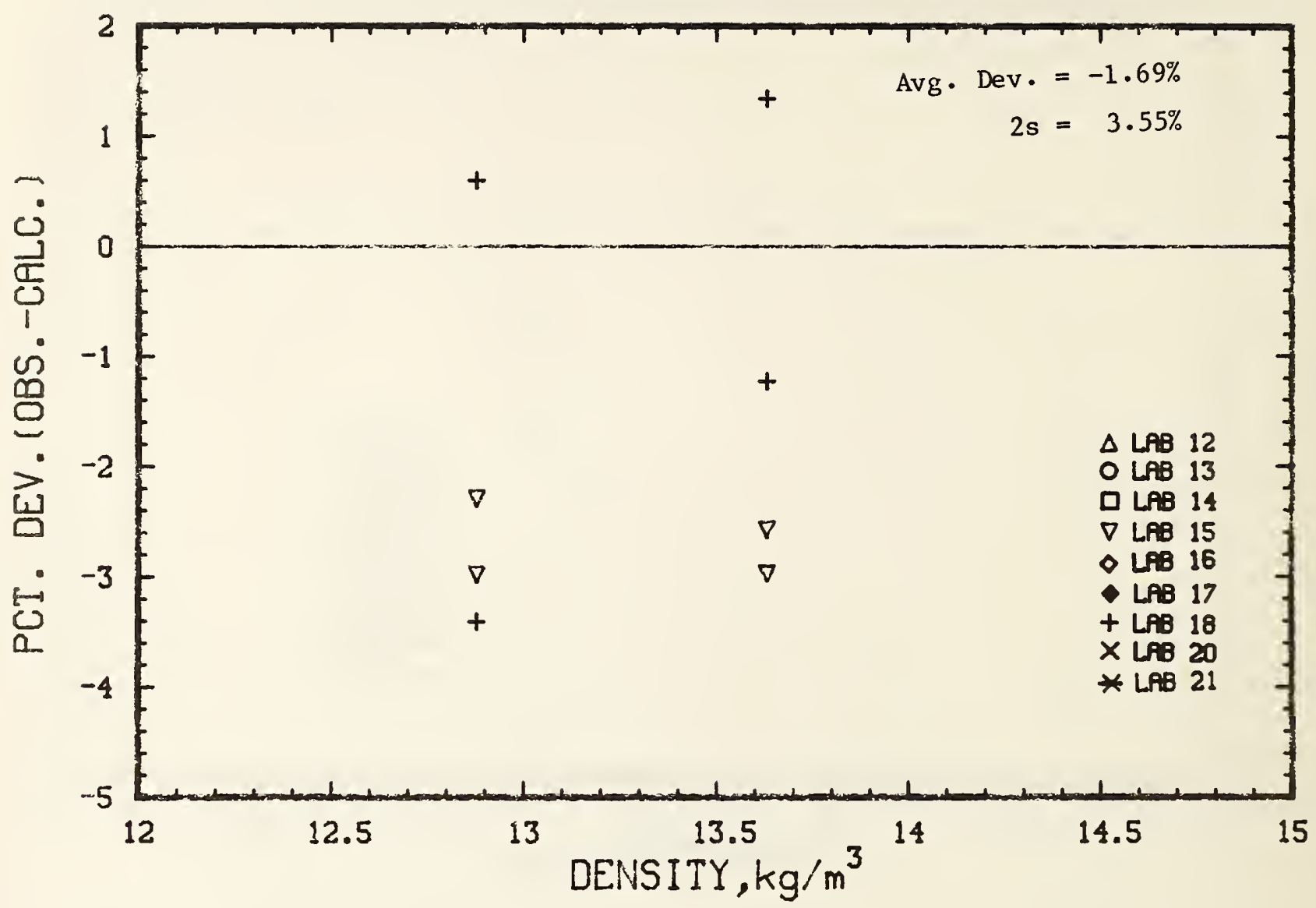

Figure 6.7 Deviations between Thermal Conductivity Data from the Guarded Hot Plate Apparatus from Round Robin I and Values Calculated from the Model versus Density. 


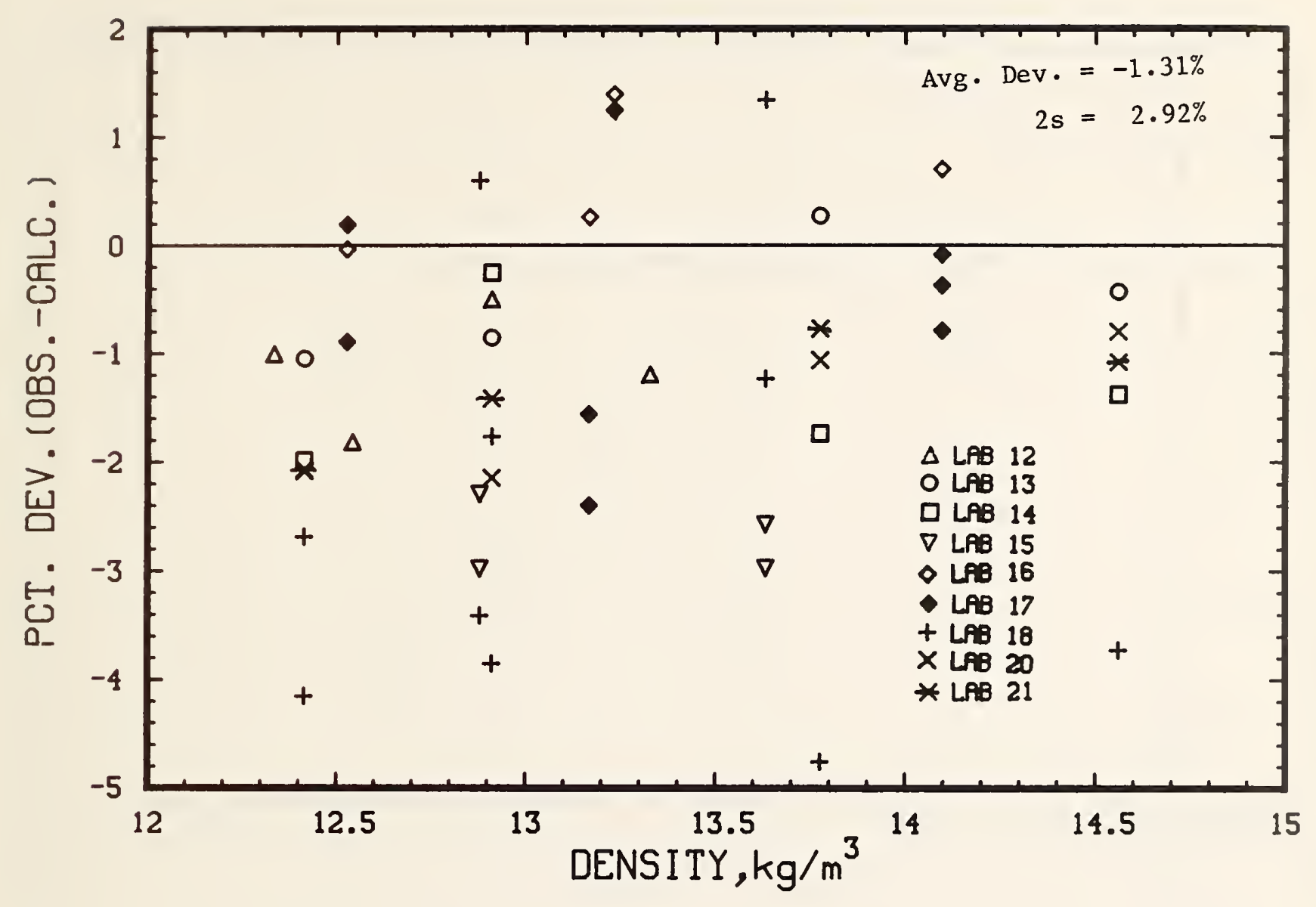

Figure 6.8 Deviations between all Thermal Conductivity Data from Round Robin I and Values Calculated from the Model versus Density. 


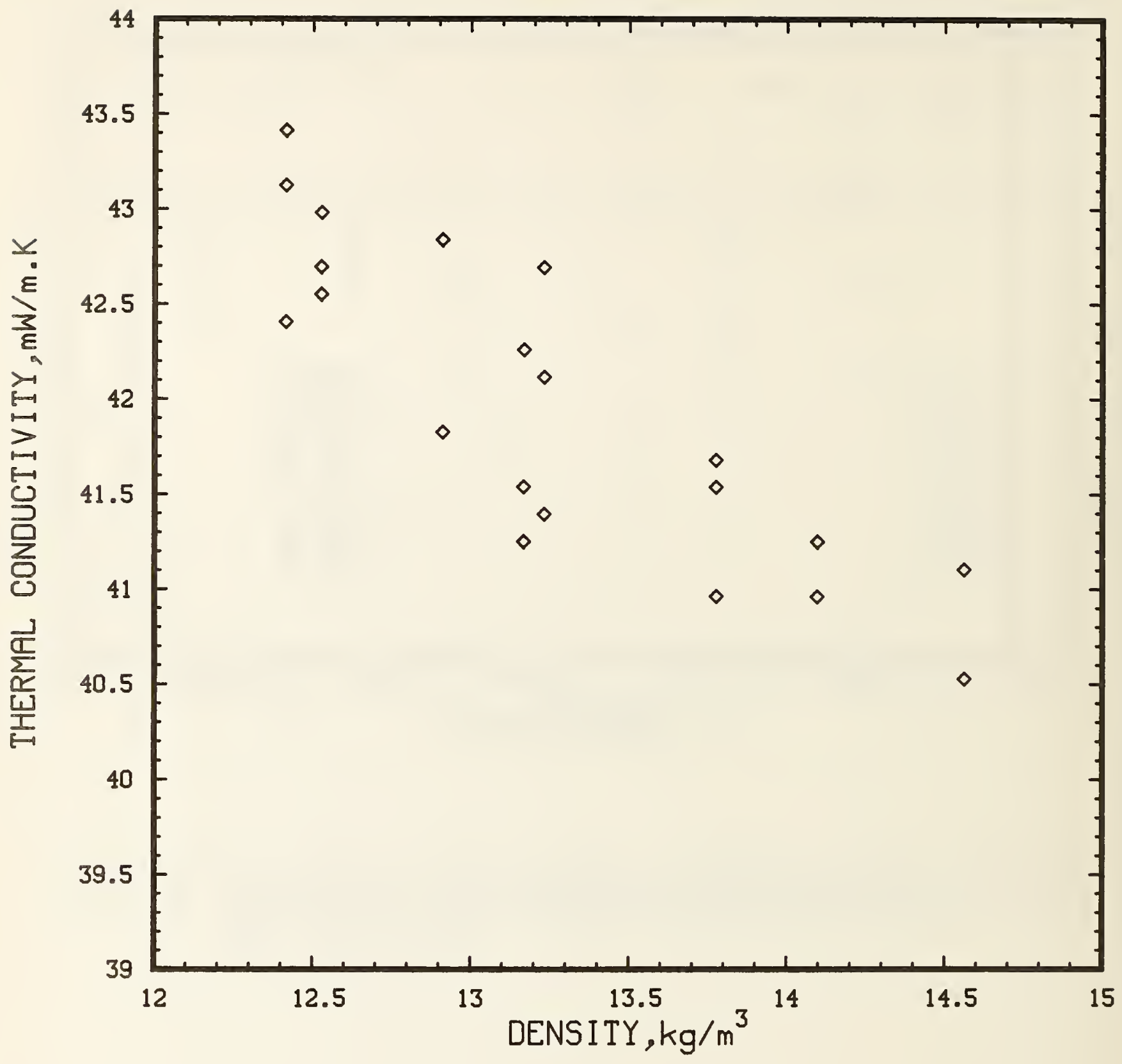

Figure 6.9 Thermal Conductivity versus Density for Control Data taken by Lab 17 for Round Robin I over the period 1976 to 1980. 


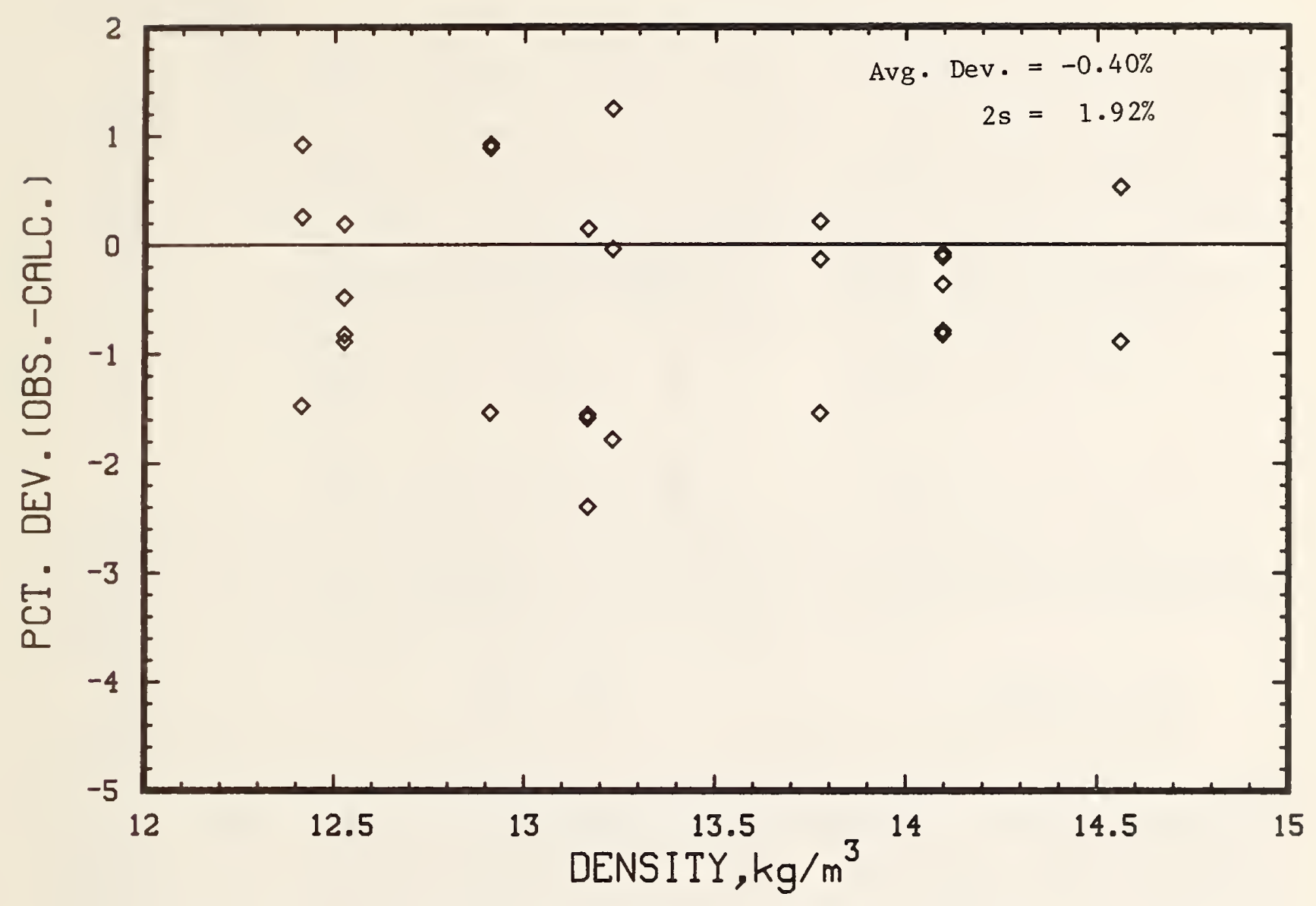

Figure 6.10 Deviations between Control Data from Lab 17 and Values Calculated from the Model versus Density 

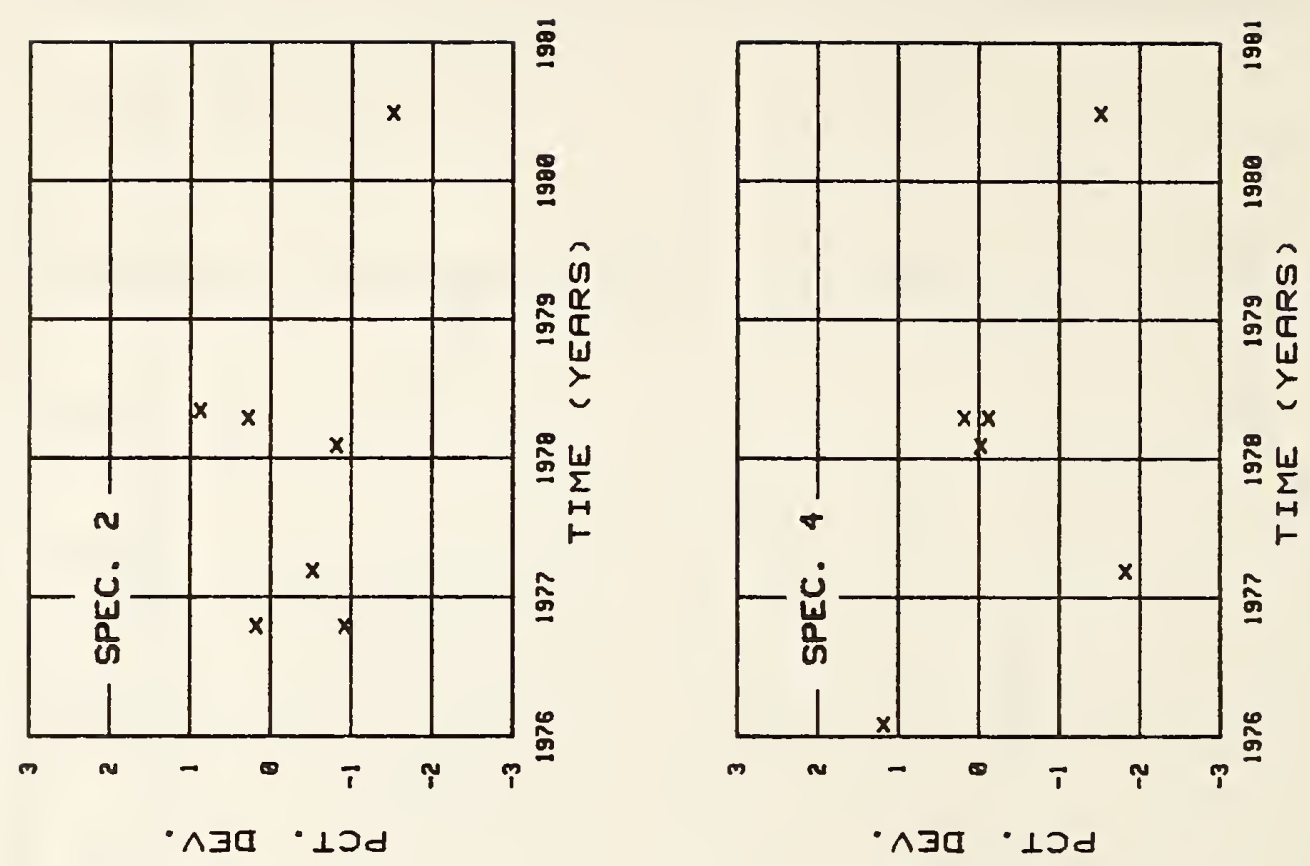

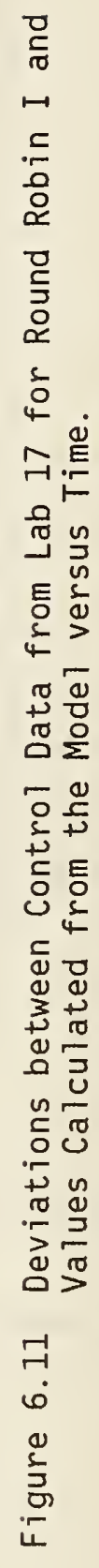
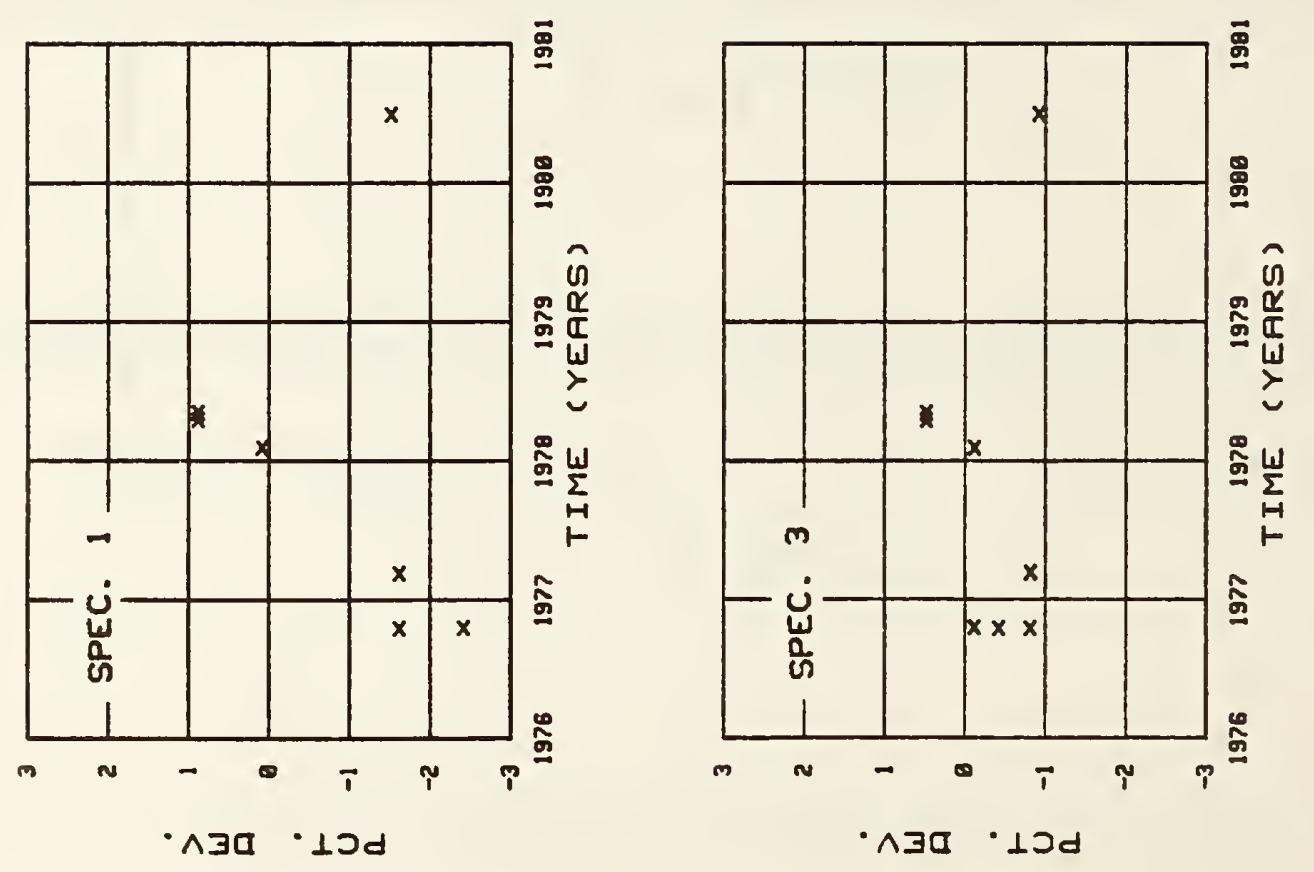


\section{ROUND ROBIN II}

\section{1 Overview}

This round robin, started in February 1977, was initiated in order to evaluate the thermal insulation testing community's capability when measuring thermal insulations of low density where the effects of plate emittance can have an influence on the results due to radiative heat transfer. The only reference standard (NBS's SRM-1450) [12] [13] available to evaluate the performance of the equipment is too dense $\left(120-160 \mathrm{~kg} / \mathrm{m}^{3}\right)$ to allow the perception of a change in surface plate emittance. While some of the tests, by the originating laboratory, were performed early (June 1974 for the original reference values) and late, at the end of the program (July 1981 and November 1983), the majority of the tests were carried out between February 1977 and May 1979.

The C-16.30 Task Force member consisted solely of C.M. Pelanne-Chairman.

The specimens (appliance insulation) were part of a select group of specimens prepared by Manville Research and Development Center as calibrated reference specimens referenced to similar specimens measured by the National Bureau of Standards, Gaithersburg, MD (NBS Dec. 1974). Further information relating to the reference values has been published [9].

Seven HFM (C518) [2], three GHP (C177) [1] and one reported as a GHP yielding results on single specimens were involved in these measurements.

The majority of the tests were performed at $25 \mathrm{~mm}$ ( 1.0 in) test thickness and $24^{\circ} \mathrm{C}\left(75^{\circ} \mathrm{F}\right)$. Some special tests were performed by participants wishing to evaluate their equipment beyond the scope of the round robin. These data are reported but not incorporated in the analysis. They include tests at temperatures above and below $24^{\circ} \mathrm{C}$ and tests with and without opaque sheets between layers of insulation (septa).

Tables 7.1 through 7.5 show the results of all of the measurements obtained during the course of this round robin. Further explanation of the tables can be found in the appendix.

\subsection{Test Specimens}

The test specimens consisted of four pairs of matched $25.4 \mathrm{~mm}$ ( 1.0 in) blankets of appliance insulation. The specimens were circulated to all of the participating laboratories. The nominal densities of the pairs were 11.1, $16.9,25.5$, and $32.9 \mathrm{~kg} / \mathrm{m}^{3}\left(0.69,1.05,1.59\right.$, and $\left.2.071 \mathrm{~b} / \mathrm{ft}^{3}\right)$. The $305 \times 305 \mathrm{~mm}$ ( $12 \times 12$ in) test specimens were provided with $610 \times 610 \mathrm{~mm}$ ( $24 \times 24$ in) frames of the same material to facilitate testing in larger apparatus. These specimens were referenced to similar specimens measured by the National Bureau of Standards, Gaithersburg, $\mathrm{MD}$ over the same density range and at about $-18^{\circ} \mathrm{C}\left(0^{\circ} \mathrm{F}\right)$, $24^{\circ} \mathrm{C}\left(75^{\circ} \mathrm{F}\right)$, and $54^{\circ} \mathrm{C}\left(130^{\circ} \mathrm{F}\right)$ mean temperature. More details about this program may be found in a paper presented at the 17th Thermal Conductivity Conference held in Gaithersburg in June 1981, [9]. 
The densities were determined on the total specimen and, in order to relate the test density to the test area of the apparatus, the specimens were cut and weighed to successively smaller sizes matching the test areas. Thus for this series of tests seventy six individual density determinations were made. The details about these measurements are given in Table 13.5 of the appendix.

\subsection{Test Equipment}

Eleven apparatus, seven HFM's, three GHP's and one plate stated to be a GHP (the results were reported for individual specimens), were involved in this round robin. These were as follows:

\begin{tabular}{|c|c|c|c|c|c|}
\hline \multicolumn{3}{|c|}{ Apparatus type } & Number & Overall size & Test area \\
\hline Heat & flow & meter & 3 & $\begin{array}{l}610 \times 610 \mathrm{~mm} \\
(24 \times 24 \mathrm{in})\end{array}$ & $\begin{array}{l}254 \times 254 \mathrm{~mm} \\
(10 \times 10 \mathrm{in})\end{array}$ \\
\hline " & $"$ & $"$ & 1 & $\begin{array}{l}406 \times 406 \mathrm{~mm} \\
(16 \times 16 \mathrm{in})\end{array}$ & $\begin{array}{l}203 \times 203 \mathrm{~mm} \\
(8 \times 8 \mathrm{in})\end{array}$ \\
\hline$" 1$ & $"$ & $"$ & 1 & $\begin{array}{l}305 \times 305 \mathrm{~mm} \\
(12 \times 12 \mathrm{in})\end{array}$ & $\begin{array}{l}152 \times 152 \mathrm{~mm} \\
(6 \times 6 \mathrm{in})\end{array}$ \\
\hline 11 & " & " & 2 & $\begin{array}{l}305 \times 305 \mathrm{~mm} \\
(12 \times 12 \mathrm{in})\end{array}$ & $\begin{array}{l}102 \times 102 \mathrm{~mm} \\
(4 \times 4 \mathrm{in})\end{array}$ \\
\hline Guarc & ded $h$ & ot plate & 1 & $\begin{array}{l}610 \times 610 \mathrm{~mm} \\
(24 \times 24 \mathrm{in})\end{array}$ & $\begin{array}{l}305 \times 305 \mathrm{~mm} \\
(12 \times 12 \mathrm{in})\end{array}$ \\
\hline " & & " & 1 & $\begin{array}{l}457 \times 457 \mathrm{~mm} \\
(18 \times 18 \mathrm{in})\end{array}$ & $\begin{array}{l}305 \times 305 \mathrm{~mm} \\
(12 \times 12 \mathrm{in})\end{array}$ \\
\hline 11 & & 11 & 1 & $\begin{array}{l}305 \times 305 \mathrm{~mm} \\
(12 \times 12 \mathrm{in})\end{array}$ & $\begin{array}{l}152 \times 152 \mathrm{~mm} \\
(6 \times 6 \mathrm{in})\end{array}$ \\
\hline
\end{tabular}

G. H. P. ?

1

?

?

\subsection{Results}

The apparent thermal conductivity data resulting from the main part of RR II, that is, the test results obtained at $24^{\circ} \mathrm{C}\left(75^{\circ} \mathrm{F}\right)$ mean temperature and $25.4 \mathrm{~mm}$ ( $1.0 \mathrm{in})$ test thickness except for the data from laboratory 19 that were taken at $15.6^{\circ} \mathrm{C}\left(60^{\circ} \mathrm{F}\right)$ mean temperature, are plotted in Figures $7.1,7.2$, and 7.3. The data pertaining to the tests performed at different temperatures, different thicknesses and with or without septa are listed in Table 7.5 and plotted in Figure 7.4. Further details on the tests with and without septa performed during the course of this round robin can be found in an earlier paper [14].

The HFM data ( 37 points) are shown in Figure 7.1 , the "GHP" data (10 points as pairs and 8 points for individuals) are shown in Figure 7.2 and the composite of all of the RR II data (total 55 points) are shown in Figure 7.3. 
The deviations of the RR II data from the model are shown in Figures 7.5 through 7.8 in the same sequence as Figures 7.1 to 7.4. The deviation (observed - calculated) are also listed in the last column of Tables 7.1 through 7.5.

The average deviation from the model and the $2 \mathrm{~s}$ value for each data subset are given in each deviation plot.

Figures 7.5 shows the $2 \mathrm{~s}$ value for the HFM's is $1.73 \%$, which is about the same as for the RR I data. Figure 7.6 shows the GHP data from laboratory 15 at about the same level as the major part of the HFM data. The data from laboratory 19 however is considerably lower (10\%) than the mean value for both round robins. Figure 7.7 shows the composite of all of the data. The model values are $0.74 \%$ larger than the mean experimental values for RR II (disregarding the data from laboratory 19). Again the interlaboratory spread is larger than the intralaboratory spread.

These results do not indicate any effect resulting from plate emittance variations. This would be reflected in a greater spread in the data at the lowest densities. It should be noted that the data from laboratory 13 (Table 5.2) and laboratory 18 (Table 7.5) cover a range of temperature from 256 to $332 \mathrm{~K}$ and they agree to within $\pm 2 \%$. Since the three round robins are closely related, the discussion of the significance of these results is relegated to section 9 .

Any changes in the thermal resistance of the specimens over and beyond the extent of the round robin can be verified through the tests performed by laboratory 17. In Table 7.4, the test data given for measurement with apparatus $\mathrm{H} 1206$ cover tests on the same apparatus from June 1974 to November 1983, $(6 / 74,2 / 77,5 / 79,7 / 81,11 / 83)$. Similar tests performed on $1 / 78$ and $3 / 78$ using apparatus $\mathrm{H} 2410$ are listed in Table 7.3. All of these results are plotted in Figures 7.9 and 7.10. The results from the H1206 apparatus vary by no more than $\pm 1 \%$ except in the case of specimen 5 for which indication of damage is reported. The deviations for the $\mathrm{H} 1206$ results are plotted versus time in Figures 7.11 and 7.12. No systematic trend is observed other than for specimen 5. The apparent thermal conductivity of specimen 5 increased by $3.8 \%$. No further round robin tests were performed after the damage was observed, the last tests are dated 11/79, except for the verification test. This indicates that most of the variation in the test results is related to the testing and not to changes in the specimens. 


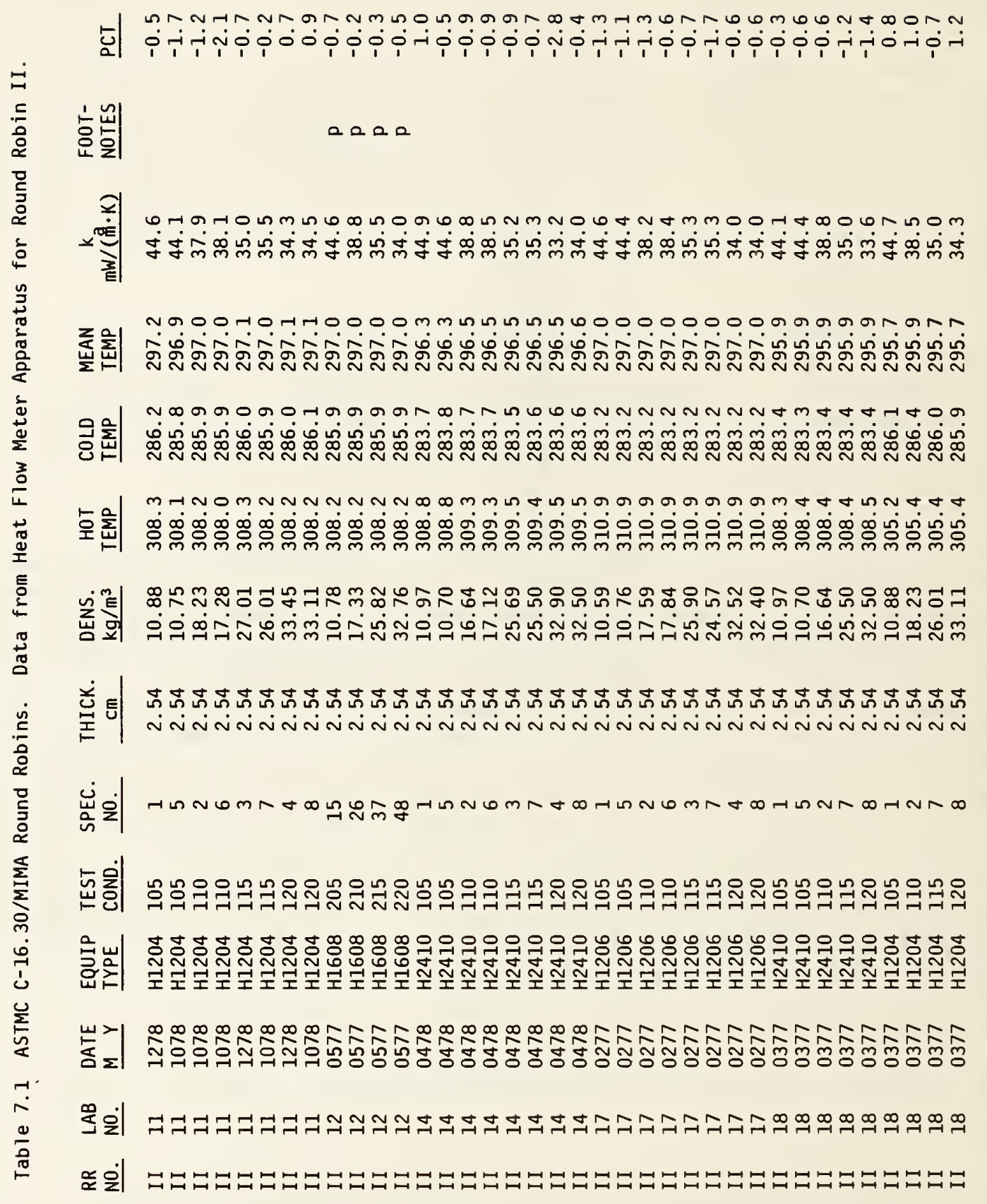




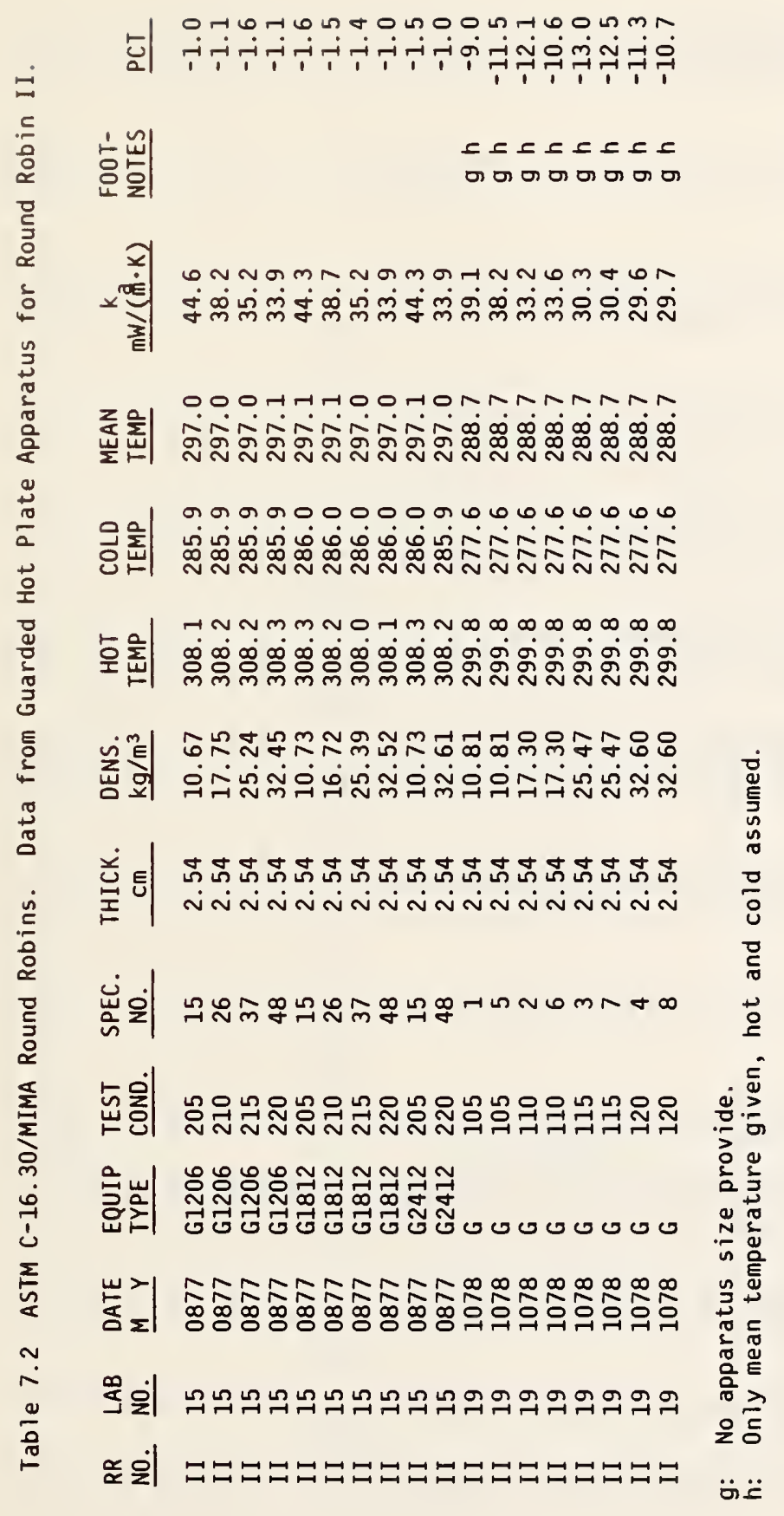




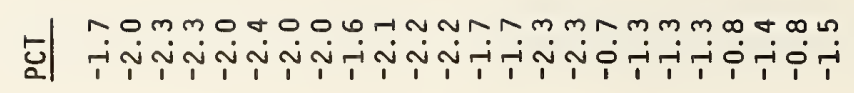

宫苟| E

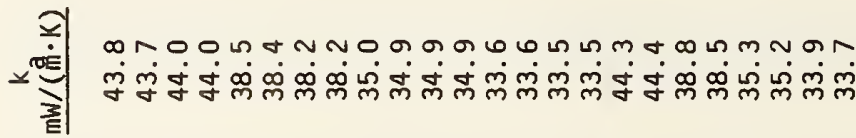

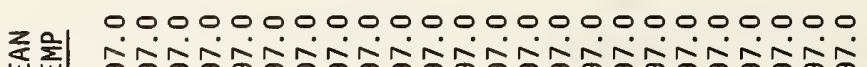

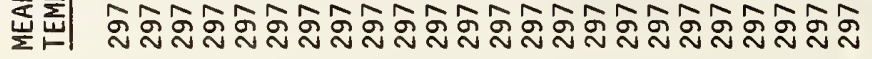

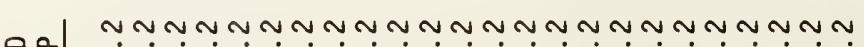

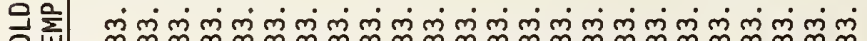

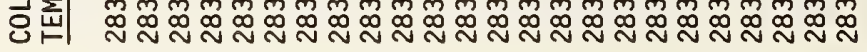

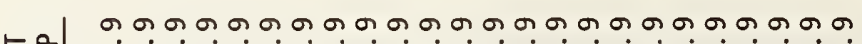

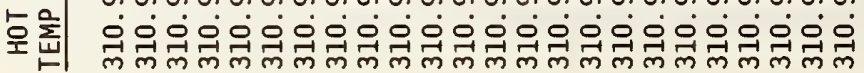

녜

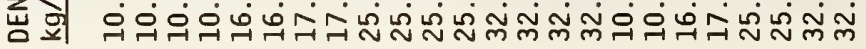

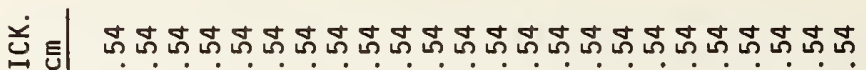

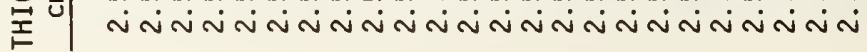
岕完|

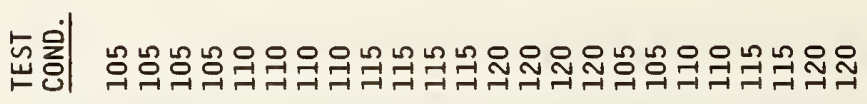

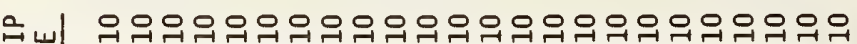

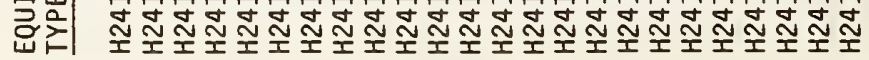
山

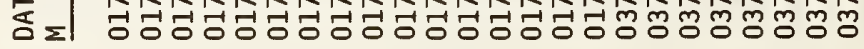

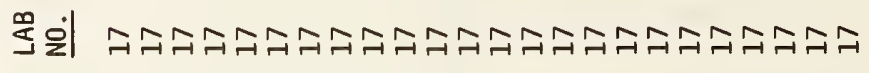

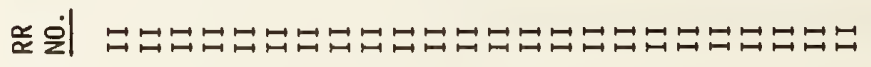


mn+ U

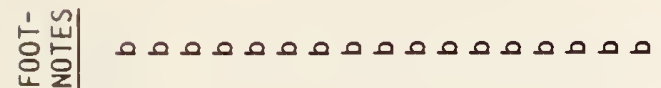

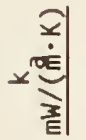

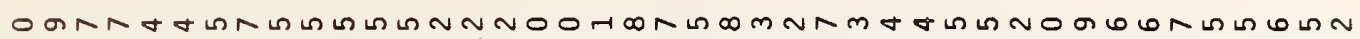

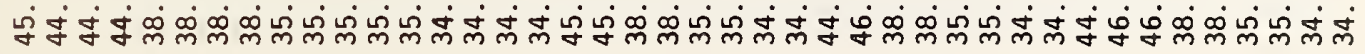

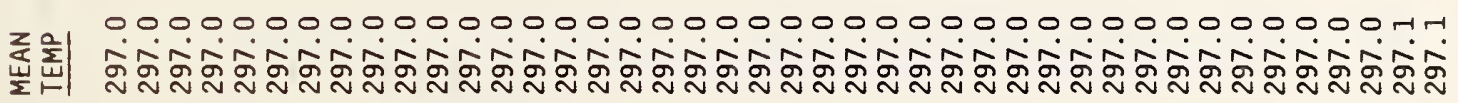

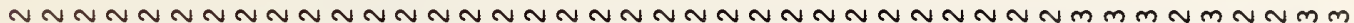
ஸ्

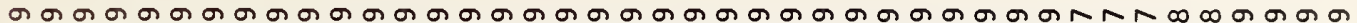

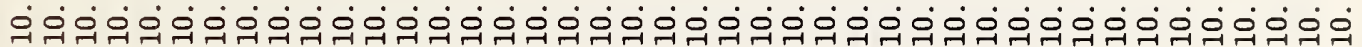

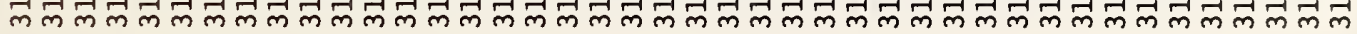

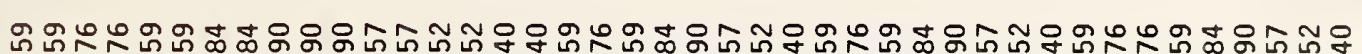

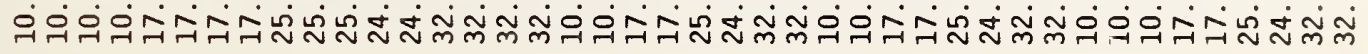

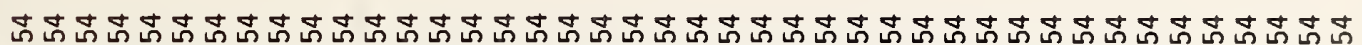

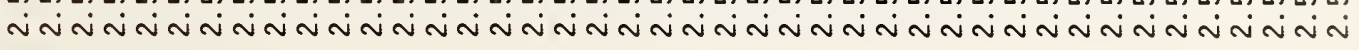

峁定

H

占号

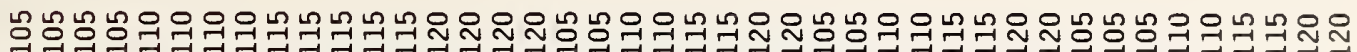

음눈

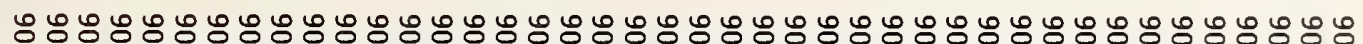

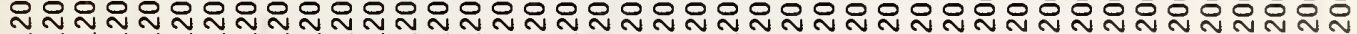

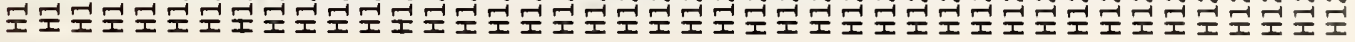

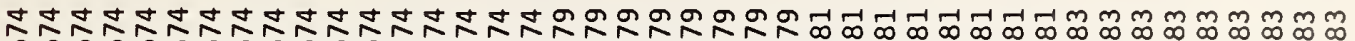

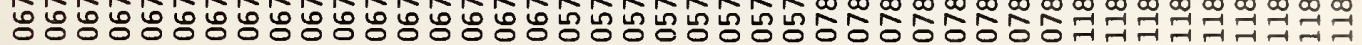

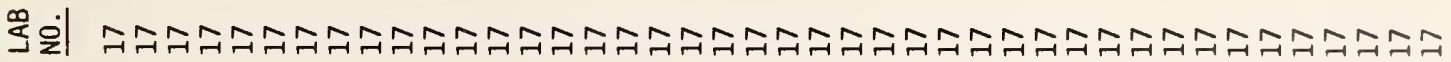

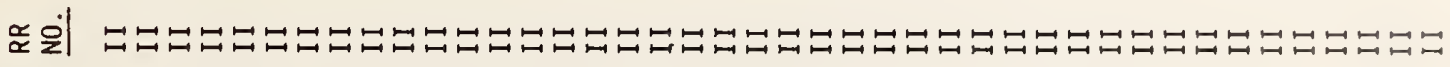


h

它总产

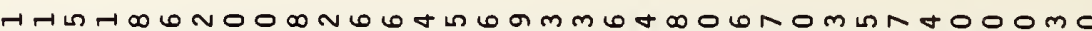

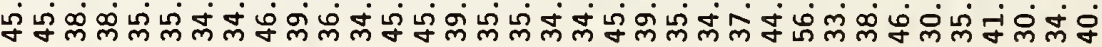

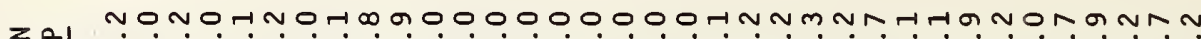

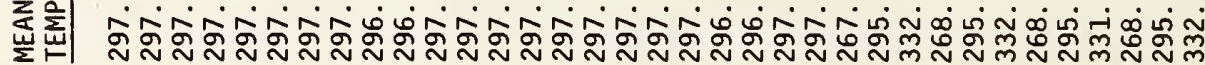

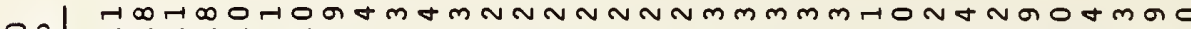
它部

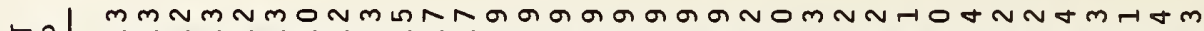

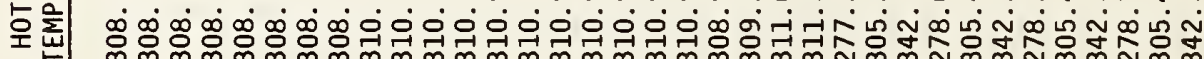

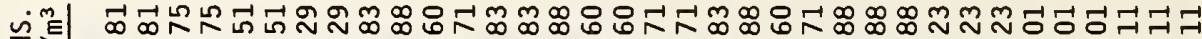

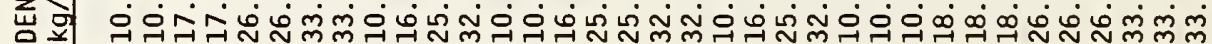

艺目 مأ

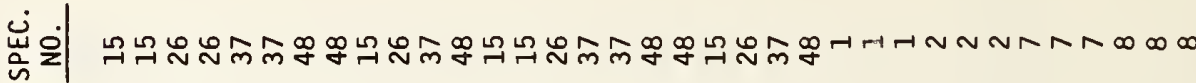

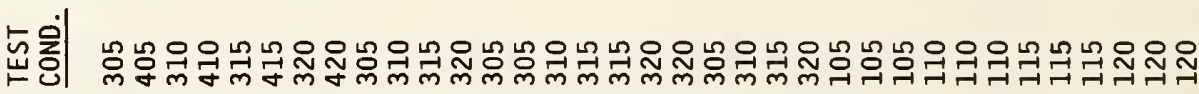

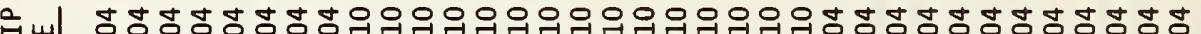

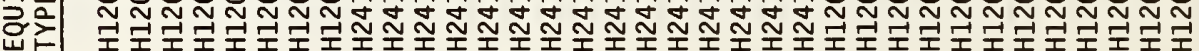

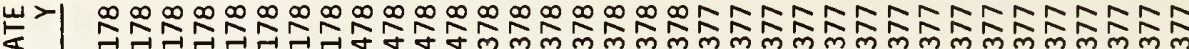

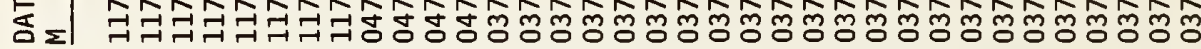

品

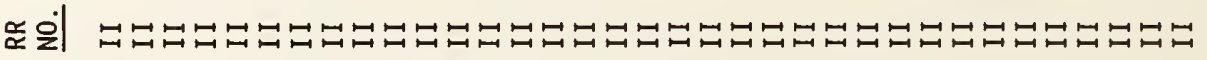




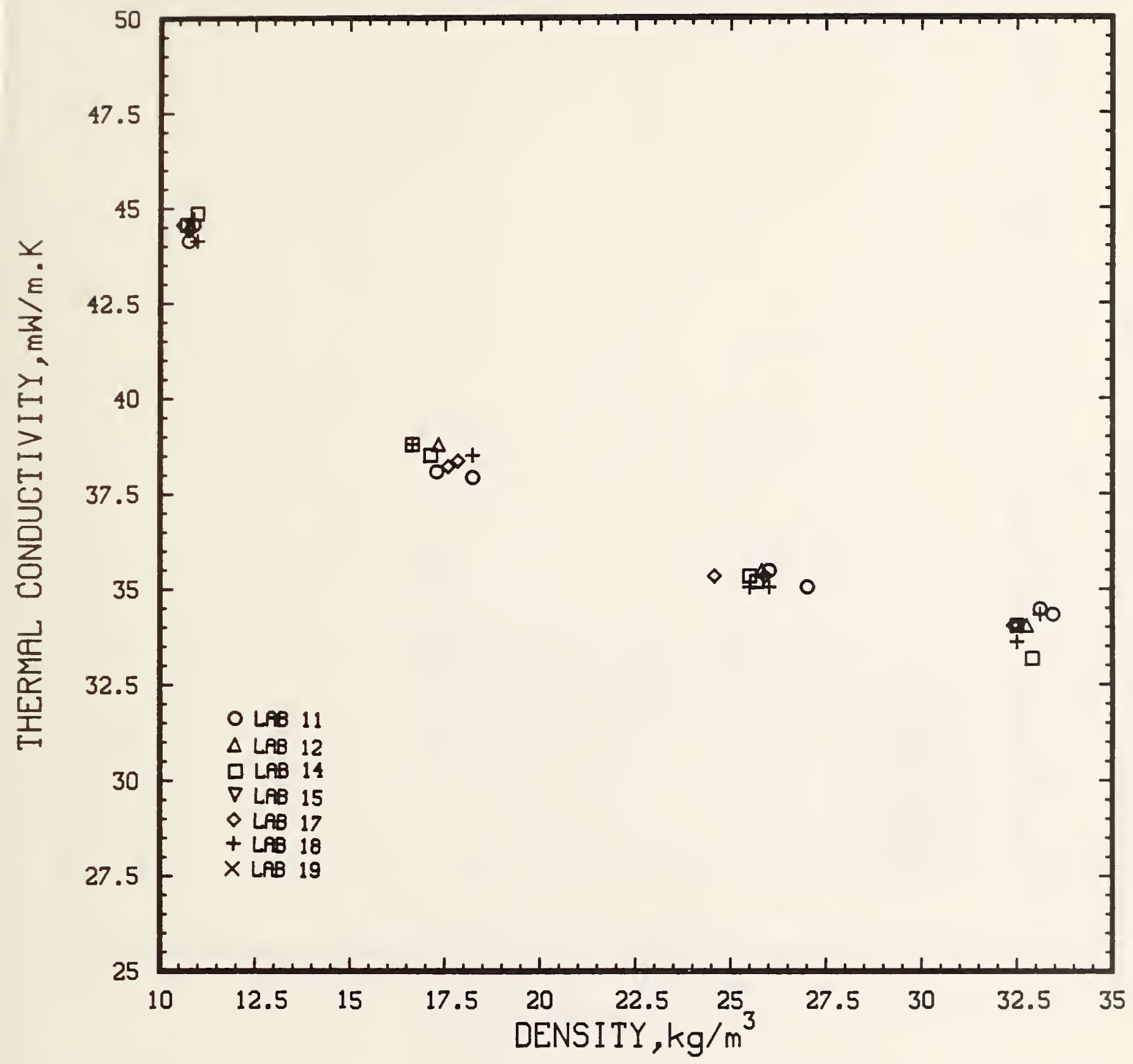

Figure 7.1 Thermal Conductivity versus Density for Heat Flow Meter Apparatus from Round Robin II. 


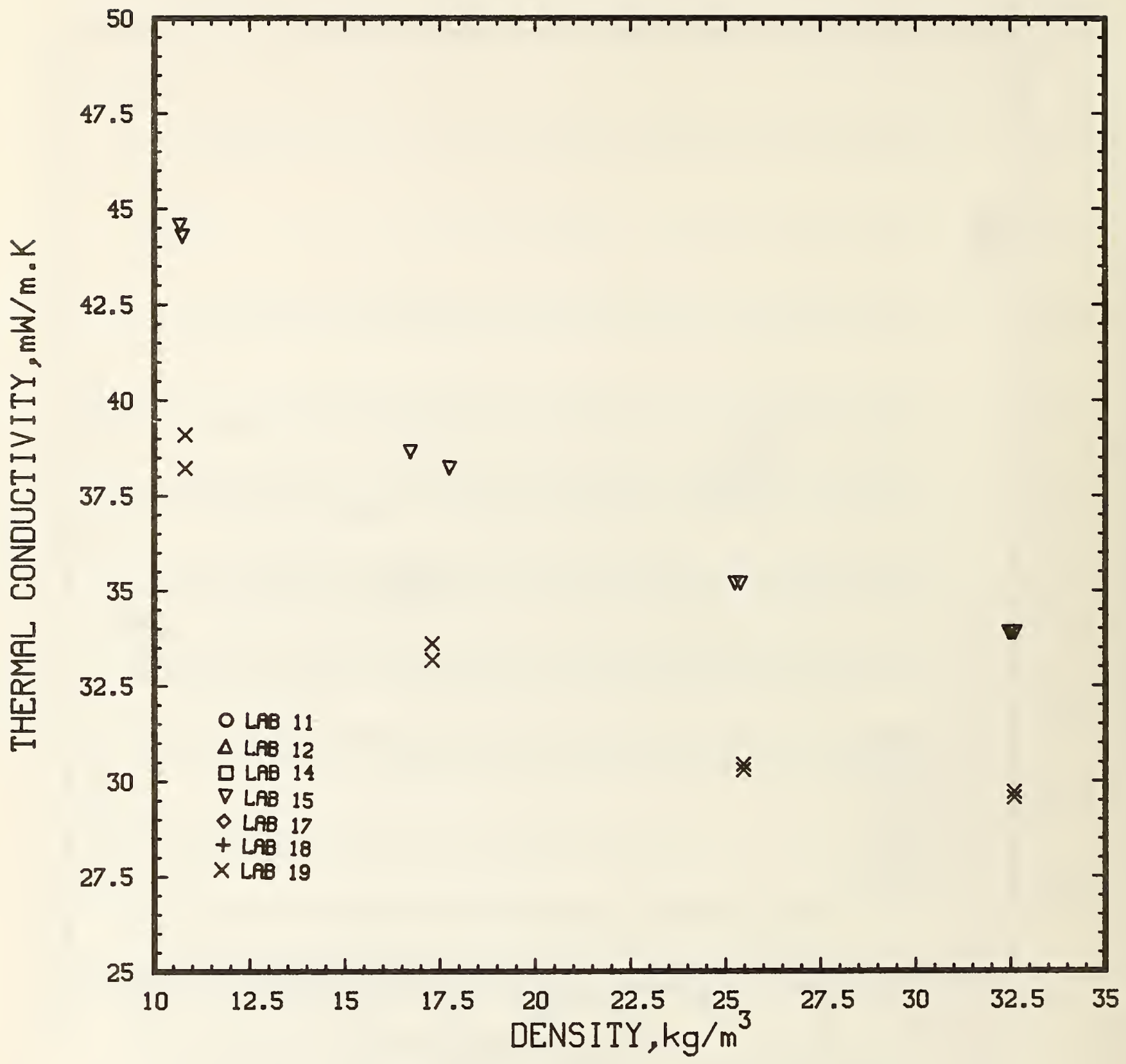

Figure 7.2 Thermal Conductivity versus Density for Guarded Hot Plate Apparatus from Round Robin II. 


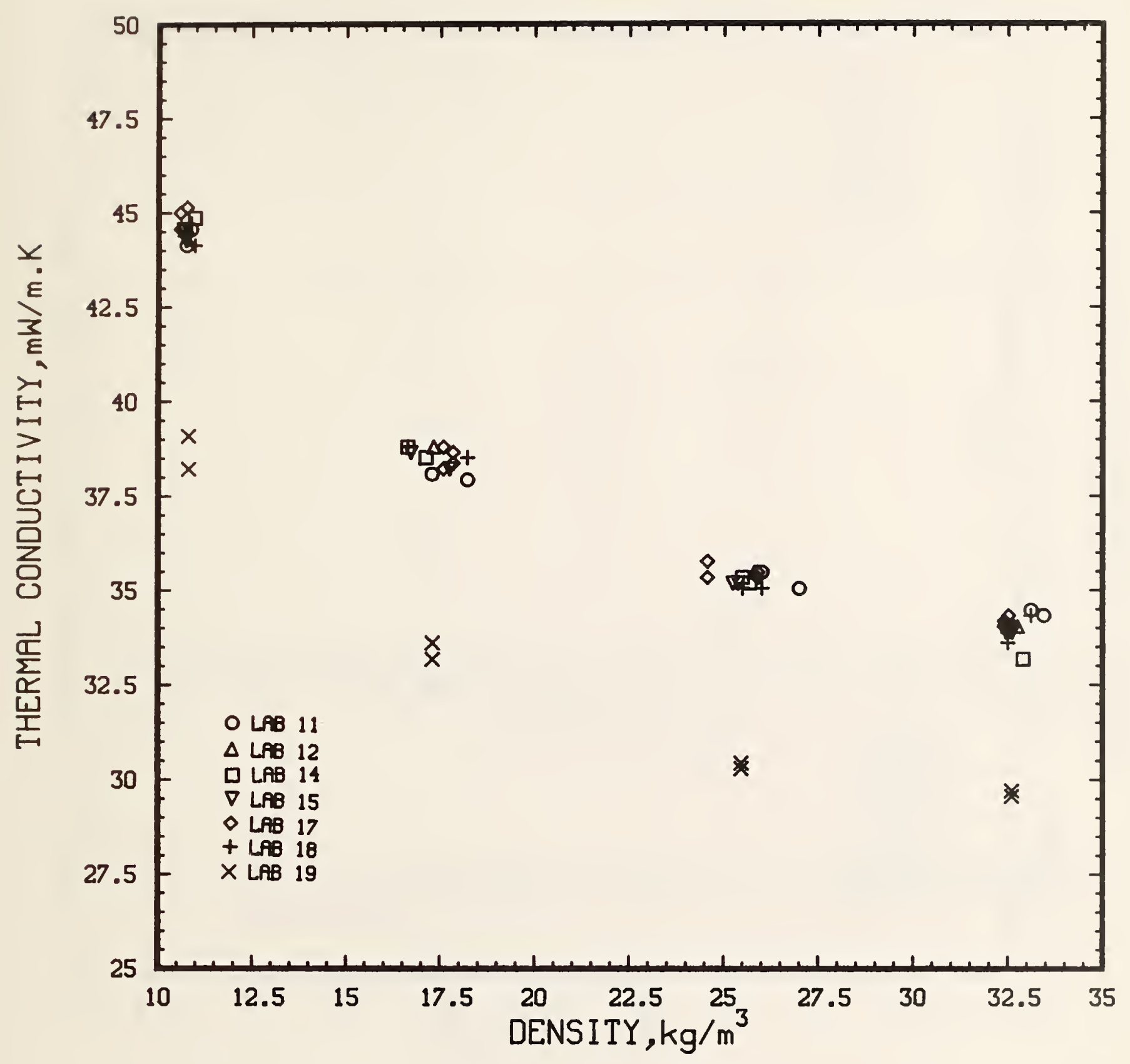

Figure 7.3 Thermal Conductivity versus Density for all Primary Round Robin II Data. 


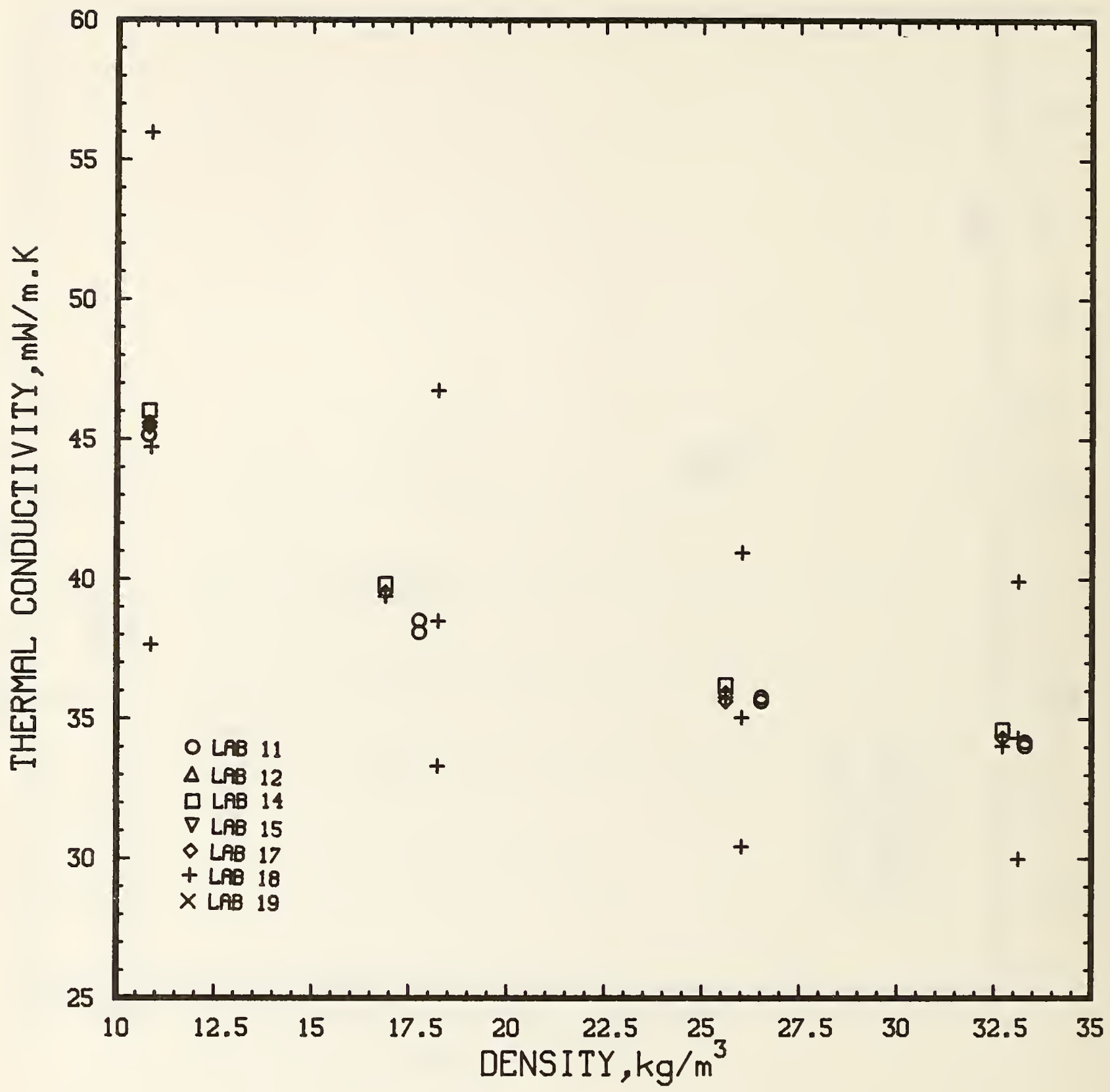

Figure 7.4 Thermal Conductivity versus Density for Supplementary Round Robin II Data. 


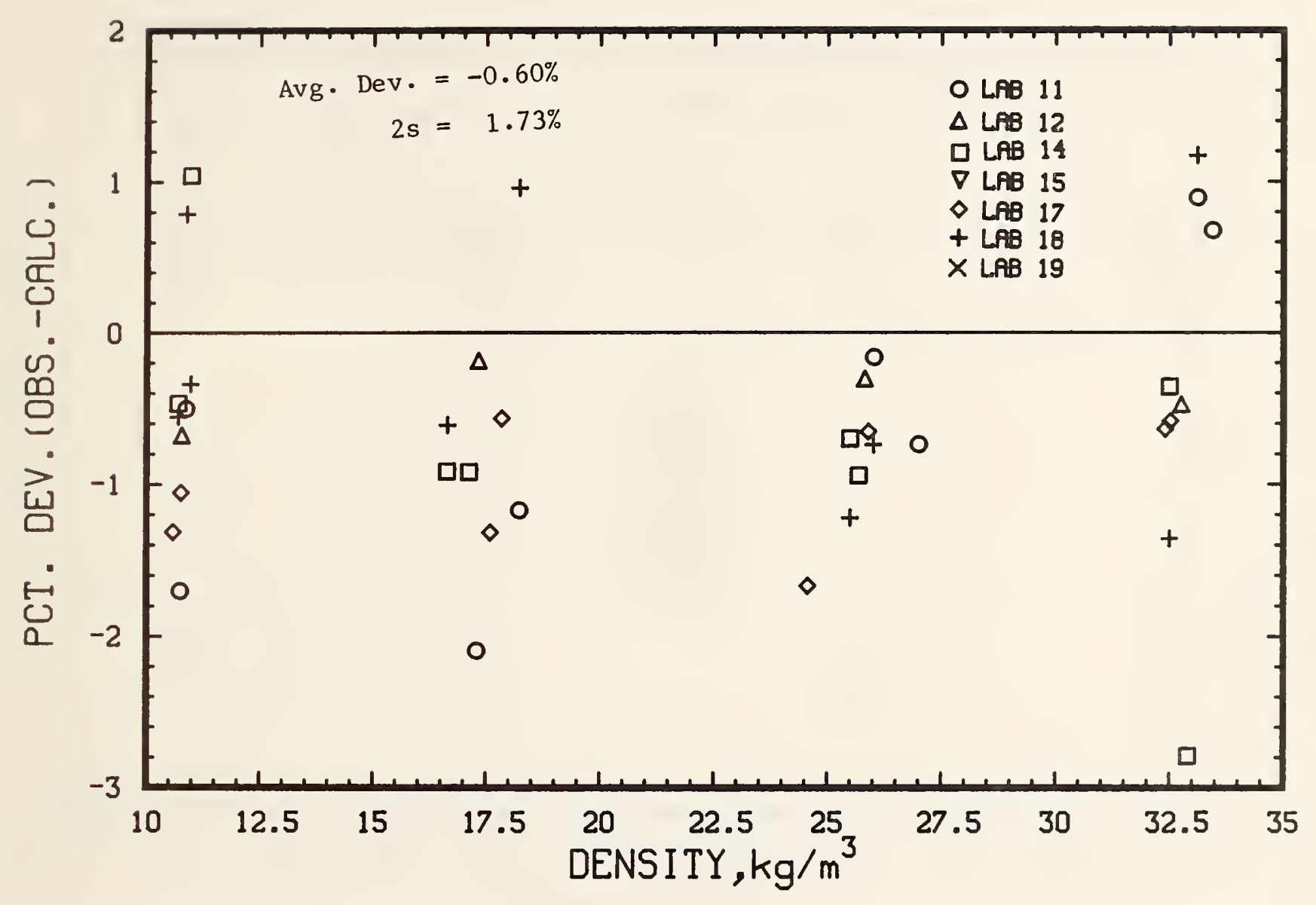

Figure 7.5 Deviations between Thermal Conductivity Data for Heat Flow Meter Apparatus from Round Robin II and Values Calculated from the Model versus Density. 


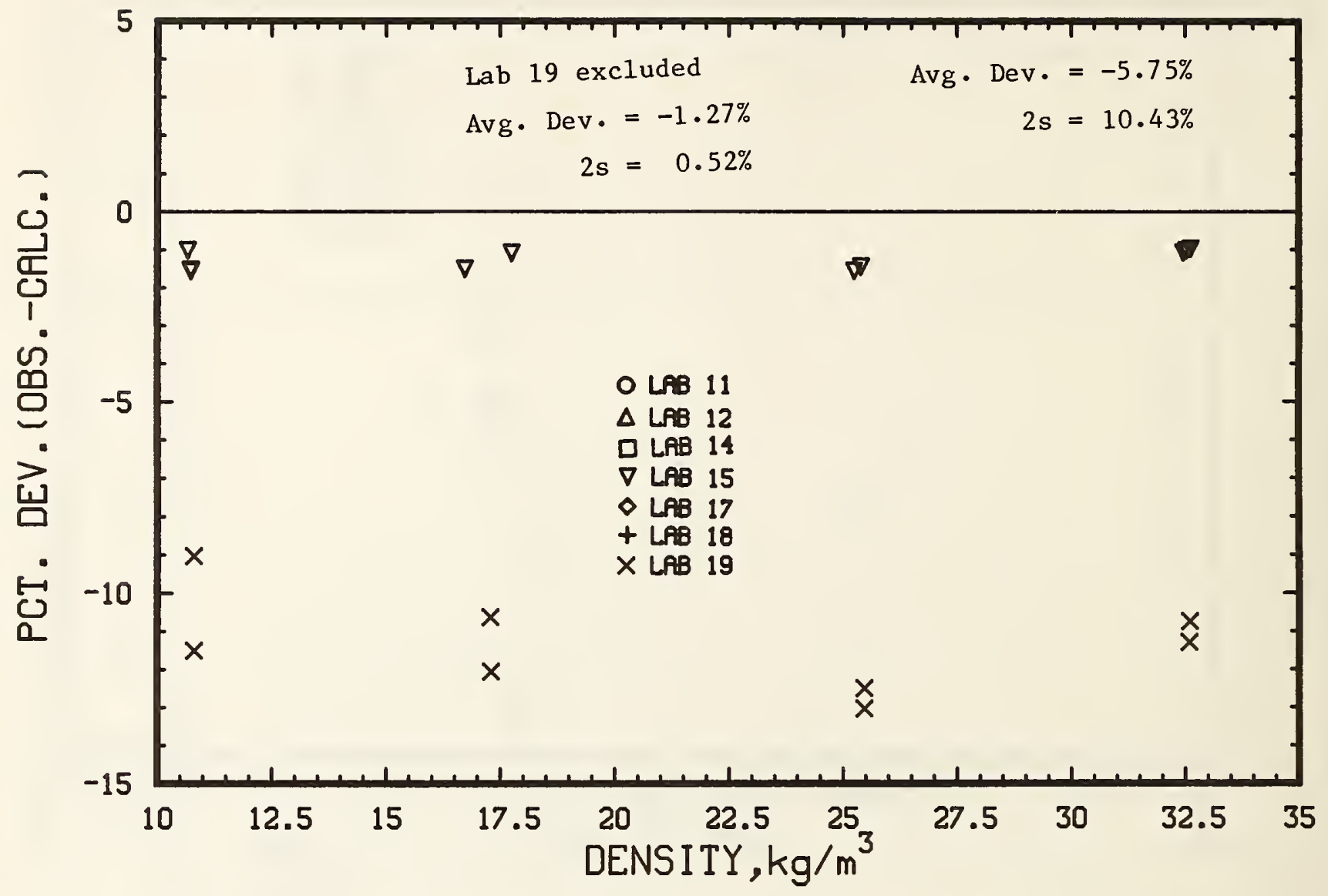

Figure 7.6 Deviations between Thermal Conductivity Data for Guarded Hot Plate Apparatus from Round Robin II and Values Calculated from the Model versus Density. 


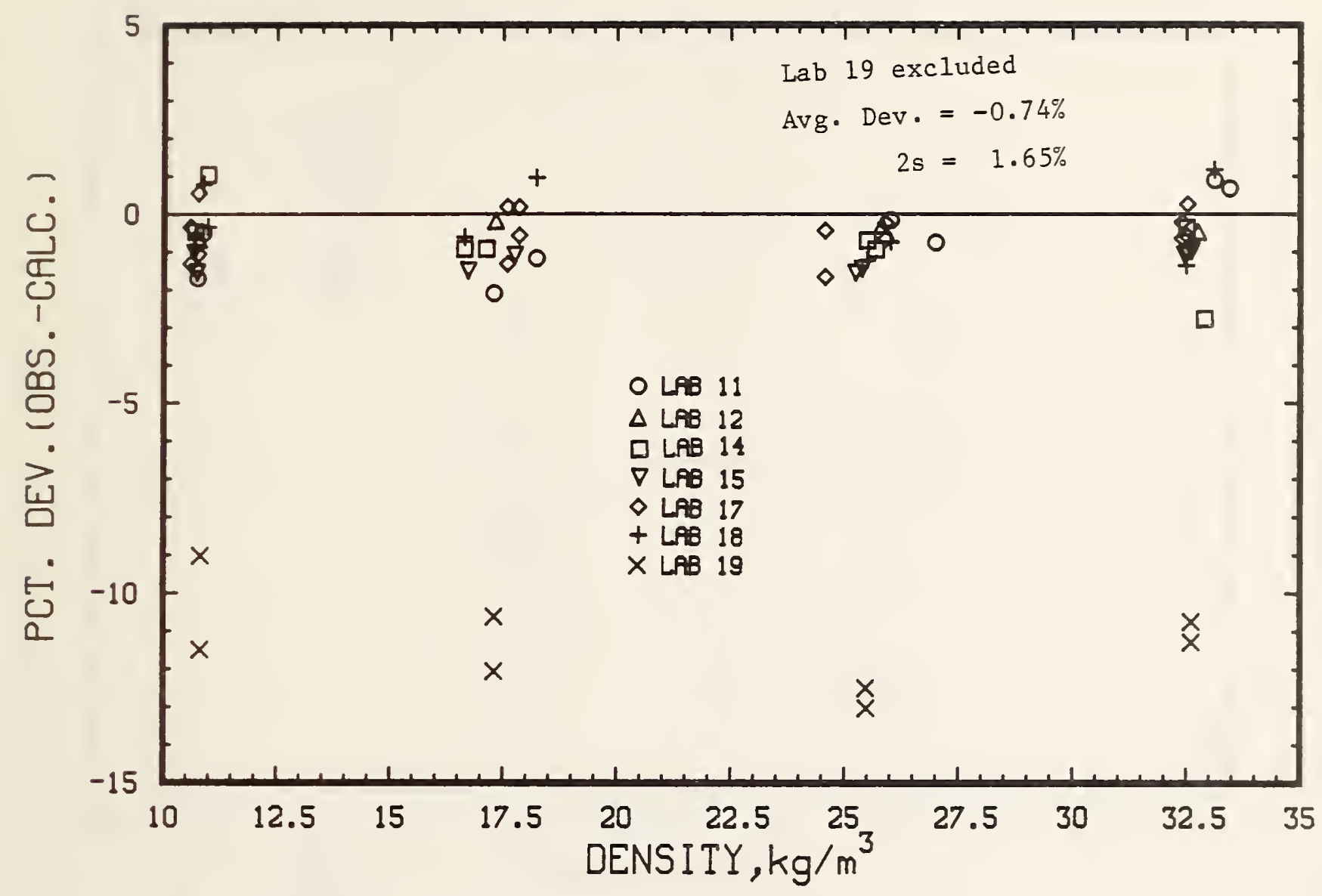

Figure 7.7 Deviations between al1 Primary Thermal Conductivity Data from Round Robin II and Values Calculated from the Model versus Density. 


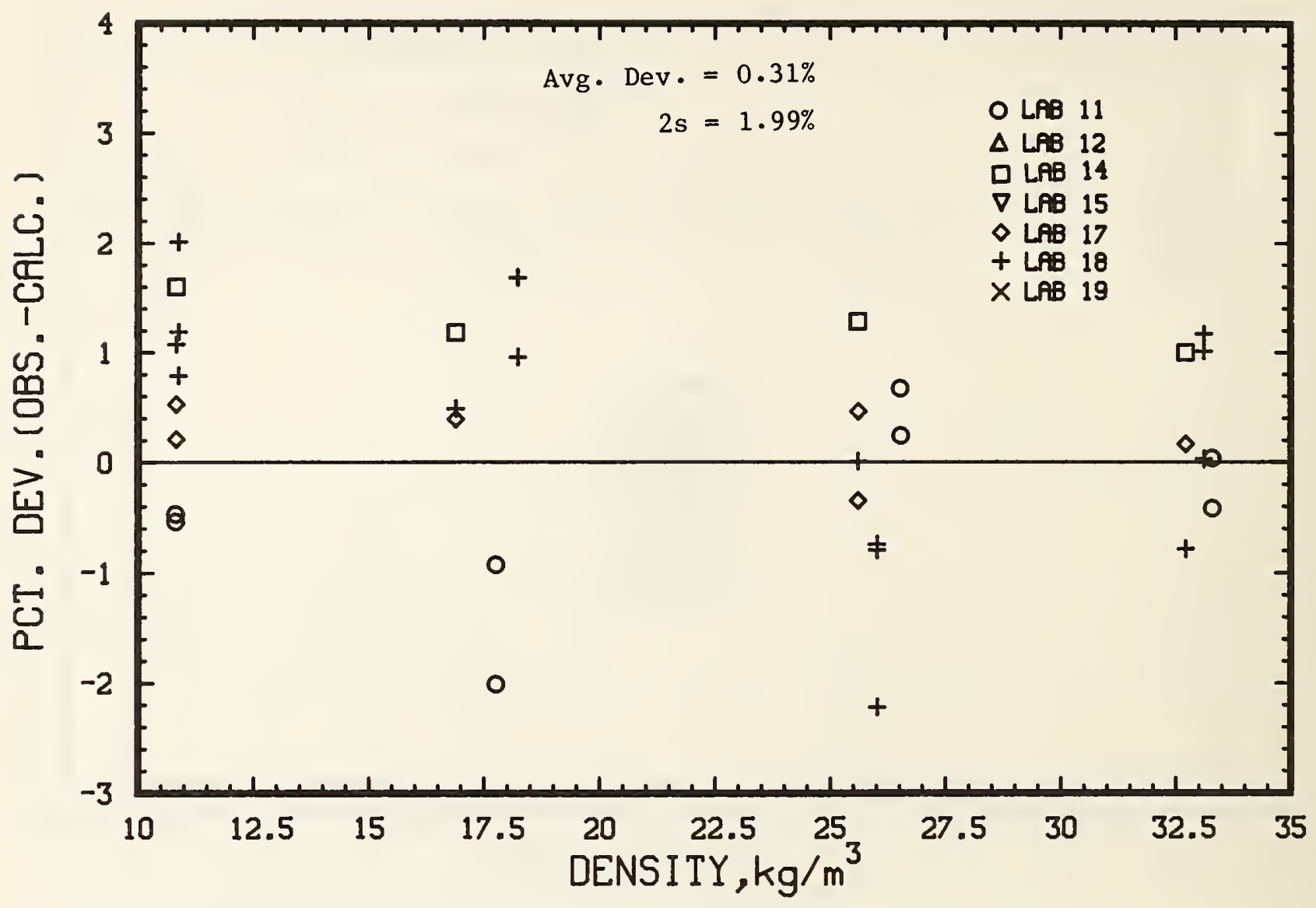

Figure 7.8 Deviations between Supplementary Thermal Conductivity Data from Round Robin II and Values Calculated from the Model versus Density. 


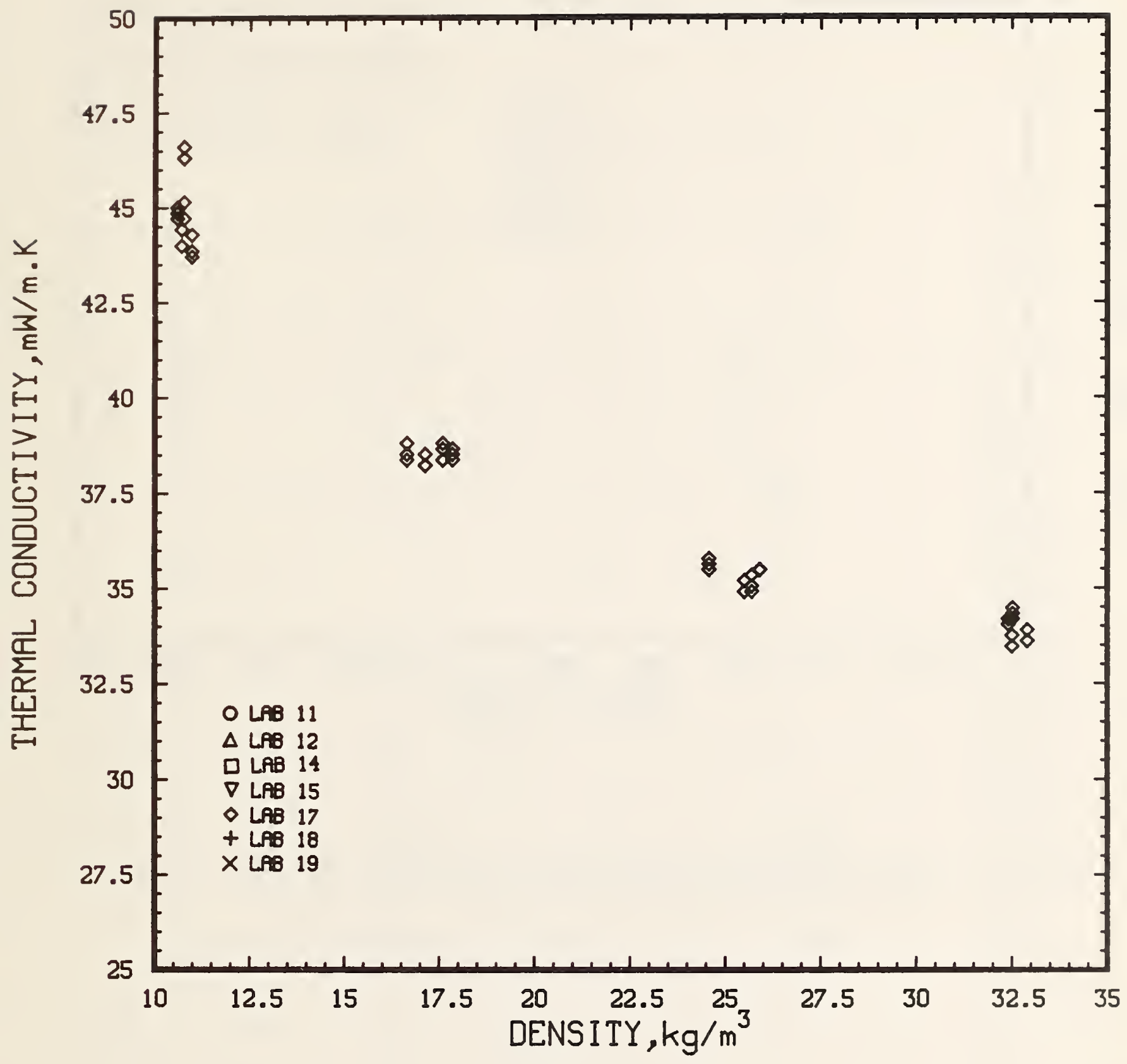

Figure 7.9 Thermal Conductivity versus Density of Control Data taken by Lab 17 for Round Robin II over the Period 1974 to 1983. 


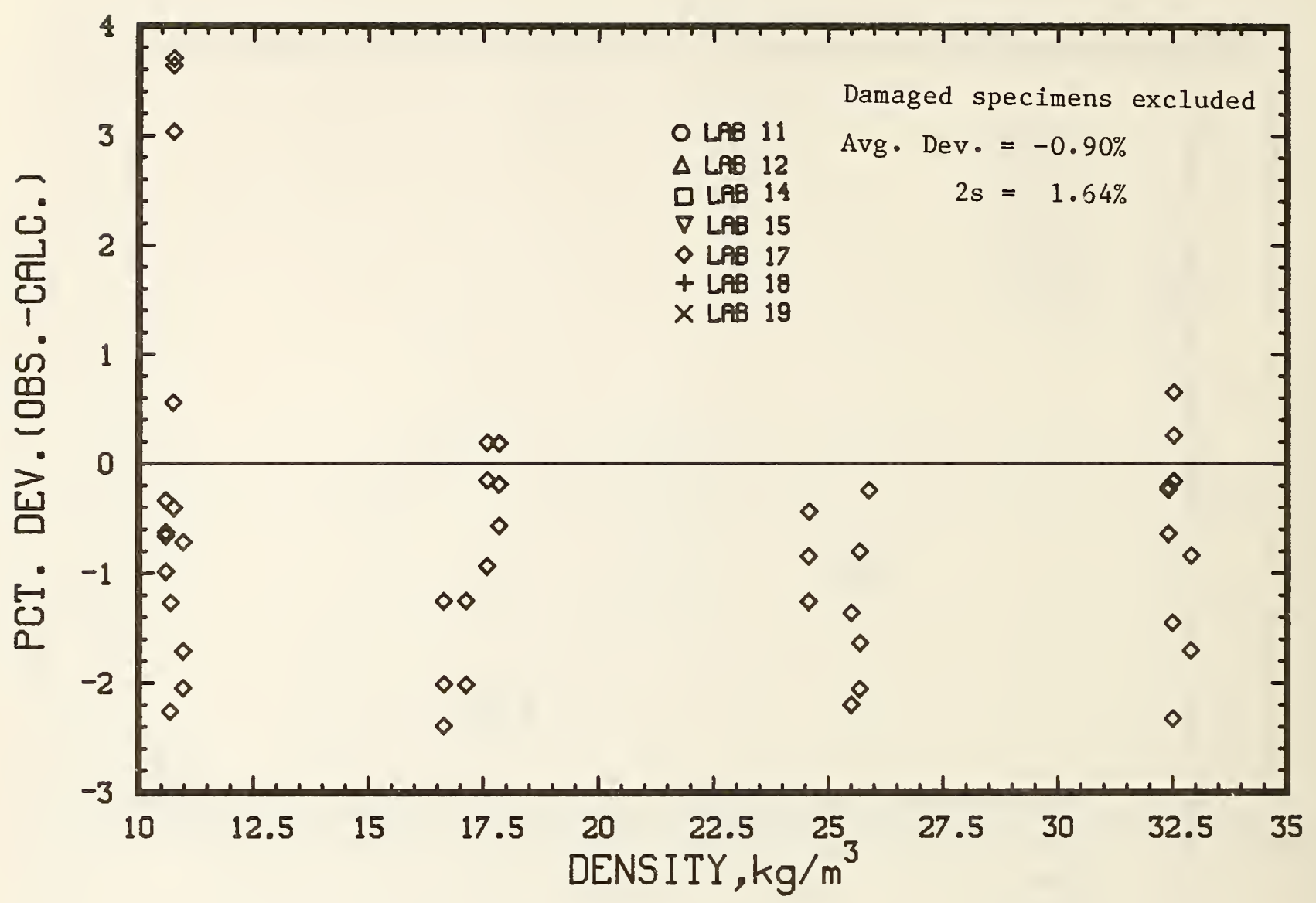

Figure 7.10 Deviations between Control Data from Lab 17 for Round Robin II and Values Calculated from the Model versus Density. 

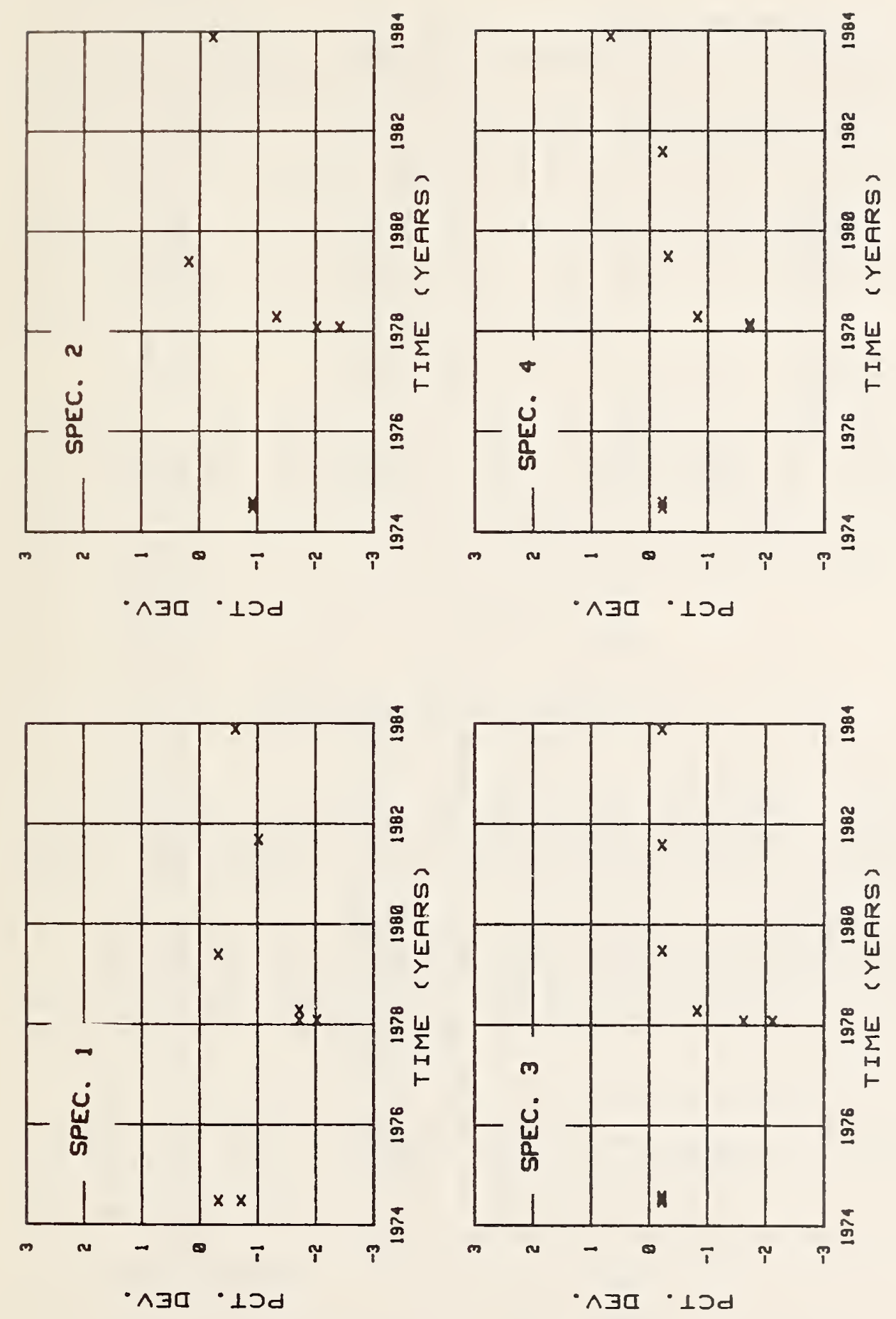

吕

동

동

o.

곡

กิ

튼

草

응

동

엉

ᄃ

岂岂

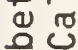

ปั

중

to

흠

ㄱ. 

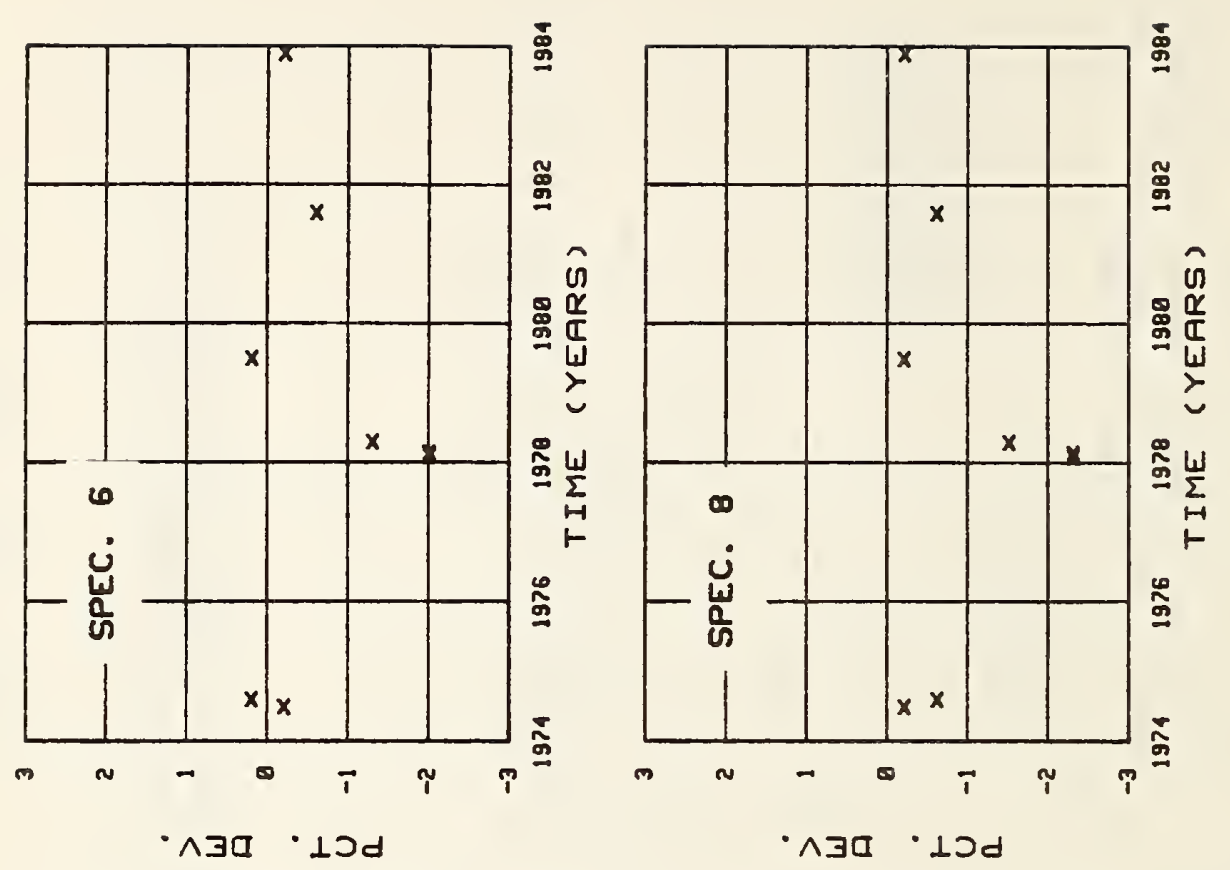

舁

5

ํำ

홍

ธै

운

곡

오 ํํำ

틍 व

我

夢

응

ᄂ

x
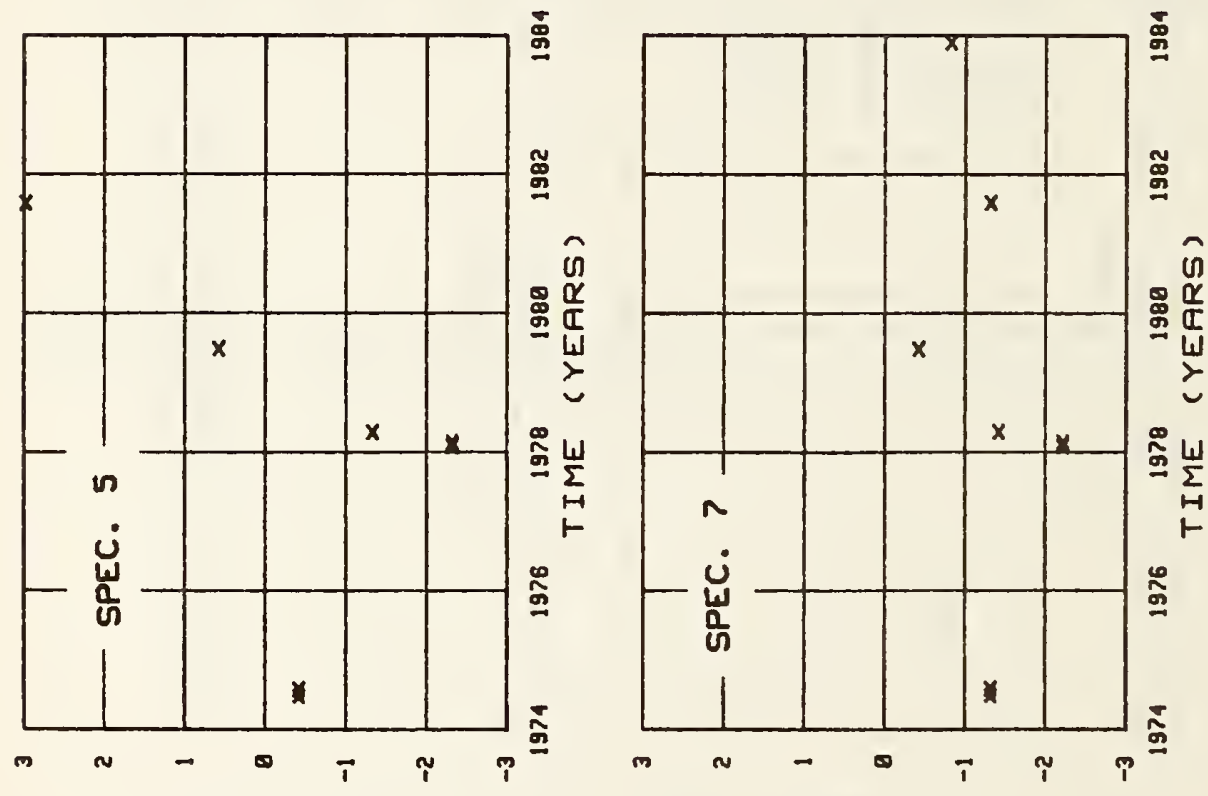

ठㅇ

ธั

至

范

气

등

开

.

造

N

- $\wedge \exists[\cdot 1 \partial d$

- 1 ja 


\subsection{Overview}

Round robin III was initiated following two meetings late in 1979 . On September 13, 1979, a meeting was held at the National Bureau of Standards (NBS) in Gaithersburg, MD to review the status of development of the one meter line-source GHP [16] which is intended to extend the thermal measurement capabilities of NBS. One of the first and the most urgent tasks to be performed was to provide reference specimens to verify GHP's (ASTM C177) [1] and calibrate HFM's (ASTM C518) [2] for tests on low density thermal insulations at thicknesses greater than $25.4 \mathrm{~mm}$ ( $1.0 \mathrm{in})$. It was agreed that the ongoing ASTM $C-16.30$ round robin program could provide helpful information in the evaluation of the new NBS GHP and provide information on the measurement capabilities of existing test equipment.

On October 7, 1979, at the regular meeting of ASTM C-16 in Nashville, TN task force representatives and participants of the September 13th meeting met to consider the request. The task force agreed to carry out a round robin with increasing thicknesses of glass fiber insulation initially to cover GHP's but with future extention to large HFM's*. The tests would be limited to equipment capable of testing specimens at least $100 \mathrm{~mm}\left(4.0^{\prime \prime}\right)$ thick. The tests were carried-out between January 1980 and Apri 11983.

The $\mathrm{C}-16.30$ Task Force Members were,

Charles M. Pelanne, (Chairman);

Diana Kirkpatrick, (NVLAP), and Jerome G. Hust.

The material used for the round robin consisted of eight matched pieces of $25.4 \mathrm{~mm}$ ( 1 in) thick specimens of three densities of glass fiber insulation batts. The specimens were supplied from the NVLAP inventory of low density glass fiber samples obtained from the Manville Research and Development Center.

All of the tests were performed on matched pairs of specimens at $25.4 \mathrm{~mm}$ (1 in), $50.8 \mathrm{~mm}$ ( $2 \mathrm{in}$ ), $76.2 \mathrm{~mm}$ ( $3 \mathrm{in}$ ), and $101.6 \mathrm{~mm}$ (4 in) test chickness and $24^{\circ} \mathrm{C}\left(75^{\circ} \mathrm{F}\right)$ mean temperature. The same specimens were circulated to all of the participating laboratories.

Table 8.1 and 8.2 show the results of the measurements as obtained during the course of RR III. The NBS data for RR III are listed in Table 5.2. Table 8.3 provides data on the matched sets as individuals instead of pairs as in the main part of the program. The data was obtained by HFM and are provided for reference only.

\subsection{Test Specimens}

The specimens consisted of three sets of glass fiber insulation batts, each set made up of eight, $25.4 \mathrm{~mm}$ ( 1 in) thick, matched, $610 \times 610 \mathrm{~mm}(24 \times$ 24 in) pieces. These specimens were provided by NVLAP of NBS in order to expedite the program.

*The HFM portion of this plan was not carried out. 
The specimens were selected by the task force chairman from a stock of NVLAP characterized glass fiber insulation specimens. The selection and characterization of the specimens held at NBS by NVLAP allowed for a very accurate selection of the specimens required for this program. The selection was made on the basis of uniformity of weight, the predicted apparent thermal conductivity and the uniformity of density distribution within the central test area, for each of the three density groups. The apparent thermal conductivity was predicted for each specimen on the basis of weight and light transmission [15] measurements performed as part of the contract. The density distribution was also determined by means of the light transmission measurements. The specimens with the selection characteristics are listed below.

\section{Side one}

Teststack Specimen Density

order*

Set Number 1

1
2
3
4

Set Number 2

1
2
3
4

Set Number 3

1
2
3
4

81247
82278
50134
81257

80831

80914

80762

85855
Predicted $\left(\mathrm{mW} \cdot \mathrm{m}^{\mathrm{k}}{ }^{\mathrm{k}} \cdot \mathrm{K}^{-1}\right)$ Specimen
Side two

Density

Predicted

To allow testing in large GHP's $1220 \times 1220 \times 25.4 \mathrm{~mm}(48 \times 48 \times 1$ in) pieces of insulation from the same production lot as the material supplied to NBS for the NVLAP program were provided. These large pieces were selected to match the density of the specimens they were to guard. The stacking order for these pieces and the test specimens is shown in the appendix. The center 610 $\times 610 \mathrm{~mm}$ portions were cut out to form frames for the test specimens.

The density of each individual piece was determined for the whole $610 \mathrm{~mm}$ specimen and in order to relate the test density to the apparatus test area each piece was cut and weighed to successively smaller sizes matching the test areas. A total of one hundred and twenty density determinations for individual specimens covering the range of test areas and nominal densities were made. Ninety cumulative density calculations were made for the various stacked thicknesses. The details are reported in Table 13.6.

\footnotetext{
* Teststack order indicates the order in which the specimens were stacked to achieve the various test thicknesses.
} 


\subsection{Test Equipment}

Five GHP's were involved in this round robin. These were as follows;

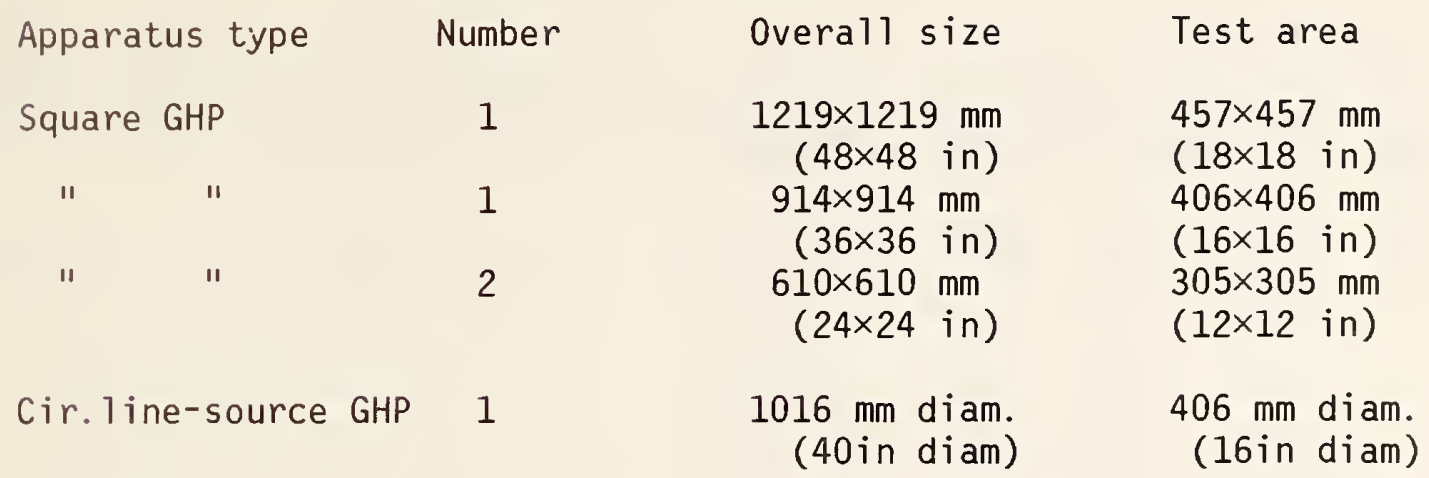

\subsection{Results}

The test dates ran from January 1980 to April 1983. In some instances the tests were performed in two different periods during the course of the round robin.

Round robin III was conducted on three sets of specimens with different nominal densities and at four thicknesses, the results were analyzed as a function of both density and thickness.

All of the apparent thermal conductivity data are plotted as a function of density in Figure 8.1. It is interesting to note that the spread of the data is nearly the same for each nominal density. The spread is a measure of a) specimen inhomogeneity, b) experimental imprecision (both intra- and inter laboratory) and c) the effect of thickness. The latter is expected to be larger at low density but the effect is nearly hidden in the overall scatter on this plot. All of the data are plotted as a function of thickness in Figure 8.2. The data are grouped in three categories representing each of the nominal densities. Here the effect of thickness is clearer but it should be noted that the effect is only marginally greater than the overall spread in the data for each density. The effect of thickness at the highest density is within the spread of the data. Some overlap exists between the results obtained on the two higher densities. The deviation of all of the RR III results from the model are shown in Figure 8.3 as a function of density and in Figure 8.4 as a function of thickness.

The average deviation from the model and the $2 \mathrm{~s}$ value for each data subset are shown on the deviation plots.

These figures show that the interlaboratory spread is about $2.5 \%$ around the experimental mean value, which is greater than for RR I and RR II. The intralaboratory spread is about half of the interlaboratory spread.

In this case, it was desirable to separately plot the deviations for each nominal density as a function of thickness and for each thickness as a function of density. Figures 8.5 through 8.8 show the deviations as a function of density for the $25.4,50.8,76.2$ and $101.6 \mathrm{~mm}$ thicknesses, respectively. 
Figures 8.9 through 8.11 show the deviations as a function thickness for the three nominal densities, 11,16 , and $19 \mathrm{~kg} / \mathrm{m}^{3},\left(0.7,1.0\right.$, and $\left.1.21 \mathrm{~b} / \mathrm{ft}^{3}\right)$, respectively.

The percent deviations (observed - calculated) are also listed in the last column of Tables $5.2,8.1$, and 8.2. Since the three round robins are closely related, the detailed discussion of the significance of these results is relegated to section 9 of this report. 
Table 8.1 ASTM C-16.30/MIMA Round Robins. Primary Data for Round Robin III.*

\begin{tabular}{|c|c|c|c|c|c|c|c|c|c|c|c|c|c|}
\hline $\begin{array}{l}\text { RR } \\
\text { NO. }\end{array}$ & $\begin{array}{l}\text { LAB } \\
\text { NO. }\end{array}$ & $\begin{array}{l}\text { DATE } \\
M \quad Y \\
\end{array}$ & $\begin{array}{l}\text { EQUIP } \\
\text { TYPE } \\
\end{array}$ & $\begin{array}{l}\text { TEST } \\
\text { COND. }\end{array}$ & $\begin{array}{l}\text { SPEC. } \\
\text { NO. }\end{array}$ & $\begin{array}{c}\text { THICK. } \\
\mathrm{cm} \\
\end{array}$ & $\begin{array}{l}\text { DENS. } \\
\mathrm{kg} / \mathrm{m}^{3} \\
\end{array}$ & $\begin{array}{r}\text { HOT } \\
\text { TEMP } \\
\end{array}$ & $\begin{array}{l}\text { COLD } \\
\text { TEMP } \\
\end{array}$ & $\begin{array}{l}\text { MEAN } \\
\text { TEMP } \\
\end{array}$ & $\begin{array}{c}k \\
m W /\left(\frac{a}{m} \cdot k\right) \\
\end{array}$ & $\begin{array}{l}\text { FOOT- } \\
\text { NOTES }\end{array}$ & PCT \\
\hline III & 12 & 0180 & G4818 & 507 & 1 & 2.54 & 11.58 & 308.2 & 286.1 & 297.1 & 43.8 & & 1.7 \\
\hline III & 12 & 0180 & G4818 & 707 & 123 & 7.62 & 11.44 & 308.2 & 286.0 & 297.1 & 44.7 & & 2.0 \\
\hline III & 12 & 0180 & G4818 & 807 & 1234 & 10.16 & 11.39 & 308.2 & 286.0 & 297.1 & 44.9 & & 2.0 \\
\hline III & 12 & 0180 & G4818 & 509 & 1 & 2.54 & 15.68 & 308.2 & 286.0 & 297.1 & 39.7 & & 0.7 \\
\hline III & 12 & 0180 & G4818 & 609 & 12 & 5.08 & 15.71 & 308.2 & 286.0 & 297.1 & 40.2 & & 1.6 \\
\hline III & 12 & 0180 & G4818 & 512 & 1 & 2.54 & 19.40 & 308.2 & 286.0 & 297.1 & 37.6 & & 0.8 \\
\hline III & 12 & 0180 & G4818 & 612 & 12 & 5.08 & 19.09 & 308.2 & 286.0 & 297.1 & 38.1 & & 1.1 \\
\hline III & 12 & 0180 & G4818 & 712 & 123 & 7.62 & 19.33 & 308.2 & 286.0 & 297.1 & 38.2 & & 1.6 \\
\hline III & 12 & 0180 & G4818 & 812 & 1234 & 10.16 & 19.25 & 308.2 & 286.1 & 297.1 & 38.5 & & 2.2 \\
\hline III & 15 & 1080 & G2412 & 507 & 1 & 2.54 & 11.85 & 310.9 & 283.3 & 297.1 & 43.1 & & 0.9 \\
\hline III & 15 & 1080 & G2412 & 607 & 12 & 5.08 & 11.47 & 310.8 & 283.0 & 296.9 & 43.7 & & 0.3 \\
\hline III & 15 & 1080 & G2412 & 709 & 123 & 7.62 & 15.60 & 310.9 & 283.0 & 296.9 & 40.0 & & 0.6 \\
\hline III & 15 & 1080 & G2412 & 809 & 1234 & 10.16 & 15.51 & 310.5 & 282.9 & 296.7 & 40.1 & & 0.7 \\
\hline III & 15 & 1180 & G2412 & 512 & 1 & 2.54 & 19.21 & 311.0 & 283.2 & 297.1 & 37.5 & & 0.1 \\
\hline I I I & 15 & 1180 & G2412 & 612 & 12 & 5.05 & 18.89 & 310.5 & 283.0 & 296.8 & 37.6 & & -0.2 \\
\hline II I & 15 & 1180 & G2412 & 712 & 123 & 7.59 & 19.32 & 310.9 & 283.0 & 297.0 & 37.8 & & 0.6 \\
\hline III & 15 & 1180 & G2412 & 812 & 1234 & 10.16 & 19.27 & 310.5 & 282.9 & 296.7 & 38.1 & & 1.3 \\
\hline III & 18 & 0483 & G2412 & 507 & 1 & 2.54 & 11.85 & 309.7 & 282.5 & 296.1 & 43.4 & ed & 2.1 \\
\hline III & 18 & 0483 & G2412 & 607 & 12 & 5.08 & 11.47 & 311.0 & 283.8 & 297.4 & 45.0 & ed & 2.8 \\
\hline III & 18 & 0483 & G2412 & 707 & 123 & 7.62 & 11.50 & 311.2 & 283.7 & 297.4 & 44.6 & ed & 1.6 \\
\hline III & 18 & 0483 & G2412 & 807 & 1234 & 10.16 & 11.39 & 311.2 & 283.5 & 297.3 & 44.6 & ed & 1.2 \\
\hline III & 18 & 0483 & G2412 & 509 & 1 & 2.54 & 15.30 & 311.2 & 284.4 & 297.8 & 39.2 & ed & -1.5 \\
\hline III & 18 & 0483 & G2412 & 609 & 12 & 5.08 & 15.49 & 310.0 & 283.1 & 296.6 & 40.1 & ed & 1.1 \\
\hline II I & 18 & 0483 & G2412 & 709 & 123 & 7.62 & 15.60 & 311.2 & 283.0 & 297.1 & 39.8 & ed & 0.1 \\
\hline III & 22 & 0481 & G3616 & 509 & 1 & 2.54 & 15.70 & 304.8 & 286.8 & 295.8 & 39.8 & cpu & 1.8 \\
\hline III & 22 & 0481 & G3616 & 609 & 12 & 5.08 & 15.78 & 308.3 & 284.8 & 296.5 & 40.5 & cpu & 2.7 \\
\hline II I & 22 & 0481 & G3616 & 709 & 123 & 7.62 & 15.76 & 308.3 & 284.8 & 296.5 & 40.8 & cpu & 3.2 \\
\hline I I I & 22 & 0481 & G3616 & 809 & 1234 & 10.16 & 15.68 & 310.3 & 286.5 & 298.4 & 40.8 & cpu & 2.0 \\
\hline I I I & 22 & 0481 & G3616 & 512 & 1 & 2.54 & 19.41 & 306.8 & 286.9 & 296.8 & 38.2 & cpu & 2.4 \\
\hline I I I & 22 & 0481 & G3616 & 612 & 12 & 5.08 & 19.11 & 309.3 & 284.8 & 297.1 & 38.8 & cpu & 3.0 \\
\hline II I & 22 & 0481 & G3616 & 712 & 123 & 7.62 & 19.43 & 310.1 & 284.7 & 297.4 & 39.1 & cpu & 3.7 \\
\hline III & 22 & 0481 & G3616 & 812 & 1234 & 10.16 & 19.38 & 309.3 & 284.8 & 297.0 & 40.0 & срu & 5.9 \\
\hline
\end{tabular}

* Lab 13 data are given in Table 5.2

cpi: Tests performed with insulated cold plates

cpu: Tests performed wtih uninsulated cold plates

ed: Equipment difficulty reported 


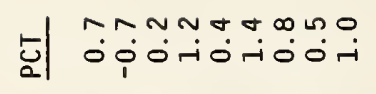

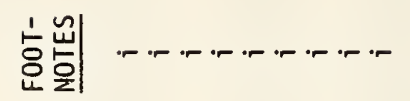

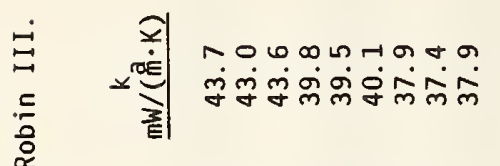

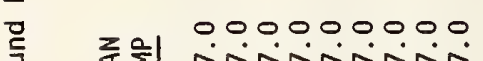

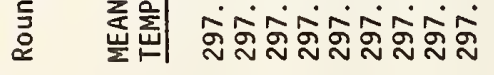

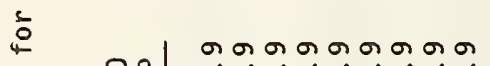
4

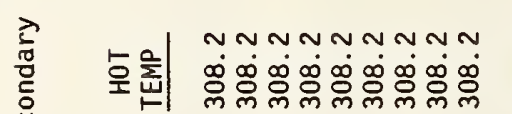

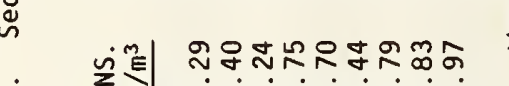

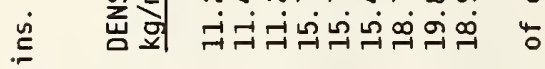

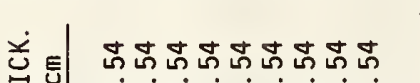
至 讪完 Nmonmonmo

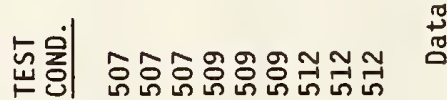

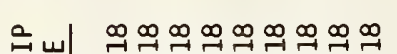
实崖|

$\infty$

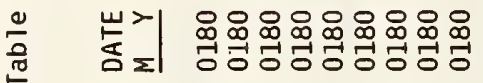

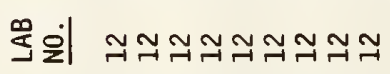

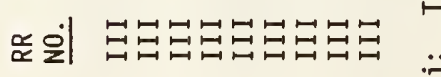




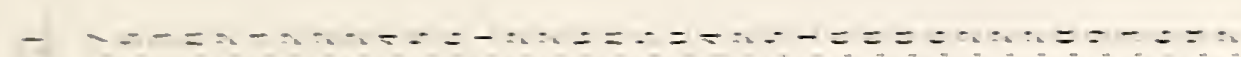

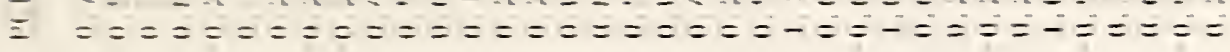

三

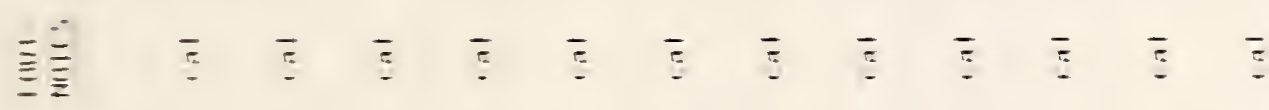

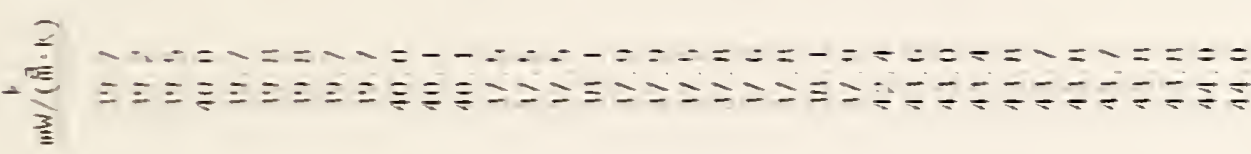

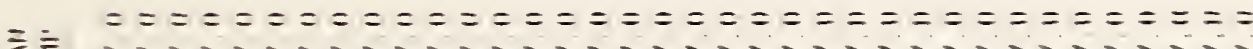

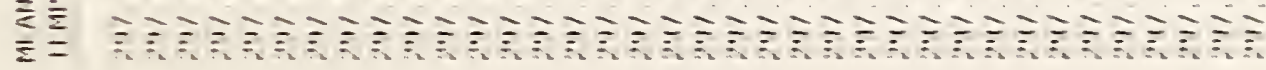

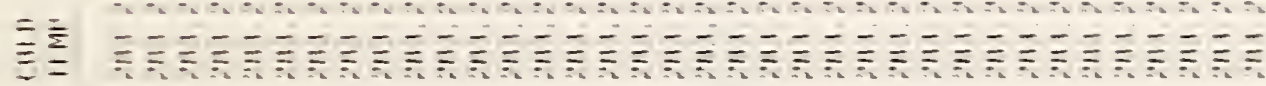

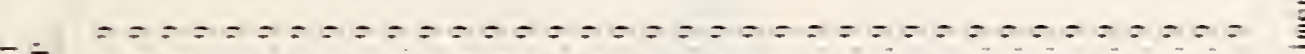

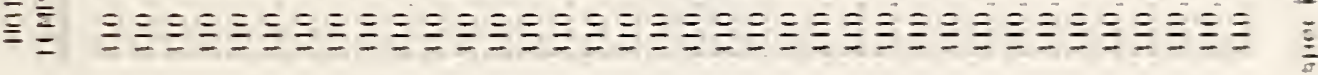

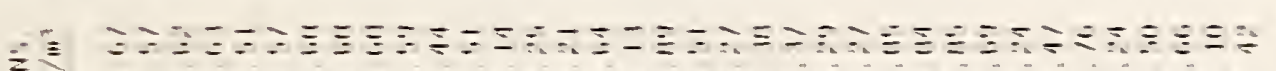

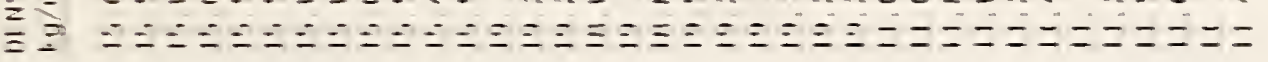

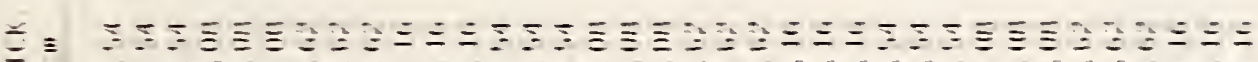

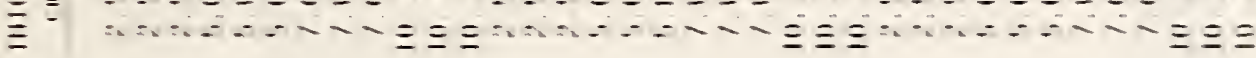

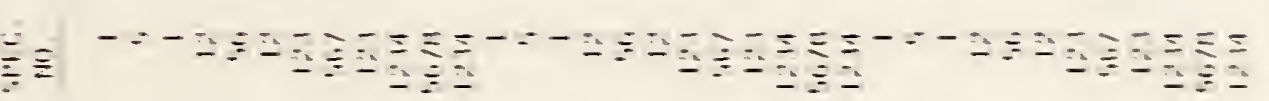

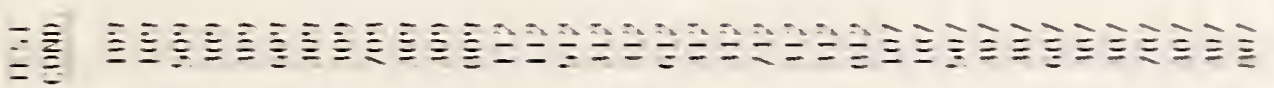

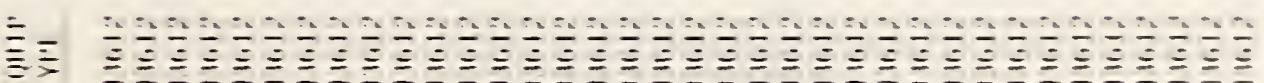
要要

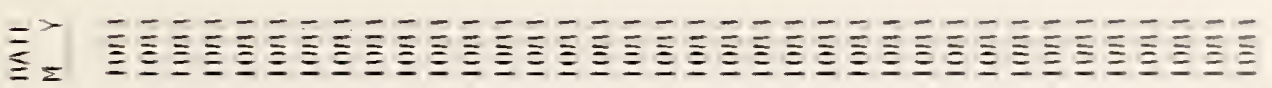

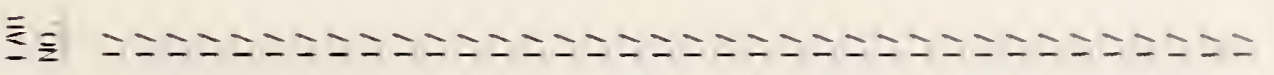

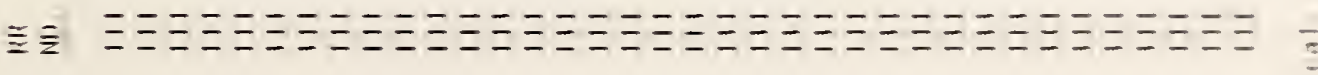




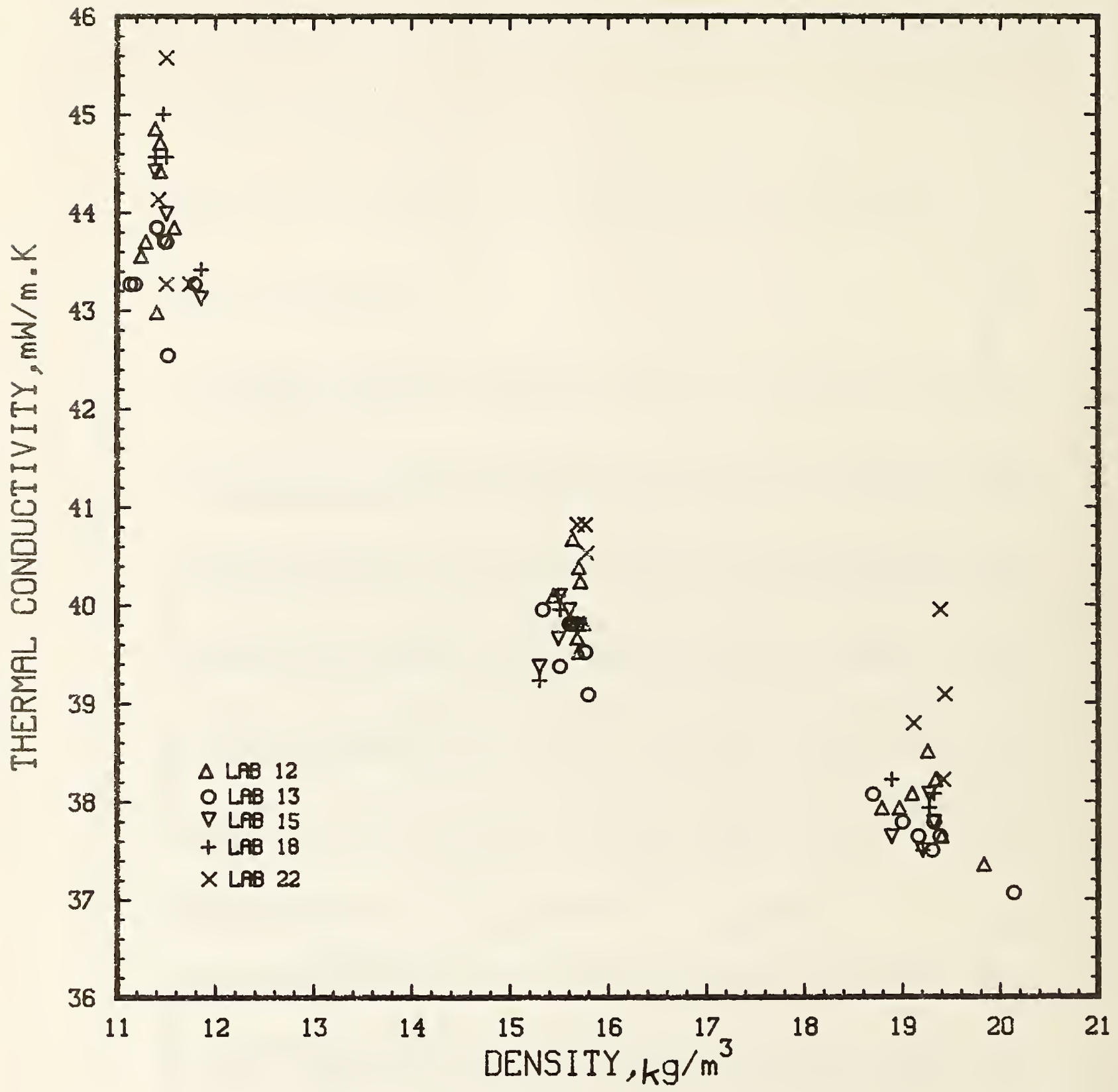

Figure 8.1 Thermal Conductivity versus Density of all Round Robin III Data. 


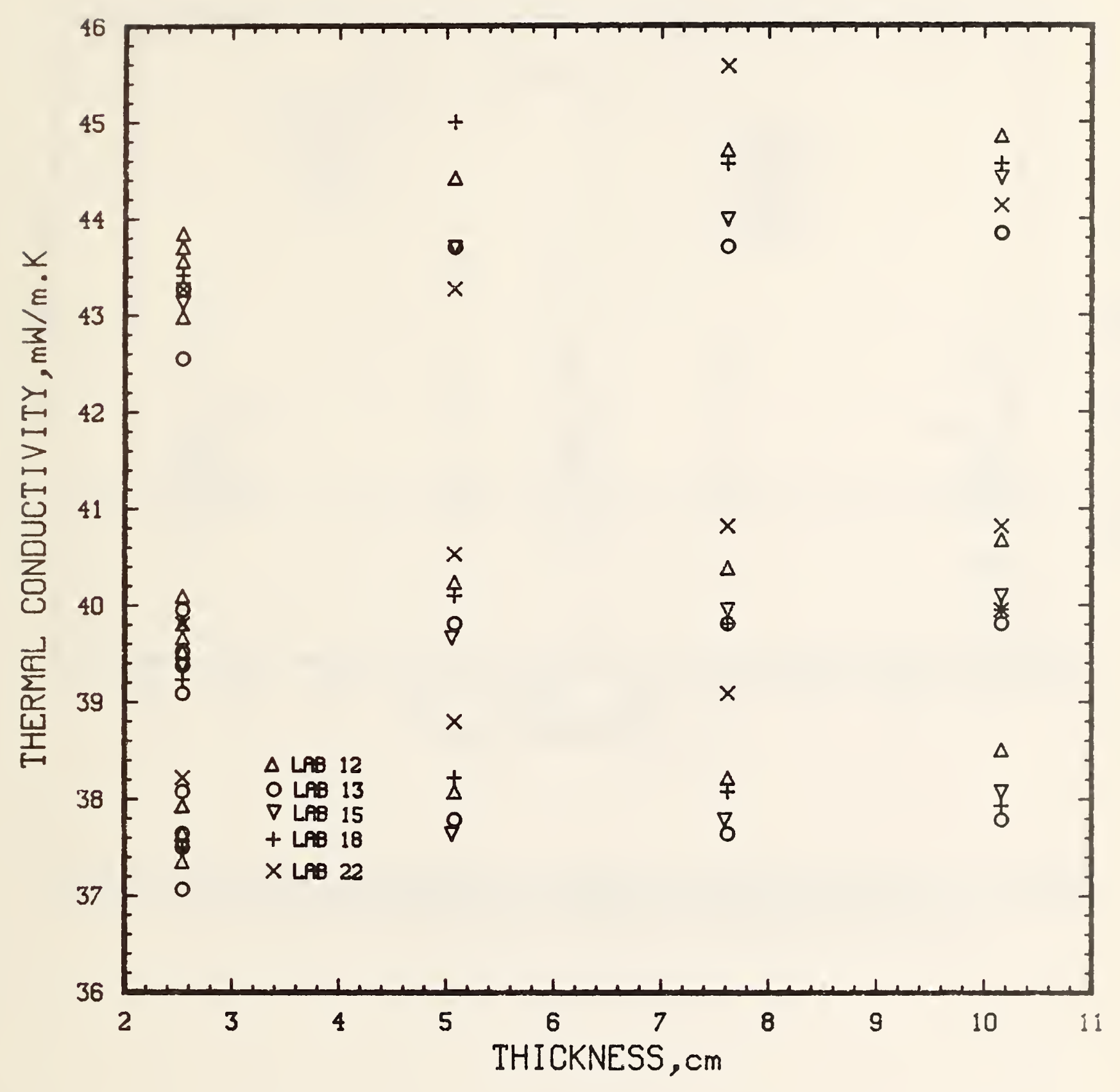

Figure 8.2 Thermal Conductivity versus Thickness of all Round Robin III Data. 


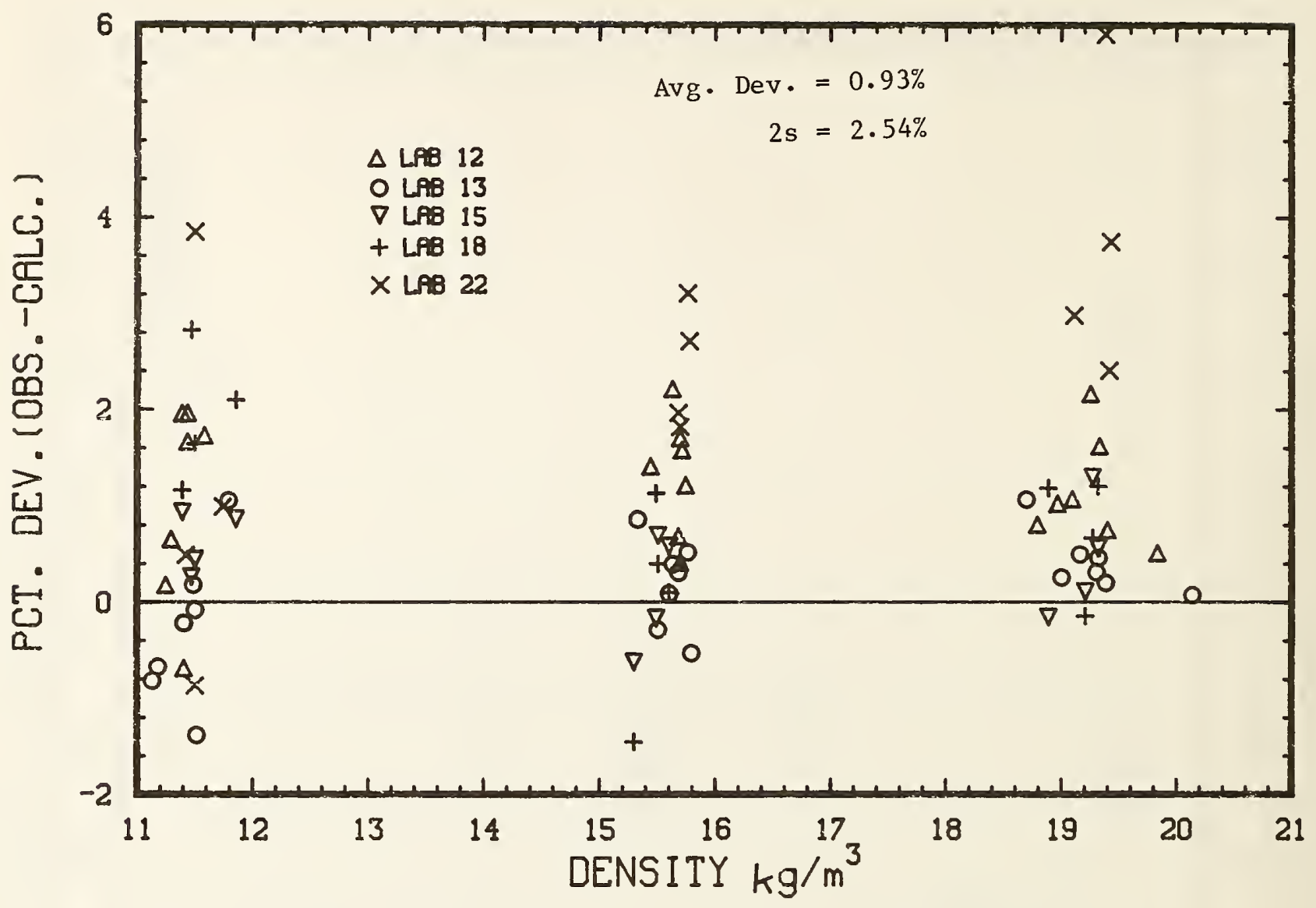

Figure 8.3 Deviations between all Thermal Conductivity Data From Round Robin III and Values Calculated from the Model versus Density. 


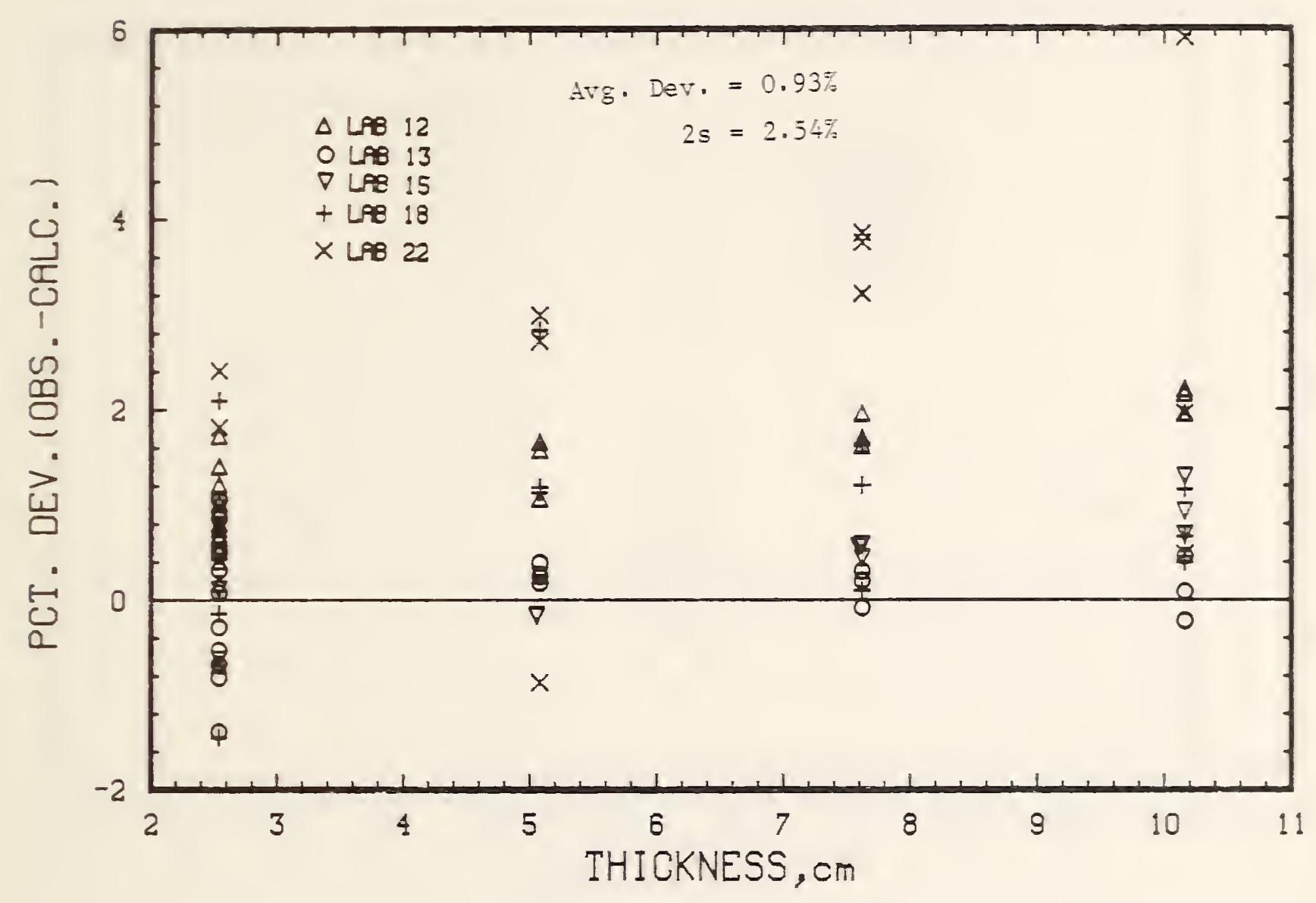

Figure 8.4 Deviations between A11 Thermal Conductivity Data from Round Robin III and Values Calculated from the Model versus Thickness. 


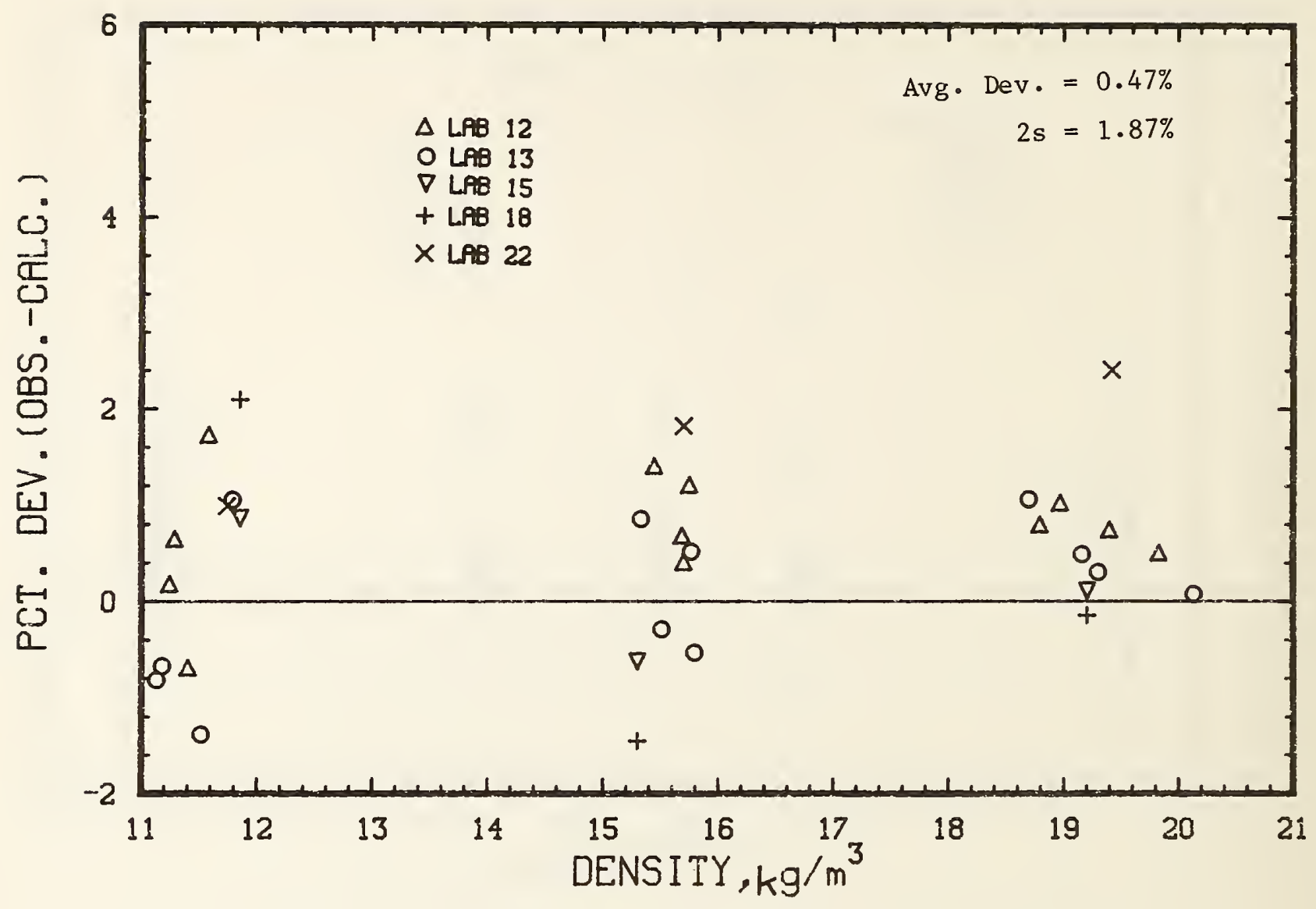

Figure 8.5 Deviations between the Thermal Conductivity Data from Round Robin III at a Thickness of $25.4 \mathrm{~mm}$ and Values Calculated from the Model versus Density. 


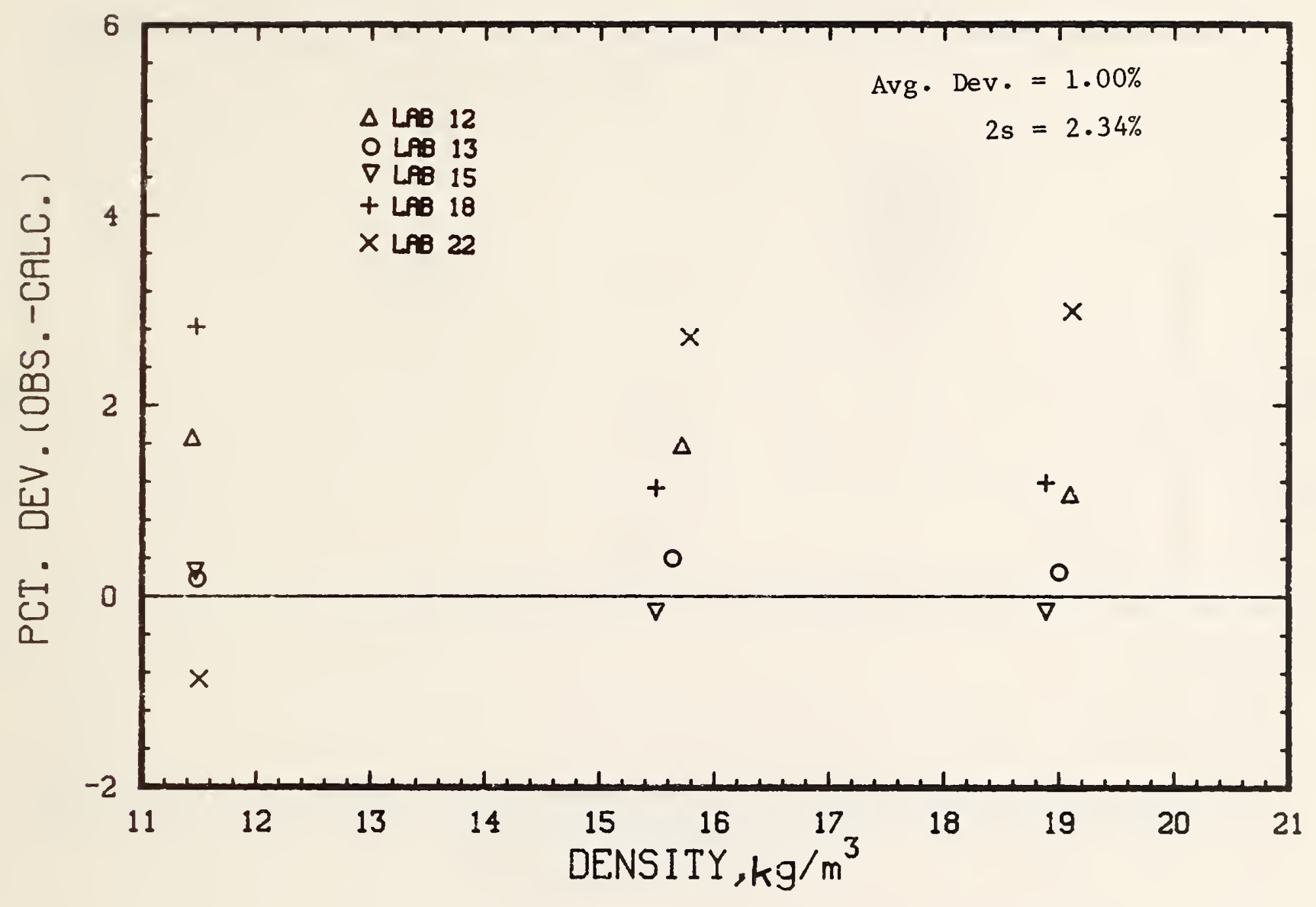

Figure 8.6 Deviations between the Thermal Conductivity Data from Round Robin III at a Thickness of $50.8 \mathrm{~mm}$ and values Calculated from the Model versus Density. 


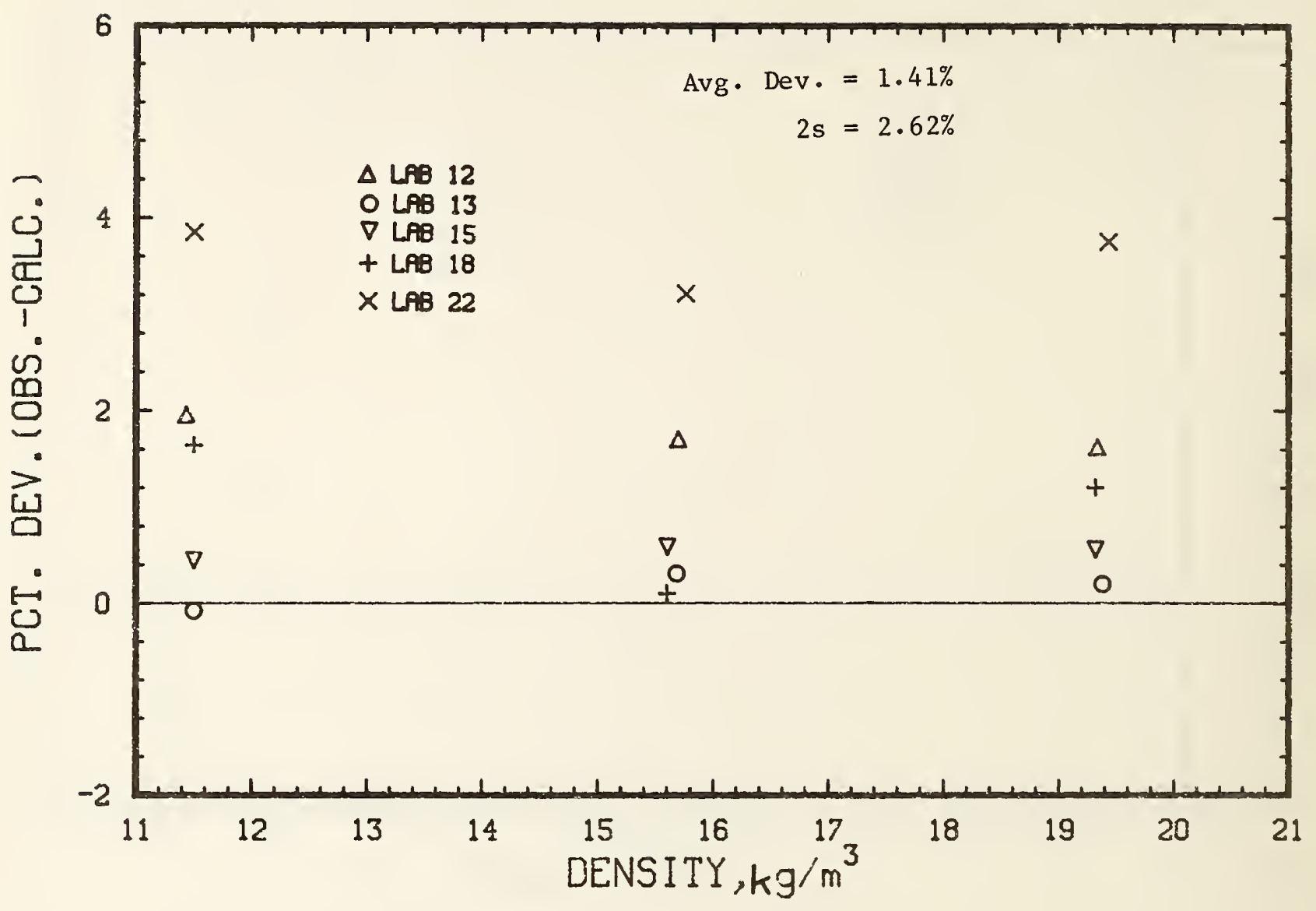

Figure 8.7 Deviations between the Thermal Conductivity Data from Round Rob in III at a thickness of $76.2 \mathrm{~mm}$ and values Calculated from the Model versus Density. 


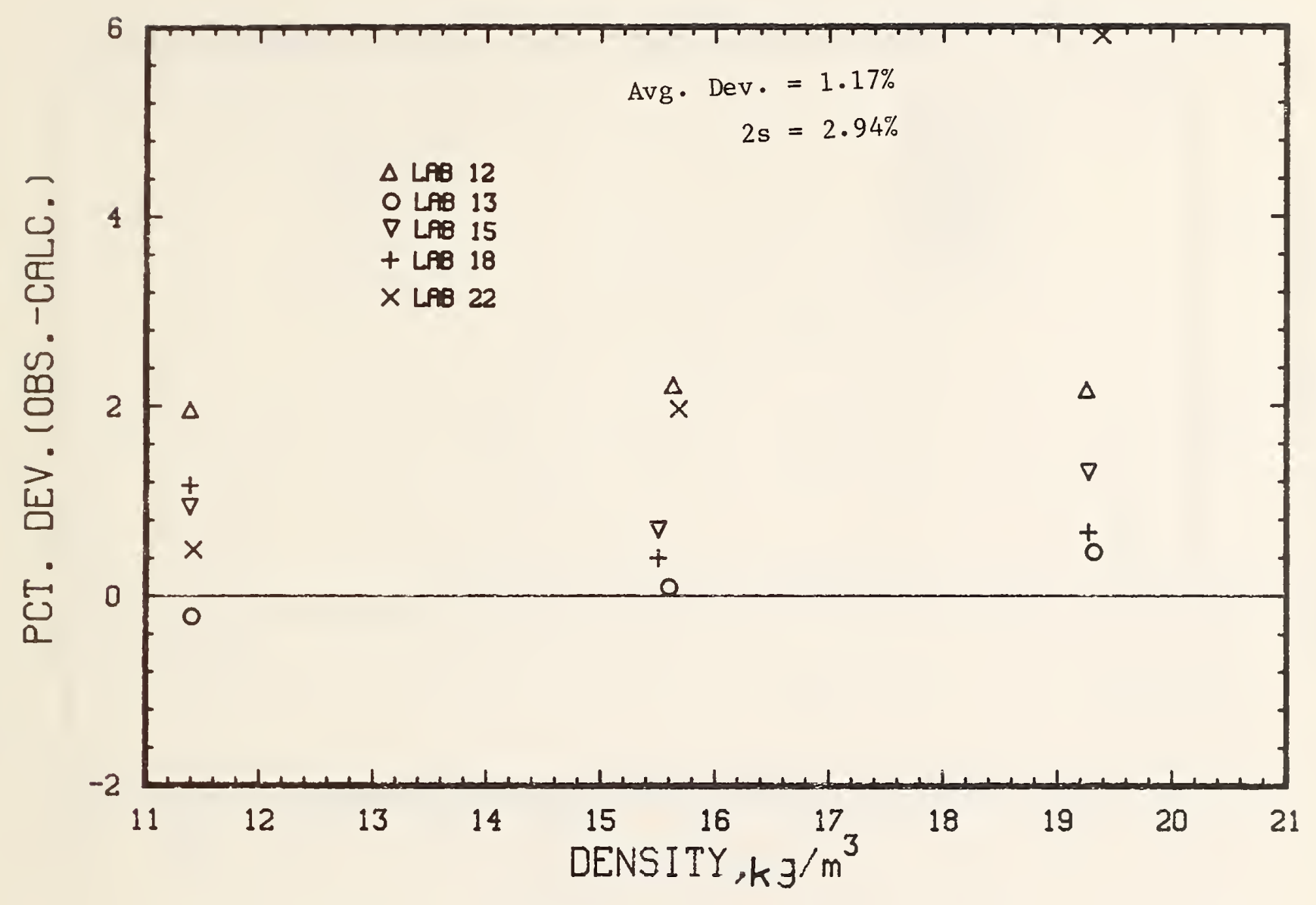

Figure 8.8 Deviations between the Thermal Conductivity Data from Round Robin III at a thickness of $101.6 \mathrm{~mm}$ and values Calculated from the Model versus Density. 


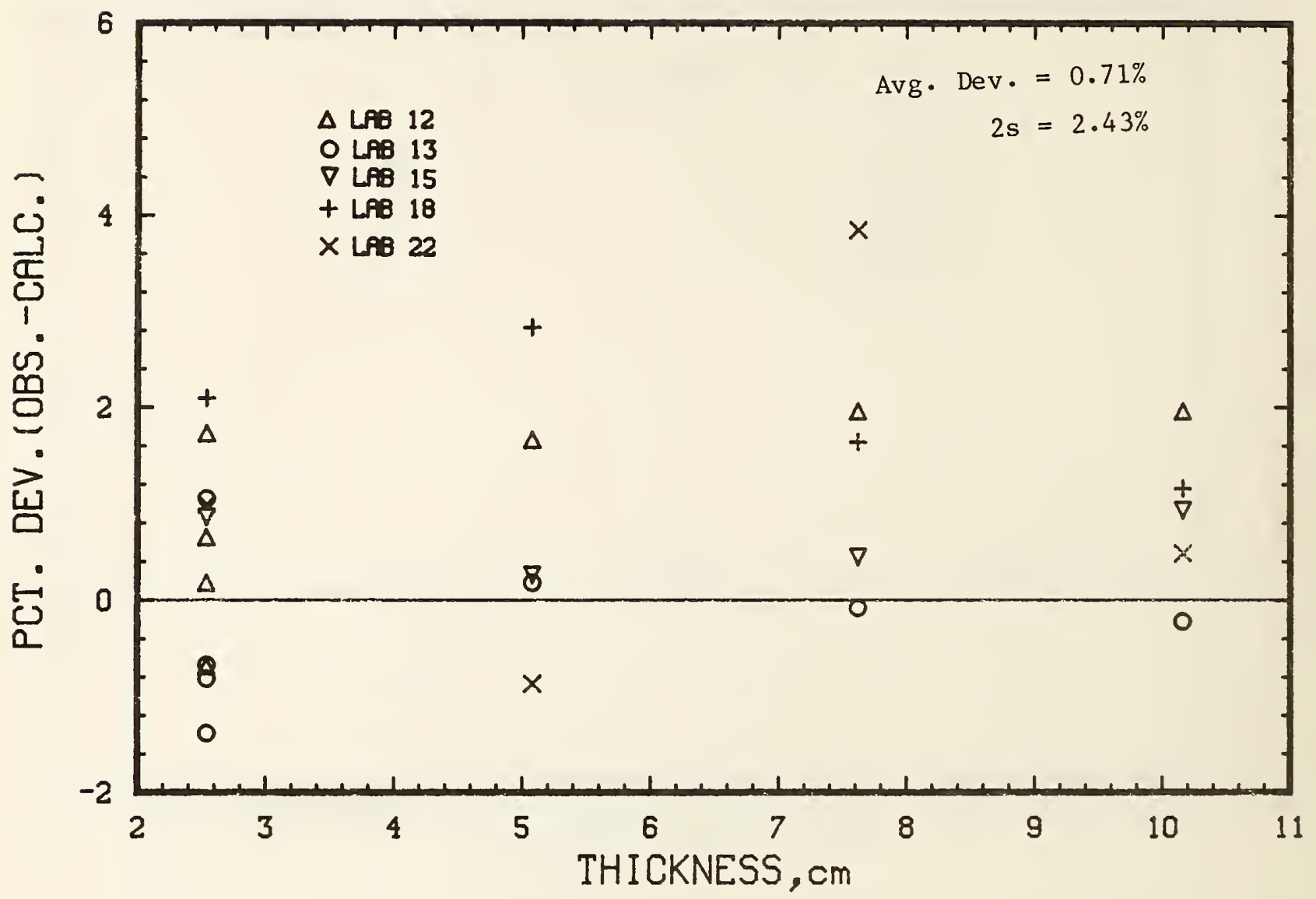

Figure 8.9 Deviations between the Thermal Conductivity Data from Round Robin III at a Nominal Density of $11 \mathrm{~kg} / \mathrm{m}^{3}$ and Values Calculated from the Model versus Thickness. 


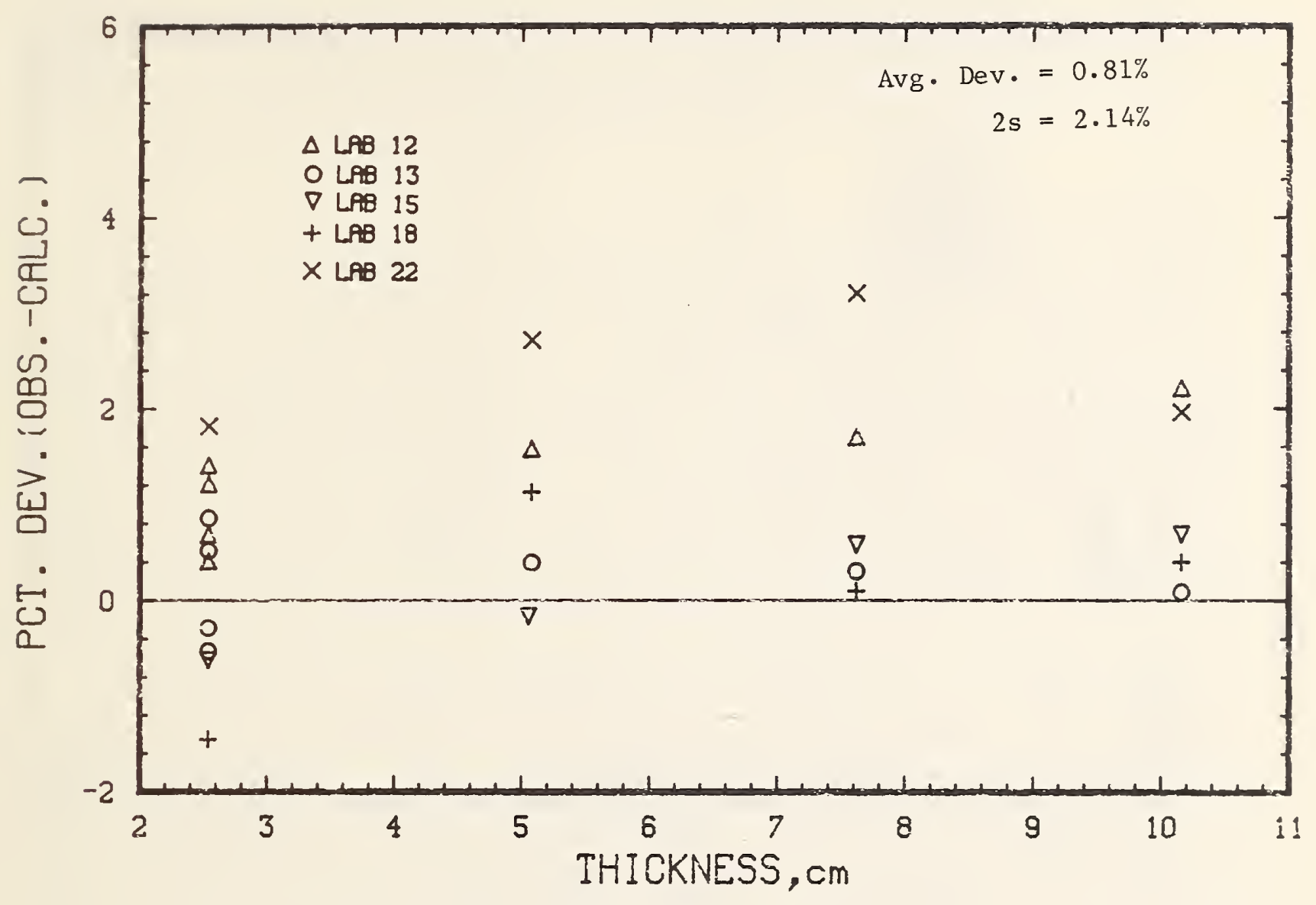

Figure 8.10 Deviations between the Thermal Conductivity Data from Round Robin II at a Nominal Density of $16 \mathrm{~kg} / \mathrm{m}^{3}$ and Values Calculated from the Model versus Thickness. 


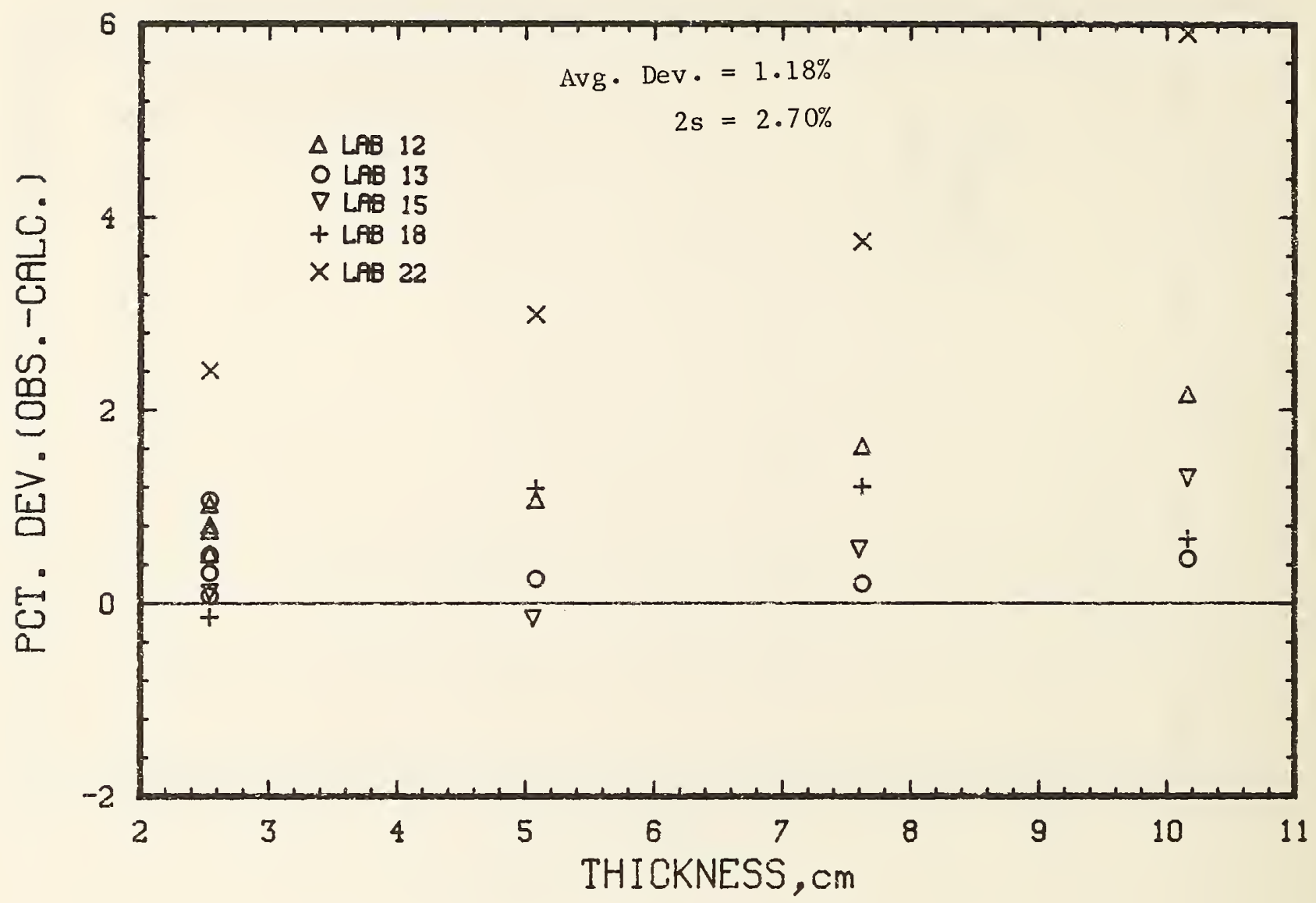

Figure 8.11 Deviations between the Thermal Conductivity Data from Round Robin III at a Nominal Density of $19 \mathrm{~kg} / \mathrm{m}^{3}$ and Values Calculated from the Model versus Thickness. 


\section{SUMMARY AND CONCLUSIONS}

Because of the interrelationship of the objectives and conclusions of the three round robins, the discussion for each of them will be given in this section. First we address the separation of test result variability caused by specimen inhomogeneity as contrasted with that caused by measurement imprecision. Then we discuss the conclusions for each round robin.

\section{1 Separation of Variabilities}

The usual objective of a round robin study is to determine the measurement variability of a group of laboratories for a given property of a given test specimen. This objective is frequently complicated, as it is here, by the effect of unquantified specimen characteristics because of differences in apparatus size and configuration. In these round robins the objective is further complicated because of the range of test conditions investigated (temperature, specimen density and thickness). The test results have been compared here to the model described in section 6 to minimize the effect of the additional range of test conditions. To the extent that the model provides a description of these dependencies, that objective has been achieved. Since essentially all of the data are within a few percent of the model and systematic dependencies of the deviations are minimal, the differences in test conditions do not contribute significantly to the overall variability.

In addition to the above ranges of test conditions, the complex heat transfer processes in thermal insulations may depend on unquantified specimen and apparatus characteristics. For example, the dependence on plate emittance, fiber diameter, fiber orientation, phenolic content, and shot content is not well known. The test methods generally require a minimum value of 0.8 for plate emittance but the actual measured values are not reported. The fiber diameters, given earlier, are representative for each of the insulations used here, but the variations in fiber diameter among specimens is unknown. The effect of these unquantified characteristics establishes a minimum value below which laboratory variability can not be assessed.

The first task is to estimate the minimum variability due to these unknowns. The total variability is the combined effect of this minimum variability plus intralaboratory (within laboratory, usually meaning the imprecision of a single apparatus) and interlaboratory (between laboratory) variabi1ity. To facilitate this analysis, the average deviations and $2 \mathrm{~s}$ values given in the previous deviation plots are compiled in Table 9.1.

The intralaboratory variability can be estimated from repeat measurements on a given specimen using a single apparatus. Subsets $6 / 5$ and $7 / 5$ contain the bulk of the repeat measurements. The deviations of the data in subset $6 / 5$ are plotted for each specimen in Figure 6.11. These data are actually obtained from two HFM apparatus but the results show them to be indistinguishable. The spread of the data for two of the four specimens is comparable to the spread for all of the specimens combined as shown in Figure 6.10. Thus the intralaboratory variability is estimated as $1.9 \%$. The deviations of the data in subset $7 / 5$ are plotted for each of the eight specimens in Figures 7.11 and 7.12. Again two apparatus were used to obtain these data but they are readily separable. The data plotted for 1978 are taken with one apparatus while all the others with another. A difference of about $1 \%$ between the two apparatus is noted. In this case the variability of the results for each apparatus is 


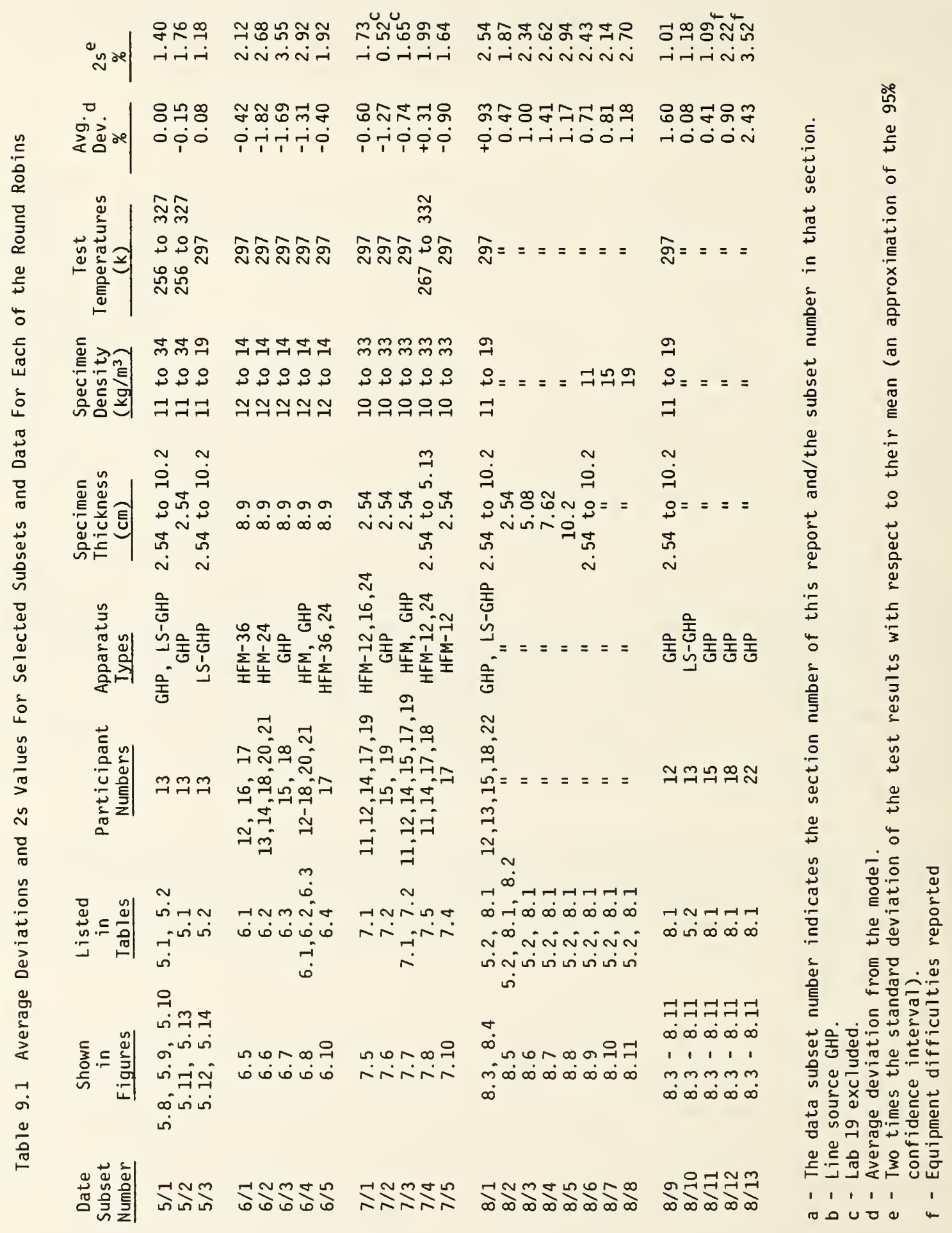


smaller than for subset 6.5, the spread of data for each specimen is about 0.5\%. From this we conclude that for laboratory 17 the intralaboratory variability is as high as $1.9 \%$ for a thickness of $8.9 \mathrm{~cm}$ and about $0.5 \%$ for 2.54 $\mathrm{cm}$. The intralaboratory variability for the other laboratories can not be assessed since repeat measurements were not required. The combined effect of intralaboratory variability and unquantified specimen characteristics can be estimated from measurements on a group of specimens by the same laboratory. Again we refer to subsets $6 / 5$ and $7 / 5$. For both of these subsets the spread of values for all specimens is about the same as the spread for each specimen separately. Thus the variability caused by unquantified specimen characteristics appears to be a small portion of the total. Subsets $5 / 2,5 / 3$ and $8 / 9$ through $8 / 13$ are also valid for assessing the above combined effects. The $2 \mathrm{~s}$ values for these subsets range from 1.01 to $3.52 \%$. The two highest values ( 2.22 and $3.52 \%$ ) are based on test results that were considered somewhat suspect (due to apparatus difficulties) by the laboratory reporting the results. If these two subsets are ignored the remaining range of $2 \mathrm{~s}$ values is 1.01 to 1.76\%. It is concluded that the combined variability is in the range of 1 to $2 \%$. Consequently interlaboratory comparisons below this 1 to $2 \%$ range are not meaningful, i.e., differences below this range are not statistically significant.

\subsection{Round Robin I}

The objective of RR I was to evaluate the testing community's measurement capabilities for building insulation at thicknesses above which reference standards were available. Reference standards at that time were available only at $2.54 \mathrm{~cm}$ thickness. To assess the measurement capability at $2.54 \mathrm{~cm}$ thickness we examined data from all of the round robins. The principal subsets at $2.54 \mathrm{~cm}$ thickness are $5 / 2,7 / 3$, and $8 / 2$. The $2 \mathrm{~s}$ value for these subsets include a range of density from 10 to $34 \mathrm{~kg} / \mathrm{m}^{3}$. The measurement capabi1ity at $8.9 \mathrm{~cm}$ thickness is represented by the $2 \mathrm{~s}$ value of $2.92 \%$ from subset $6 / 4$. The range of $2 \mathrm{~s}$ values of the subsets in RR I is 1.92 to $3.55 \%$. Thus, it is concluded that the measurement capability is degraded by about $1 \%$ at 8.9 $\mathrm{cm}$ thickness as compared to measurement at $2.54 \mathrm{~cm}$ thickness. It is noted that the density range for RR I is only 12 to $14 \mathrm{~kg} / \mathrm{m}^{3}$.

\subsection{Round Robin II}

The objective of RR II was to evaluate the testing community's ability to measure building insulations of sufficiently low density where the effect of variability in plate emittance may be significant. This effect would be exhibited by an increase in indicated variability as density decreases. RR II included specimen densities from 10 to $33 \mathrm{~kg} / \mathrm{m}^{3}$. Although $2 \mathrm{~s}$ values were not computed for the four nominal densities involved, it is clear from Figure 7.5 that the spread is not a significant function of density. Subsets $8 / 6,8 / 7$, and $8 / 8$ from RR III ( $2 \mathrm{~s}$ values of $2.43,2.14$, and 2.70 for densities of 11 , 15 , and $19 \mathrm{~kg} / \mathrm{m}^{3}$, respectively) also confirm this conclusion. RR II, performed nearly entirely at specimen thicknesses of $2.54 \mathrm{~cm}$, exhibited the lowest $2 \mathrm{~s}$ value, $1.65 \%$ overall.

\subsection{Round Robin III}

The objective of RR III was threefold a) to provide information on the testing community's ability to measure at thicknesses of at least $10.2 \mathrm{~cm}, \mathrm{~b}$ ) 
to provide helpful information on the evaluation of the new NBS line-source GHP, and c) to establish data on the thickness effect of a low-density insulation. The entire data set from RR III resulted in a $2 \mathrm{~s}$ value of $2.54 \%$ (subset $8 / 1$ ). This is only about $1 \%$ greater than the $2 S$ value for measurement at 2.54 $\mathrm{cm}$. The range of $2 \mathrm{~s}$ values at thicknesses from 2.54 to $10.2 \mathrm{~cm}$ is 1.87 to 2.94\%. An increase of about $1 \%$ from 2.54 to $10.2 \mathrm{~cm}$ is in agreement with the result observed in RR I (subsets $8 / 2$ to $8 / 5$ ). The $2 \mathrm{~s}$ values for the five laboratories ranged from 1.01 to $3.52 \%$ (subsets $8 / 9$ to $8 / 13$ ).

Figure 8.3 shows that the NBS 1 ine-source GHP produces test results near the lower end of the range of the five laboratories participating in RR III. In addition, Figure 8.4 reveals that the NBS line-source GHP yields a thickness effect near the lower end of the range for the five laboratories. The model described in section 5 is based on the NBS test results. Therefore, the model also yields a thickness effect below that of the average of the participating laboratories. The average thickness effect (change in $k$ from $2.54 \mathrm{~cm}$ to $10.2 \mathrm{~cm}$ ) as indicated by 211 of the data is about $1 \%$ greater than the mode 1 prediction for each of the three nominal densities of RR III.

The thickness effect from $2.54 \mathrm{~cm}$ to $10.2 \mathrm{~cm}$ as indicated by the RR III data is the sum of that given by the model (see figures 5.17 and 5.20 ) and the average residual systematic trend exhibited by figures $8.9,8.10$, and 8.11 . At a temperature of $300 \mathrm{~K}$, density of $10 \mathrm{~kg} / \mathrm{m}^{3}$, fiber diameter of $5.0 \mu \mathrm{m}$, and a plate emittance of 0.9 , the indicated thickness effect from 2.54 to $10.2 \mathrm{~cm}$ is about $3.3 \%$. Values for other test conditions can, of course, be calculated from the model.

\subsection{General Summary}

The results of these round robins reveal that, within the range of these test conditions and for this group of participating laboratories, the commonly accepted view that apparent thermal conductivity can be measured to within $\pm 2 \%$ is approximately correct. The results also reveal exceptions to this rule as exhibited by the data of laboratory 19 in RR II and to a lesser extent by the data of laboratory 18 and 22 in RR III. The variability of these test results establish lower limits to the precision and bias of the insulation community's measurement capability. These lower limits may be especially significant for the enforcement of energy conservation regulations. These test results will also be valuable as a basis for the precision and bias statements required for ASTM test methods $\mathrm{C} 177$ and $\mathrm{C518.}$

The results show that the variability from GHP's and HFM's are comparable and that the size of the plates (within the limits established by the test methods) over the range of this study was not an important factor in the results. The test results also indicate that only moderate degradation in testing capability occurs with increased thickness.

It should be noted that the participants in these round robins have generally exhibited good measurement practices using proven apparatus. The results of this study can not be extended to include all other laboratories in the industry. This can only be done on the basis of similar programs involving a large number of participants. 
In addition, a relatively simple model was developed that represented the dependencies of test results from the three round robins to within approximately the imprecision of the whole set of data. The model yields apparent thermal conductivity values as a function of temperature (256 to $332 \mathrm{~K}$ ), density (10 to $34 \mathrm{~kg} / \mathrm{m}^{3}$ ), thickness $(2.54$ to $10.2 \mathrm{~cm}$ ), fiber diameter and plate emittance. This has been a valuable analytical tool for intercomparison of data and may prove useful for future comparisons. 


\section{RECOMMENDATIONS}

As measurement capabilities expand and improve, further round robins will be required to assess the reliability of new apparatus and measurements. The existence of NVLAP and NBS reference materials will aid this self-assessment process.

The present round robin results indicate that the observed variability is caused mainly by apparatus imprecision and bias. The variability caused by unquantified specimen characteristics appears to be a small portion of the total variability. Thus the main emphasis in reducing test result variability should be directed toward apparatus improvements. It is important to recognize that the variability resulting from unknown specimen characteristics in this case was small due largely to the excellent specimen selection and characterization procedures used. As measurement capabilities improve, specimen selection and characterization procedures will become even more crucial, especially for the development of a model which provides a useful tool for data intercomparisons.

A knowledge of certain apparatus characteristics will be helpful to determine and reduce the sources of apparatus variability. For example, measured values for plate emittance may be helpful for low-density insulation specimens. An error analysis for each apparatus, such as that given by Powell and Rennex [16] and Smith, Hust and Van Pollen [17] would aid the analyst. Measurements showing the dependencies of test results on gap and edge temperature unbalances are very informative to both the participant and the analyst. A knowledge of the magnitude of plate temperature non-uniformity and plate temperature drift will assist in establishing some of the apparatus variability. For HFM apparatus the required use of the same reference material for calibration prior to round robin testing would reduce test result variability. Judiciously chosen repeat measurements on the same specimens by each participant would help establish intralaboratory variability.

The effect of unquantified specimen variability is always an important issue to the success of a round robin. For insulations, the main source of unquantified specimen variability is believed to be related to variation in the structure of the matrix (such as fiber diameter distribution, fiber orientation, binder content, shot content, and density distribution). Current technology frequently requires the destruction of the specimen to accurately determine these parameters. The development of alternate means to characterize the effect of those parameters are recommended, e.g., the light transmission technique described by Pelanne [15].

Within the current measurement capabilities the effect of thickness from $2.54 \mathrm{~cm}$ to $10.2 \mathrm{~cm}$ has been established for the glass fiber insulation used in RR III. Further work needs to be done at greater thicknesses and for other products since the effect of thickness is expected to vary significantly with the optical characteristics of the product.

Although some round robin activities are nearing completion for higher temperatures, further studies will be needed to assess and improve the measurement capabilities at temperatures above $297 \mathrm{~K}\left(75^{\circ} \mathrm{F}\right)$. Because radiative heat transmission increases approximately as the third power of the mean temperature, a knowledge of the scattering and absorption properties of the specimens and the plate emittance will take on increased significance. 


\section{ACKNOWLEDGMENTS}

The authors, in behalf of the thermal measurement community, wish to express their thanks to each of the participants involved in these round robins. Without their interest, concern and diligence, the information presented here could not have been available for the benefit of all. The authors also wish to express their appreciation for the co-sponsorship of these round robins by ASTM C-16.30 Subcommittee on Thermal Measurements and the Mineral Insulation Manufacturers Association. Appreciation is expressed to the members of the community who provided the materials for these measurements, OwensCorning Fiberglas Corporation, Manville Corporation, the National Bureau of Standards, and the National Voluntary Laboratory Accreditation Program. The financial assistance of the Department of Energy, Oak Ridge National Laboratory in providing for the completion of this project is gratefully acknowledged. 


\section{REFERENCES}

[1] ASTM C177, "Standard Test Method For Steady-State Thermal Transmission Properties by Means of the Guarded Hot Plate" ASTM Book of Standards, Section 4, Volume 04.06 (1984).

[2] ASTM C518, "Standard Test Method for Steady-State Thermal Transmission Properties by Means of the Heat Flow Meter" ASTM Book of Standards, Section 4, Volume 04.06 (1984).

[3] C.M. Pelanne, "Thermal Insulation Heat Flow Measurements:

Requirements for Implementation" ASHRAE Journal, March 1979 pp 51-58.

[4] C.M. Pelanne, "ASTM and the Technical Community's Response to Conceptual Changes in Thermal Insulation Measurements" ASTM Standardization News, December 1982, pp 19-22.

[5] H.E. Robinson \& T.W. Watson, "Interlaboratory Comparison of Thermal Conductivity Determinations with Guarded Hot Plates" ASTM Special Technical Publication \#119, (STP 119), Philadelphia, PA 1951.

[6] I.I.R, "International Comparative Measurements of Thermal Conductivity" Thermal Insulating Measurements, (Essais D'Insolants Thermiques), Commission II of the International Institute of Refrigeration, Report by the Chairman of the Committee, Carl F. Kayan, 1968.

[7] I.S.0. "International Thermal Conductance Round Robin" Frank J. Powe 11, Convener, Working Group 6, Round-Robin Tests Subcommittee 1, ISO 163, Thermal Insulation. Round Robin in progress, almost completed in 1984.

[8] ASTM C16.30 "Round Robin for Guarded and Calibrated Hot Boxes" E.L. Bales Chairman, Task Force 4.3, Hot Box RR Section 4 - Test Methods for Building Systems, ASTM C-16.30 Round Robin to be reported in March 1985.

[9] C.M. Pelanne, "The Development of Low-Density Glass-Fiber Insulation as Thermal Transmission Reference Standards" Thermal Conductivity 17, J.G. Hust, Editor, Plenum 1983, pp 763-776.

[10] B. Rennex, "Low-Density Thermal Insulation Calibrated Transfer Samples- - A Description and a Discussion of the Material Variability" NBSIR 82-2538, NBS, Gaithersburg, MD June 1982.

[11] D.R. Smith, J.G. Hust \& L.J. Van Poolen, "Effective Thermal Conductivity of a glass Fiberblanket Standard Reference Material" NGSIR 81-1640, NBS, Boulder, C0, February 1981.

[12] M.C.I. Siu, "Fibrous Glass Board as a Standard Reference Material for Thermal Resistance Measurement Systems" (SRM-1450), "Thermal Insulation Performance," ASTM STP 718, American Society for Testing and Materials, Philadelphia, (1980), pp 343-360.

[13] D.R. Smith \& J.G. Hust, "Effective Thermal Conductivity of a Glass Fiberboard Standard Reference Material" (SRM-1450), NBSIR 81-1639, NBS, Boulder C0, February 1981. 
[14] C.M. Pelanne, "Discussion on Experiments to Separate the "Effect of Thickness" from Systematic Equipment Errors in Thermal Transmission Measurements", "Thermal Insulation Performance," ASTM STP 718, American Society for Testing and Materials, Philadelphia, (1980), pp 322-334.

[15] C.M. Pelanne, "Light Transmission Measurements Through Glass Fiber Insulations", "Thermal Transmission Measurements of Insulations, " ASTM STP 660, American Society for Testing and Materials, Philadelphia, (1978), pp 263-280.

[16] F.J. Powell and B.G. Rennex, "The NBS Line-Heat-Source Guarded Hot Plate for Thick Materials", Proceedings of the ASHRAE/DOE Conference, Thermal Performance of the Exterior Envelopes of Buildings II, ASHRAE SP38, ASHRAE, At 7 anta, GA, 1983, pp. 657-672.

[17] D.R. Smith, J.G. Hust, and L.J. Van Poolen, "A Guarded-Hot-Plate Apparatus for Measuring Effective Thermal Conductivity of Insulations Between 80 and 360 K," NBSIR 81-1657, NBS, Boulder, C0, December 1981.

[18] M. Albers, Manville Research and Development Center, Denver, Colorado (Private Communication).

[19] M.B. Lacher, Owens-Corning Fiberglas Corp., Granville, Ohio.

[20] S.H. Cady, Mineral Insulation Manufacturers Association, Summit, New Jersey. 



\section{APPENDIX*}

Figure 13.1 shows a description of the samples for the round robins. Fig. 13.2 shows the standardized reference values for the RR II samples (as prepared for participants). study.

Table 13.1 lists the participants and reviewers for this round robin

To conveniently tabulate the extensive information for these round robin studies a coding scheme was necessary. The coding methodology for the tables is given in Table 13.2.

Table 13.3 shows the data form used for reporting the round robin test results.

Tables 13.4 through 13.6 lists the measured weights and calculated densities for each cut size of the specimens for round robin I, II and III, respectively.

Tables 13.5.1 through 13.8.3 list the data from each of the round robins in the units originally reported.

*The data reported in the tables and figures of the appendix are in units customary to the insulation industry and as reported by the participants of these round robins. It is noted that these units are not consistent with normal NBS usage. 
R R No. 1 - Samples $15 \times 48 \times 3.5$-in.

Test Design as run by J-M for Illustration

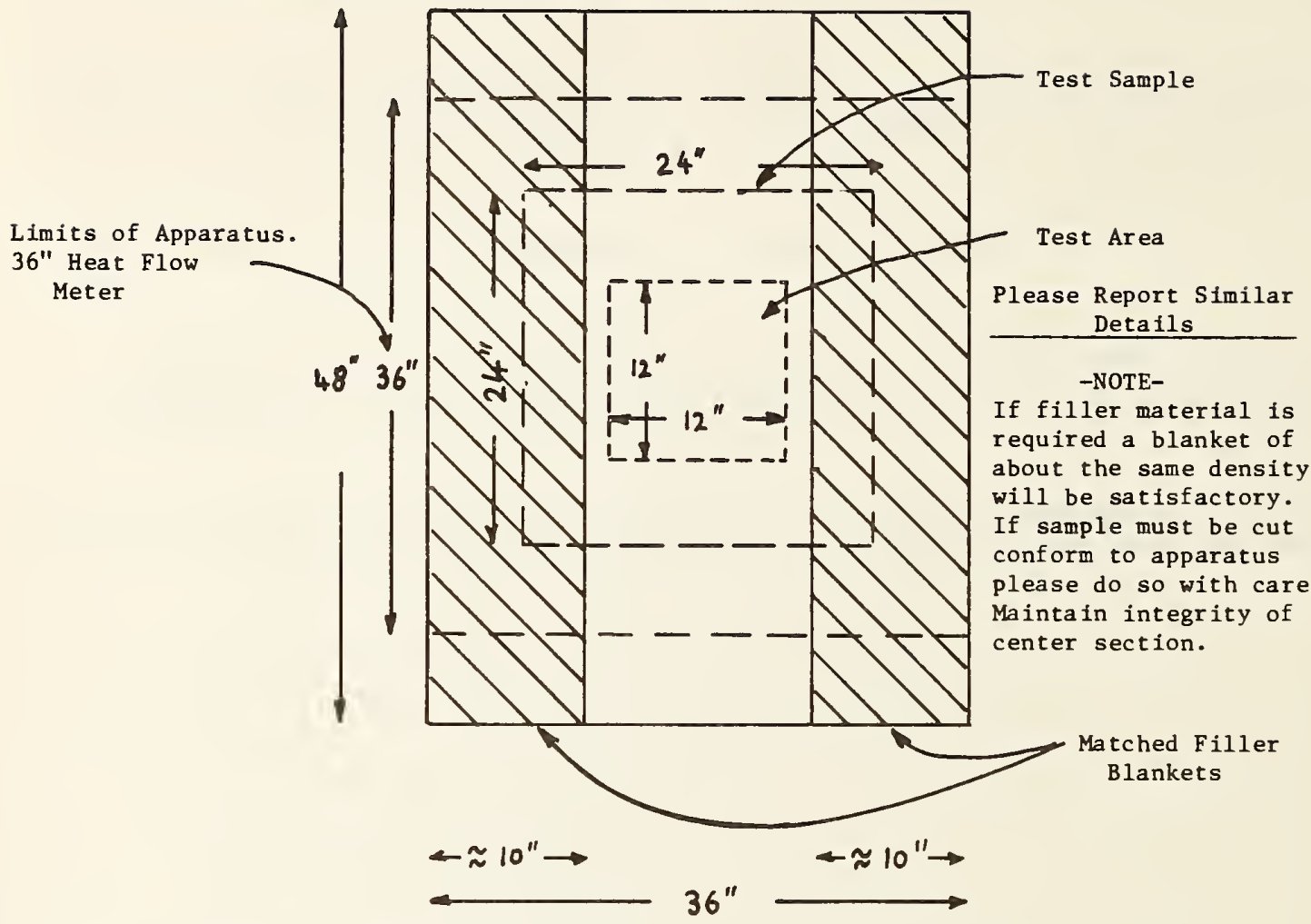

R R No. 2 - Samples $24 \times 24 \times 1$-in.

$24^{\prime \prime}$

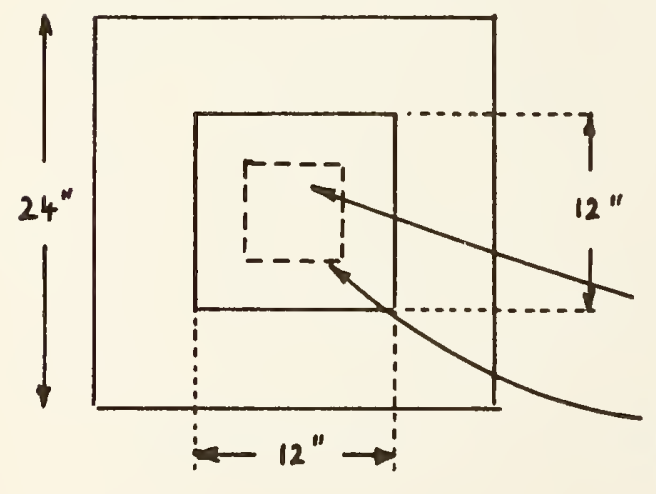

-NOTE-

The total sample is $24 \mathrm{x}$ 24 inch with a center $12 \times 12-i n$. section separated for testing in small equipment. If the sample must be cut further please do it --- so as to maintain the sample integrity. If needed, consult with C. M. Pelanne.

Figure 13.1 Description of Samples for Round Robin. 


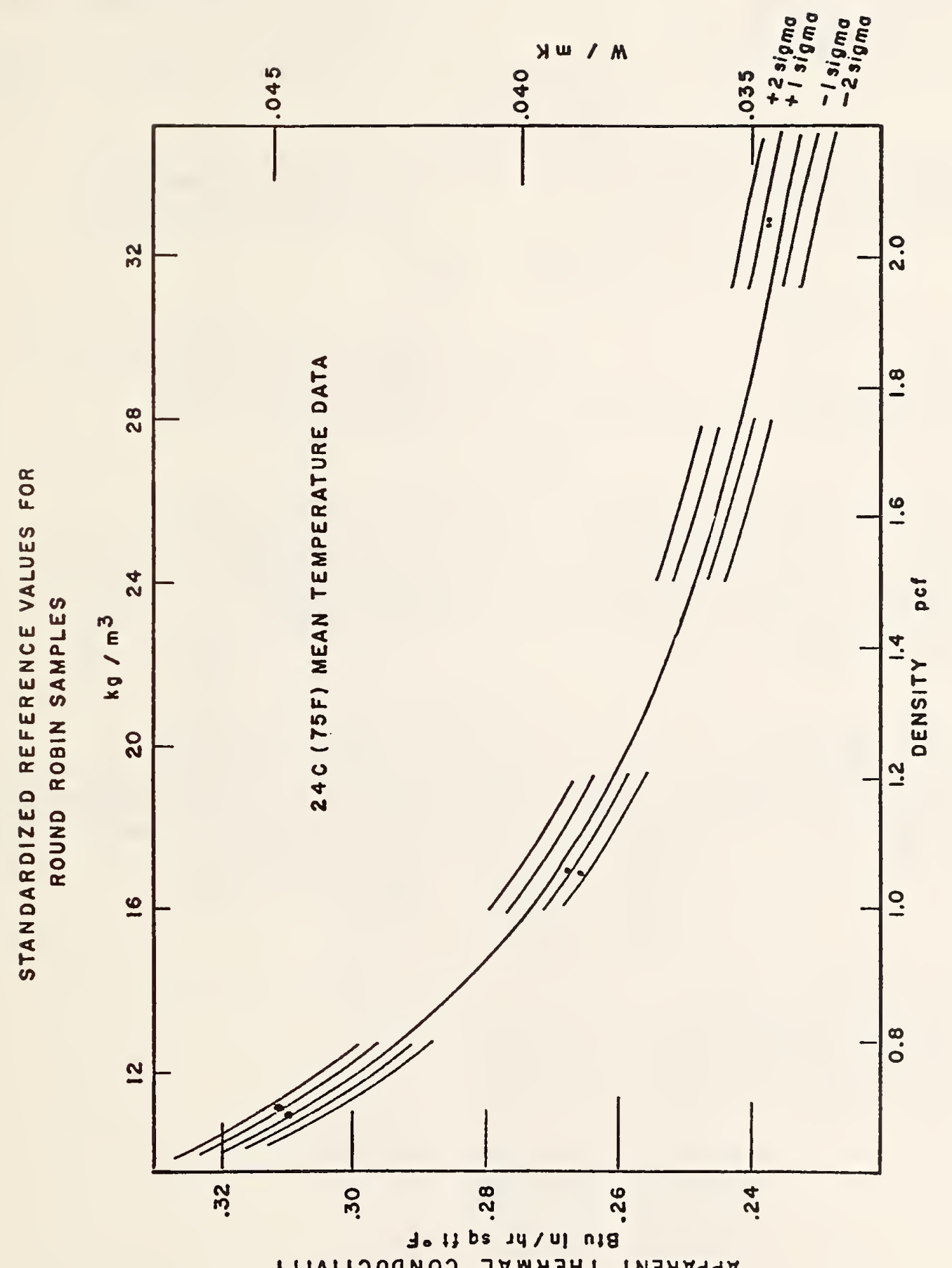

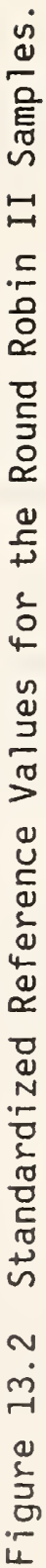

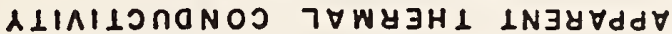


Table 13.1 ASTM C-16.30/MIMA Round Robins.

Participants and Reviewers

Dr. Mark Bomberg

National Research Council

Division of Building Research

Ottawa, Ont. Canada K1A 0R6

Mr. Sheldon H. Cady

Mineral Insulation Mfgrs. Assn.

382 Springfield Avenue, Suite 312

Summit, NJ 07901

Mr. Andre 0. Desjarlais

Mr. R.P. Tye

Dynatech R/D Company

99 Erie Street

Cambridge, MA 02139

Mr. William M. Edmunds

Mr. M. Lacher

Owens-Corning Fiberglas Corporation

Technical Center

P. 0. Box 415

Granville, $\mathrm{OH} 43023$

Mr. Stanley L. Matthews

Mr. Jesse L. Bridwell

Rockwool Industries Inc.

P. 0. Box 5170

Denver, CO 80217

Dr. David J. McCaa

Mr. Joseph F. Kimpflen

Certain-Teed Corporation

1400 Union Meeting Road

Blue Be11, PA 19422
Dr. David L. McElroy

Oak Ridge National Laboratory P.0. Box $X$

Oak Ridge, TN 37830

Dr. Gerry R. Miller

Jim Walter Research Corp.

10301 9th Street North

St. Petersburg, FL 33702

Dr. Benjamin Mosier, Pres.

Institute for Research, Inc.

8330 Westglen Drive

Houston, TX 77063

Mr. Frank J. Powe 11

Dr. Brian Rennex

National Bureau of Standards

USG Commerce

Gaithersburg, MD 20899

Mr. Charles Pelanne

$\mathrm{Mr}$. Richard Troyer

Manville Service Corporation

Research and Development Center

P. 0. Box 5108

Denver, C0 80217 
Table 13.2 ASTM C-16.30/MIMA Round Robins.

Coding Methodology

Table

Column

1

$2-3$

$4-7$

$8-12$

13-15 Testing code:

Round robin phase: I, II , III or NBS: $(1,2,3,4)$

Participant: $11,12,13,14,15,16,17,18,19,20,21,22$

Date: Month/Year

Equipment: digit

$8-\mathrm{G}=\mathrm{GHP}, \mathrm{H}=\mathrm{HFM}$

$9 \& 10$ - Overal1 size (inches)

$11 \& 12$ - Test Area Size (inches)

Col. 13 testing combination id. as follows;

1 = specimen tested as one

2 = 1 pair of specimens, specimens, average value

3 = stacked pair $w / 0$ septum

$4="$ " $w /$ septum

$5=1$ pair of specimens, average, RR III

$6=2$ pairs of speciment, average, RR III

$7=3$ pairs of specimens, average, RR III

$8=4$ pairs of specimens, average, RR III

Cols. 14 \& 15 density identification coded as follows:

Phase I; 08

Phase II; $05,10,15,20$

Phase III; $07,09,12$

NBS Refer; 06, 11, 16, 21

16-20 Specimen identification number: specimen number $(X)$,

Phase I; $\quad(8)=1,(9)=3,(10)=2,(11)=4$

as pairs; $(8+9)=1$

Phase II; set 05: $(04)=1, \quad(09)=5$

set $10: \quad(18)=2, \quad(24)=6$

set 15: $\quad(49)=3, \quad(50)=7$

set $20: \quad(14)=4, \quad(15)=8$

Phase III; set 07 ;

level $1 ; \quad(81247)=1, \quad(50138)=5$

" $2 ; \quad(82278)=2,(50975)=6$

" $3 ; \quad(50134)=3,(50533)=7$

" $4 ; \quad(81257)=4,(61663)=8$

set 09 ;

level $1 ; \quad(80831)=1, \quad(81065)=5$

" $2 ; \quad(80914)=2 \quad(80738)=6$

" $3 ; \quad(80762)=3 \quad(80874)=7$

" $4 ; \quad(85855)=4,(85545)=8$

set 12 ;

level $1 ; \quad(11931)=1, \quad(11761)=5$

" $2 ; \quad(11141)=2,(11911)=6$

" $3 ; \quad(12115)=3,(10155)=7$

" $4 ; \quad(10615)=4,(11575)=8$

note; when tested as pairs $1=1 \& 5,2=2 \& 6$ 
Phase II (NBS);

Series

0500

1000

1500

2000

21-25

$26-30$

$31-35$

$36-40$

41-45

46-51

$52-57$

\section{Density}

06

11

16

21

Specimen Identification Code.

Pair 1

$$
\begin{array}{ll}
10=(1)+17=(3) & 32=(2)+36=(4) \\
11=(1)+10=(3) & 33=(2)+35=(4) \\
13=(1)+52=(3) & 54=(2)+62=(4) \\
35=(1)+37=(3) & 06=(2)+09=(4)
\end{array}
$$

$$
\text { Pair } 2
$$

Test thickness in inches

Test area density in $1 \mathrm{~b} / \mathrm{ft}^{3}$

Hot face temperature in ${ }^{\circ} \mathrm{F}$

Cold face temperature in ${ }^{\circ} \mathrm{F}$

Mean temperature in ${ }^{\circ} \mathrm{F}$

Apparent thermal conductivity in Btu.in/h. $\mathrm{ft}{ }^{2} \cdot{ }^{\circ} \mathrm{F}$

Footnotes as required 
TABLE 13.3 Typical Data Form used for Reporting Test Results.

$$
\begin{aligned}
\text { NMWIA - } & \text { Round Robin - Mean Temperature }-75^{\circ} \mathrm{F} \\
& \text { Appliance Insulation Test Results }
\end{aligned}
$$

Laboratory Name:

Date of Tests:

Apparatus Description:

Operator:

Reporter:

TEST RESULTS

Nominal Density, pcf

0.7

1.0

\section{Sample Identification} Number

$0500-4$

$1000-18$

$1000-24$

Density, pcf

Measurement Area:

Thickness, inch:

1.0

1.0

1.0

1.0

Hot Surface ${ }^{\circ} \mathrm{F}$

Cold Surface ${ }^{\circ} \mathrm{F}$

Mean Temperature ${ }^{\circ} \mathrm{F}$

Apparent Therma]

Conductivity

COMMENTS: 
TABLE 13.4 Specimen Sizes, Weights, and Densities for Round Robin I.

\begin{tabular}{|c|c|c|c|c|}
\hline Specimen Sizes (in) & $15.25 \times 24.0$ & $16 \times 16^{\star}$ & $12 \times 12$ & $10 \times 10$ \\
\hline $\begin{array}{l}\text { Specimen } 8(1) \\
\text { Weight }(\mathrm{g}) \\
\text { Density }\left(\mathrm{lb} / \mathrm{ft}^{3}\right)\end{array}$ & $\begin{array}{l}261.47 \\
0.778\end{array}$ & $\begin{array}{l}189.53 \\
0.806\end{array}$ & $\begin{array}{l}108.70 \\
0.822\end{array}$ & $\begin{array}{l}74.08 \\
0.806\end{array}$ \\
\hline $\begin{array}{l}\text { Specimen } 9(3) \\
\text { Weight }(\mathrm{g}) \\
\text { Density }\left(\mathrm{lb} / \mathrm{ft}^{3}\right)\end{array}$ & $\begin{array}{l}283.24 \\
0.842\end{array}$ & $\begin{array}{l}195.68 \\
0.832\end{array}$ & $\begin{array}{l}116.48 \\
0.880\end{array}$ & $\begin{array}{l}83.47 \\
0.909\end{array}$ \\
\hline $\begin{array}{l}\text { Specimen } 10(2) \\
\text { Weight }(\mathrm{g}) \\
\text { Density }\left(1 \mathrm{~b} / \mathrm{ft}^{3}\right)\end{array}$ & $\begin{array}{l}244.54 \\
0.727\end{array}$ & $\begin{array}{l}181.19 \\
0.770\end{array}$ & $\begin{array}{l}103.44 \\
0.782\end{array}$ & $\begin{array}{l}71.20 \\
0.775\end{array}$ \\
\hline $\begin{array}{l}\text { Specimen } 11(4) \\
\text { Weight }(\mathrm{g}) \\
\text { Density }\left(1 \mathrm{~b} / \mathrm{ft}^{3}\right)\end{array}$ & $\begin{array}{l}259.68 \\
0.772\end{array}$ & $\begin{array}{l}184.21 \\
0.783\end{array}$ & $\begin{array}{l}109.30 \\
0.826\end{array}$ & $\begin{array}{l}78.99 \\
0.860\end{array}$ \\
\hline
\end{tabular}

${ }^{*}$ Adjusted from $15.25 \times 16$ measurement 
TABLE 13.5 Specimen Sizes, Weights, and Densities for Round Robin II.

$\begin{array}{llllllll}\text { Specimen Sizes (in) } & 24 \times 24 & 18 \times 18 & 12 \times 12 & 10 \times 10 & 8 \times 8 & 6 \times 6 & 4 \times 4\end{array}$

Set 05

$\begin{array}{llllllll}\begin{array}{l}\text { Specimen 04(1) } \\ \text { Weight }\end{array} & 99.52 & 57.20 & 25.50 & 17.98 & 11.44 & 6.25 & 2.85 \\ \begin{array}{l}\text { Density } \\ \text { Specimen 09(5) }\end{array} & 0.658 & 0.673 & 0.675 & 0.685 & 0.681 & 0.661 & 0.697 \\ \begin{array}{l}\text { Weight } \\ \text { Density }\end{array} & 103.47 & 58.07 & 25.13 & 17.54 & 11.17 & 6.35 & 2.82 \\ & 0.684 & 0.683 & 0.665 & 0.668 & 0.665 & 0.672 & 0.671\end{array}$

Set 10

Specimen $18(2)$

Weight

Density

Specimen 24(6)

Weight

Density

$\begin{array}{lllllll}158.03 & 88.80 & 39.10 & 27.28 & 18.12 & 10.38 & 4.78 \\ 1.045 & 1.044 & 1.037 & 1.039 & 1.079 & 1.098 & 1.138 \\ & & & & & & \\ 163.20 & 90.00 & 39.77 & 28.07 & 18.22 & 10.53 & 4.53 \\ 1.079 & 1.058 & 1.052 & 1.069 & 1.085 & 1.114 & 1.079\end{array}$

Set 15

Specimen 49(3)

Weight*

Density**

Specimen 50(7)

Weight

Density

$\begin{array}{lllllll}283.14 & 137.24 & 59.98 & 42.10 & 27.36 & 15.28 & 7.08 \\ 1.575 & 1.614 & 1.587 & 1.604 & 1.629 & 1.617 & 1.686 \\ & & & & & & \\ 240.96 & 135.58 & 59.85 & 41.80 & 26.79 & 14.50 & 6.82 \\ 1.594 & 1.594 & 1.583 & 1.592 & 1.595 & 1.534 & 1.624\end{array}$

Set 20

Specimen $14(4)$

Weight

Density

Specimen 15(8)

Weight

Density

$\begin{array}{lllllll}313.32 & 173.72 & 77.12 & 53.93 & 35.19 & 19.18 & 8.77 \\ 2.072 & 2.043 & 2.040 & 2.054 & 2.095 & 2.095 & 2.088 \\ 314.65 & 174.65 & 76.82 & 53.27 & 33.50 & 19.12 & 8.68 \\ 2.081 & 2.054 & 2.032 & 2.029 & 1.994 & 2.023 & 2.067\end{array}$

*Weight in grams

**Density in $1 \mathrm{~b} / \mathrm{ft}^{3}$ 
TABLE 13.6 Specimen Sizes, Weights, and Densities for Round Robin III.

Specimen

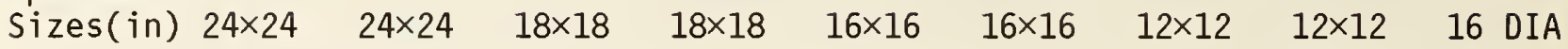
weight density weight density weight density weight density density

Set 07

\begin{tabular}{|c|c|c|c|c|c|c|c|c|}
\hline $\begin{array}{l}81247(1) \\
50138(5)\end{array}$ & $\begin{array}{l}105.2 \\
103.4\end{array}$ & $\begin{array}{l}0.729 \\
0.715\end{array}$ & $\begin{array}{l}61.50 \\
61.48\end{array}$ & $\begin{array}{l}0.723 \\
0.723\end{array}$ & $\begin{array}{l}49.33 \\
49.25\end{array}$ & $\begin{array}{l}0.734 \\
0.732\end{array}$ & $\begin{array}{l}27.98 \\
27.93\end{array}$ & $\begin{array}{l}0.740 \\
0.739\end{array}$ \\
\hline $\begin{array}{l}82278(2) \\
50975(6)\end{array}$ & $\begin{array}{l}103.7 \\
102.7\end{array}$ & $\begin{array}{l}0.719 \\
0.716\end{array}$ & $\begin{array}{l}60.23 \\
59.81\end{array}$ & $\begin{array}{l}0.708 \\
0.703\end{array}$ & $\begin{array}{l}48.05 \\
46.61\end{array}$ & $\begin{array}{l}0.714 \\
0.693\end{array}$ & $\begin{array}{l}27.27 \\
25.10\end{array}$ & $\begin{array}{l}0.721 \\
0.664\end{array}$ \\
\hline $\begin{array}{l}134(3) \\
533(7)\end{array}$ & $\begin{array}{l}101.4 \\
101.1\end{array}$ & $\begin{array}{l}0.699 \\
0.707\end{array}$ & $\begin{array}{l}61.16 \\
59.97\end{array}$ & $\begin{array}{l}0.719 \\
0.705\end{array}$ & $\begin{array}{l}48.89 \\
47.55\end{array}$ & $\begin{array}{l}0.727 \\
0.707\end{array}$ & $\begin{array}{l}27.97 \\
26.55\end{array}$ & $\begin{array}{l}0.740 \\
0.702\end{array}$ \\
\hline $\begin{array}{l}1257(4) \\
1663(8)\end{array}$ & $\begin{array}{l}102.7 \\
102.3\end{array}$ & $\begin{array}{l}0.712 \\
0.710\end{array}$ & $\begin{array}{l}60.15 \\
59.35\end{array}$ & $\begin{array}{l}0.707 \\
0.697\end{array}$ & $\begin{array}{l}47.87 \\
46.28\end{array}$ & $\begin{array}{l}0.712 \\
0.688\end{array}$ & & $\begin{array}{l}0.712 \\
0.668\end{array}$ \\
\hline $\begin{array}{r}\text { Set } \\
0831(1) \\
1065(5)\end{array}$ & $\begin{array}{l}09 \\
147.96 \\
148.10\end{array}$ & $\begin{array}{l}0.978 \\
0.979\end{array}$ & $\begin{array}{l}83.90 \\
82.70\end{array}$ & $\begin{array}{l}0.986 \\
0.972\end{array}$ & $\begin{array}{l}66.70 \\
65.08\end{array}$ & $\begin{array}{l}0.992 \\
0.968\end{array}$ & $\begin{array}{l}36.87 \\
35.37\end{array}$ & $\begin{array}{l}0.975 \\
0.935\end{array}$ \\
\hline $\begin{array}{l}914(2) \\
0738(6)\end{array}$ & $\begin{array}{l}149.36 \\
148.13\end{array}$ & $\begin{array}{l}0.987 \\
0.979\end{array}$ & $\begin{array}{l}83.90 \\
83.25\end{array}$ & $\begin{array}{l}0.986 \\
0.979\end{array}$ & $\begin{array}{l}66.27 \\
66.72\end{array}$ & & & \\
\hline $\begin{array}{l}0762(3) \\
0874(7)\end{array}$ & $\begin{array}{l}148.79 \\
148.00\end{array}$ & $\begin{array}{l}0.983 \\
0.978\end{array}$ & $\begin{array}{l}83.13 \\
83.52\end{array}$ & $\begin{array}{l}0.977 \\
0.982\end{array}$ & $\begin{array}{l}65.75 \\
66.50\end{array}$ & $\begin{array}{l}0.978 \\
0.989\end{array}$ & $\begin{array}{l}36.68 \\
38.11\end{array}$ & \\
\hline $\begin{array}{l}5855(4) \\
5545(8)\end{array}$ & $\begin{array}{l}145.76 \\
148.58\end{array}$ & $\begin{array}{l}0.963 \\
0.982\end{array}$ & $\begin{array}{l}83.18 \\
80.83\end{array}$ & $\begin{array}{l}0.978 \\
0.950\end{array}$ & $\begin{array}{l}65.45 \\
64.10\end{array}$ & $\begin{array}{l}0.973 \\
0.953\end{array}$ & $\begin{array}{l}36.63 \\
35.25\end{array}$ & $\begin{array}{l}0.969 \\
0.932\end{array}$ \\
\hline $\begin{array}{r}\text { Set } \\
1931(1) \\
1761(5)\end{array}$ & $\begin{array}{r}180.56 \\
181.73\end{array}$ & $\begin{array}{l}1.193 \\
1.201\end{array}$ & $\begin{array}{l}103.05 \\
103.00\end{array}$ & $\begin{array}{l}1.211 \\
1.211\end{array}$ & $\begin{array}{l}81.90 \\
81.03\end{array}$ & $\begin{array}{l}1.218 \\
1.205\end{array}$ & $\begin{array}{l}45.17 \\
45.45\end{array}$ & $\begin{array}{l}1.195 \\
1.202\end{array}$ \\
\hline $\begin{array}{l}1141(2) \\
1911(6)\end{array}$ & $\begin{array}{l}175.54 \\
177.14\end{array}$ & $\begin{array}{l}1.160 \\
1.170\end{array}$ & $\begin{array}{l}99.56 \\
100.00\end{array}$ & $\begin{array}{l}1.170 \\
1.176\end{array}$ & $\begin{array}{l}78.60 \\
79.39\end{array}$ & $\begin{array}{l}1.169 \\
1.181\end{array}$ & $\begin{array}{l}42.81 \\
44.83\end{array}$ & $\begin{array}{l}1.132 \\
1.186\end{array}$ \\
\hline $\begin{array}{l}2115(3) \\
0115(7)\end{array}$ & $\begin{array}{l}191.95 \\
182.00\end{array}$ & $\begin{array}{l}1.268 \\
1.203\end{array}$ & $\begin{array}{l}113.0 \\
102.72\end{array}$ & $\begin{array}{l}1.269 \\
1.207\end{array}$ & $\begin{array}{l}89.5 \\
81.45\end{array}$ & $\begin{array}{l}1.296 \\
1.211\end{array}$ & $\begin{array}{l}50.3 \\
46.20\end{array}$ & $\begin{array}{l}1.297 \\
1.222\end{array}$ \\
\hline $\begin{array}{l}615(4) \\
575(8)\end{array}$ & $\begin{array}{l}173.22 \\
177.10\end{array}$ & $\begin{array}{l}1.144 \\
1.170\end{array}$ & $\begin{array}{l}100.41 \\
101.00\end{array}$ & $\begin{array}{l}1.180 \\
1.188\end{array}$ & $\begin{array}{l}79.98 \\
81.10\end{array}$ & $\begin{array}{l}1.190 \\
1.206\end{array}$ & $\begin{array}{l}44.78 \\
45.55\end{array}$ & $\begin{array}{l}1.184 \\
1.205\end{array}$ \\
\hline
\end{tabular}




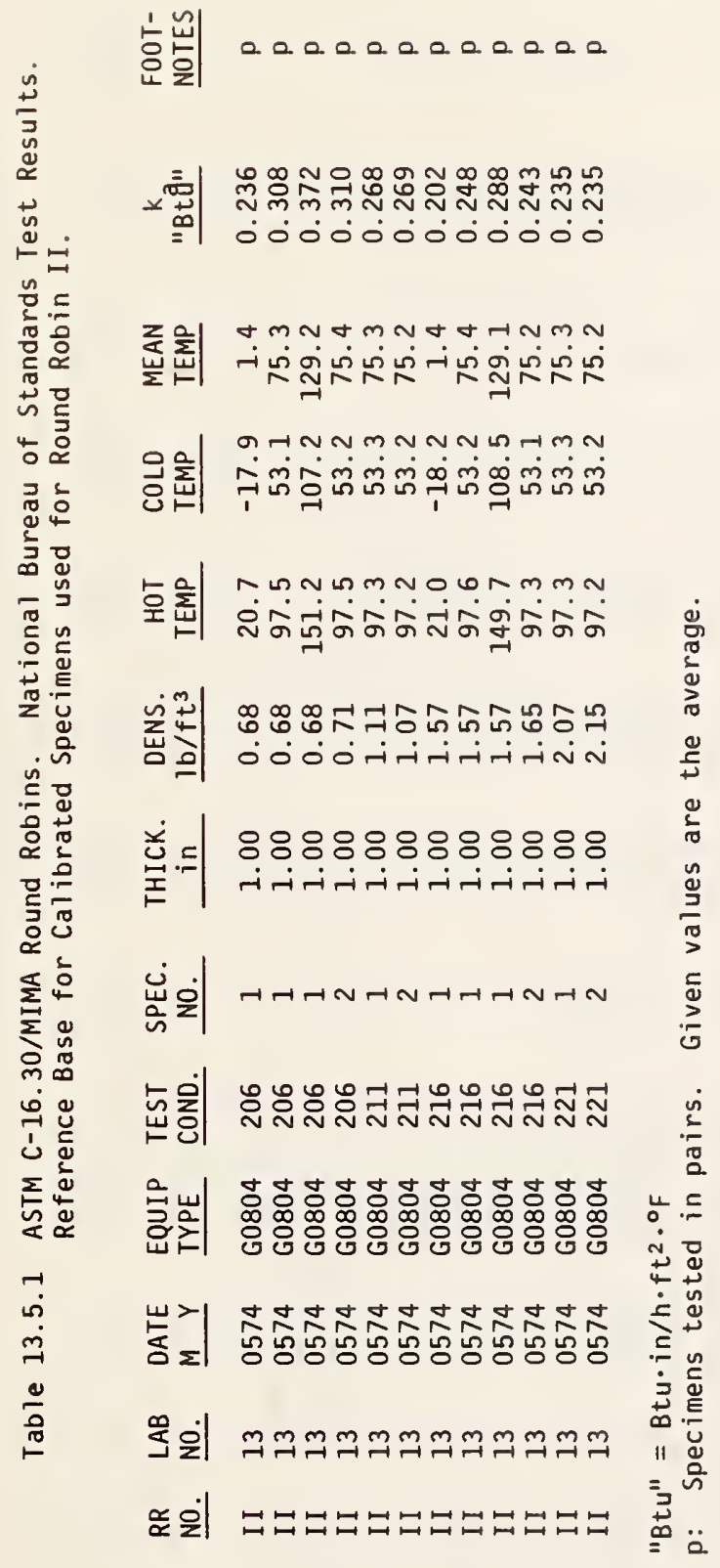




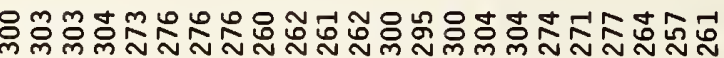
ó0ं0்

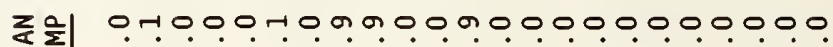

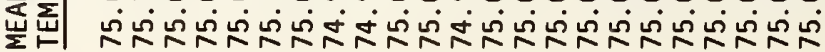

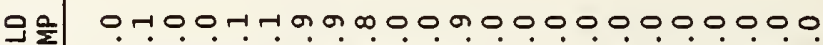
ठํ

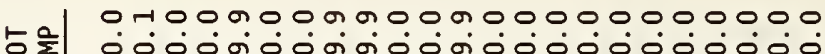

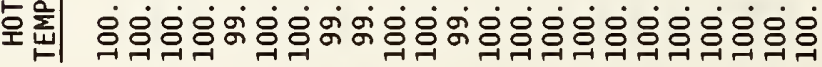

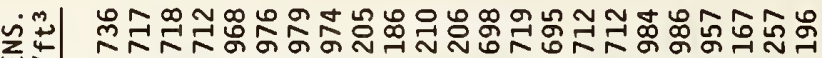

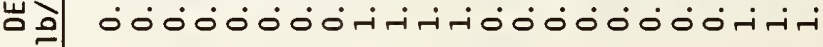
茯

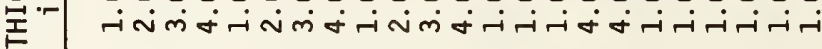

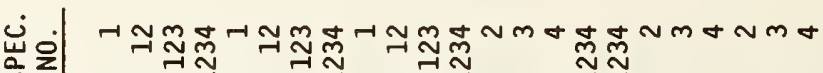
त्र

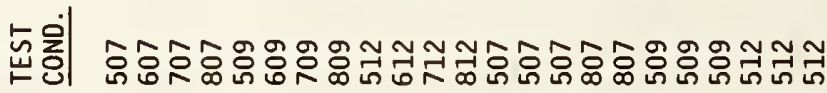
․

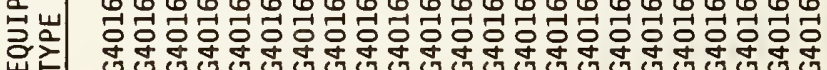

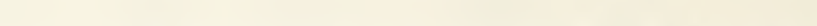

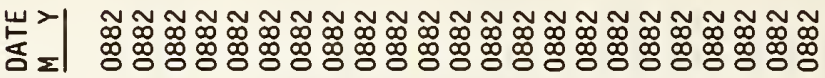
这这

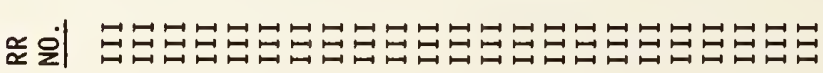


兵皆

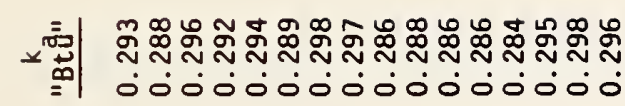

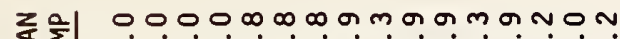

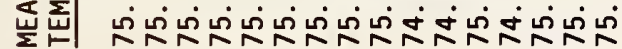

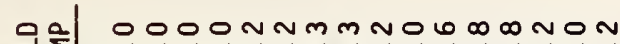

ठํำ

เ이 $0000 m m n+m \infty N \infty 0$ N

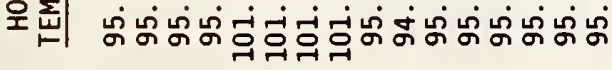

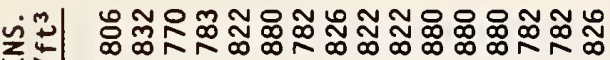

㟔

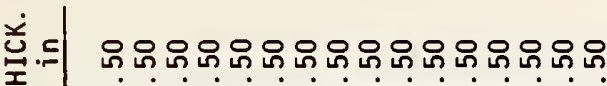

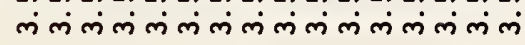

岀完|rmN

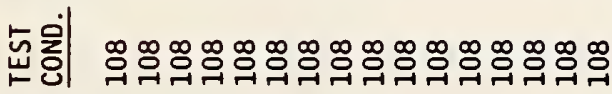

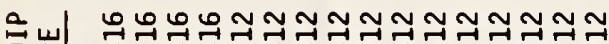

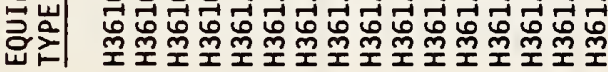

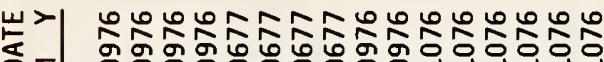




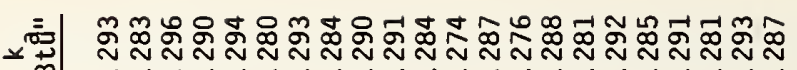

U U

苟

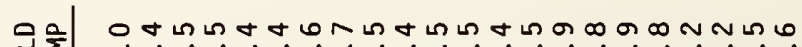

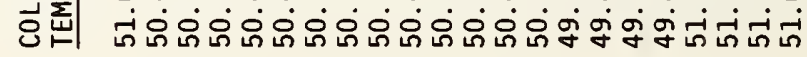

-

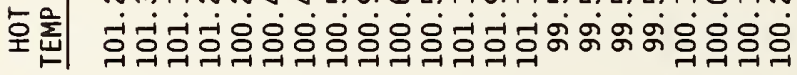

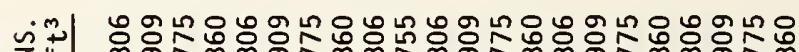

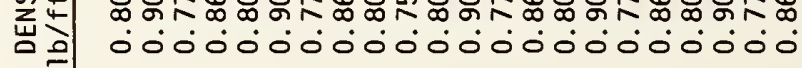

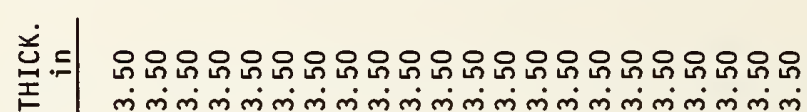

눈

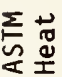

幽完

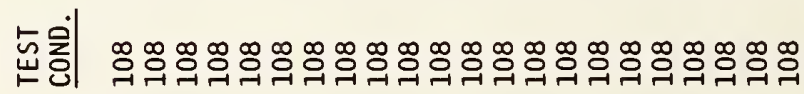

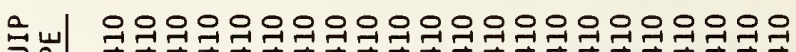

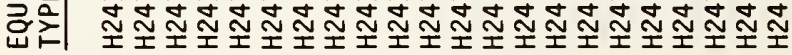

崖>

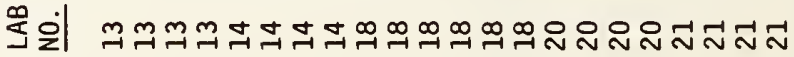

인

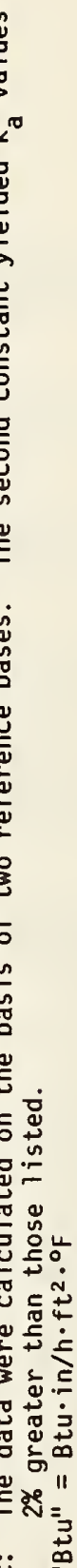




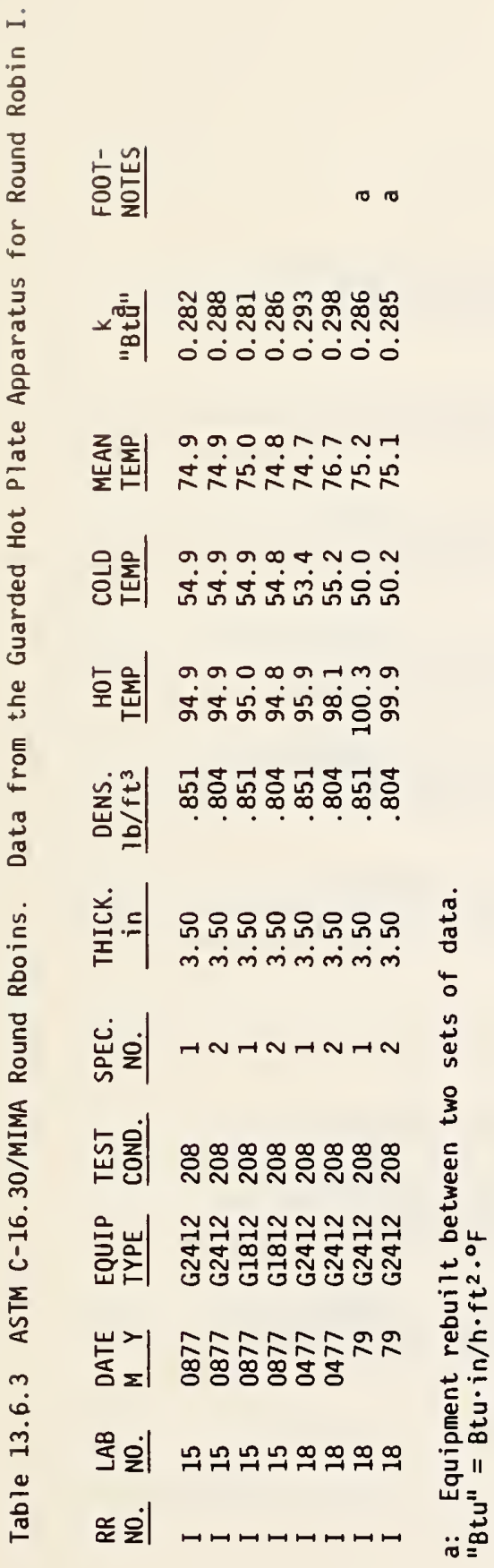




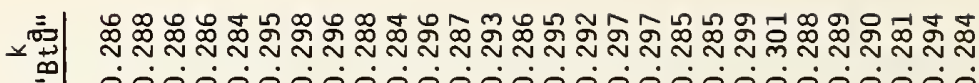

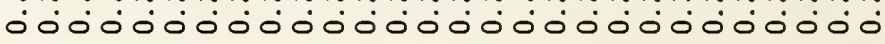

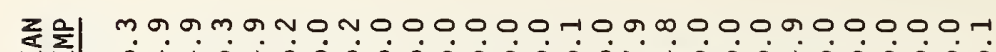

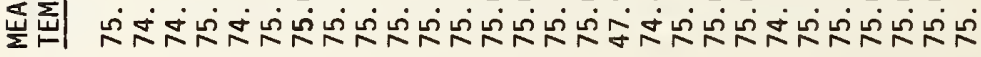

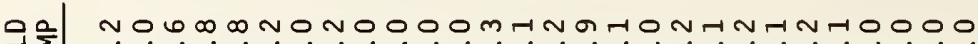

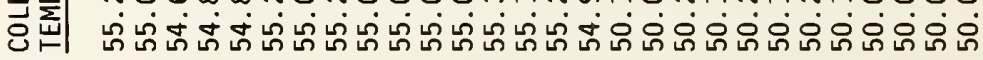

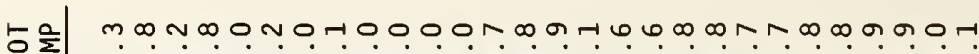
오 ฝூં

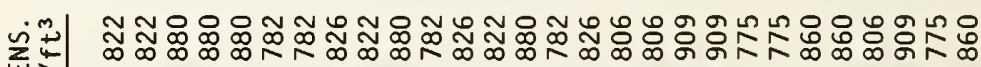
岩

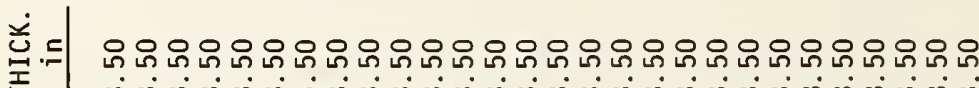

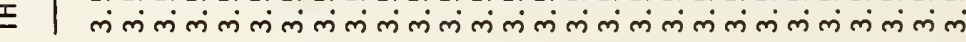

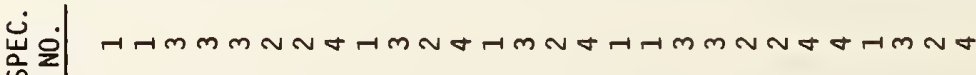

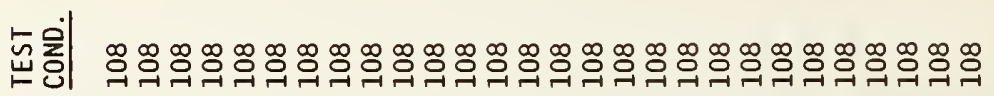
은

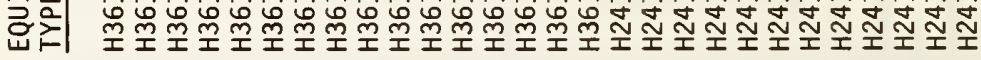

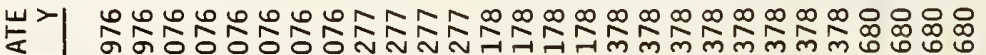

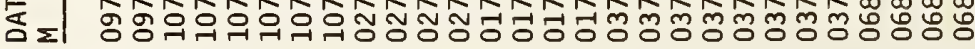

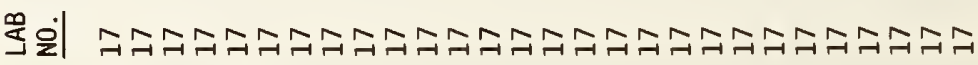
웅이 


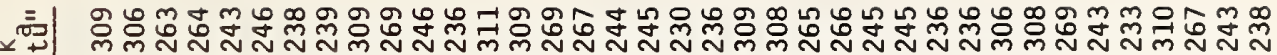

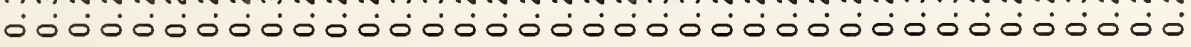

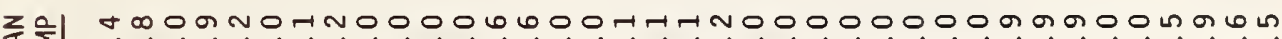

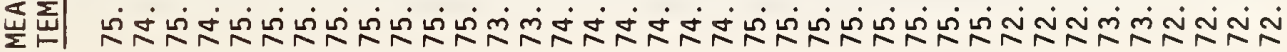

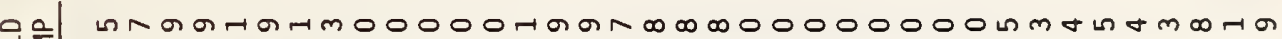

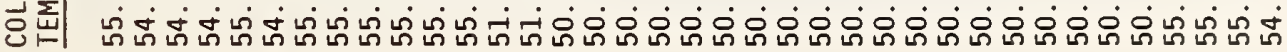

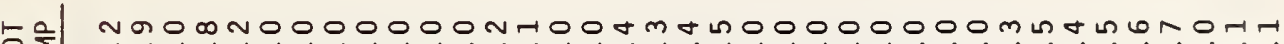

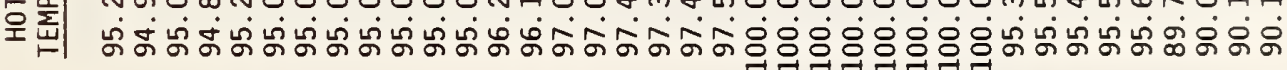
之芒 Шै

炎. 至 幽完 $\rightarrow$ ก

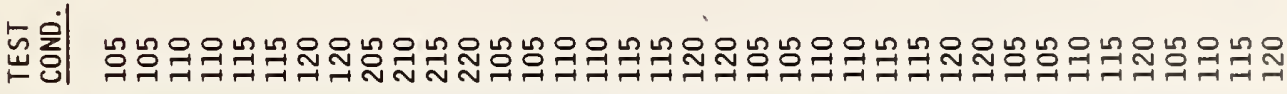

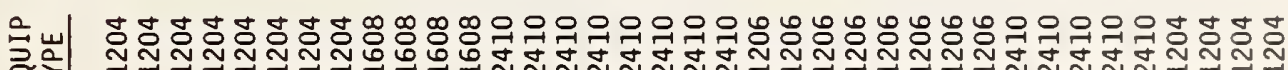

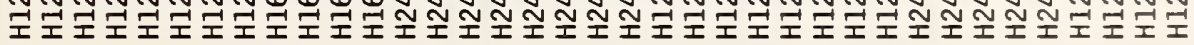

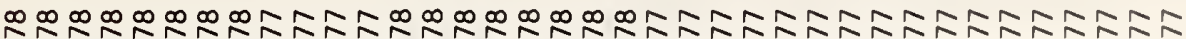

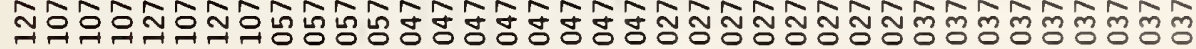

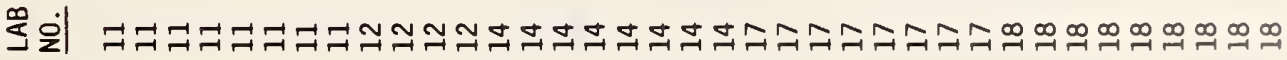

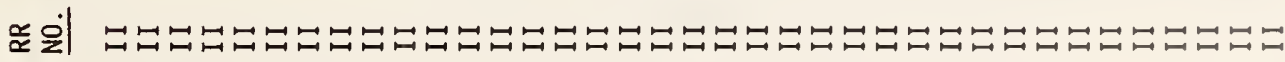




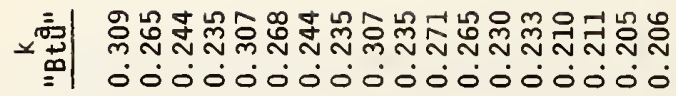

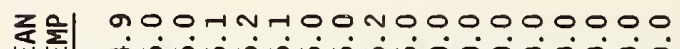

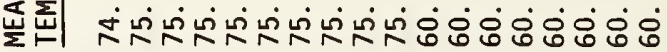

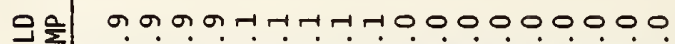

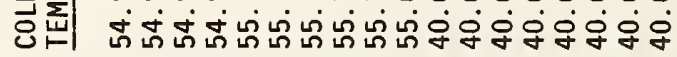

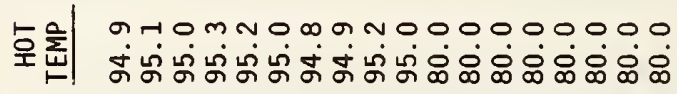

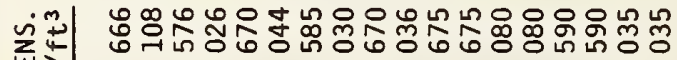

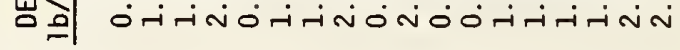

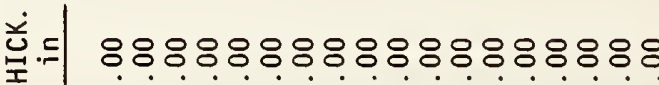
I

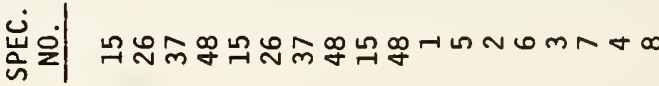

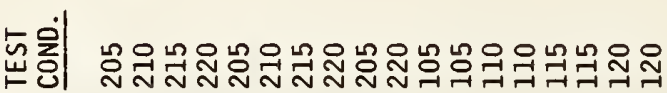

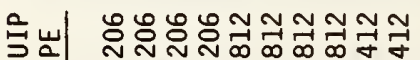

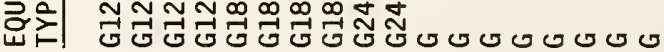

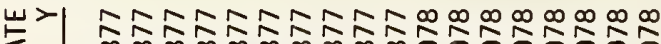
造

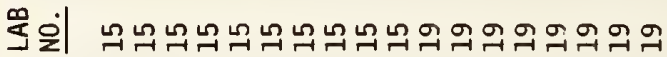

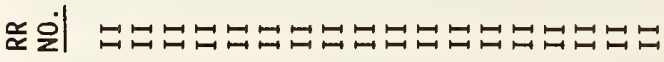


它突究

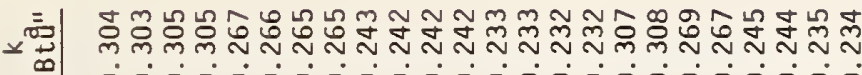
000000000000000000000000

zol 000000000000000000000000

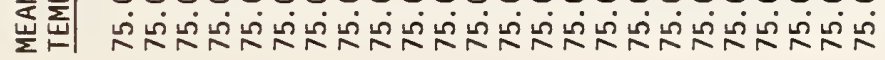

al 00000000000000000000000

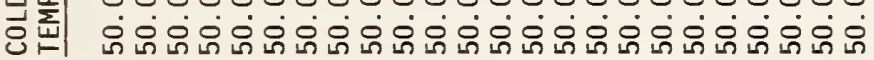
000000000000000000000000

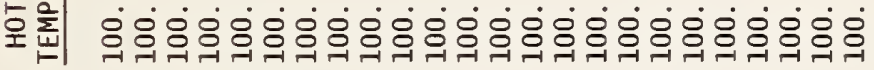

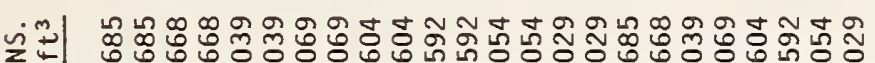

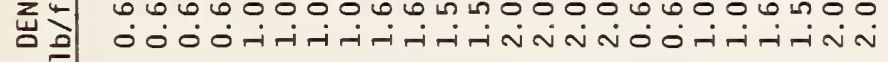

兰.

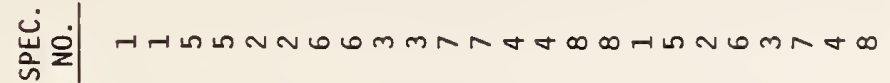

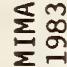

政

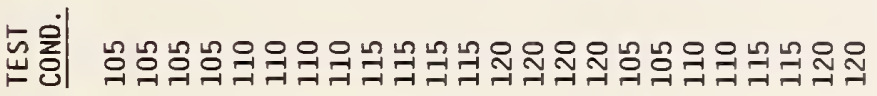

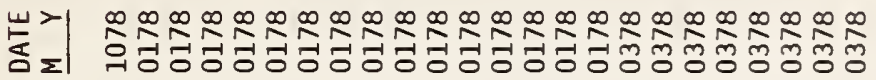

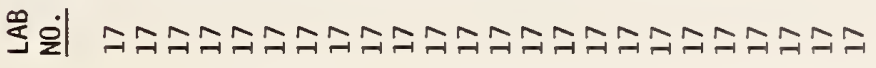

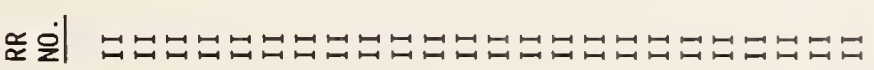




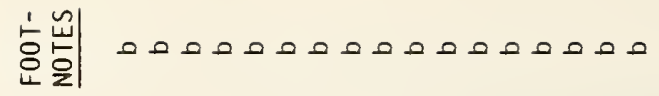

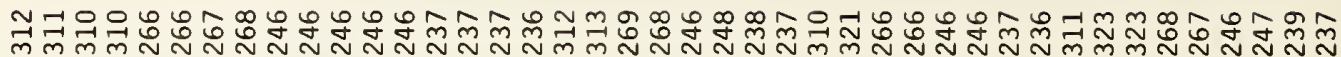
000000000000000000000000000000000000000000

$00000000000000000000000000000000000000007-1$

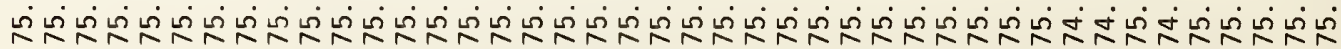

I 000000000000000000000000000000000 NnTnHAnN

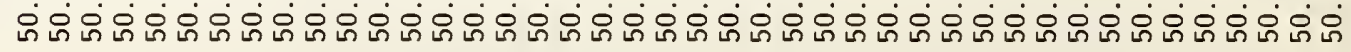
0.0000000000000000000000000000000000000000000000 鿷

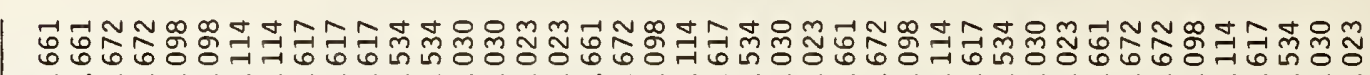

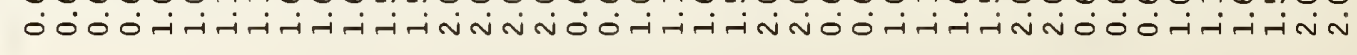

৪৪৪৪৪৪৪৪৪৪৪৪৪৪৪৪৪৪৪৪৪৪৪৪৪৪৪৪৪৪৪৪৪৪৪৪৪৪৪৪৪৪ મં H

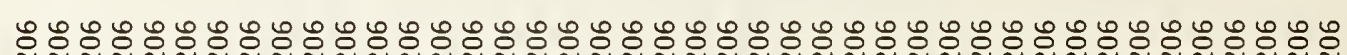

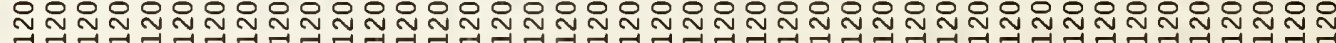

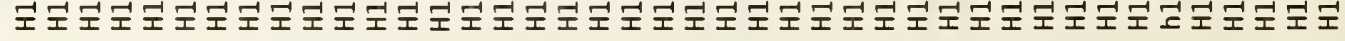

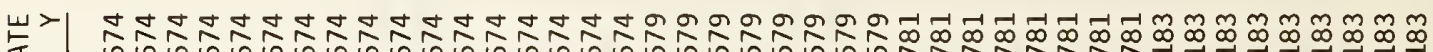

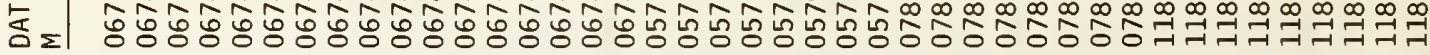

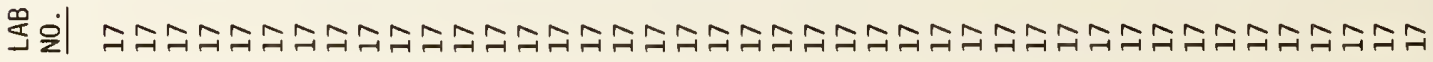

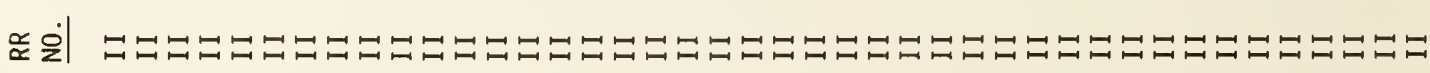




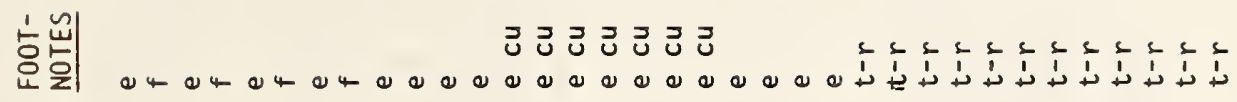

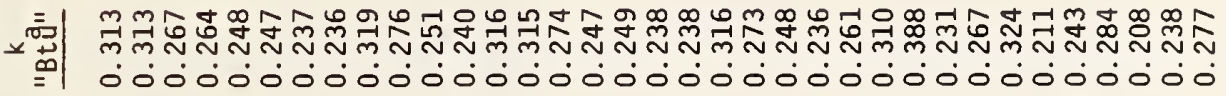

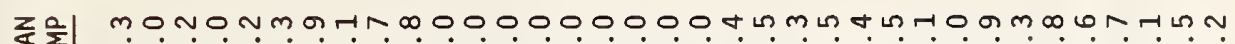

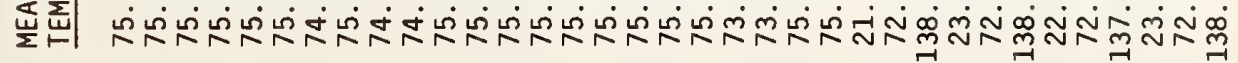

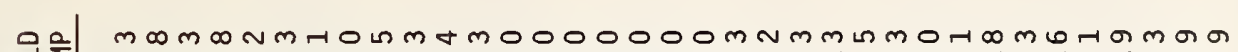

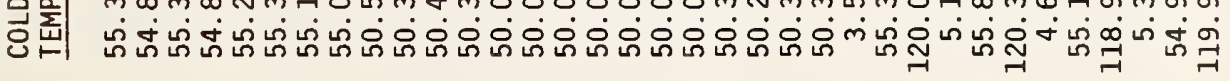
-

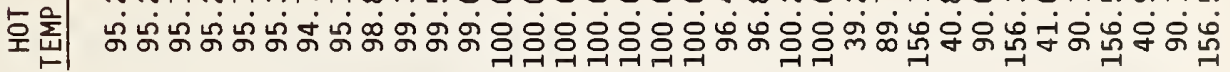

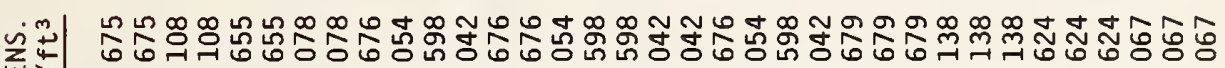
嵌

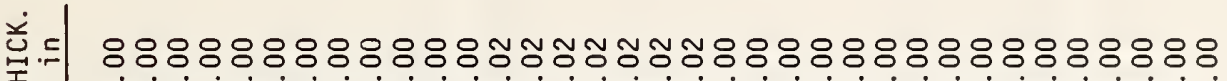

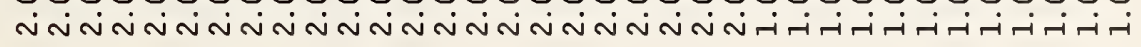

㟧完|

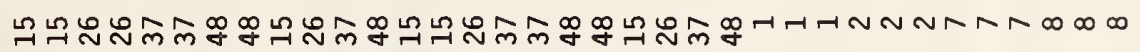

岀导

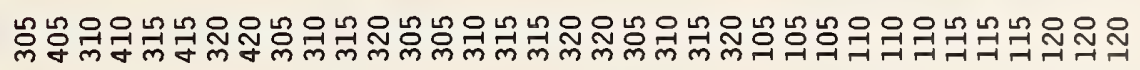

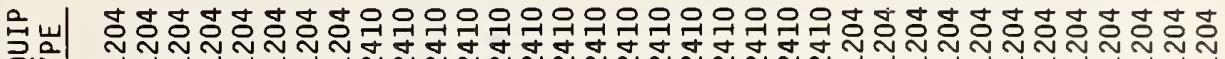

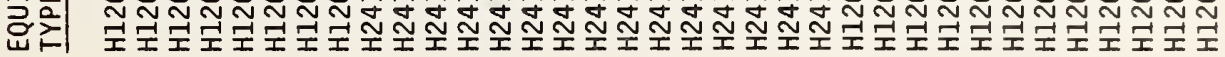

แ山山 吉

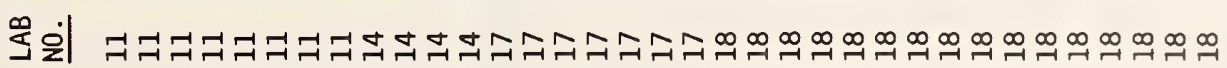

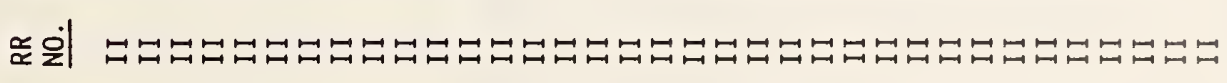


Table 13.8.1 ASTM C-16.30/MIMA Round Robins. Primary Data for Round Robin III. *

\begin{tabular}{|c|c|c|c|c|c|c|c|c|c|c|c|c|}
\hline $\begin{array}{l}\text { RR } \\
\text { NO. } \\
\end{array}$ & $\begin{array}{l}\text { LAB } \\
\text { NO. }\end{array}$ & $\begin{array}{l}\text { DATE } \\
M \quad Y \\
\end{array}$ & $\begin{array}{l}\text { EQUIP } \\
\text { TYPE } \\
\end{array}$ & $\begin{array}{l}\text { TEST } \\
\text { COND. } \\
\end{array}$ & $\begin{array}{l}\text { SPEC. } \\
\text { NO. } \\
\end{array}$ & $\begin{array}{c}\text { THICK. } \\
\text { in }\end{array}$ & $\begin{array}{r}\text { DENS. } \\
1 \mathrm{~b} / \mathrm{ft}^{3} \\
\end{array}$ & $\begin{array}{r}\text { HOT } \\
\text { TEMP } \\
\end{array}$ & $\begin{array}{l}\text { COLD } \\
\text { TEMP } \\
\end{array}$ & $\begin{array}{l}\text { MEAN } \\
\text { TEMP } \\
\end{array}$ & $\begin{array}{r}k \\
\text { "Btä" } \\
\end{array}$ & $\begin{array}{l}\text { FOOT- } \\
\text { NOTES }\end{array}$ \\
\hline I II & 12 & 0180 & G4818 & 507 & 1 & 1.00 & 0.723 & 95.0 & 55.3 & 75.2 & 0.304 & \\
\hline I I I & 12 & 0180 & G4818 & 607 & 12 & 2.00 & 0.714 & 95.0 & 55.2 & 75.1 & 0.308 & \\
\hline I I I & 12 & 0180 & G4818 & 707 & 123 & 3.00 & 0.714 & 95.0 & 55.2 & 75.1 & 0.310 & \\
\hline I I I & 12 & 0180 & G4818 & 807 & 1234 & 4.00 & 0.711 & 95.0 & 55.2 & 75.1 & 0.311 & \\
\hline I I I & 12 & 0180 & G4818 & 509 & 1 & 1.00 & 0.979 & 95.1 & 55.2 & 75.2 & 0.275 & \\
\hline I I I & 12 & 0180 & G4818 & 609 & 12 & 2.00 & 0.981 & 95.1 & 55.2 & 75.2 & 0.279 & \\
\hline I I I & 12 & 0180 & G4818 & 709 & 123 & 3.00 & 0.980 & 95.2 & 55.1 & 75.2 & 0.280 & \\
\hline I I I & 12 & 0180 & G4818 & 809 & 1234 & 4.00 & 0.976 & 95.1 & 55.1 & 75.1 & 0.282 & \\
\hline II I & 12 & 0180 & G4818 & 512 & 1 & 1.00 & 1. 211 & 95.0 & 55.2 & 75.1 & 0.261 & \\
\hline I I I & 12 & 0180 & G4818 & 612 & 12 & 2.00 & 1.192 & 95.1 & 55.2 & 75.2 & 0.264 & \\
\hline I I I & 12 & 0180 & G4818 & 712 & 123 & 3.00 & 1.207 & 95.0 & 55.2 & 75.1 & 0.265 & \\
\hline I I I & 12 & 0180 & G4818 & 812 & 1234 & 4.00 & 1.202 & 95.1 & 55.3 & 75.2 & 0.267 & \\
\hline I I I & 15 & 1080 & G2412 & 507 & 1 & 1.00 & 0.740 & 100.0 & 50.2 & 75.1 & 0.299 & \\
\hline I I I & 15 & 1080 & G2412 & 607 & 12 & 2.00 & 0.716 & 99.7 & 49.7 & 74.7 & 0.303 & \\
\hline I I I & 15 & 1080 & G2412 & 707 & 123 & 3.00 & 0.718 & 100.8 & 49.9 & 75.4 & 0.305 & \\
\hline I I I & 15 & 1080 & G2412 & 807 & 1234 & 4.00 & 0.711 & 100.6 & 50.0 & 75.3 & 0.308 & \\
\hline I I I & 15 & 1080 & G2412 & 509 & 1 & 1.00 & 0.955 & 99.7 & 50.1 & 74.9 & 0.273 & \\
\hline I I I & 15 & 1080 & G2412 & 609 & 12 & 1.99 & 0.967 & 100.0 & 49.8 & 74.9 & 0.275 & \\
\hline I I I & 15 & 1080 & G2412 & 709 & 123 & 3.00 & 0.974 & 99.9 & 49.7 & 74.8 & 0.277 & \\
\hline I I I & 15 & 1080 & G2412 & 809 & 1234 & 4.00 & 0.968 & 99.2 & 49.6 & 74.4 & 0.278 & \\
\hline I I I & 15 & 1180 & G2412 & 512 & 1 & 1.00 & 1.199 & 100.2 & 50.1 & 75.2 & 0.260 & \\
\hline I I I & 15 & 1180 & G2412 & 612 & 12 & 1.99 & 1.179 & 99.3 & 49.8 & 74.6 & 0.261 & \\
\hline I I I & 15 & 1180 & G2412 & 712 & 123 & 2.99 & 1.206 & 100.0 & 49.7 & 74.9 & 0.262 & \\
\hline III & 15 & 1180 & G2412 & 812 & 1234 & 4.00 & 1.203 & 99.2 & 49.6 & 74.4 & 0.264 & \\
\hline I I I & 18 & 0483 & G2412 & 507 & 1 & 1.00 & 0.740 & 97.8 & 48.8 & 73.3 & 0.301 & ed \\
\hline II I & 18 & 0483 & G2412 & 607 & 12 & 2.00 & 0.716 & 100.2 & 51.2 & 75.7 & 0.312 & ed \\
\hline II I & 18 & 0483 & G2412 & 707 & 123 & 3.00 & 0.718 & 100.5 & 50.9 & 75.7 & 0.309 & ed \\
\hline II I & 18 & 0483 & G2412 & 807 & 1234 & 4.00 & 0.711 & 100.5 & 50.6 & 75.6 & 0.309 & ed \\
\hline I I I & 18 & 0483 & G2412 & 509 & 1 & 1.00 & 0.955 & 100.5 & 52.3 & 76.4 & 0.272 & ed \\
\hline III & 18 & 0483 & G2412 & 609 & 12 & 2.00 & 0.967 & 98.4 & 49.9 & 74.2 & 0.278 & ed \\
\hline I I I & 18 & 0483 & G2412 & 709 & 123 & 3.00 & 0.974 & 100.5 & 49.8 & 75.2 & 0.276 & ed \\
\hline I I I & 18 & 0483 & G2412 & 809 & 1234 & 4.00 & 0.968 & 99.1 & 50.0 & 74.6 & 0.277 & ed \\
\hline I I I & 18 & 0483 & G2412 & 512 & 1 & 1.00 & 1.199 & 100.5 & 51.7 & 76.1 & 0.260 & ed \\
\hline I I I & 18 & 0483 & G2412 & 612 & 12 & 2.00 & 1.179 & 99.6 & 50.9 & 75.3 & 0.265 & ed \\
\hline I I I & 18 & 0483 & G2412 & 712 & 123 & 3.00 & 1.206 & 99.9 & 50.6 & 75.3 & 0.264 & ed \\
\hline I I I & 18 & 0483 & G2412 & 812 & 1234 & 4.00 & 1.203 & 100.2 & 50.4 & 75.3 & 0.263 & ed. \\
\hline I I I & 22 & 1182 & G3616 & 507 & 1 & 1.00 & 0.733 & 92.4 & 57.2 & 74.8 & 0.300 & cpi \\
\hline I I I & 22 & 1182 & G3616 & 607 & 12 & 2.00 & 0.718 & 100.0 & 50.8 & 75.4 & 0.300 & cpi \\
\hline I I I & 22 & 1182 & G3616 & 707 & 123 & 3.00 & 0.718 & 99.8 & 51.41 & 75.6 & 0.316 & cpi \\
\hline I I I & 22 & 1182 & G3616 & 807 & 1234 & 4.00 & 0.713 & 98.7 & 51.3 & 75.0 & 0.306 & cpi \\
\hline I I I & 22 & 0481 & G3616 & 509 & 1 & 1.00 & 0.980 & 88.9 & 56.5 & 72.7 & 0.276 & $\mathrm{cpu}$ \\
\hline II I & 22 & 0481 & G3616 & 609 & 12 & 2.00 & 0.985 & 95.3 & 52.9 & 74.1 & 0.281 & $\mathrm{cpu}$ \\
\hline I I I & 22 & 0481 & G3616 & 709 & 123 & 3.00 & 0.984 & 95.2 & 52.9 & 74.1 & 0.283 & $\mathrm{cpu}$ \\
\hline III & 22 & 0481 & G3616 & 809 & 1234 & 4.00 & 0.979 & 98.8 & 56.1 & 77.5 & 0.283 & $\mathrm{cpu}$ \\
\hline I I I & 22 & 0481 & G3616 & 512 & 1 & 1.00 & 1. 212 & 92.6 & 56.7 & 74.7 & 0.265 & $\mathrm{cpu}$ \\
\hline I I I & 22 & 0481 & G3616 & 612 & 12 & 2.00 & 1.193 & 97.1 & 53.0 & 75.1 & 0.269 & cpu \\
\hline III & 22 & 0481 & G3616 & 712 & 123 & 3.00 & 1.213 & 98.5 & 52.8 & 75.7 & 0.271 & $\mathrm{cpu}$ \\
\hline I I I & 22 & 0481 & G3616 & 812 & 1234 & 4.00 & 1.210 & 97.0 & 53.0 & 75.0 & 0.277 & $\mathrm{cpu}$ \\
\hline
\end{tabular}

"Btu" = Btu $\cdot \mathrm{in} / \mathrm{h} \cdot \mathrm{ft}^{2} \cdot{ }^{\circ} \mathrm{F}$

*Lab 13 data given in Table 13.5.2

cpi: Tests performed with insulated cold plates

cpu: Tests performed with uninsulated cold plates

ed: Equipment difficulty reported 


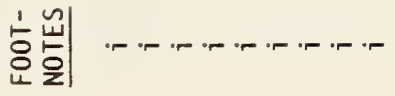

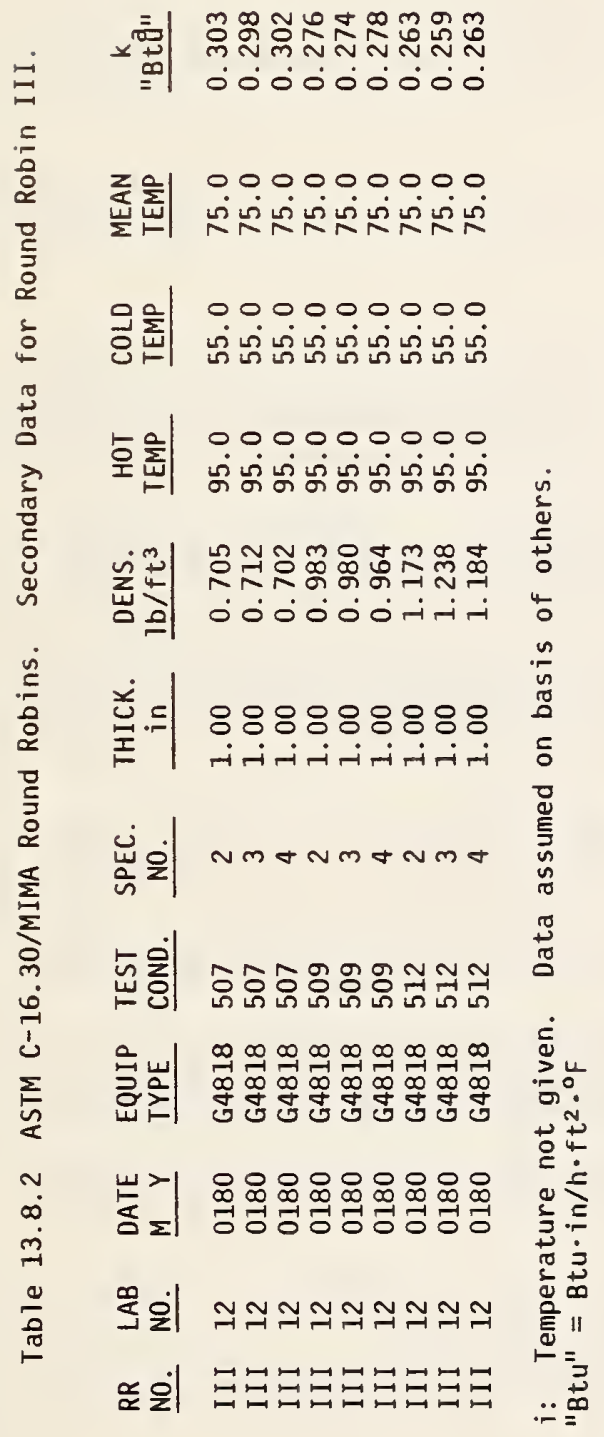




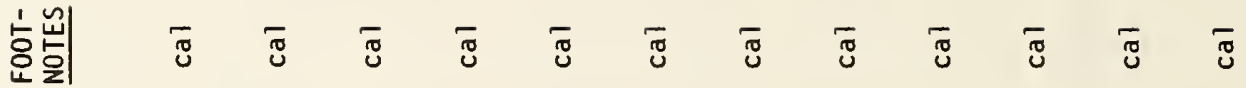

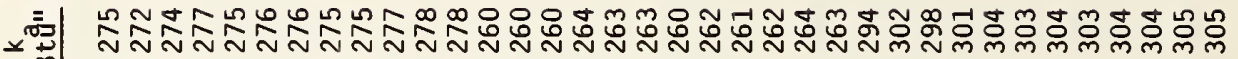

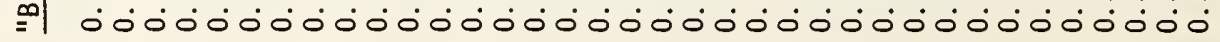

z이 000000000000000000000000000000000000

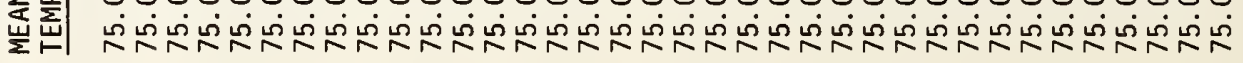

익 000000000000000000000000000000000000

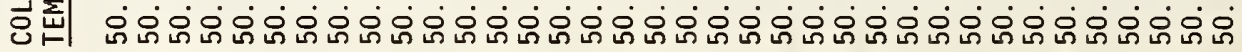
- 000000000000000000000000000000000000

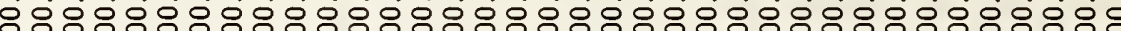

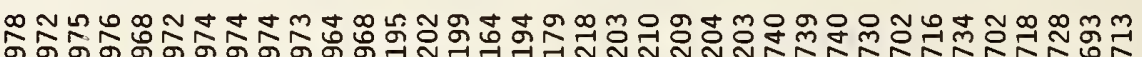

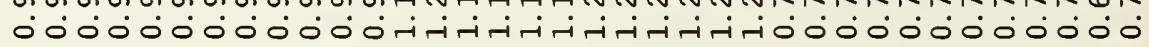

ㅇㅇㅇㅇㅇㅇㅇㅇㅇㅇㅇㅇㅇㅇㅇㅇㅇㅇㅇㅇㅇㅇㅇㅇㅇㅇㅇㅇㅇㅇㅇㅇㅇㅇㅛ

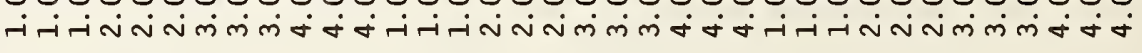
峲完 占它它|

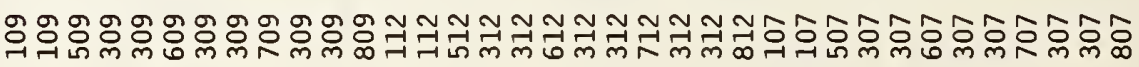
ด

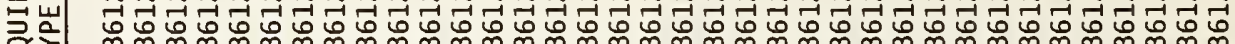

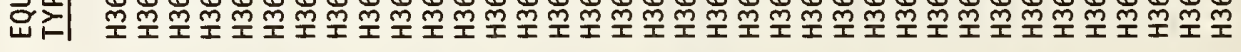
س|

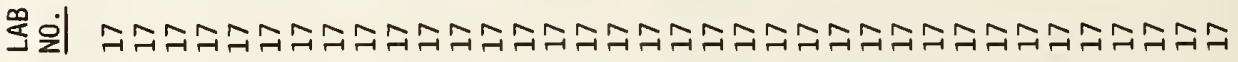

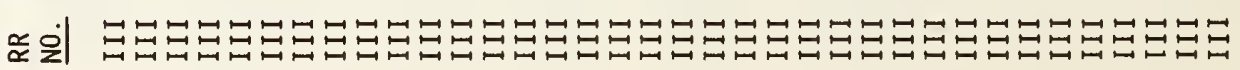


NBS.IIAA REV. 2.BCI

U.S. DEPT. OF COMM.

1. PUBLICATION OR

2. Performing Organ. Report No.

3. Publication Date

BIBLIOGRAPHIC DATA

REPORT NO.

SHEET (See instructions)

NBSIR 85-3026

May 1985

4. TITLE AND SUBTITLE

Round Robins on the Apparent Thermal Conductivity of Low-Density Glass Fiber

Insulations Using Guarded Hot Plate and Heat Flow Meter Apparatus

5. AUTHOR(S)

J. G. Hust and C. M. Pelanne

6. PERFORMING ORGANIZATION (If joint or other than NBS, see instructions)

7. Contract/Grant No.

NATIONAL BUREAU OF STANDARDS

DEPARTMENT OF COMMERCE

WASHINGTON, D.C. 20234

8. Type of Report \& Period Covered

9. SPONSORING ORGANIZATION NAME AND COMPLETE ADDRESS (Street, City, State, ZIP)

U.S. Department of Energy

Oak Ridge National Laboratory

P.O. Box X

Oak Ridge, TN 37830

10. SUPPLEMENTARY NOTES

Document describes a computer program; SF-185, FIPS Software Summary, is attached.

11. ABSTRACT (A 200-word or less factual summary of most significant information. If document includes a significant bibliography or literature survey. mention it here)

This National Bureau of Standards report presents the results and the data analysis pertaining to these results for three round robins on the thermal performance of guarded hot plates and heat flow meters when measuring the thermal resistance properties of low density glass fibrous thermal insulations. The three round robins were carried out under the sponsorship of the American Society for Testing and Materials (ASTM) Subcommittee C-16.30 on Thermal Measurements and the Mineral Insulation Manufacturers Association (MIMA).

The test results are compared to a reference equation and to each other to illustrate intralaboratory and interlaboratory reproducibility as well as the dependencies on temperature, density, plate emittance, specimen thickness, and fiber diameter.

The study shows that, with good laboratory practices, interlaboratory agreement of about $2 \%$ is obtained. Over 300 test results obtained by 12 different laboratories are reported. This report also discusses the magnitude of the specimen thickness effect and its dependence on plate emittance.

12. KEY WORDS (Six to twelve entries; alphabetical order; capitalize only proper names; ond separate key words ty semicolons) apparent thermal conductivity; guarded hot plate; heat flow meter; low density; Round Robins; thermal insulation; thickness effect

13. AVAILABILITY

X. Unlimited

For Official Distribution. Do Not Release to NTIS

Order From Superintendent of Documents, U.S. Government Printing Office, Washington, D.C. 20402.

X Order From National Technical Information Service (NTIS), Springfield, VA. 2216I

14. NO. OF PRINTED PAGES

134

15. Price 




